\title{
ANÁLISE DE ESTRATÉGIAS PARA PROCESSAMENTO DE REDES GEODÉSICAS COM O SISTEMA DE POSICIONAMENTO GLOBAL - GPS
}

\section{Ana Paula Camargo Larocca}

Dissertação apresentada à Escola de Engenharia de São Carlos da Universidade de São Paulo, como parte dos requisitos para obtenção do título de Mestre em Engenharia Civil - Área de Concentração Transportes.

ORIENTADOR: Prof. Dr. Paulo Cesar Lima Segantine 


\section{FOLHA DE APROVACÃO}

Candidata: Engenheira ANA PAULA CAMARGO LAROCCA

Dissertação defendida e aprovada em 10-03-2000 pela Comissão Julgadora:

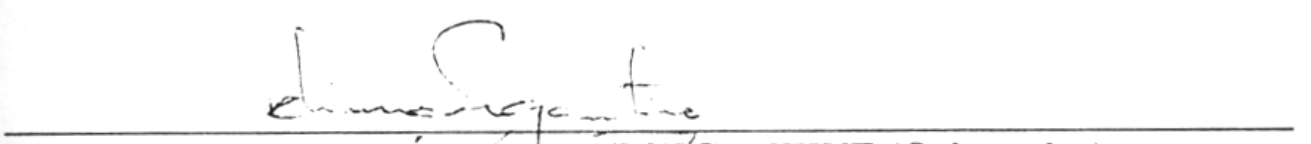

Prof. Doutor PAULO CÉSAR LIMA SEGANTINE (Orientador)

(Escola de Engenharia de São Carlos - Universidade de São Paulo)

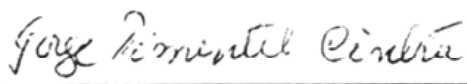

Prof. Associado JORGE PIMENTEL CINTRA

(Escola Politécnica - Universidade de São Paulo)

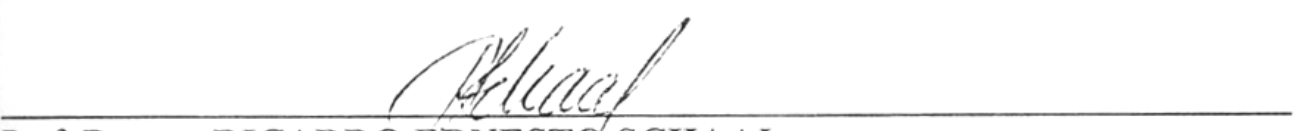

Prof. Doutor RICARDO ERNESTO SCHAAL

(Escola de Engenharia de São Carlos - Universidade de São Paulo)

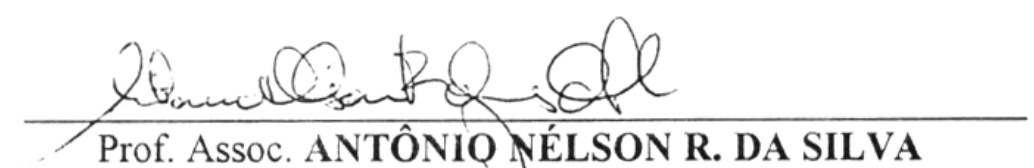

Coordenador da Ârega de Transportes

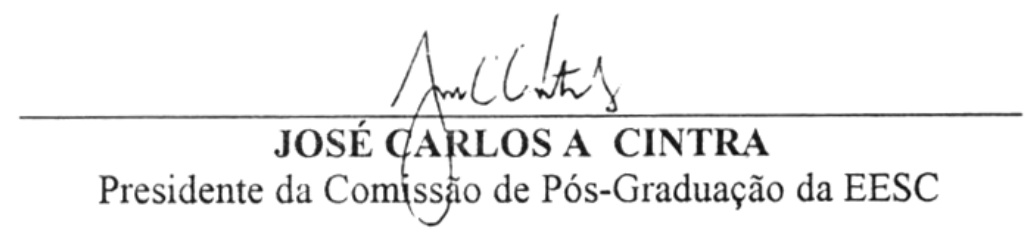


Aos meus pais, Adsir Paula Camargo Larocca e José Larocca, meus exemplos de vida. 


\section{Agradecimentos}

Ao amigo e orientador Prof. Dr. Paulo Cesar Lima Segantine, pelas críticas e sugestões neste trabalho.

Ao Prof. Dr. Ricardo Ernesto Schaal, pela importante colaboração no desenvolvimento e finalização deste trabalho.

Ao Prof. Dr. Antônio Marozzi Righetto e ao Prof. Dr. Arthur Mattos, pela colaboração no entendimento e obtenção de dados meteorológicos.

Ao Prof. Dr. Antônio Nélson Rodrigues da Silva, pelo apoio na pósgraduação.

Ao Prof. Edvaldo Simões da Fonseca Jr., por sugestões no início deste trabalho.

À Sra. Denise Regina S. Abreu e ao Sr. Orivaldo Brunini, do IAC, pelo fornecimento dos dados meteorológicos.

Aos responsáveis pelo Serviço de atendimento do IBGE, em especial à Sra. Kátia D. Pereira, pelas informações concedidas.

A Joseph S. Gispert Jr., da Coast Guard Liasion, HQ Air Force Space Command (DORS), pelo envio de materiais solicitados.

A Stephen Malys, do $\mathcal{N} I M \mathcal{A}$, e a Zuheir Altamimi, do IGSN, pela atenção no esclarecimento de dúvidas e envio de materiais solicitados.

Ao Prof. Dr. Irineu da Silva, pelo empréstimo da chave de dupla freqüência do programa SKI.

À amiga Lisle, pelo constante apoio e incentivo.

A todos os colegas, professores e funcionários do Departamento de Transportes da EESC-USP.

Às amigas Adriana, Ane, Dri, Cintia, e Lú.

À CAPES, pela bolsa de estudos concedida. 
“É preciso lutar por um ideal. Essa é minha meta. $\mathcal{N a ̃ o ~ v o u ~ c o m p e t i r ~ a p e n a s ~ p o r ~ c o m p e t i r . ~}$ Vencer faz parte da minha filosofia." Ayrton Senna 


\section{SUMÁRIO}

USTA DE RGURAS vii

USTA DE TABEAAS xii

USTA DE ABREVIATURAS E SIGLAS xvi

USTA DE SÍMBOLOS xix

RESUMO xix

ABSTRACT $\mathbf{x x}$

CAPÍtULO 1 1

1- Introdução 2

1.1 - Objetivos do Trabalho 3

1.2 - J ustific ativas do Trabalho 4

CAPÍTLO 2 - REDES GEODÉSICAS 5

2 - Introdução 6

2.1. - Redes Geodésicas Horizontais 7

2.2 - Redes Geodésic as Verticais 7

2.3 - Redes Geodésic as com GPS 8

2.3.1 - Rede GPS Mundial (IGS) 8

2.3.2 - Rede Continental Sul - Americ a na (SIRGAS) 9

2.3.3 - Rede Nacional GPS 11

2.3.4 - Rede Brasileira de Monitoramento Contínuo (RBMC) 11

2.3.5 - Redes Regiona is, Subregiona is e Distrita is 11

2.3.5.1 - Rede GPS do Estado de São Paulo 11

\section{CAPÍTULO 3 - LEVANTAMENTOS COM GPS} 14

3.1 - Caractenísticas Desejáveis na Escolha dos Pontos a serem Determinados com GPS: 15

3.2 - Fatores que Determinam o Tempo de uma Obsenvação: 15

3.3 - Método Estático 16

3.4 - Métodos para Levantamento 17

3.5 - Estratégias de Obsenvação 17

3.6 - Processamento dos Dados do Levantamento 18

3.7 - Verificação da Qualidade dos Dados do Levantamento 19 
4.3 - Limitação Intenc ional da Precisão do Sistema

4.3.1- Standard Positioning Service (SPS) ___ 24

4.3.2 - Precise Positioning Service (PPS)___ 24

4.3.3- Anti-Spoofing (AS) __ 25

4.3.4- Selec tive Ava ilbility (SA)__ 25

CAPÍTLO 5 - INFUÊNTES SOBRE A PROPAGAÇÃO DO SINALGPS__ 26

5 - Introdução ____________ 27

5.1 - Atraso de Propagação na lonosfera ________________________ 27

5.1.1 - Influência da aurora polare da atividade solar__ 30

5.1.2.- Influência da cintilação ionosférica __ 31

5.2 - Atraso de Propagação na Troposfera______ 32

5.2.1 - Modelos Troposféric os___ 33

5.2.1.1 - Modelo do atraso total de Saastamoinen: ___ 34

5.2.1.2 - Modelo do atraso total de Hopfield ___ 35

5.3 - Efeito do Multicaminhamento nas proximidades da Antena do Receptor ___ 35

5.4 - Influência da Variação do Centro de fase da Antena ____ 36

5.5 - Influência Meteorológica _____ 37

5.6 - Sensibilidade ao Vapor de Água __________________ 39

5.7 - Perda de Cic los _____ 41

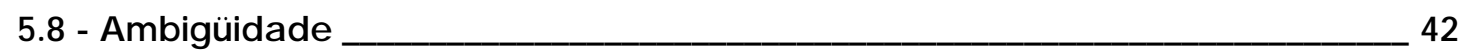

5.9 - Enos do Relógio ______________________________________

CAPÍTLO 6 - GRANDEZAS OBSERVÁVES GPS________________________________ 45

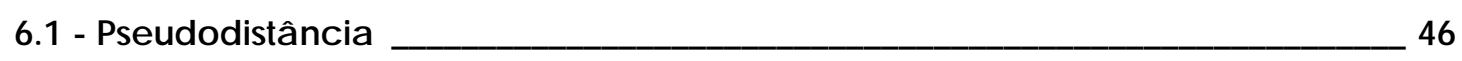

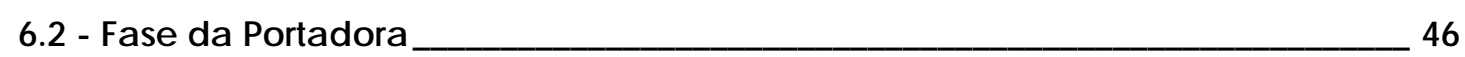

6.2.1 - Simples diferença ___ 46

6.2.2 - Dupla diferença __ 47

6.2.3 - Tripla diferença ___ 48 
7 - Introdução 50

7.1 - Sistema de Referência WGS 84 50

7.2 - IERS - Intemational Earth Rotation Service 52

7.2.1 - Referênc ia is IERS 52

7.2.1.1 - Referência is ITRF 52

7.3 - Relações entre o WGS 84 e o ITRF 54

7.3.1 - Concordância entre o WGS 84 e o IRF 54

7.3.2 - Transformação de Sistemas 55

\section{CAPÍTULO 8 - ELABORAÇÃO DA CONFG URAÇÃO VETORIAL PARA AS ESTRATÉGIAS DE} PROCESSAMENTOS

8.1 - Dados Necessánios 58

8.2 - Escolha dos Pontos de Injunção 60

8.3 - Escolha dos Vetores para a Composição da Estratégia de Processamento 62

8.4 - Análise ao Nível de Planejamento das Sessões de Obsenvação 65

8.4.1 - Observa ções so bre as sessões determina das em 1994 68

8.5 - Apresentação da Estratégia Proposta 69

CAPIIULO 9 - ESTRATIEGIAS DE PROCESSAMENTOS 76

9 - Introdução 77

9.1. - Estratégia de Processamento 1 77

9.2 - Estratégia de Processamento 2 78

9.3 - Estratégia de Processamento 3 79

9.4 - Estratégia de Processamento 4 80

CAPITULO 10 - RECURSOS NEC ESSÁRIOS PARA OS PROC ESSAMENTOS 81

10.1 - Programas Computacionais para Processamentos 82

10.1.1 - Considerações sobre os programas 83

10.2 - Dados Meteorológicos 84

10.3 - Dados de Efemérides Precisas 87

10.4 - Dados de Efemérides Transmitidas 89 
11.1 - Considerações sobre os Critérios do Programa para Realização dos Processamentos 91

11.2 - Intervenções Realizadas Manualmente no Processamento 92

11.3 - Resultados dos Processamentos 97

11.3.1 - Coordena das prelimina res das estações para o a justa mento 97

11.3.2 - Valores das diferenças em relação a os eixos cartesia nos X, Y e Zdos vetores processa dos

CAPÍTULO 12 - AJUSTAMENTOS 99

12.1 - Programas Computacionais 100

12.2 - Resultados dos Ajustamentos 102

12.2.1 - Resulta dos dos ajustamentos da estratégia com tempo total 102

12.2.1.1 - Estratégia 1 - Injunções mínimas CHUA e CAPA 102

12.2.1.2 - Estratégia 1.1 - Injunções mínima S CAPA e UEPP 104

12.2.2 - Resultados dos ajusta mentos da s estra tég ia com 2:30h 106

12.2.2.1 - Estratégia 2 - Injunções mínimas CHUA e CAPA 106

12.2.2.2 - Estratégia 3 - Injunções mínimas CHUA e CAPA 108

12.2.2.3 - Estratégia 4 - Injunções mínimas CHUA e CAPA 110

CAPÍIULO 13 - EUPSES DE ERROS 113

13.1 - Elipses de Enos da Estratégia 1 113

13.2 - Elipses de Emos da Estratégia 1.1 115

13.3 - Elipses de Enos da Estratégia 2 117

13.4 - Eipses de Enos da Estratégia 3 119

13.4 - Elipses de Enos da Estratégia 4 121

CAPÍULO 14 - ANÁUSES DOSAJ USTAMENTOS 123

14.1 - Análise 1 - Venificação da Sufic iência de Sessões com 2:30 horas de Obsenvação 126

14.2 - Análise 2 - Venificação da Influência da utilização de valores atmosféricos reais

14.3 - Análise 3 - Venificação da Influência da utilização de efemérides prec isas e das transmitidas

14.4 - Análise 4 - Venificação da Influência de vetores maiores que 150km processadas em conjunto com vetores menores que $150 \mathrm{~km}$. 
14.5 - Análise 5 - Comparação das Coordenadas obtidas dos Ajustamentos realizados com Diferentes Injunções

14.5.1 - Comparações das coordena das de CAPA 159

14.5.2 - Comparações das coordena das de UEPP 160

14.5.3 - Compa rações das coord enadas do Vértice CHUA 161

CAPÍTLO 15 - CONCLUSÕES E RECOMENDAÇÕES 163

15.1- Conc lusões sobre o Programa de Processamento 164

15.2 - Conc lusões sobre os programas de ajustamento 165

15.3 - Conclusões sobre a qualidade dos dados coletados em 1994 166

15.4 - Conc lusões sobre o Ajustamento das Estratégias 1 e 2 166

15.5 - Conc lusões sobre os Ajustamentos das Estratégias 2 e 3 167

15.6 - Conc lusões sobre os ajustamentos das estratégias 2 e 4 168

15.7 - Conclusões sobre os ajustamentos para venificação da influência de vetores maiores que $150 \mathrm{~km}$ processadas em conjunto com vetores menores que $150 \mathrm{~km}$.

15.8 - Conc lusões sobre os Ajustamentos das Estratégias 1 e 1.1 169

15.8.1 - Conclusões sobre compa rações das coordenadas de CAPA 170

15.9 - Recomendações 172

ANEXO A 174

ANEXO B 176

ANEXO C 182

ANEXO D 191

ANEXO E 192

ANEXO F 196

ANEXO G 198

REFERÊNCIAS BIBUOGRÁACAS 201

APÊNDICE I 
FGURA 01 - Estações oc upa das durante a campanha GPS SIRGAS 95 10

RGURA 02 - Estações da Rede GPS do Estado de São Paulo____ 12

FGURA 03 - Cic lo das A tividades Solar _____ 31

RGURA 04 - O bservação da simples diferença ____________________

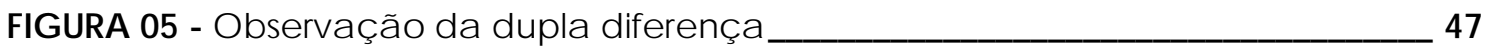

FGURA 06 - Observa ção da tripla diferença________________________________

FGURA 07 - Sistemas Cartesia nos _________________________

FGURA 08 - Localiza ção das estações da rede GPS do Estado de São Paulo____ 59

FGURA 09 - Construção gráfic a original dos veto res observa dos na sessão do DOY 072 63

FGURA 10- Construção gráfica original dos vetores observados na sessão do DOY 332 64

FGURA 11 - Construção gráfic a final da sessão DOY 072 (a partir da FIG URA 10) 66

RGURA 12 - Construção gráfic a final da sessão DOY 332 (a partir da FIG URA 02) 67

FGURA 13 - Construção gráfica geral dos sentidos de caminhamentos para processamento dos vetores 70

FGURA 14 - Construção gráfic a vetorial da estratégia de proc essa mento proposta _ 75

RGURA 15 - Exemplo de sa télite com dado ruim____ 93

FGURA 16 - Da dos dos sa télites sem c orreção - Taqua russu - DOY $335 \_$___ 94

FGURA 17 - Da dos dos sa télites a pós correções ma nua is - Ta quarussu - DOY 335

FGURA 18 - Dados dos sa télites sem correção - Pa raibuna - DOY 069 ___ 95

FGURA 19 - Da dos dos sa télites a pós correções ma nua is- Pa ra ibuna - DOY 069 __ 95

RGURA 20 - Exemplo de ocorrência de perdas de ciclos____ 96

FGURA 21 - Configuração gráfica vetorial da rede para a Estratégia 1 - Injunções CHUA e CAPA 104

FGURA 22 - Configura ção gráfica vetorial da rede para a Estratégia 1.1 106

FGURA 23 - Configuração gráfica vetorial da rede para a Estratégia 2 108

FGURA 24 - Configuração gráfica vetorial da rede para a Estratégia 3 110

FGURA 25 - Configuração gráfica vetorial da rede para a Estratégia 4 112

FGURA 26 - Elipses de Erros - Estratégia 1 113

FGURA 27 - Elipses de Erros - Estratégia 1.1 115

RGURA 28- Elipses de Erros - Estratégia 2 117

RGURA 29- Elipses de Erros - Estratégia 3 119

FGURA 30 - Elipses de Erros - Estratégia 4 121

FGURA 31 - Gráfico dos valores das diferenç as obtidas nas Direções N e E do ponto USPP 127 
RGURA 32 - Gráfico dos valores das diferenças das alturas do ponto USPP

FGURA 33 - G ráfico dos va lores das diferenç as obtidas nas Direções N e E do ponto VAU

FGURA 34 - Gráfico dos va lores das diferenç as das a lturas do ponto VAL

FGURA 35 - Gráfico dos va lores das diferenç as obtidas nas Direções $\mathrm{N}$ e E do ponto MARI

FGURA 36- Gráfic o dos valores das diferenças das alturas do ponto MARI

FGURA 37 - G ráfico dos valores das diferenç as obtidas nas Direções N e E do ponto ILHA 130

FGURA 38 - Gráfico dos valores das diferenças das alturas do ponto ILHA 130

FGURA 39 - Gráfico dos va lores das diferenç as obtidas nas Direções N e E do ponto SJ RP 131

RGURA 40 - G ráfico dos valores das diferenç as das alturas do ponto SJ RP 131

FGURA 41 - Gráfico dos va lores das diferenç as obtidas nas Direções N e E do ponto REG I

FGURA 42 - Gráfico dos valores das diferenç as das alturas do ponto REGI 132

FGURA 43 - G ráfico dos va lores das diferenç as obtidas nas Direções N e E do ponto USP - SP

RGURA 44 - Gráfico dos valores das diferenças das alturas do ponto REGI

FGURA 45 - G ráfico dos va lores das diferenç as obtidas nas Direções $\mathrm{N}$ e E do ponto VAU 135

RGURA 46 - Gráfico dos valores das diferenças das alturas do ponto VAL

FGURA 47 - G ráfico dos va lores das diferenç as obtidas nas Direções $\mathrm{N}$ e E do ponto MARI 136

RGURA 48 - Gráfico dos valores das diferenças das alturas do ponto MARI 136

FGURA 49 - G ráfico dos va lores das diferenç as obtidas nas Direções N e E do ponto ILHA 137

FGURA $\mathbf{5 0}$ - G ráfico dos valores das diferenç as das alturas do ponto ILHA 137

FGURA 51 - Gráfico dos va lores das diferenç as obtidas 
nas Direções N e E do ponto SJ RP

RGURA 52 - Gráfico dos valores das diferenças das alturas do ponto SJ RP 138

FGURA 53 - Gráfico dos va lores das diferenç as obtidas nas Direções N e E do ponto REG I

FGURA 54 - Gráfico dos valores das diferenças das alturas do ponto REG I

FGURA 55 - Gráfico dos va lores das diferenç as obtidas nas Direções N e E do ponto USPP

RGURA 56 - Gráfico dos valores das diferenças das alturas do ponto USPP

FGURA 57 - Gráfico dos va lores das diferenç as obtidas nas Direções $\mathrm{N}$ e E do ponto VAU 142

FGURA 58 - G ráfico dos valores das diferenç as das alturas do ponto VAU

FGURA 59 - Gráfico dos va lores das diferenç as obtidas nas Direções N e E do ponto MARI 143

RGURA 60 - Gráfico dos valores das diferenç as das alturas do ponto MARI 143

FGURA 61 - Gráfico dos va lores das diferenç as obtidas nas Direções N e E do ponto ILHA 144

RGURA 62 - Gráfico dos valores das diferenças das alturas do ponto ILHA

FGURA 63 - Gráfico dos va lores das diferenç as obtidas nas Direções $\mathrm{N}$ e E do ponto SJ RP

RGURA 64 - Gráfico dos valores das diferenç as das alturas do ponto SJ RP 145

FGURA 65 - Gráfico dos va lores das diferenç as obtidas nas Direções N e E do ponto REGI

RGURA 66 - Gráfico dos valores das diferenças das alturas do ponto REG I 146

FGURA 67 - Gráfico dos va lores das diferenç as obtidas nas Direções $\mathrm{N}$ e E do ponto USPP 148

FGURA 68 - G ráfico dos valores das diferenças das alturas do ponto USPP 148

FGURA 69 - Gráfico dos va lores das diferenç as obtidas nas Direções N e E do ponto VAU 149

RGURA 70 - G ráfico dos valores das diferenças das 
alturas do ponto VAU

FGURA 71 - Gráfico dos va lores das diferenç as obtidas

nas Direções N e E do ponto MARI

150

RGURA 72 - G ráfico dos valores das diferenç as das alturas do ponto VAU

FGURA 73 - G ráfico dos va lores das diferenç as obtidas

nas Direções N e E do ponto ILHA 151

RGURA 74 - G ráfico dos valores das diferenças das alturas do ponto ILHA

FGURA 75 - G ráfico dos va lores das diferenç as obtidas nas Direções N e E do ponto SJ RP 152

FGURA 76 - Gráfico dos valores das diferenças das alturas do ponto SJ RP 152

FGURA 77 - Gráfico dos va lores das diferenç as obtidas nas Direções N e E do ponto REG I 153

FGURA 78 - Gráfico dos valores das diferenças das alturas do ponto REGI 153

FGURA 79 - G ráfico dos va lores das diferenç as obtidas nas Direções N e E do ponto USP - SP

FGURA 80 - Gráfico dos valores das diferenças das alturas do ponto USP - SP 156

FGURA 81 - G ráfico dos va lores das diferenç as obtidas nas Direções N e E do ponto VAU 157

RGURA 82 - G ráfico dos valores das diferenças das alturas do ponto VAL 157

FGURA 83- Gráfic o dos valores das diferenç as obtidas

nas Direções N e E do ponto MARI 158

RGURA 84 - Gráfico dos valores das diferenças das alturas do ponto MARI

FGURA 85- Gráfic o dos va lores das diferenç as obtidas nas Direções N e E do ponto CAPA 159

RGURA 86 - G ráfico dos valores das diferenças das alturas do ponto CAPA 160

FGURA 87 - G ráfico dos va lores das diferenç as obtidas nas Direções $N$ e E do ponto UEPP 161

FGURA 88 - G ráfico dos valores das diferenç as das alturas do ponto UEPP 161

FGURA 89 - Gráfico dos valores das diferenç as obtidas 
nas Direções N e E do ponto Vértice CHUA 162

RGURA 90 - Gráfico dos valores das diferenças das

alturas do ponto Vértice CHUA 162

FGURA 91 - Parte de um arquivo de efemérides transmitidas 182 
TABEA 01 - Pontos GPS em regiões do Estado de São Pa ulo ___ 13

TABEA 02 - Pontos GPS em regiões do Estado de São Paulo ________ 13

TABEA 03 - Componentes dos sina is dos sa télites_______________ 22

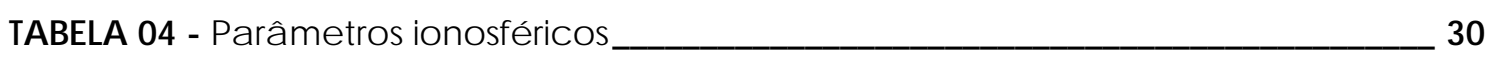

TABEA 05 - Orga niza ção do IERS ____ 52

TABEA 06 - Pa râ metros de transformaçã o de ITRF94 para ITRF92____ 56

TABEA 07 - Identific a dores dos Pontos da Rede GPS do Esta do de São Paulo ___ 58

TABEA 08 - Desc rição das sessões de observação_______ 60

TABEA 09 - Coordenadas do Vértice CHUA ____________ 61

TABEA 10 - Coordenadas da Estação Cachoeira Paulista - SIRGAS____ 61

TABEA 11 - Coordenadas da Estação Presidente Prudente - SIRGAS______ 62

TABEA 12 - Desc rição dos vetores obsenva dos e proc essa dos (DOY 072)______ 63

TABEIA 13 - Desc rição dos vetores observa dos e proc essa dos (DOY 332)_______ 64

TABEA 14 - Descrição dos vetores observa dos esc olhidos (DOY 072)_____ _ 66

TABEIA 15 - Desc rição dos vetores observados escolhidos_____________ 67

TABEA 16 - Sessões que fazem parte da estratégia proposta ______ 69

TABEA 17 - Vetores a partir de CHUA, na sessão do DOY 073

TABEA 18 - Vetores a partir de CHUA, na sessão do DOY 072

TABEA 19 - Vetores a partir de CHUA, na sessão do DOY $071 \_71$

TABEA 20 - Vetores a partir de CHUA, na sessão do DOY $074 \_71$

TABEA 21 - Vetores a partir de CHUA, na sessão do DOY 075___ 72

TABEA 22 - Vetores a partir de CHUA, na sessão do DOY 076____ 72

TABEA 23 - Vetores a partir de CAPA, na sessão do DOY 327

TABEA 24 - Vetores a partir de CAPA, na sessão do DOY 069

TABEA 25 - Vetores a partir de CAPA, na sessão do DOY $070 \_73$

TABEA 26 - Vetores a partir de CAPA, na sessão do DOY 328

TABEA 27 - Vetores a partir de CAPA, na sessão do DOY 329

TABEA 28 - Vetores a partir de CAPA, na sessão do DOY $332 \_73$

TABEA 29 - Vetores a partir de CAPA, na sessão do DOY 333___ 74

TABEA 30 - Vetores a partir de CAPA, na sessão do DOY 076___ 74

TABEIA 31 - Vetores a partir de CAPA, na sessão do DOY 335____ 74

TABEA 32 - Vetores a partir de CAPA, na sessão do DOY 334

TABEA 33 - Duração das sessões de obsenação, tempo inicial e final de processamento para a estratégia 1

TABEA 34 - Duração das sessões de observação, tempo inicial e final de processamento 
TABEA 35 - Semana GPS, DOY e data

TABEA 36 - Resulta dos do a justamento da Estra tég ia 1, a presenta dos em c oordena das geográfic as geodésic as referentes ao WGS 84 103

TABEA 37 - Resulta dos do a justamento da Estra tégia 1.1, a presenta dos em c oordena das geográfic as geodésic as referentes ao WGS 84 105

TABEA 38 - Resulta dos do a justamento da Estra tégia 2, a presenta dos em c oordena das geográfic as geodésic as referentes ao WGS 84 107

TABEA 39 - Resultados do a justamento da Estratégia 3, a presenta dos em coordena das geográfic as geodésic as referentes ao WGS 84 109

TABEAA 40 - Resulta dos do a justamento da Estra tég ia 4, a presenta dos em coordena das geográfic as geodésic as referentes ao WGS 84

TABEA 41 - Va lores dos Semi-Eixos Ma ior e Menor e Altura, das elipses - Estratégia 1

TABEA 42 - Va lores dos Semi-Eixos Ma ior e Menor e Altura, das elipses da Estratégia 1.1

TABEA 43 - Va lores dos Semi-Eixos Ma ior e Menor e Altura, das elipses- Estratégia 2 118

TABEA 44 - Va lores dos Semi-Eixos Ma ior e Menor e Altura, das elipses - Estratégia 3 120

TABEA 45 - Va lores dos Semi-Eixos Ma ior e Menor e Altura, das elipses - Estratégia 4 121

TABEA 46 - Va lores dos emos méd ios das elipses e va riâncias a posteriori 124

TABEA 47- Estratégia 1 e estratégia 2 126

TABEA 48 - Coordena das UTM do Ponto USP-SP 127

TABEA 49 - Coordena das UTM do Ponto Valinhos 128

TABEA 50 - Coordena das UTM do Ponto Mańlia 129

TABEA 51 - Coordenadas UTM do llha Solteira 130

TABeAA 52 - Coordenadas UTM do Ponto São J osé do Rio Preto 131

TABEA 53 - Coordena das UTM do Ponto Registro 132

TABEA 54 - Estratégia 2 e estratégia 3 133

TABEA 55 - Coordena das UTM do USP - SP 134

TABeA 56 - Coordenadas UTM do Ponto Valinhos 135

TABEA 57 - Coordenadas UTM do Ponto Marília 136

TABEA 58- Coordenadas UTM do Ponto llha Solteira 137

TABe日A 59- Coordenadas UTM do Ponto São J osé do Rio Preto 138

TABEAA 60 - Coordena das UTM do Ponto Registro 139

TABEA 61 - Comparação Estratégia 2 e Estra tégia 4 140

TABEA 62- Coordenadas UTM do Ponto USP -SP 141 
TABEA 63 - Coordena das UTM do Ponto VAL 142

TABEA 64- Coordena das UTM do Ponto MARI 143

TABEA 65 - Coordenadas UTM do Ponto ILHA 144

TABEA 66 - Coordenadas UTM do Ponto SJ RP 145

TABEA 67 - Coordenadas UTM do Ponto REGI 146

TABEA 68 - Coordena das UTM do Ponto USP -SP 148

TABelA 69 - Coordena das UTM do Ponto Va linhos 149

TABEA 70 - Coordenadas UTM do Ponto Marilia 150

TABEA 71- Coordenadas UTM do Ponto llha Solteira 151

TABEA 72 - Coordenadas UTM do Ponto São J osé do Rio Preto 152

TABelA 73- Coordena das UTM do Ponto Registro 153

TABEA 74- Valores de variância a posteriori da estratégia 1 154

TABEA 75 - Comparação Estratégia 1 e Estra tégia 1.1 155

TABEA 76 - Coordenadas UTM do ponto USP - SP 156

TABEA 77 - Coordenadas UTM do ponto VAL 157

TABEAA 78 - Coordena das UTM do ponto Maŕlia 158

TABEA 79 - Coordenadas UTM do ponto Cachoeira Paulista 159

TABEA 80 - Coordenadas UTM do ponto UEPP 160

TABEA 81 - Coordena das UTM do Vértice CHUA 162

TABEA 82 - Da dos Meteo rológic os dos pontos observa dos no DOY 069 176

TABEA 83 - Da dos Meteo rológicos dos pontos observa dos no DOY 070 176

TABEA 84 - Da dos Meteorológic os dos pontos observa dos no DOY 071 177

TABEA 85 - Da dos Meteorológic os dos pontos observa dos no DOY 072 177

TABEA 86 - Dados Meteorológic os dos pontos observa dos no DOY 073 177

TABEA 87 - Da dos Meteorológic os dos pontos observa dos no DOY 074 178

TABEA 88 - Da dos Meteorológic os dos pontos observa dos no DOY 075 178

TABEA 89 - Da dos Meteorológic os dos pontos observa dos no DOY 076 179

TABEA 90 - Da dos Meteorológic os dos pontos observa dos no DOY 327 179

TABEA 91 - Da dos Meteorológic os dos pontos observa dos no DOY 328 179

TABEA 92 - Da dos Meteorológic os dos pontos observa dos no DOY 329 180

TABEA 93 - Da dos Meteo rológic os dos pontos observa dos no DOY 332 180

TABEA 94 - Da dos Meteo rológic os dos pontos observa dos no DOY 333 180

TABEA 95 - Da dos Meteorológic os dos pontos observa dos no DOY 334 181

TABEA 96 - Da dos Meteorológic os dos pontos observa dos no DOY 335 181

TABEA 97 - Coordena das preliminares para a Estra tégia 1 192

TABEA 98 - Coordena das prelimina res para a Estratégia 2 193

TABEA 99 - Coordenadas prelimina res para a Estratégia 3 194 
TABEA 100 - Coordenadas prelimina res para a Estratégia 4 195

TABEA 101 - Valores de $\Delta \mathrm{X}, \Delta \mathrm{Y}$ e $\Delta \mathrm{Z}$ 196

TABEA 102 - Coordenas geográfic as geodésic a - IBGE (referencial WG S 84) 198

TABEA 103 - Coordenas geográficas geodésica - SEG ANTINE (1995) (referencial WGS 84)

TABEA 104 - Coordenas geográfic as geodésica - FO NSECA J r. (1996) (referencial WGS 84) 200

TABEA 105 - Sa télites Exc luíd os (com menos de 15\% do total de época s reg istra das)Apêndice I 


\section{LISTA DE ABREVIATURAS E SIGLAS}

AS - Anti - Spoofing

BIH - Bureau Intemational de L'Heure

C/A - Coarse/Acquisition-code

CEAPLA - Centro de Aná lise e Planeja mento Ambiental

CPIEC/INPE - Centro de previsão de Tempo e Estudos Climáticos/Instituto de Pesquisas Espacias

CTRS - Conventional Terrestrial Reference System

DAEE - Departa mento de Águase Energia Elétric a

Datum - Conjunto de parâmetros que descrevem as relações entre um elipsóide local e um sistema global de referência geodésic os

DoD - Department of Defense

DOS - Disk Operating System

DOY - Day of Year

ECEF- Earth-Centered Earth-Fixed

EESC-USP - Escola de Engenharia de São Carlos - Universida de de São Paulo

EPUSP/PIR - Escola Politécnica da Universisdade de São Paulo/ Departamento de Engenharia de Transportes

GPS - G lobal Positioning System

GRS- Geodetic Reference System

IAC - Instituto Agronômico de Campinas

IAG - Instituto Astronômic o e Geofísic o da USP

IBGE - Instituto Brasileiro de Geografia e Estatística

ICRF - IERS Celestial Reference Frame

IERS - Intemational Earth Rotation Service

IGBE - Interagency GPS Exec utive Board

IGS - Intemational G PS Senvice

INMET- Instituto Nacional de Meteorologia

Intemet- Rede de Comunic ação mundial composta de diversas redes pequenas

ITRF - IERS Terrestrial Reference Frame 
IUGG - Intemational Union of Geodesy and Geopysics

J PL- J et Propulsion Laboratory

WR- Lunar Laser Ranging,

NASA - National Aeronautic s and Space Administration

NAVSTAR - NAVigation System with Time and Ranging

NCA - National Command Authorities

NGS - National Geodetic Survey

NIMA - National Imagery and Mapping Agency

NSWC - Naval Surface Warfare Center

OMNI - Programa desenvolvido no NGS sob a supervisão do Dr. Gerald Mader

OPNET- Operational Network

PPP - Precise Point Positioning

PPS - Precise Positioning Senvice

RINEX - Receiver Independent Exchange Format

SA - Selec tive Ava ilability

SCIGN - Southem Califomia Integrated GPS Network

SIRGAS - Sistema de Referência Geocêntrico para a Améric a do Sul

SR-Satellite Laser Ranging

SPS - Standard Positioning Service

TEC - Total Electron Content

VLBI - Very Long Baseline Interferometry

WG - Working Groups

WGS- Word Geodetic System 


\section{LISTA DE SÍMBOLOS}

$f$ - freqüência do sinal em $\mathrm{Hz}$

$\Delta$ - correção do atraso em m

$P_{o}$ - pressão ao nível do mar em mb

M - massa molardo ar

$g$ - aceleração da gravidade

$R$ - consta nte universal dos gases

$\beta$ - valorigual a $-6.81^{\circ} \mathrm{k} / \mathrm{km}$

$T_{o}$ - temperatura a o nível do marem $\stackrel{\circ}{K}$

E - ângulo de elevação do usuário

$\phi$ - latitude local

$\mathrm{h}$ - a ltitude da estação em km

$B(m b)$ e $\delta_{R}(m)$ - termos de correção em relação à altitude h do usuá rio

$h_{d}$ e $h_{w}$ - altitude onde são medidos os índices de refração seco e úmido.

$\Delta \mathrm{X}, \Delta \mathrm{Y}$ e $\Delta \mathrm{Z}$ - valores das diferenças em relação aos eixos cartesia nos $\mathrm{X}, \mathrm{Y}$ e Z, dos vetores processa dos. 


\section{RESUMO}

LAROCCA, A. P. C. Análise de Estratégias para Processamento de Redes Geodésicas com o Sistema de Posicionamento Global - GPS. São Carlos, 2000. 207p. Dissertação (Mestrado) - Escola de Engenharia de São Carlos, Universida de de São Paulo.

O presente trabalho consiste de apresentação de metodologia para estudo, elaboração e análise de estratégias para processamento de observáveis GPS, para a constituição de redes geodésicas. No desenvolvimento deste trabalho foram utilizados os dados observados da rede geodésica do Estado de São Paulo, concluída em 1994. Esta rede é constituída por vinte e quatro pontos distribuídos pelo estado, ma is o vértice CHUA, que é o vértice fundamental da triangulação do Sistema Geodésico Bra sileiro. Atra vés das estra tégias ela bora das são a na lisa dos diversos fa tores de importância relevante nos processamentos dos dados GPS, como: influência de dados meteorológicos no processamento de linhas bases longas; resultados de processamentos com efemérides transmitidas e precisas; resultados de processamentos com linhas bases de comprimentos homogêneos e menores ou igual a $150 \mathrm{~km}$; resultados de processamentos considerando apenas duas horas e trinta minutos do tempo total de duração das sessões de observação. Os resulta dos dos a justamentos destas estratégias são comparados entre si e apresenta-se, então, análises e conclusões sobre a influência dosfatores analisa dos.

Palavras chave: redes geodésicas, GPS, Geodésia, efemérides, estratégias de processamentos, processamento de observáveis. 


\section{ABSTRACT}

LAROCCA, A. P. C. Analyses of Strategies for Processing of Geodetic Networks with the Global Positioning System - GPS. Sa o Carlos, 2000. 207p. Dissertation (Master's degree) - Sa o Carlos Engineening School, University of Sa o Paulo.

The present work consists in the presentation of a methodology for study, elaboration and analyses of strategies to process GPS observables for geodetic networks. In the development of this work, GPS data of the geodetic network of the State of Sa o Paulo, concluded in 1994, were used. This network is composed twenty-four points scattered in the State, plus the vertex CHUA, that is the fundamental point of the triangulation of the Brazilian Geodesy System. Through the strategies elaborated, several factors of main importance for data GPS processing, are analyzed, such as: the influence of meteorological data processing of long baselines; the results of data processing with broadcast and precise ephemenis; the results of data processing with baselines of homogeneous lengths and smaller than or equal to $150 \mathrm{~km}$; the results of data processing considering only two hours and thirty minutes of the total time of duration of the observation sessions. The results of the adjustment of these strategies a re compared to each other, followed by analyses and conclusions about the influence of these factors on data processing.

Keywords: geodetic network, GPS, Geodesy, ephemeris, strategies of processing, data processing. 


\section{CAPÍTULO 1}

"Sábio não é quem dá as verda deiras respostas; é quem formula as verda deiras questões. "

Thomas Davis (1814-1845), poeta e político irlândes. 


\section{1 - Introdução}

O Sistema de Posicionamento Global (GPS1) foi desenvolvido pelo Departamento de Defesa Norte-Americano $\left(D^{2} D^{2}\right)$ como um recurso de navegação e posic ionamento global, para uso militare civil.

É um sistema espacial de navegação que pode ser usado sob quaisquer condições meteorológicas, para determinar, em tempo real e instantâneo, a posição de pontos em três dimensões (latitude, longitude e altura geométrica ou elipsoidal) e o tempo, em relação a um sistema de referência definido para qualquer ponto sobre a superfície terrestre, próximo a ela ou no espaço.

Está baseado numa constelação mínima de 24 satélites orbitando a Terra a quase $20.200 \mathrm{~km}$ acima da superfície terrestre, distribuídos em seis planos orbitais, garantindo aos receptores GPS captarem, 24h por dia, no mínimo 4 satélites acima do plano do horizonte do obsenvador. Esta configuração garante a condição geométrica mínima necessánia à navegação em tempo real.

Atua Imente, o sistema GPS tem sido utilizado em todos os tipos de levantamentos de áreas, controle geodésico de redes, monitoramento de edificações, monitoramento dos movimentos da crosta terrestre, gerenciamento de recursos naturais, exploração costeira, gerenciamento de transporte de frotas, monitoramento de navios petroleiros nas entradas de portos, etc. 


\section{1 - Objetivos do Trabalho}

[1] Verificar, através do dados GPS da rede do Estado de São Paulo, a viabilidade da utilização, no processamento, de um período mais curto de dados, escolhido a o longo do período total das sessões;

[1] Comparar os resultados de ajustamentos, obtidos do processamento considerando o período total da sessão e considerando um período ma is c urto;

[1] Analisar a influência da utilização de valores observados de temperatura, umidade e pressão atmosférica, ao invés de se utilizar os valores propostos pelos programas de processamento;

[1] Processar os dados observados considerando as efemérides transmitidas e as precisa s e a na lisa r as possíveis divergências;

[1] Analisar os resultados de processamentos de vetores de comprimentos diversificados (> $150 \mathrm{~km}$ ), processados em conjunto com vetores de comprimentos $\leq 150 \mathrm{~km}$;

[Dalisar os resultados de processamento apenas com vetores de comprimentos $\leq 150 \mathrm{~km}$ e ma is semelhantes possíveis;

(1) Verificar a qualidade dos dados GPS coletados em 1994 para a rede GPS do Estado de São Paulo, analisando e quantificando a ocorência de perdas de ciclos, comportamento dos resíduos, localização de épocas ruins dos sa télites, etc;

[D] Apresentar comparação das coordenadas ajustadas obtidas, com as coordenadas oficiais divulgadas pelo IBGE $^{3}$, as apresentadas por SEG ANTINE (1995) e as a presenta das por Fonseca J r. (1996).

${ }_{3}$ IBGE: Instituto Brasileiro de Geografia e Estatística 


\section{2 - Justificativas do Trabalho}

Dentre os diversos fatores que motivaram o desenvolvimento deste trabalho, destacam-se:

$\checkmark$ Carência na literatura brasileira de escritos e até mesmo de pesquisas que abordem os objetivos deste trabalho;

$\checkmark$ Carência na literatura de escritos que mostrem de maneira veemente as diferenças existentes nas coordenadas de algumas estações da rede GPS do Estado de São Paulo;

$\checkmark$ Apresentar, então, conclusões e argumentos que levantem discussões para uma futura reocupação dos pontos da rede GPS do Estado de São Paulo. 


\section{CAPÍTULO 2}

\section{REDES GEODÉSICAS}

"Há doistipos de gente, dizia meu a vô: os que trabalham e os que levam o crédito. Aconselhou-me a pertencer aos primeiros - a

competição é muito menor. "

Indira Gandhi (1917-1984) foi primeira - ministra da Índia.

\section{Sumário detalhado do Capítulo 2}

2 - Introdução 6

2.1. - Redes Geodésicas Horizontais 7

2.2 - Redes Geodésicas Verticais 7

\section{3 - Redes Geodésicas com GPS} 8

2.3.1 - Rede GPS Mundial (IGS) 8

2.3.2 - Rede Continental Sul - Americana (SIRGAS) 9

2.3.3 - Rede Nacional GPS 11

2.3.4 - Rede Brasileira de Monitoramento Contínuo (RBMC) 11

2.3.5 - Redes Regionais, Subregionais e Distritais 11

2.3.5.1 - Rede GPS do Estado de São Paulo 11 
Sempre que uma grande área da superfície terrestre necessita ser levantada é conveniente estabelecer uma rede ou dispor de pontos de controle, denominados marcos geodésicos.

Os pontos de controle, especialmente construídos ou definidos por pontos já construídos (alguma edificação) têm suas posições, isto é, suas coordenadas, obtidas em relação a um sistema de referência adotado. E estes pontos, uma vez conhecida suas coordenadas terrestres, podem ser usados para estudos geofísicos, monitoramento de satélites artificiais, na locação de fronteiras nacionais e intemacionais, na confecção de mapas ou exploração de recursos naturais, monitoramento de estruturas, etc. Por fim, devem satisfazer as exigências das investigações científicas e da engenharia geodésica.

Uma rede geodésica pode ser dita como um objeto geométrico, no qual seus pontos são exclusivamente definidos por suas coordenadas. As coordenadas não são observáveis diretamente, mas são obtidas por observações entre seus diversos pontos.

Segundo SEGANTINE (1995) e SANTOS (1998), as redes geodésicas clássicas são classificadas em quatro ordens. A rede de primeira ordem constitui-se de polígonos de lados de grande extensão, que variam entre 20 e $50 \mathrm{~km}$ ou mais. A rede de segunda ordem têm lados de comprimentos entre 10 e $20 \mathrm{~km}$. A rede de terceira ordem possui lados que medem entre 5 e $10 \mathrm{~km}$ e a rede de quarta ordem possui ladosque medem entre 1 a $3 \mathrm{~km}$.

Tradicionalmente, o temo de coordenadas usadas para descrever as posições de pontos sobre a superfície terrestre tem sido separado em componentes horizontais e verticais. Isto resultou em redes geodésicas horizonta is e redes geodésicas vertica is. 


\section{1. - Redes Geodésicas Horizontais}

De acordo com KRAKIWSKI et al. (1986), redes geodésic as horizonta is consistem de pontos cujas coordenadas são tomadas em relação à um sistemas de referência. As altitudes ortométricas $(H)$ dos pontos de controle de uma rede geodésica horizontal são deteminados de forma aproximada.

O sistema de referência usado para o estabelecimentos de redes horizonta is é constituído por um elipsóide rotacional, cujo tamanho e forma são tradicionalmente dados pelos comprimentos do semi-eixo maior e semieixo menor, a e b, respectivamente. As redes horizonta is são baseadas na superfíc ie deste elipsóide de referência.

Países como Estados Unidos da América, Canadá, República Federal da Alemanha, Austrália, Suíça, Áustria e outros países europeus possuem redes geodésicas horizontais. No Brasil há a Rede de Triangulação do Sistema Geodésico Brasileiro, cujo ponto de origem é o vértice CHUA, em Uberaba, Minas Gerais.

\section{2 - Redes Geodésicas Verticais}

São redes de pontos definidos somente por uma coordenada $H$, dada em relação à altura acima do nível do mar, ou mais precisamente, com relação ao geóide. São também conhecidas como redes de alturas geodésicas, a lgumas vezes ta mbém chamadas de 'redes vertica is'.

É evidente que mesmo as redes de pontos verticais precisam ter alguns pontos horizontais associados. A principal diferença entre redes de pontos vertic ais e horizontais está no fato que para a de pontos vertica is, o posicionamento horizontal é conhecido, mascom pouca precisão, e para a de pontos horizontais, o posicionamento vertical é determinado de maneira aproximada.

Países como Alemanha, Estados Unidos da América, Canadá, Suíça, Áustria e outros países europeus possuem rede geodésicas verticais. No 
Brasil, há a Rede de Triangulação de Referências de Níveis (RN), de Nivelamento Geométrico, cujo vértice de origem é o ponto de Imbituba, em Santa Catarina.

\section{3 - Redes Geodésicas com GPS}

O advento da tecnologia GPS revolucionou o conceito de redes geodésicas. Hoje, os posic ionamentos geodésicos com GPS são ca pazes de fomecer, facilmente, resultados com precisões da ordem de 1 a 2 ppm, passíveis de serem obtid os por qualquer empresa usuá ria de receptores que observam a fase da portadora (IBGE, 1994).

Atualmente, fala-se no estabelecimento de "super-redes" de alta precisão com as tec nologias VLBI ${ }^{4}, L R^{5}$, SLR ${ }^{6}$ e GPS.

\subsection{1 - Rede GPS Mundial (IGS ${ }^{7}$ )}

Ela foi proposta pela NASA8 em 1989 e o tratado para sua

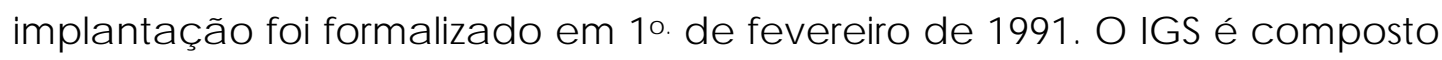
por uma rede intemacional com aproximadamente, duzentas estações operando continuamente com receptores de dupla freqüência, doze Centros Regiona is de análise de dados, três Centros Globais de dados, sete Centros de Análise e uma agência Central, situada no JPL9.

O IGS coleciona dados de observação GPS, que são usados para gerar os seguintes produtos: efemérides precisas, parâmetros de rotação de Terra, coordenadas e velocidades das estações IGS, informação de relógio das estações. A exatidão desses produtos pemite a poiar atividades como: monitorando deformações da crosta terrestre, determinação das órbitas de satélites, monitoramento da ionosfera, etc.

\footnotetext{
4 VLBI: Very Long Baseline Interferometry

5 ШR: Luna r Laser Ranging,

6 SLR: Sa tellite La ser Ranging

7 IGS: Intemational GPS Service

8 NASA: National Aerona utic s and Space Administration

9 J PL: J et Propulsion Laboratory
} 


\subsection{2 - Rede Continental Sul - Americana (SIRGAS)}

O projeto para implantação do Sistema de Referência Geocêntrico para a América do Sul (SIRGAS) foi iniciado na Conferência Intemacional para definição de um Datum ${ }^{10}$ Geocêntrico para a América do Sul, em 1993, em Assunção no Paraguai. Foram adotadas, então, as seguintes definições para o sistema de referência e o datum geocêntrico para o continente:

$\checkmark$ Como sistema de referência SIRGAS: IERS (Intemational Earth Rotation Service) Terrestrial Reference Frame (IRRF'11);

$\checkmark$ Datum geocêntrico: eixos coordenados baseados no sistema de referência SIRGAS e parâmetros do elipsóide "Geodetic Reference System (GRS) de 1980".

Os participantes da Conferência de Assunção definiram, então, as 58 estações integrantes da rede, sendo que onze estão no Brasil, nas cidades de Manaus, Fortaleza, Imperatrizes, Bom Jesus da Lapa, Cuiabá, Brasília, Viçosa, Presidente Prudente, Cachoeira Paulista, Rio de Janeiro e Curitiba; uma estação na Antártida; dez estações na Argentina; seis na Bolívia; sete no Chile; cinco na Colômbia; três no Equador; uma na Guiana Francesa; duasno Paraguai; quatro no Peru; três no Uruguai e cinco na Venezuela.

As atividades do Projeto SIRGAS têm sido projetadas no sentido da adoção, no continente, de uma rede de referência de precisão compatível com as técnicas modemas de posicionamento, principalmente as asso cia das a o sistema GPS (SIRGAS - RELATÓ RIO FINAL, 1997).

\footnotetext{
10 Datum: Conjunto de parâmetros que descrevem as relações entre um elipsóide local e um sistema global de referência geodésicos

11 ITRF: IERS Terrestrial Reference Frame
} 
$\mathrm{Na}$ FIGURA 01 podem ser vistas as estações ocupadas nas campanhas GPS SIRGAS de 1995.

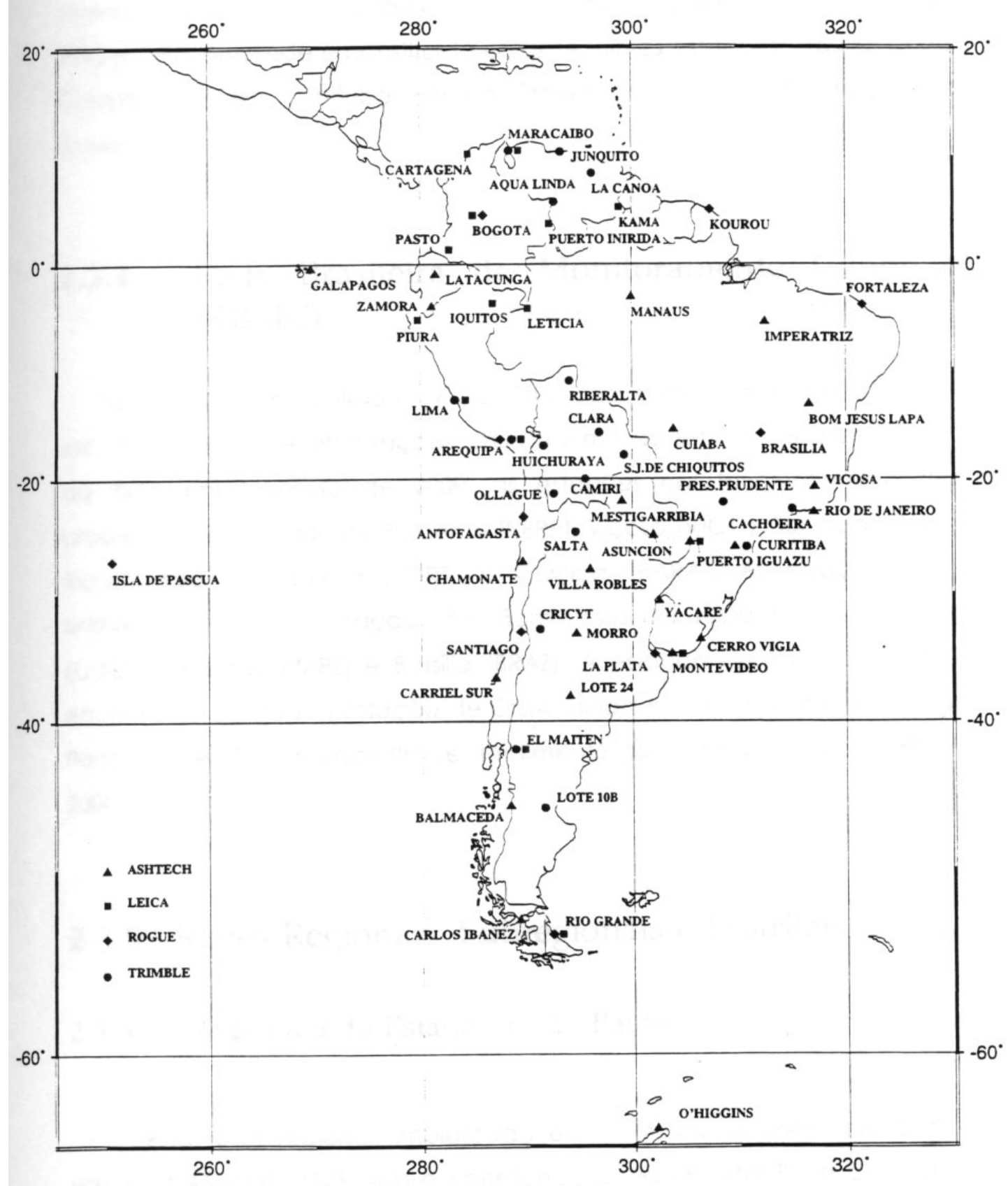

FGURA 01 - Esta ções oc upadas durante a campanha GPS SIRGAS 95 


\subsection{3 - Rede Nacional GPS}

O IBGE estabeleceu uma rede nacional se aproveitando dos dados de diversa s campanhas naciona is e intemaciona is em que esteve envolvido de 1991 a 1992. Esta rede é constituída pelas seguintes estações: Brasília, Chuá, Cuiabá, Fortaleza, Imbituba, Paraná, Presidente Prudente, Recife, Rio de J a neiro e São Paulo.

\subsection{4 - Rede Brasileira de Monitoramento Contínuo (RBMC)}

Faz parte de um projeto do IBGE, junto com instituições públicas, criado em 1991. Conforme informações obtidas junto ao serviço de atendimento do IBGE, em fevereiro de 2000, as estações em funcionamento sem problemas são: Presidente Prudente (UEPP), Viçosa (VICO), Salvador (SALV), Recife (RECF), Fortaleza (FORT) e Coritiba (PARA). As estações com problemas de comunicação são: Bom Jesus da Lapa (BOMJ), Cuiabá (CUIB), Imperatriz (IMPZ) e Brasília (BRAZ). A estação de Manaus (MANA) se encontra parada, a estação de Crato ainda não foi implantada e a de Porto Alegre (POAL), encontra-se, totalmente, sem comunicação (PEREIRA, 2000).

\subsection{5 - Redes Regionais, Sub-regionais e Distritais}

\subsubsection{1 - Rede GPS do Estado de São Paulo}

Esta rede regional implantada em 1994 foi estabelecida com o sistema NAVSTAR ${ }^{12} / \mathrm{GPS}$, sob a coordenação da EPUSP/PTR ${ }^{13}$ e do IBGE. É uma típica rede regional formada de 24 pontos distribuídos pelo Estado de São Paulo e mais o vértice CHUÁ (FIG URA 02).

\footnotetext{
12 NAVSTAR: NAVigation System with Time and Ranging

13 EPUSP/PTR: Escola Politécnica da Universisdade de São Paulo/ Departamento de Engenharia de Transportes
} 
Os pontos da rede foram obsenvados a partir de sessões de observações previamente estabelecidas, nos meses de março, novembro e dezembro de 1994. As sessões tiveram peńodos de 6 e 8 horas, utilizando o número mínimo de quatro receptores. Foram usados receptores de dupla freqüência Geodetic Surveyor of Trimble Series 4000SST.

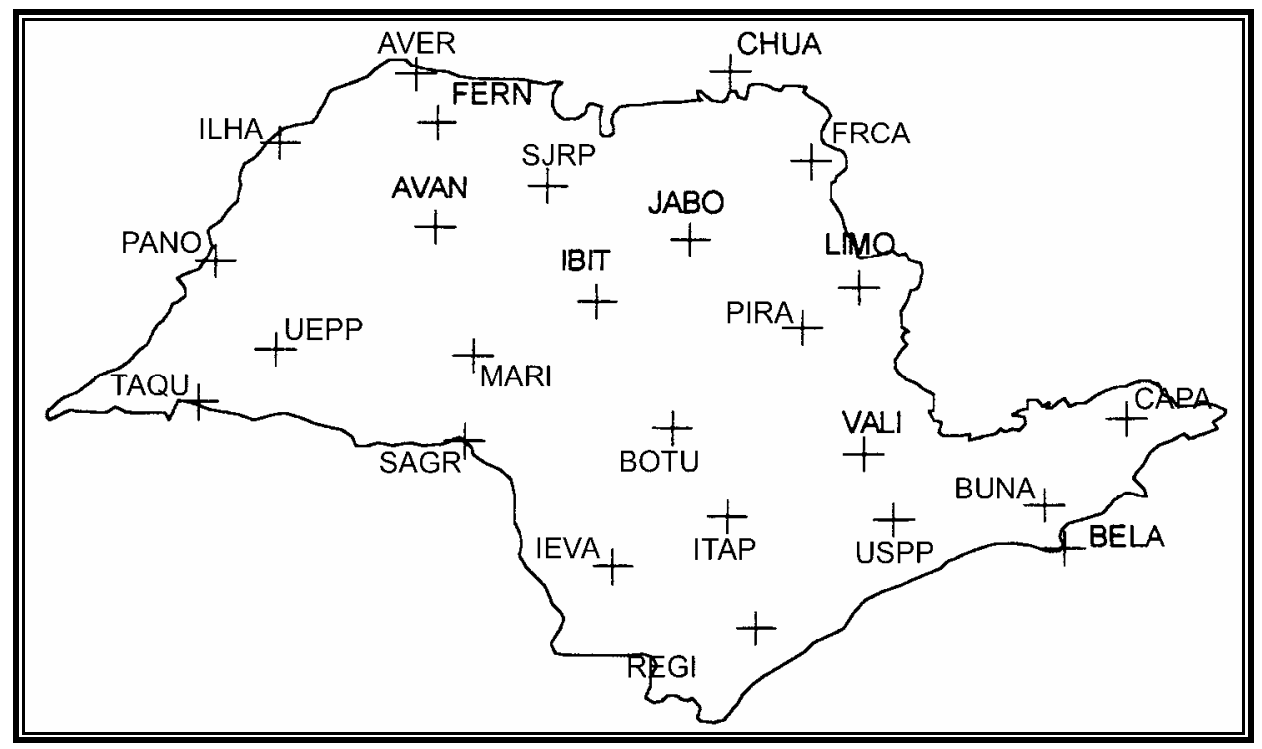

RGURA 02 - Estações da Rede GPS do Estado de São Paulo

Outros estados estão em fase de implantação de redes GPS: Rio de Janeiro, Santa Catanina, Pemambuco e Mato Grosso do Sul. O estado do Paraná, porsua vez, já implantou sua rede GPS.

Como exemplos de redes GPS sub-regionais têm-se as redes municipais de Campinas e Guarulhos, no Estado de São Paulo. E como exemplo de redes GPS distrita is ou setoria is, a rede do Metrô, em São Paulo.

Ainda, na tentativa de atualização quantitativa e qualitativa de pontos determina dos com GPS no estado de São Paulo, realizou-se, junto à algumas empresas atuantes no estado, uma breve pesquisa:

A empresa Aerocarta S/A enviou informações sobre a quantidade de pontos GPS e as respectivas regiões, mas não as informações sobre tipo de receptor utilizado e se estes pontos estão amarrados a algum ponto 
da rede GPS do estado de São Paulo. As infomações fomecidas estão apresentadas na TABELA 01, abaixo (PESSO A, 1999).

TABEA 01 - Pontos G PS em regiões do Esta do de São Paulo

\begin{tabular}{lc}
\hline \multicolumn{1}{c}{$\begin{array}{c}\text { Região do } \\
\text { Estado de São Paulo }\end{array}$} & $\begin{array}{c}\text { Quantidade de } \\
\text { pontos GPS }\end{array}$ \\
\hline Alumínio & 06 \\
Americana & 19 \\
Catanduva & 08 \\
Paragua çú Paulista & 08 \\
Presidente Prudente & 09 \\
Presidente Venceslau & 07 \\
Vale do Ribeira & 06 \\
\hline \hline
\end{tabular}

Fonte: Empresa Aeroc arta S/A

$\checkmark$ A empresa SETA Engenharia e Agrimensura LTDA fomeceu informações sobre a quantidade de pontos GPS e as respectivas regiões, relatando que os mesmos foram coletados com receptores da marca SOKKIA, de uma freqüência, com período de rastreio de 1 e estão amarrados à Rede de Triangulação do Estado de São Paulo. As informações fomecidas estão a presenta das na TABELA 02, a baixo (MENZORI, 1999).

TABEA 02 - Pontos G PS em regiões do Esta do de São Paulo

\begin{tabular}{lc}
\hline \multicolumn{1}{c}{$\begin{array}{c}\text { Região do } \\
\text { Estado de São Paulo }\end{array}$} & $\begin{array}{c}\text { Quantidade de } \\
\text { pontos GPS }\end{array}$ \\
\hline Santos & 10 \\
São Paulo - Mogi das Cruzes & 600 \\
Soroc aba & 30 \\
Botuc atu & 10 \\
Araraqua ra & 20 \\
\hline
\end{tabular}

$\overline{\text { Fonte: Empresa SETA Engenharia e Agrimensura LTDA }}$ 


\section{CAPÍTULO 3}

\section{OBSERVAÇÕES COM GPS}

"Se você quer ser bem suc edido precisa ter dedicação total, buscar seu último limite e daro melhor de si mesmo."

Ayrton Senna

Sumário detalhado do Capitulo 3

3.1 - Características Desejáveis na Escolha dos Pontos a serem Determinados com GPS: 15

3.2 - Fatores que Determinam o Tempo de uma Observação: 15

3.3 - Método Estático 16

3.4 - Métodos para Levantamento 17

3.5 - Estratégias de Observação 17

3.6 - Processamento dos Dados do Levantamento 18

3.7 - Verificação da Qualidade dos Dados do Levantamento 19 
Os levantamentos executados com o GPS apresentam como característica, a independência das condições atmosféricas e não há necessidade de intervisibilidade entre as estações.

\section{1 - Características Desejáveis na Escolha dos Pontos a serem Determinados com GPS:}

De acordo com SEEBER (1993), HOFMANN-WELENHOF et al. (1997) e SEGANTINE (1998), as seguintes condições devem ser consideradas para a escolha dos pontos a serem determinados com GPS:

> Visão desobstruída do horizonte para ângulos superiores a $10^{\circ}$ de elevação para as antenas da estação base e $1^{\circ}$ para as antenas remotas;

> O receptor não deve estar posicionado próximo a objetos e lamina de água que provoquem reflexão dos sinais emitidos pelos satélites (para reduzir o efeito do multic a minhamento );

> Fácil acesso (de preferência por veículos, para ganhar tempo entre as sessões) e loca is limpos;

> Osmarcos geodésic os não devem estar sujeitos a vanda lismos;

> Devem ser escolhidos pontos situados em áreas públicas, com a finalidade de garantir a proteção dos mesmos.

\section{2 - Fatores que Determinam o Tempo de uma Observação:}

De a cordo com HOFMANN-WELLENHOF et al. (1997), há c inc os fa tores que deteminam o tempo mínimo de uma observação: 
> A geometria relativa dos sa télites;

$>$ O número de satélites;

$>$ o grau de perturbação ionosférica (para receptores de uma freqüência);

> O comprimento dos vetores;

> A quantidade de obstruções no local de observação.

Em geral, quanto maior o número de satélites disponíveis no momento da observação e uma boa condição geométrica, menor o tempo necessário de rastreamento.

Todas as observações realizadas simultaneamente, durante uma cobertura de satélites num projeto GPS, são chamadas de sessão.

Segundo SEGANTINE (1995), um método para deteminar o tempo ótimo de observação, é realizar no primeiro dia, um período de observação maior que o mínimo exigido. Essas observações podem ser processadas usando apenas porções dos dados e os resultados, então obtidos, devem ser comparados com o resultado do processamento total dos dados. Assim, pode-se identificar os melhores peńodos de observação e conseqüentemente, realizar processamento direcionado.

\section{3 - Método Estático}

É a técnica onde dois ou mais receptores envolvidos na missão, permanecem fixos nas estações durante toda a sessão de observação. Este processo requer algumashoras de observações para medir a fase dos sina is emitidos pelos satélites. É o mais usado, no estabelecimento de redes geodésicas, visto que requer somente que os pontos observados tenham uma visão desobstruída do horizonte e sem a presença de objetos que possam interferir na captação dos sina is. 
Existem outros métodos de observação, como os métodos rápidos, que neste trabalho não estão abordados, mas podem ser vistos em HOFFMANN-WELIENHOF (1997), LEICK (1995), SEEBER (1993).

\section{4 - Métodos para Levantamento}

As redes têm sido estabelecidas por triangulação, trilateração e poligonação.

Poligonação: consiste no estabelecimento de pontos (estações) intervisíveis com seu anterior e subseqüente, que são escolhidos a fim de estabelecer poligonais básicas, nas quais se apóiam outros levantamentos de ordem inferior. O levantamento consiste das medições de ângulos e distâncias entre as estações.

Thiangulação: utiliza uma série de figuras geométricas (polígonos), com ponto central, ou não, onde os vértices são materializados e suas coordenadas são esta belecidas com precisã o.

Tílateração: ocorre quando há três estações com posições conhecidas e determina-se a posição de uma quarta estação. É um método puramente geométrico de deteminação de coordenadas (SEEBER, 1993).

\section{5 - Estratégias de Observação}

Segundo SEEBER (1993), existem três estratégias básicas de observação: 
> conceito de posicionamento pontual (receptor simples): a posição absoluta pode ser determinada continuamente com uma precisão de 10 a $15 \mathrm{~m}$, sem efeito $\mathrm{SA}^{30}$ e com precisão de 30 a $50 \mathrm{~m}$ sob o efeito SA;

conceito de base (observações relativas de duas estações): necessita de pelo menos dois receptores GPS operando simultaneamente. Pode ser a plicado para uma antena móvel ou estacionária;

conceito de multi-estação (três ou mais receptores operando simultaneamente): este método ocupa pontos adjacentes, formando polígonos e permite uma alta precisão relativa.

SEEBER (1993), também afima, baseado em experiências, que os seguintes critérios devem ser adotados:

> Cada estação deve ser ocupada pelo menos duas vezes, sob diferentes condições, para identificar possíveis erros e garantir a execução de uma rede;

> Estações a djacentes devem ser oc upa das simulta nea mente, visto que a solução da ambigüidade apresenta melhores resultados para pequenas bases;

> Para projetos de dimensões médias, o uso de 4 a 10 receptores garante uma boa confiabilidade e uma superabundância de vetores para um mesmo tempo de observação.

\section{6 - Processamento dos Dados do Levantamento}

Existem do is tipos de programas de processamento:

> Vetor por vetor ou base simples: é o mais comum e deve ser usado a priori no processamento da solução por multipontos. Se os pontos forem

30 SA: Selec tive Ava ila bility 
processados juntos, um possível erro de um ponto será distribuído entre os demais e ficará encoberto. Os programas que resolvem vetor por vetor oferecem, portanto, melhores condições de verificação e identific ação das bases que a presentam problemas;

Solução pormultipontos: que não será abordada neste trabalho e

Precise point positioning (PPP): surgiu em 1997 e consiste de um serviço de análise automática dos dados GPS, que é oferecido pelo JPL e está disponível via Intemet31. Os dados GPS têm que ser observados com receptores de dupla freqüência durante pelo menos uma hora. Estando em formato RINEX 32 padrão, os dados devem ser enviados ao JPL por meio de 'correio eletrônico' (ag@cobra.jpl.nasa.gov.). Após a a nálise destes dados, o JPL através de correio eletrônico, avisa o usuário onde os resulta dos estarão disponíveis no ftp (file tra nsfer program) (ZMBERGE et al., 1999; SEGANTINE et al., 1999).

\section{7 - Verificação da Qualidade dos Dados do Levantamento}

De a cord o com SEGANTINE (1995),

$>$ O primeiro passo para a verificação do fechamento de um levantamento é a elaboração de um esquema das bases medidas. As bases devem ser numeradas no sentido da obtenção, fazendo-se referência a certos pontos de controle da rede;

$>$ O segundo procedimento é definir as injunções mínimas (pontos cujas coordenadas são consideradas como conhecidas e fixas) no ajustamento pelos mínimos quadrados.

31 Intemet: Rede de Comunicação mundial composta de diversas redes pequenas

32 RINEX: Receiver Independent Exchange Format 
Uma outra forma de averiguar a qualidade dos dados observados é verificar os resíduos resultantes do ajustamento. Segundo HOFMANNWELENHOF et al. (1997) os resíduos dos componentes dos vetores devem ser consistentes com os comprimentos das bases, ou seja, pequenos valores para bases curtas e grandesvalores para baseslongas. 


\section{CAPÍTULO 4}

\section{CARACTERÍSTICAS DO SINAL GPS}

"Pensar é ma is interessante do que saber, masé menos interessante do que olhar." J ohann Wolfgang von Goethe (1749-1832), Escritor a lemão.

\section{Sumário detalhado do Capítulo 4}

4.3.1- Standard Positioning Service (SPS)

4.3.2 - Precise Positioning Service (PPS) 24

4.3.3- Anti-Spoofing (AS) 25

4.3.4- Selective Availbility (SA) 25 


\section{1 - Estrutura do Sinal GPS}

A chave da precisão do sistema GPS se dá pelo fato dos componentes dos sina is serem precisamente controlados por relógios atômicos. A freqüência fundamental (banda L) de 10,23 MHZ é produzida por um sistema de alta precisão.

Todos os sa télites da constela ção GPS transmitem continuamente na mesma freqüência. Os componentes dos sinais dos satélites e suas freqüências estão resumidos na TABELA abaixo:

TABELA 03 - Componentes dos sina is dos sa télites

\begin{tabular}{cc}
\hline \hline Componente & Freqüência (MHz) \\
\hline Freqüência fundamental & $f_{o}=10,23$ \\
Portadora L1 & $154 f_{o}=1575,42(\cong 19,0 \mathrm{~cm})$ \\
Portadora L2 & $120 f_{o}=1227,60(\cong 24,4 \mathrm{~cm})$ \\
Código-P & $f_{o}=10,23$ \\
Código C/A & $f_{o} / 10=1,023$ \\
Mensagem de navegação & $f_{0} / 204600=50 * 10^{-6}$ \\
\hline \hline
\end{tabular}

As portadoras $L 1$ e $L 2$ são essenciais para eliminação da maior fonte de erro, a refração ionosférica, em baseslongas.

O primeiro código é o código C/A (Coarse/Acquisition-code), também designado como SPS17, que está disponível para a comunidade civil. Tem um comprimento efetivo de onda de aproximadamente $300 \mathrm{~m}$. $\mathrm{O}$ código C/A é modulado somente na portadora Ll e é propositadamente omitido na $L 2$.

O segundo código é O código-P (Precision-code), que foi intencionalmente projetado para uso militar e está disponível para usuários a utorizados. Também designado como PPS18, tem um comprimento efetivo de onda de aproximadamente $30 \mathrm{~m}$. O código P é modelado em ambas as portadoras L1 e L2 (HOFMANN-WELLENHOF et al., 1997).

17 SPS: Standard Positioning Service 


\section{2 - Implementação do Terceiro Sinal GPS para Civis}

Em 15 de janeiro de 1999, um memorando da Casa Branca ${ }^{19}$ notificou a criação de dois novos sina is GPS, representando um marco histórico, nos termos de atingir o potencial completo da proposta do sistema GPS. Com o objetivo de melhorara capacidade, os Departamentos de Estado, Defesa e Transportes reuniram esforços para conseguir a autorização do DoD para operar na faixa $1176 \mathrm{MHz}$ e coexistir com o terceiro sinal (chamado de L5) sem causar interferências prejudic ia is à segurança dos usuários da a viação civil e outros meios de transportes. O memorando da Casa Branca, também foi direcionado a Interagency GPS Executive Board (IGEB), para o desenvolvimento de um projeto para a implementação da L5 GPS, o que foi realizado.

O IGEB criou um grupo para coordenara implementação do terceiro sinal civil, através do monitoramento de quatro grupos de trabalho (WG Working Groups), responsáveis pela execução de todos os esforços analíticos. Estes esforços englobam quatro áreas: projeto do sinal (WG3), viabilidade técnica de coexistência (WG1), impacto operacional e public ação dos custos (WG2) e coordenação intemacional (WG4).

Muitas opiniões foram consideradas e a nalisa das para estabelecer a performance do novo sinal GPS. O novo sinal está planejado para a faixa de $960-1215 \mathrm{MHz}$, a qual é utilizada intemacionalmente, para ajudar a navegação aérea.

O custo da implementação da freqüência L5 está estimado em 406 milhões de dólares, que serão gastos em seis a nos e estará em capacidade operacional completa em 2013 (FINAL REPORT, 1999). 


\section{3 - Limitação Intencional da Precisão do Sistema}

Há basicamente dois serviços para limitar o acesso, dos usuários, à precisão total do sistema. O SPS e o PPS.

\subsection{1- Standard Positioning Service (SPS)}

SPS é o nível de padrão especificado de precisão e tempo de posicionamento, que está disponível, sem restrições, para qualquer usuário. O SPS permite uma precisão de posicionamento da ordem de 100 metros (95\% de confiança) horizontalmente e 156 metros (95\% de confiança) verticalmente. Decisões para modificar os modos operaciona is do GPS, incluindo degradação na precisão do GPS para usuários civis é feita pelo $N C A^{20}$. O SPS usa o código C/A na freqüência $L 1$.

\subsection{2 - Precise Positioning Service (PPS)}

PPS é a disponibilidade de infomações diretas e precisas de posicionamento, velocidade, e tempo. Este serviço é operado pelo DoD e está disponível a penas para usuários autorizados. O código-P (Y, explicado em 4.3.3) capacita o equipamento dos usuários a obter precisão de posicionamento de pelo menos 22 metros (95\% de confiança) horizontalmente e 27 metros vertic almente (95\% de confiança). O PPS usa o código $P(Y)$ em a mbas as freqüências $L 1$ e de $L$.

Embora a L2 não seja parte do Standard Positioning Service, muitos usuários civis empregam tecnologias de receptores de dupla freqüência para alcançar suas próprias precisões (FEDERAL RADIONAVIGATION PLAN, 1996).

\footnotetext{
20 NCA: National Command Authorities
} 
SEEBER (1993), LEICK (1995) e outros autores a fimam a existência de dois modos de limitações e eles estão a tualmente, ativos. Eles são o AntiSpoofing (AS) e o Selective Availa bility (SA).

\subsection{3- Anti-Spoofing (AS)}

Anti-Spoofing impõe uma limitação ao código-P, isto é, utiliza um código de proteção chamado código-Y, como meio de alteraro acesso ao código-P. Assim, o acesso ao código-P é permitido somente aos usuários autoriza dos quando o AS está a tivado.

\subsection{4- Selective Availbility (SA)}

Selective Availbility (SA) é uma degradação intencional imposta aos sina is GPS, através da manipulação de dados de efemérides transmitidas e/ou da perturbação da estabilidade dos relógios dos satélites. O SA provoca erro de posicionamento da ordem de $100 \mathrm{~m}$ com confiança de 95\%. No entanto, atualmente, têm-se conhecimento da obtenção de trabalhos com grande precisão a pesar deste efeito. 


\section{CAPÍTULO 5}

\section{INFLUENNTES SOBRE A PROPAGAÇÃO DO SINAL GPS}

" Surpreender-se, a dmirar-se, é começara entender."

\section{Sumário detalhado do Capítulo 5}

5 - Introdução 27

5.1 - Atraso de Propagação na Ionosfera 27

5.1.1 - Influência da aurora polar e da atividade solar 30

5.1.2.- Influência da cintilação ionosférica 31

5.2 - Atraso de Propagação na Troposfera 32

5.2.1 - Modelos Troposféricos 33

5.2.1.1 - Modelo do atraso total de Saastamoinen: 34

5.2.1.2 - Modelo do atraso total de Hopfield 45

5.3 - Efeito do Multicaminhamento nas proximidades da Antena do Receptor 45

5.4 - Influência da Variação do Centro de fase da Antena 46

5.5 - Influência Meteorológica 47

5.6 - Sensibilidade ao Vapor de Água 49

5.7 - Perda de Ciclos 51

5.8 - Ambigüidade 52

5.9 - Erros do Relógio 53 


\section{5 - Introdução}

A atmosfera é composta por gases secos e vapor de água. A estrutura da atmosfera pode ser descrita por meio de diversas camadas atmosféricas (ionosfera, troposfera, atmosfera superior e inferior, magnetosfera, mesosfera, etc) com diferentes propriedades físicas e químicas.

De acordo com SEEBER (1993), os sina is, no ca minho entre o sa télite e a estação terrestre, propagando através das diferentes regiões atmosféricas estão sujeitos a diferentes tipos de influências. Podem sofrer variações nas direções, na velocidade e na intensidade de propagação dos sinais.

Para os usuários é interessante a recepção de sinais sem perturbações atmosféricas. Assim, as influências atmosféricas têm que ser determinadas diretamente por medições e/ou por modelos, de modo a serem considerados no processamento dos dados.

Desta forma, com relação à propagação do sinal, a subdivisão entre troposfera e ionosfera é aconselhável, porque as condições particula res de propagação são bastante diferentes.

\section{1 - Atraso de Propagação na Ionosfera}

A ionosfera é a região da atmosfera entre aproximadamente 50 a $1000 \mathrm{~km}$ de altitude, onde a radiação ultravioleta do Sol ioniza frações de moléculas de gás local gerando elétrons livres.

A maior parte da ionosfera é eletricamente neutra, mas quando radiações solares atingem os componentes químicos desta região da atmosfera, os elétrons são desalojados dos átomos e moléculas para produzir o plasma ionosférico. Isto ocorre no lado da Terra iluminado pelo 
Sol. A presença destas partíc ulas carregadas toma a atmosfera superior um condutor elétric o que afeta as ondas de rádio.

Os sina is GPS, como qualquer sinal eletromagnético que se propaga por um meio ionizado, são afetados pelas caracteństicas de dispersão não linea res deste meio.

A ionosfera é composta pelas regiões denominadas de D, E, F1 e F2, nomeadas em ordem crescente de altitude.

As características ma is importantes de cada região e os efeitos da ionosfera sobre os sina is G PS são:

- Região D, 50-90km: esta região, produzida pela ionização de diversas espécies de moléculas, não causam perturbações sobre as freqüências do GPS;

* Região E, 90-140 km: produz perturbações mínimas sobre os sina is GPS, mas pode causar efeitos de cintilação. De qualquer modo, seus efeitos sobre as freqüências GPS são desprezados;

- Região F1, 140-210 km: esta região em conjunto com a região E pode responder por mais de $10 \%$ do atraso ionosférico encontrado nos sina is GPS;

- Região F2, 210-1000 km: é a mais densa e causa a maioria das perturbações nos sina is GPS. A altitude em que se registram as maiores densidade de elétrons varia de 250 a $400 \mathrm{~km}$. A região F2 e parte da F1 respondem pela maior parte das perturbações na propagação das freqüências do GPS;

- Altitude maior que $\mathbf{1 0 0 0} \mathbf{~ k m : ~ i n i c i a - s e ~ a ~ c a m a d a ~ d a ~ a t m o s f e r a ~}$ chamada protonosfera, que se estende além da altitude da órbita dos satélites GPS ( $\cong 20.200 \mathrm{~km}$ ). A contribuição da protonosfera corresponde à $10 \%$ do total do a traso ionosférico (KLOBUCHAR, 1996). 
Irregularidades na ionosfera terrestre produzem variações na amplitude e na fase do sinal e grande número de perda de ciclos (WANNING ER, 1992; PEIERSO N et al., 1997).

O efeito ionosférico é proporcional ao número de elétrons livres (chamado de TEC ${ }^{21}$ ), encontrados ao longo do caminho percomido pelo sinal até a antena receptora e também proporcional ao inverso do quadrado da freqüência da portadora $\left(1 / f^{2}\right)$. Estes efeitos são menos sensíveis nas zonas temperadas, ao passo que, próximo ao Equador ou dos pólos magnéticos ocorrem de maneira considerável (PARKINSON et al., 1996). A propagação dos efeitos ionosféricos sobre as ondas de rádio é quantific ada pelo índice de refração da ionosfera (n²) (KLOBUCHARD, 1996).

Ainda, TEC é definido como o número de elétrons livres existentes em uma sessão de cilindro, na ionosfera, na direção do caminho do sinal do sa télite até o receptor (WARNANT, 1997).

$$
1 T E C=10^{16} \text { elétrons } / \mathrm{m}^{2}
$$

A ionosfera varia muito por causa das mudanças nas duas fontes de ionização e por causa das mudanças na parte neutra da atmosfera superior, da qual faz parte. Esta região da atmosfera é conhecida por termosfera. A ionosfera varia em um peńodo de 24 horas, entre o dia e a noite, em um ciclo de 11 anos da atividade solar.

Esta variabilidade é apresentada na TABELA 04, onde está ilustrada variabilidade diuma e o ciclo solar, na região $F$, dos três parâmetros ionosféricos: $N_{\max }$ (densidade de elétrons), MUF (máxima freqüência usual) e TEC.

TABEA 04 - Parâmetros ionosféricos

\begin{tabular}{lll}
\hline \multicolumn{1}{c}{ Parâmetro lonosférico } & \multicolumn{1}{c}{ Variabilidade Diuma (latitude) } & \multicolumn{1}{c}{ Ciclo solar(dia) } \\
\hline$N_{\max }$ & $1 \times 10^{5}$ a $1 \times 10^{6}$ elétrons $/ \mathrm{cm}^{3}$ & $4 \times 10^{5}$ a $2 \times 10^{6}$ elétrons $/ \mathrm{cm}^{3}$ \\
Freqüência máxima usual & 12 a $36 \mathrm{MHz}$ & 21 a $42 \mathrm{MHz}$ \\
TEC & 5 a $50 \times 10^{16}$ elétrons $/ \mathrm{m}^{2}$ & 10 a $50 \times 10^{16}$ elétrons/ $\mathrm{m}^{2}$ \\
\hline \hline
\end{tabular}

21 TEC: Total Electron Content 
A maior freqüência usual depende da densidade dos picos de elétrons na região $\mathrm{Fe}$ do ângulo de incidência da onda de rádio.

A freqüência mais baixa usual (LUF) é severamente afetada por cintilações sola res.

\subsection{1 - Influência da aurora polar e da atividade solar}

Para a ltas altitudes há outra fonte de ionização, chamada de aurora. A aurora é a exposição de luz, causada por elétrons e prótons, golpeando a atmosfera em alta velocidade. As partículas vindas da magnetosfera produzem um espetacular caminho de luz e quando elas atingem a atmosfera, produzem ionização. A aurora oval, assim chamada por causa de sua forma, ocorre nos hemisférios norte e sul, aproximadamente acima de $60^{\circ}$ de latitude.

Segundo GREER (1999), o ano de 1994 caracterizou-se pela ocorência de baixa atividade solar. A baixa atividade solar caracteriza-se por períodos em que as manchas solares são pequenas. E períodos de baixa atividade solar diminuem a atividade da aurora; o que ocorreu em 1994. Informações diárias de previsões sobre o comportamento atividade solarpodem ser obtidas no endereço eletrônico: http://sec.noaa.gov/info/.

De acordo com EVANS (1999), a atividade solar pode ser medida pelo tamanho das manchas solares (sunspot), calculadas diariamente.

Estas manchas solares vêm sendo monitoradas há muito tempo. Analisadas, permitiram detectar regularidades em seus períodos de ocorência, definindo, para o sol, um ciclo de onze anos, ou seja, há um período de 4 anos até a ocorrência da máxima ativida de solar, seguido de uma declinação gradual, em sete anos, a té a ocorrência da ativida de solar mínima. A FIGURA 04 ilustra a ocorrência do ciclo das atividades solares. 


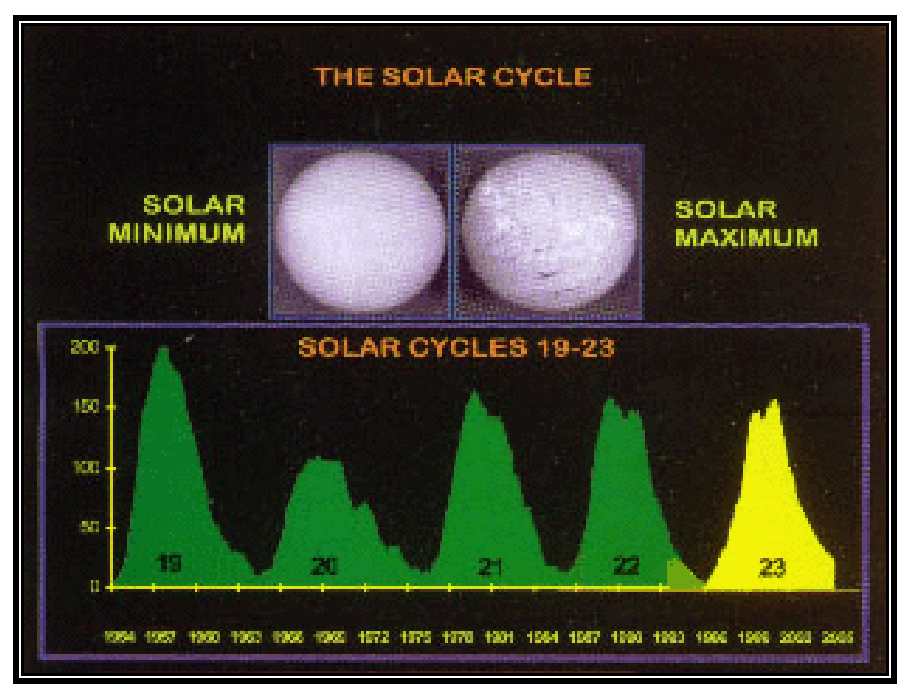

FGURA 03 - Ciclo das a tivida des solares

\subsection{2. - Influência da cintilação ionosférica}

Cintilações ionosféricas causam variações rápidas na amplitude da fase do sinal, resultantes de densidades irregulares na ionosfera. O maior impacto da cintilação ocorre sobre as comunicações via satélite e os sistemas de navegação.

Há certas regiões da ionosfera (principalmente altas altitude e baixas altitudes da região F) e certos horários, (principalmente após o pôr-do-sol) quando a ionosfera pode tomar-se altamente turbulenta, até aproximadamente, a meia-noite (KLOBUCHAR, 1996). Assim, este período deve ser evitado para medições precisas. Ainda, os efeitos de cintilação são menos signific a tivos de abril a agosto na América do Sul.

"Turbulência" é definida aqui, como a presença de anomalidades, em grande escala (dezenas de quilômetros), no ambiente ionosférico. Sob condições favoráveis, as irregularidades na densidade do plasma ocorrem exatamente após o pôr-do-sol na região equatorial. Em altas altitudes, estas irregularidades podem ser geradas durante o dia ou a noite. Para ambas regiões de baixas e altas altitudes as irregularidades de pequena escala ocorrem mais freqüentemente durante o período do ciclo solarmáximo. 
E nestas regiões, as cintilações têm capacidade para afetar todo o sistema GPS, incluindo ambas as freqüências, simplese dupla. Aumentam os erros de medições de distâncias pelo código ou pela portadora, bem como a probabilidade de perda de sinal. Ainda, dependendo da geometria e constelação dos satélites e de irregularidades na ionosfera, estes efeitos podem traduzir-se em precisão muito baixa de medidas. Pesquisas são desenvolvidas, hoje, com o objetivo desenvolver um modelo de cintilação que fomeça previsões de probabilidade de sua ocorrência, distribuição espacial e intensidade (KNIGHTet al.,1998).

\section{2 - Atraso de Propagação na Troposfera}

Troposfera é a parte inferior da atmosfera terrestre que se estende da superfíc ie terrestre a té a proximadamente $40 \mathrm{~km}$ de altitude.

O componente vapor de água da atmosfera encontra-se confinado na troposfera até $12 \mathrm{~km}$ de altitude do nível do mar e sua maior concentração ocorre abaixo de $4 \mathrm{~km}$ de altitude.

Variações de temperatura, pressão e umidade contribuem para variações na velocidade das ondas de rádio. Tanto o código como a portadora sofre o mesmo atraso.

O atraso troposférico de propagação é crítico para posicionamento preciso e para deteminação de linhas bases, porque os parâmetros troposféricos se correlacionam pobremente em grandes distâncias. Ele é composto pelos atrasos causados pela componente úmida e pela componente seca.

A componente seca que é facilmente modelada é responsável pela maior parte do atraso troposférico e varia com a temperatura local e a pressão atmosférica. 
A componente úmida, que depende da distribuição do vapor de água na atmosfera, provoca atraso de ordem dez vezes menor que o provocado pela seca.

O efeito de cintilação troposférico ocorre principalmente, nos primeiros quilômetros a cima da superfíc ie terrestre. Varia com o ângulo de elevação e com as condições do tempo. Para as freqüências do GPS estes efeitos são rela tiva mente pequenos (SPILKER J r., 1996).

Segundo WELLS et al. (1986), os modelos troposféricos disponíveis, mesmo com dados meteorológicos em tempo real, reduzem os efeitos troposféricos em 92\% a 95\%, dependendo do montante de informações atmosféricas disponíveis para o usuário. Usuários com bons conhecimento das condições atmosféricas, nas proximidades dos locais de observações, terão um erro residual menor que usuários que confiam em dados médios ou a proxima dos.

\subsection{1 - Modelos Troposféricos}

Existem diversos modelos, Hopfield Model; Black and Eisner (B\&E) Model; Water Vapor Zenith Delay Model - Beman; Davis, Chao and Marini Mapping Functions; Altshuler and kalaghan Delay Model; Ray Tracing and Simplified Models (SPILKER J r., 1996), que neste momento são apenas citados.

Apresenta-se abaixo o modelo de atraso troposférico de Saastamoinen, que é o modelo utilizado no programa de processamento OMNI v4.0 e o modelo de atraso troposférico de Hopfield. 


\subsubsection{1 - Modelo do atraso total de Saastamoinen:}

Em uma série de documentos de 1972 e 1973, Saastamoinen apresentou um dos primeiros modelos de refração de troposfera que estimava o atraso em relação ao ângulo de elevação. Saastamoinen descreveu um modelo preciso e um modelo padrão para o atraso troposférico. Somente o atraso troposférico do modelo padrão é apresentado aqui. A correção do atraso para as freqüências variando-se o ângulo de elevação acima de $10^{\circ}$ é dada abaixo:

$$
\Delta=0.002277(1+D) \sec \psi_{o}\left[P_{o}+\left(\frac{1255}{T_{o}}+0.05\right) e_{o}-B \tan ^{2} \psi_{o}\right]+\delta_{R} m
$$

onde, $\Delta$ é a correção do a traso em m;

$P_{o}$ é a pressão ao nível do marem mb;

$e_{o}$ advém de $e=e_{o}\left(T / T_{o}\right)^{-4 g M / R \beta}$, onde M é a massa molar do ar; $g$ é a aceleração da gravidade;

$R$ é a constante universal dos gases; $\beta$ é o valor $-6.81^{\circ} \mathrm{K} / \mathrm{km}$;

$T_{o}$ é a temperatura a o nível do mar em ${ }^{\circ} \mathrm{K}$;

$\psi_{0}=90^{\circ}-\mathrm{E}$, onde $\psi_{\circ}$ é o ângulo zenital e $\mathrm{E}$ é o ângulo de elevação (este modelo considera apenas as freqüências de rádio captadas em ângulo de elevação $E \geq 10^{\circ}$ );

$\mathrm{D}=0.0026 \cos 2 \phi+0.00028 h$, onde $\phi$ é a latitude local e h é a altitude da estação em km;

$B(m b)$ e $\delta_{R}(m)$ são termos de correção em relação à altitude $\mathrm{h}$ do usuário, dados por uma tabela, que não é a presentada no momento (SPILKER J r., 1996). 


\subsubsection{2 - Modelo do atraso total de Hopfield}

Calcula o atraso total através dos atrasos causados pelas componentes seca e úmida. O índice de refração vertical da umidade, ou seja o atraso provocado pelas componentes seca e úmida é calculado integrando-se os índices de refração seco e úmido, para a superfície onde $h$ é a altitude; daí o nome integração vertical da umidade.

Osíndic es de refração que serão integrados são:

$\checkmark$ Índice de refração seco: $N_{d}(h)=N_{d 0}\left(1-\frac{h}{h_{d}}\right)^{4}$ para $h \leq h_{d}=43 \mathrm{~km} \quad \mathrm{e}$ $\checkmark$ Índice de refração úmido: $N_{w}(h)=N_{w 0}\left(1-\frac{h}{h_{w}}\right)^{4} \quad$ para $h \leq h_{w}=12 \mathrm{~km}$,

Sendo que $h_{d}$ e $h_{w}$ referem-se às altitudes onde as superfícies de refração $N_{d 0}$ (seca) e $N_{w 0}$ (úmida) são medidas, respectivamente.

Após integração, o atraso troposférico é dado por:

$$
\Delta=\frac{10^{-6}}{5}\left[N_{d 0} h_{d}+N_{w 0} h_{w}\right]=\Delta_{d}+\Delta_{w} \text { (SPILKER J r., 1996). }
$$

\section{3 - Efeito do Multicaminhamento nas proximidades da Antena do Receptor}

O efeito do multicaminhamento é descrito pelo próprio nome: o sinal emitido pelo satélite chega à antena receptora por mais de um caminho. É causado principalmente pela reflexão dos sinais em superfícies 
consideradas refletoras, edifício, nos, veículos, cercas metálicas, etc (HOFMANN-WELLENHOF et al., 1997).

O multicaminhamento afeta tanto as medições do código como da portadora. O efeito sobre as observações do código-P é de ordem duas vezes maior que os efeitos sobre observações da fase da portadora. Sob condições ruins, o multicaminhamento do sinal do código pode causar a perda de contato do mesmo com o receptor. Muitas perdas de ciclos são produzidas pelo efeito do multic aminhamento.

\section{4 - Influência da Variação do Centro de fase da Antena}

O centro de fase das antenas de receptores GPS, geralmente, é assumido como o ponto que está sendo medido e não coincide com o centro geométrico da própria antena.

As variações do centro de fase da antena dependem da elevação dos satélites, da mudança da direção do sinal do satélite, da intensidade destes sina is e ressalta-se que são diferentes para as portadora s L1 e L2.

O desprezo das variações do centro de fase da antena pode conduzir a erros vertica is maiores que $10 \mathrm{~cm}$. Pesquisas, como a realizada por JOHASSON et al. (1998), na rede GPS da Suécia, mostra que foi possível constatar que um dos efeitos mais severos à precisão é a aparente variação do centro de fase da antena GPS, como uma função de ângulo de elevação de observação do sa télite.

Contudo, como as variações são sistemáticas, podem ser investigadas por meio de testes. O NGS realiza calibração de antenas através de uma série de testes, com diversas antenas, para determinar a 
posição e as variações dos centros de fase para a L1, L2 e L3 (MADER, 1999; HOFMANN-WEயENHOF et al. 1997). Nas novas a ntenas existentes, os efeitos destas va riações estã o minimiza dos.

No OMN122 v4.0 (um dos softwares que foram utilizados para o processamento de dados GPS) já está introduzido 11 modelos de antenas GPS e os respectivos offsets entre os centros de fase das porta doras L1 e $L$.

Desta forma, realizou-se o processamento dos dados da rede GPS do Estado de São Paulo, introduzindo os offsets para as variações do centro de fase da antena, em relação às portadoras L1 e L2. O tipo de antena, que foi utilizada nas observações desta rede, é a Trimble P/N:14532-00 e os valores dos offsets para as porta doras sã o: $1.51 \mathrm{~m}$ para L1 e $1.15 \mathrm{~m}$ pa ra $\mathrm{L} 2$.

\section{5 - Influência Meteorológica}

A seguir são apresentadas opiniões de pesquisadores sobre a importância de considerar dados meteorológic os reais em processamentos de observações GPS.

Segundo FABRY (1999), a influência de dados meteorológicos reais depende do que se está tentando medir e com que precisão. O GPS tem muitas aplicações de posicionamento simples, e estas aplicações têm exigências diferentes em temos de precisão. Para a maionia das a plicações em posicionamento, Fabry diz que há necessidade de dados de pressão ou temperatura. Mas, para posicionamento de alta precisão, particularmente na vertical, a pressão (integrada com a umidade) contamina a medição. E por causa disto, estão começando a usar o GPS para medir a integração vertical de umidade. Fabry ressalta, ainda, que a temperatura não tem influência por si só; porém, desde que haja uma correlação entre 
temperatura e umidade, é possível que o conhecimento da temperatura ajude, masa correção não será tão precisa quanto a inclusão da pressão.

DANA (1999), também revela que dependendo do tipo de trabalho que esteja sendo desenvolvido, modelos troposféricos podem ser melhorados significativamente, usando medidas reais de temperatura, pressão, e umidade. Diz ainda, que estas melhorias só ajudam na fase da portadora para linhas bases longas. Para levantamentos nomais com GPS, onde quase todas as medidas são feitas dentro de 10 a $39 \mathrm{~km}$ da estação de referência, o atraso troposférico é comum a ambos os receptores e assim não há problema, mas para trabalhar com linhas bases longas ( centenas de quilômetros) um bom modelo troposférico é importante e isso requer medidas boas de temperatura, pressão, umidade.

Segundo SCHERNECK (1999), quase sempre, utilizar dados meteorológic os observados é melhor que utilizar dados retirados de livros, especialmente quando os processamentos são complicados. A influência dos fenômenos meteorológic os em uma estação de GPS é particula mente importante quando se trata da umidade, mais especificamente da quantia de vapor de água na atmosfera. As influências restantes da temperatura e da pressão, porém, não são tão severas. A temperatura, gera um efeito muito pequeno e portanto, é desprezado. Ainda, medidas realizadas na superfíc ie terrestre dizem muito pouco sobre o que está acontecendo a 10 , 100 ou até mesmo $1000 \mathrm{~m}$, onde a maioria dos movimentos de vapor de água acontece. Para posicionamentos geodésicos com precisão ao nível de milímetro a situação fica mais crítica. Assim, em se tratando de vapor de água, a influência é um processo complicado, mas se é conhecida a redistribuição deste vapor de água no tempo e no espaço, não há necessidade de saber a temperatura.

HUDNUT (1999) relata que a rede SCIGN (Southem Califomia Integrated GPS Network) possui estações que registram dados de instrumentos meteorológicos. Alguns cientistas escolhem processar dados 
usando medidas atuais destes instrumentos, outros não e há poucos modelos de parâmetros atmosféricos. Tipicamente, dados de instrumentos meteorológicos são usados para pode resolver o atraso na troposfera devido a umidade.

Segundo SHUM (1999), meteorologia com GPS ou perturbação do sinal, quando este passa através da atmosfera, é uma tecnologia e conceito relativamente novos. O conceito de medir atrasos (da troposfera componente úmida e seca - e da ionosfera), os qua is são usadas para entender a atmosfera no momento de observações com GPS, tem um potencial para aumentar os conhecimento sobre o tempo, melhorando sua predição. O GPS, em essência, mede atrasos integrados (soma) ao longo do caminho do sinal: atraso na troposfera úmida (vapor de água na atmosfera) e atraso na ionosfera. Procedimentos sofisticados são necessários para "separar" estes atrasos e tem-se que assumir alguns conhecimentos sobre as condições atmosféricas, por exemplo, pressão e temperatura.

Estas explanações confirmam a validade de um dos objetivos deste trabalho, verificar a influência de dados meteorológico reais no processamento de linhas bases longas, através do processamento dos dados obsenvados da rede GPS do Estado de São Paulo utilizando dados meteorológic os rea is.

\section{6 - Sensibilidade ao Vapor de Água}

Atualmente, em virtude da comprovação do atraso do sinal GPS provocado pelo vapor de água existente na atmosfera, estudos estão sendo desenvolvidos com o objetivo de formar um banco de dados sobre quantia de vapor de água na atmosfera, para ser utilizado em processamentos, pelo usuário do sistema GPS. 
WARE et al. (1995) a firmam que sinais de GPS são perturbados pelo vaporde água atmosférico, causando atrasos em sua propagação.

GUTMAN (1997) relatou que as previsões de precipitação estão, atualmente, limitadas por falta de informações sobre a variabilidade temporal e espacial do vapor de água na atmosfera. Superar este problema é crucial para entender melhor o ciclo hidrológico para todas as escalas (local para global), prazos (de hora em hora), e locais (terra e oceano). O conhecimento da distribuição de vapor de água na atmosfera não só é importante em meteorologia, como é necessário para outras aplicações: levantamentos GPS e na navegação. Isto porque o sinal de GPS é atrasado pelo vaporde água na troposfera.

ROCKEN et al. (1995) afimam que o vapor de água é um dos componentes ma is importantes da atmosfera, pois é o mecanismo principal pelo qual são transporta dos umidade e calor. Ainda, quantias pequenas de vapor de água atmosférico afetam significativamente a velocidade de propagação dos sinais de GPS. O sinal GPS é tão sensível ao índice de refração da atmosfera, e sendo este índice uma função de pressão, temperatura, e umidade, o GPS pode ser usado diretamente para "sentir" as propriedades da atmosfera.

Sobre efeitos troposféricos em observações geodésicas, SC HENEWERK et al. (1998), estão realizando experimentos em TMGO (Table Mountain Geophysical Observatory) para verificar o quanto os atrasos troposféricos, especificamente sua componente úmida, afetam as observações GPS. Estão sendo aguardados os resulta dos destes experimentos.

JOHASSON et al. (1998) apresentam pesquisas para verificar a correlação entre coordenadas obtidas por GPS e a variação do vapor de água na atmosfera, usando dados de umidade, dos outonos de 1995 e 1996. O trabalho está sendo desenvolvido na rede GPS da Suécia (SWEPOS). 
Constataram, até o momento, que variações atmosféricas (variações horizontais locais do vapor de água e do correspondente índice de refração) podem influenciar os resultados de GPS. Procuram, então, pela possibilidade de correlações entre variações atmosféricas e a estimativa da coordenada vertical do local. Estão sendo aguardados, também, os resulta dos destas pesquisas.

\section{7 - Perda de Ciclos}

De a cordo com SEEBER (1993) e SEG ANTINE (1995), a perda de ciclos ocorre se o receptor perde a fase do sinal do satélite. Os motivos para a perda de ciclos podem ser.

Ded Dependentes da observação:

$\checkmark$ Obstruções do sinal devido à presença de árvores, edifícios, pontes, etc;

$\checkmark$ Ruído no sinal, em particular causado por multicaminhamento e cintilações (variações na amplitude e na fase do sinal) ionosféric as;

$\checkmark$ Satélites de baixa elevação, causando sina is fracos;

$\checkmark$ Funcionamento ruim dos osciladores dos sa télites;

[D] Dependentes do receptor:

$\checkmark$ Sina is fracos, particula mente causa dos por interferência no sinal;

$\checkmark$ Inc linação da a ntena em a plic ações c inemátic as (a viões, na vios);

$\checkmark$ Falha no programa do receptor, etc. 
A perda de ciclo é identificada quando a portadora da fase apresenta um salto súbito no número inteiro de ciclos; a parte fracionária das observações da fase permanece inalterada. Ela tem que ser detectada e removida dos dados.

WELLS (1986), a firma que há várias possibilidades de correção da perda de ciclos. Um método de correção é considerar uma estação como referência, editar os dados e manualmente inspecionar a série residual correspondente às intemupções do sinal. Outro método é o processamento da tripla diferença, que permite identificar descontinuidades. A tripla diferença permite eliminar os emos de relógio do receptor ou do sa télite.

\section{8 - Ambigüidade}

Os dados observados com o GPS podem ser deduzidos a partir: da medida do tempo de percurso do sinal emitido pelo satélite até a antena receptora ou pela diferença de fase entre os sinais emitidos e os gerados intemamente pelos receptores (SEEBER, 1993).

As observações da fase da portadora, quando o sinal do satélite é recebido pela antena, são consideradas como sendo a diferença de fases entre a fase que vem do sinal do satélite e a fase gerada intemamente dentro do receptor, para um dado tempo to.

Segundo CANNON et al. (1992), a portadora, quando comparada com o comprimento de onda do sinal, apresenta uma diferença de medida entre o sa télite e a antena, relacionada com certos números de ciclos. Este número inteiro de ciclos, usualmente, conhecido por ambigüidade de ciclos, "N" é o número desconhecido de comprimentos de onda entre o satélite e a antena do receptor. 
A melhor e a possibilidade mais simples de determinação da ambigüidade pode ser a utilização de freqüências adicionais ou sinais, que são utiliza dos nas medições eletrônic as de distâncias terrestres. Infelizmente, o GPS não fomece, ainda, mais que duas freqüências e estratégias particulares foram desenvolvidas para resolver o problema das a mbigüidades.

Quando a medição de fase de uma freqüência é avaliada (L1 ou L2), as mediç ões podem ser modeladas. Muitas fontes de erros sã o a fetadas pela estimativa da aproximação das ambigüidades para valores inteiros. Algumas destas fontes são: o comprimento da linha base e os emos orbitais. Quando é utilizada a fase de dupla freqüência para resolução da ambigüidade, a situação muda significativamente. Devido à várias possibilidades de combinação linear que podem ser realizadas, àquela tarefa pode ser realizada de maneira mais rápida (CANNON et al. 1992).

Os valores de ambigüidade estimados podem ser números reais (ambiguity float ou ambiguity free solution), ou podem ser fixados em números inteiros (ambiguity fixed solution). Para linhas bases maiores que $20 \mathrm{~km}$, usualmente, não se fixa a a mbigüidade.

\section{9 - Erros do Relógio}

Há dois tipos de observáveis GPS: pseudodistâncias (pseudoranges) e fases das portadoras. Ambas observáveis são afetadas pelos erros dos relógios do satélite e do receptor (LEICK, 1995).

$\mathrm{Na}$ inicialização da recepção das mensagens de navegação, o relógio do receptor se sincroniza com o relógio dos sa télites do sistema GPS. 
No entanto, esta sincronização não é perfeita devido à diferença de qualidade dos relógios.

Uma vez que, o receptor calcula a distância entre a antena e os satélites, através do tempo de viagem dessa mensagem multiplicado pela velocidade da luz, esse tempo é o tempo real acrescido de um erro residual.

Assim, os valores de pseudodistâncias calculados irão diferir ligeiramente porque os erros individua is dos relógios dos satélites diferem, por causa dos erros de efemérides, dos atrasos devido à ionosfera e à troposfera e do multic a minhamento.

As observações da simples diferença de fase são sensíveis à diferença dos emos dos relógios, enquanto que as observações da dupla diferença são usa das para elimina r estes erros (LEICK, 1995). 


\section{CAPÍTULO 6}

\section{GRANDEZAS OBSERVÁVEIS}

"Todos vivemos sob o mesmo céu, mas nem todos vêem o mesmo horizonte. "

Konrad Adenauer (1876-1967), Estadista alemão.

\section{Sumário detalhado do Capítulo 6}

\section{1 - Pseudodistância}

6.2 - Fase da Portadora 46

6.2.1 - Simples diferença 46

6.2.2 - Dupla diferença 47

6.2.3 - Tripla diferença 48 


\section{1 - Pseudodistância}

A pseudodistância deveria ser igual à distância geométrica que o sinal percorre do instante em que é emitido pelo satélite, até a antena receptora, se esta propagação ocorresse no vácuo (onde não ocorrem desvios) e não houvesse erros nos relógios do receptor.

Assim, diz-se que a pseudodistância é o valor da distância geométrica percomida pelo sinal, acrescido dos atrasos de propagação do sinal na ionosfera e na troposfera, dos emos no relógio do receptor e do multic a minha mento (LEICK, 1995).

\section{2 - Fase da Portadora}

A fase observável é a diferença entre a fase da portadora recebida do satélite e a fase gerada pelo oscilador intemo no receptor( LEICK, 1995).

\subsection{1 - Simples diferença}

Pode ser formada entre dois receptores, dois satélites e duas épocas ou instantes. A FIGURA 04 ilustra uma configuração de observações da simples diferença. 


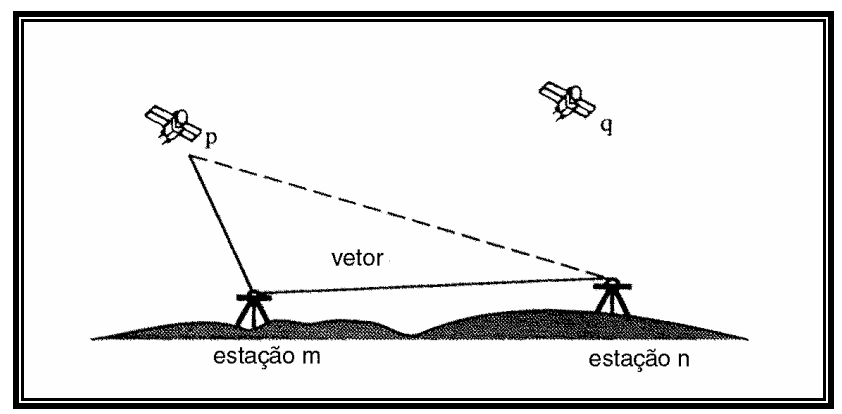

FGURA 04 - Obsenvação da simples diferença

A simples diferença entre dois receptores constitui-se de medições de pseudodistâncias de uma estação, subtraídas de medições de pseudodistâncias de uma segunda estação, utilizando os mesmos sa télites.

Se a simples diferença entre satélites é formada, isto é, observações entre dois satélites simultaneamente tomadas numa estação simples, o termo referente ao erro do relógio do receptor se cancela.

Com a simples diferença entre duas épocas para um mesmo satélite, a ambigüidade $\mathrm{N}$ se cancela, porque a fase inicial de ambigüidade não varia com o tempo (até que não ocorra uma perda de ciclo) (SEEBER, 1993).

\subsection{2 - Dupla diferença}

É usualmente formada entre receptores e satélites. Constitui-se de duas simples diferenças.

As observações da dupla diferença estão livres dos erros dos relógios dos satélites e dos receptores, devido ao fato das observações serem simultâneas. São freqüentemente usadas na edição de perdas de ciclo (SEEBER, 1993). Mas, incluem erros de propagação dos sina is, erros orbita is e não cancelam o efeito do multicaminhamento (LEICK,1995). A FIGURA 05 ilustra uma configuração de dupla diferença entre sa télites e estações. 


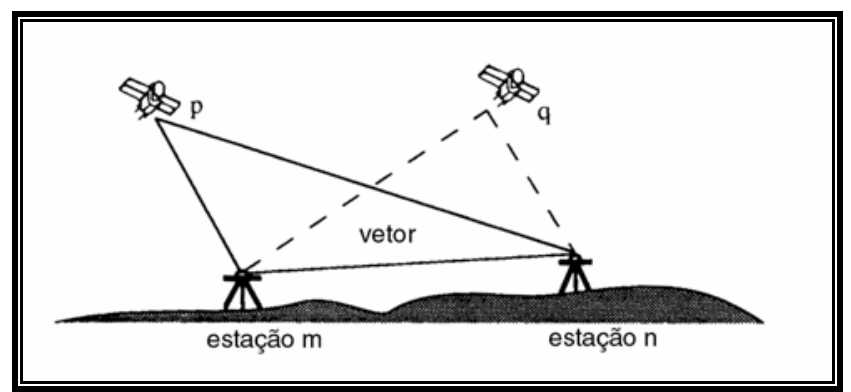

RGURA 05 - Observação da dupla diferença

\subsection{3 - Tripla diferença}

É a diferença de duas duplas diferenças em duasépocas distintas.

A tripla diferença cancela a ambigüidade. Sua solução é considerada uma técnica de pré-processamento para obter posições aproximadaspara a solução da dupla diferença.

Sua maior vantagem reside no fato de conseguir detectar a perda de ciclos e pemitir sua remoção (LEICK, 1995). A FIG URA 06 ilustra uma configuração de tripla diferença.

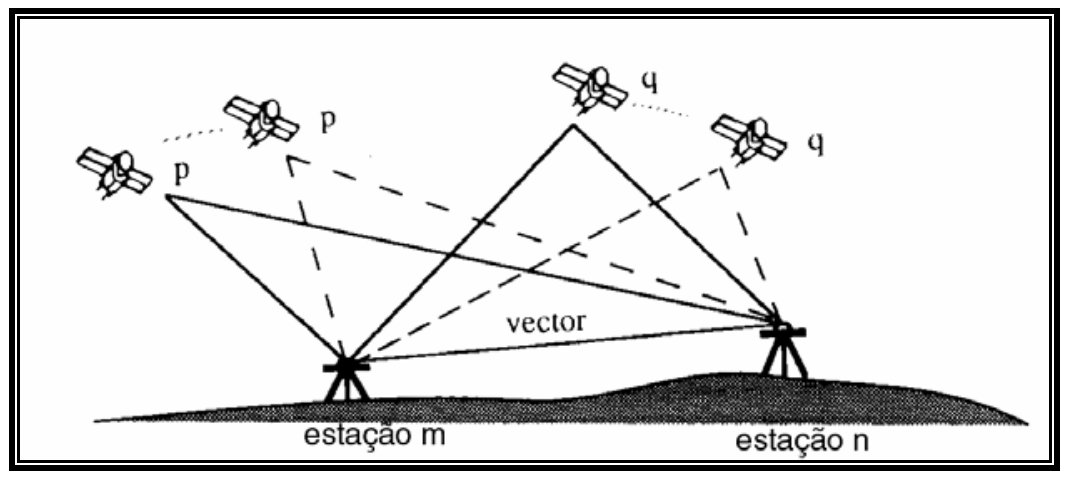

FGURA 06 - Observação da tripla diferença 


\section{CAPÍTULO 7}

\section{REFERENCIAIS}

" Fato notável acerca do sistema nervoso: resolver equações diferencia is e ver um filme de Tom \& J emy queima as mesmas

calorias. "

Do livro Matemática para o Dia - a - Dia, de Charles Seiter (Campus).

\section{Sumário detalhado do Capítulo 7}

7.2 - IERS - International Earth Rotation Service 52

7.2.1 - Referênciais IERS 52

7.2.1.1 - Referênciais ITRF 52

7.3 - Relações entre o WGS 84 e o ITRF 54

7.3.1 - Concordância entre o WGS 84 e o ITRF 54

7.3.2 - Transformação de Sistemas 55 


\section{7 - Introdução}

Os comos celestes estão sujeitos a diversos tipos de movimentos ta is como rotação, translação, acelerações e deformações, mostrando que o universo não é estático. A Geodésia, a Astronomia e a Geofísica preocupam-se com o estudo da cinemática e da dinâmica destes corpos. Os efeitos da rotação da Terra, o movimento do pólo, a tectônica de placas, as marés terrestres e oceânicas, o campo gravitacional e o campo magnético são alguns dos fenômenos dinâmicos que o homem vem estudando e tentando compreender. O movimento e a posição dos corpos não são conceitos absolutos, pois dependem de referências para serem descritos (MUELLER et al., 1977; KOVALESKY et al. 1989). Assim sendo, faz-se necessário adotar um sistema de coordenadas que seja considerado está vel dentro do que se pretende estudar.

Serão apresentadas considerações a respeito dos sistemas de referência envolvidos neste trabalho.

\section{1 - Sistema de Referência WGS 84}

O modelo de referência geocêntrico global e a coleção de modelos, conhecidos como World Geodetic System 1984 (WGS 84), têm sido desenvolvidos desde sua criação em meados de 1980. O WGS 84 continua sendo um sistema de coordenadas tridimensionais para a coleta de dados geoespaciais e na medida em que estes dados passaram a exigir um sistema de referência global, livre de distorções ou erros, uma série de aperfeiçoamentos para o WGS 84 foram desenvolvidos e serviram para refinar versão original.

Nos últimos anos, o sistema de referência WGS 84 passou por dois refinamentos, o primeiro em 1994 e o segundo em 1996. E destes dois refinamentos resultaram, respectivamente, nas versões designadas por: 'WGS 84 (G730)' e 'WGS 84 (G873)', onde 'G' indica a utilização da 
tec nologia GPS e o número seguinte à letra 'G' indica o número da semana GPS quando ocorreu a implementação pelo NIMA22 (NIMA - Technical Report 8350.2, 1997) (Technical Report 8350.2 encontra-se disponível da Intemet no endereço http://gis.nima .mil/geospatial/products/GanG/pubs.html).

As versões a ntec essoras do WG S foram: WGS 60, WGS 66, WG 72 e o WGS 84.

O sistema de coordenadas WGS 84 é um sistema do tipo CTRS (Conventional Terrestrial Reference System). A definição deste sistema de coordenadas segue o critério do Intemational Earth Rotation Service (IERS). E estes critérios são:

Origem: centro de massa da Terra, incluindo oceanos e atmosfera;

Eixo Z Direção do IERS Reference Pole (IRP). Esta direção corresponde à direção do BIH (Bureau Intemational de L'Heure) Conventional Terrestrial Pole (CTP) (época de 1984.0) com a incerteza de 0,005";

Exo X: Intersecção do Plano Meridiano do IERS (IRM) com o plano que passa entre a origem e a normal ao eixo Z O IRM coincide com o Meridiano Zero definido pelo BIH (época 1984) com a incerteza de 0,005";

Exo Y: Completa o sistema dextrogiro, Earth-Centered Earth Fixed (ECEF) sistema ortogonal de coordenada;

Pa râmetros do elipsóide:

$\checkmark$ Semi-eixo maior, $a=6378137 \mathrm{~m}$

$\checkmark$ Achatamento, $f=1 / 298,257223563$

22 NIMA: National Imagery and Mapping Agency 


\section{2 - IERS - International Earth Rotation Service}

O serviço IERS está concretizado em uma estrutura organizacional que permite processamento imediato de dados. É constituído por diversas instituições que contribuem na tarefa de observação e processamento. $O$ IERS é composto de uma Agência Central, Subagências e Centros de Coordenação, para cada uma das principais técnicas de observação, como apresentado na TABELA 05, abaixo.

TABEA 05 - Orga nizaç ão do IERS

\begin{tabular}{ll}
\hline \hline Agência Central \\
\hline Sessões & $\begin{array}{l}\text { De Referenciais Celestes } \\
\text { De Referenciais Terrestres } \\
\text { De Orientação da Terra }\end{array}$ \\
Sub-agências & $\begin{array}{l}\text { Para serviços rápidos e predições } \\
\text { Para atmosfera e momento angular }\end{array}$ \\
Centros & De Coordenação VLBI \\
& De Coordenação LLR \\
& De Coordenação SLR \\
& De Coordenação GPS \\
\hline \hline
\end{tabular}

\subsection{1 - Referenciais IERS}

Os referenciais IERS consistem do ICRF23 e do ITRF24. São abordados neste trabalho os referencia is IRF.

\subsubsection{1 - Referenciais ITRF}

O ITRF é um referencial terrestre do tipo CTRS (Conventional Terrestrial Reference Frame). 
O Sistema de Referência Convencional Terrestre segue os seguintes critérios (BOUC HER, 1990):

$\checkmark$ É geocêntrico, o centro de massa definido para a Terra inclui oceanose atmosfera;

$\checkmark$ A escala é a de um sistema terrestre local, dentro do significado da teoria gravitacional;

$\checkmark$ A orientação foi inicialmente baseada na orientação do BlH para a época 1984;

$\checkmark$ A evolução temporal da orientação não deve pemitir rotação global residual com relação à crosta.

O CTRS, monitorado pelo IERS é chamado de Intemational Terrestrial Reference System (ITRS) e está especificado pelo IUGG ${ }^{25}$, Resolução no. 2, public ada no 20th IUGG General Assembly of Vienna, em 1991.

As publicações dos ITRS são realizadas pelo IERS com o nome de Intemational Terrestrial Reference Frames (ITRF), o qual consiste de uma lista de coordenadas (e velocidades) para os locais selecionados pelo IERS (estações de monitoramento ou marcos terrestres) e por tabelas com parâmetros de tranformação dos referenciais ITRF entre si e entre outros sistemas de referência. O IRF é publicado anualmente pelo IERS nos Technical Notes (McCARTHY, 1996).

As coordenadas do ITRF são dadas em um sistema convencional onde os padrões e parâmetros estão publicados no IERS Technical Note 13 (McCARTHY, 1992). Nessa publicação é apresentado um conjunto de constantes e de modelos usados pelos centros de análise (VLBI, LUR, SLR. GPS) e a combinação de resultados realizada pela Agência Central.

25 IUG G : Intemational Union of Geodesy and Geophysic S 


\section{3 - Relações entre o WGS 84 e o ITRF}

\subsection{1 - Concordância entre o WGS 84 e o ITRF}

Em virtude na grande utilização do WGS 84 e do surgimento do TRF como um sistema de referência, que em virtude do parâmetros que são utilizadas para o cálculo de suas coordenadas, é mais preciso que o WGS 84, surgiu a necessidade de estabelecer parâmetros de correlação entre eles.

Esta correlação foi estabelecida com os conjuntos de coordenadas do WGS que passaram pelos refinamentos em 1994, resultando o conjunto denominado por 'WGS 84 (G 730)' e o realizado em 1996 denominado por 'WGS 84 (G 873)'.

O TECHNICAL REPORT (NIMA, 1997), mostra que após ajustamentos realizados com determinados parâmetros, chegou-se à conclusão de que as coordenadas do WGS 84 (G 730) correspondem às do ITRF92 $\pm 10 \mathrm{~cm}$ e as coordenadas do WGS 84 (G 873) correspondem às do ITRF94 $\pm 2 \mathrm{~cm}$. Afirma, também, que as dispersões diárias dos parâmetros que foram utilizados, mostram que estas diferenças são estatisticamente insignificantes e podem ser considera dos os mesmos, respec tiva mente.

Com o objetivo de confimar e adquirir mais informações sobre as conclusões apresentadas no TECHNICAL REPORT (NIMA, 1997), após pesquisas e contados estabelecidos por e-mails encontrou-se as seguintes a firmações:

MALYS et al. (1997), a presentam as considerações e os procedimentos realizados sobre os refinamentos do WGS 84 , mostrando, também, os 
parâmetros utilizados para a realização das comparações entre o WGS 84 (G873) e o ITRF94, chegando à conclusão que podem ser considerados equivalentes;

[D] ALTAMINI (1999), MALYS (1999) e CORNMAN (1999), através de e-mails, relatam que o WGS 84 (G730) e o ITRF92 podem ser considerados os mesmos, com incerteza de $10 \mathrm{~cm}$. Uma das mensagens recebidas por correio eletrônico está transcrita neste trecho: "The answer to your question is that there is no transfomation parameters available between WGS 84 (G 730) and ITRF92. So you can consider them as the same (within 10cm unc erta inty).(ALTAM IMI, 1999)".

\subsection{2 - Transformação de Sistemas}

Em virtude da existência de diversos sistemas de referência, surgiu a necessidade de calcular parâmetros de transformação entre os sistemas. Estes parâmetros representam a translação de um elipsóide para o outro. (GEMAEL, 1981) Estes parâmetros devem ser aplicados às coordenadas cartesianas.

Sejam dois sistemas cartesia nos, o primeiro $X_{1}, Y_{1}$ e $Z_{1}$, com origem em $\mathrm{O}_{1}$ e o segundo, $X_{2}, Y_{2}$ e $Z_{2}$, com origem em $0_{2}$, ilustra do na FIGURA 07.

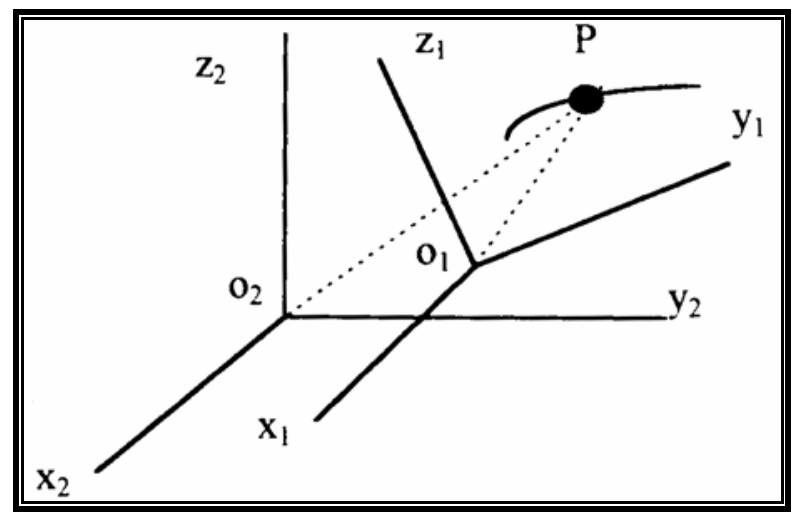




\section{FGURA 07 - Sistemas C artesia nos}

Se os ângulos de rotação forem pequenos, o que ocorre na maioria dos casos, a transfomação entre estes dois sistemas pode ser feito a través da seguinte equação:

$$
\left\{\begin{array}{l}
X_{2} \\
Y_{2} \\
Z_{2}
\end{array}\right\}=\left\{\begin{array}{l}
X_{1} \\
Y_{1} \\
Z_{1}
\end{array}\right\}+\left\{\begin{array}{l}
T 1 \\
T 2 \\
T 3
\end{array}\right\}+\left[\begin{array}{ccc}
D & -R 3 & R 2 \\
R 3 & D & -R 1 \\
-R 2 & R 1 & D
\end{array}\right]\left\{\begin{array}{l}
X_{1} \\
Y_{1} \\
Z_{1}
\end{array}\right\} \quad \text { onde }
$$

$\checkmark \quad X_{2}, Y_{2}$ e Z2 são a s coordena das tra nfforma das (sistema destino 02);

$\checkmark \quad X_{1}, Y_{1}$ e $Z_{1}$ são a s coordena das origina is (sistema origem $0_{1}$ );

$\checkmark$ T1, T2 e T3 são os parâmetros de translação de $0_{2}$ para $0_{1}$, segundo os três eixos;

R1, R2 e R3 são os parâmetros de rotação diferencial em tomo dos eixos, $X_{2}, Y_{2}$ e $Z_{2}$ respectivamente, para estabelecer o paralelismo com os eixos $\mathrm{X}_{1}, \mathrm{Y}_{1}$ e $\mathrm{Z}_{1}$

$\checkmark$ D é o fator de escala.

Para as transforma ções necessárias neste trabalho, de coordenadas no referencial IRR94 para coordenadas no referencial IRRF92, desenvolveuse um programa específico, no software MathCad Professional v7.0, apresentado no ANEXO A.

Os parâmetros de transforma ção, a presentados na TABELA 06, foram fomecidos por ALTAMIMI (1999), mas podem ser obtidos através no endereço eletrônic o: ftp://la reg.ensg.ign.fr/pub/itrf/itrf94/ITRF94.TX.

TABEA 06 - Pa râ metros de transformação de ITRF94 pa ra ITRF92 


\begin{tabular}{cccccccc}
\hline \hline De $\Rightarrow$ Para & $\mathbf{T}$ & $\mathbf{T 2}$ & $\mathbf{T 3}$ & $\mathbf{D}$ & $\mathbf{R 1}$ & $\mathbf{R 2}$ & $\mathbf{R 3}$ \\
& $\mathbf{c m}$ & $\mathbf{c m}$ & $\mathbf{c m}$ & $\mathbf{1 0}$ & $\mathbf{0 . 0 0 1 "}$ & $\mathbf{0 . 0 0 1 "}$ & $\mathbf{0 . 0 0 1 "}$ \\
\hline IIRP94 $\Rightarrow$ IIRF92 & 0.8 & 0.2 & -0.8 & -0.08 & 0 & 0 & 0 \\
\hline \hline
\end{tabular}

Fonte: ALTAMIMI (1999) 


\section{CAPÍTULO 8}

\section{ELABORAÇÃO DA CONFIGURAÇÃO VETORIAL PARA AS ESTRATÉGIAS DE PROCESSAMENTOS}

" De erro em erro, desc obre-se a verdade inteira. "

Sigmund Freud (1856-1939), a ustríaco, cujos estudos geraram a psic a nálise.

\section{Sumário detalhado do Capitulo 8}

8.1 - Dados Necessários 58

8.2 - Escolha dos Pontos de Injunção 60

8.3 - Escolha dos Vetores para a Composição da Estratégia de Processamento 62

8.4 - Análise ao Nivel de Planejamento das Sessões de Observação 65

8.4.1 - Observações sobre as sessões determinadas em 1994 68

8.5 - Apresentação da Estratégia Proposta 69 


\section{1 - Dados Necessários}

Para a elaboração das estratégias de processamento foi necessária inicia Imente a obtenção:

[- Dos dados GPS da rede do Estado de São Paulo coletados nas campanhas de observação realizadas em 1994, que foram fomecidos por SEG ANTINE (1995), em formato padrão do equipamento utilizado;

A localização e identificação das estações da rede com o nome que está relacionado à localidade da estação, uma abreviação do nome usado no processamento e a indicação do município. Estes foram extraídos de SEGANTINE (1995) e de FONSECA J r. (1996) e podem ser vistos na TABELA 07, abaixo;

TABELA 07 - Identific a dores dos Pontos da Rede GPS do Esta do de São Paulo

\begin{tabular}{|c|c|c|c|}
\hline $\begin{array}{l}\text { Número } \\
\text { do ponto }\end{array}$ & $\begin{array}{c}\text { Nome } \\
\text { abreviado }\end{array}$ & Nome do Ponto & Município/UF \\
\hline 01 & CHUA & VT- CHUA & Uberaba/MG \\
\hline 02 & AVER & Água Vermelha & Guarani d'Oeste/SP \\
\hline 03 & $\mathrm{SJ} \mathrm{RP}$ & São J osé do Rio Preto & São J osé do Rio Preto/SP \\
\hline 04 & JABO & Jaboticabal & Jaboticabal/SP \\
\hline 05 & PIRA & Pirassununga & Pirassununga/SP \\
\hline 06 & LMO & Limoeiro & Mococa/SP \\
\hline 07 & FRCA & Franca & Franca/SP \\
\hline 08 & FERN & Femandópolis & Femandópolis/SP \\
\hline 09 & AVAN & Avanhandava & Buritama/SP \\
\hline 10 & IBIT & lbitinga & Ibitinga/SP \\
\hline 11 & UEPP & UNESP - Presidente Prudente & Presidente Prudente/SP \\
\hline 12 & TAQU & Taquarussú & Itaguagé/PR \\
\hline 13 & SAGR & Salto Grande & Salto Grande/SP \\
\hline 14 & ILHA & Ilha Solteira & Selvíria/SP \\
\hline 15 & USPP & Pilar 1 - USP/SP & São Paulo/SP \\
\hline 16 & BELA & Ilha Bela & Ilha Bela/SP \\
\hline 17 & BUNA & Pa raibuna & Paraibuna/SP \\
\hline 18 & VAU & Valinhos & Valinhos/SP \\
\hline 19 & CAPA & Cachoeira Paulista & Cachoeira Paulista/SP \\
\hline
\end{tabular}


TABEA 07 - Identific a dores dos Pontos da Rede G PS do Esta do de São Paulo

\begin{tabular}{llcc}
20 & REGI & Registro & Registro/SP \\
21 & ITAP & Itapetininga & Itapetininga/SP \\
22 & IEVA & Itapeva & Itapeva/SP \\
23 & BOTU & Botucatu & Botucatu/SP \\
24 & MARI & Mańlia & Marília/SP \\
25 & PANO & Panorama & Panorama/SP \\
\hline
\end{tabular}

Fonte: SEG ANTINE (1995); FONSECA J r. (1996).

[Dapa Ma do Estado de São Paulo para visualização da localização das estações da rede, a presentado na FIG URA 08;

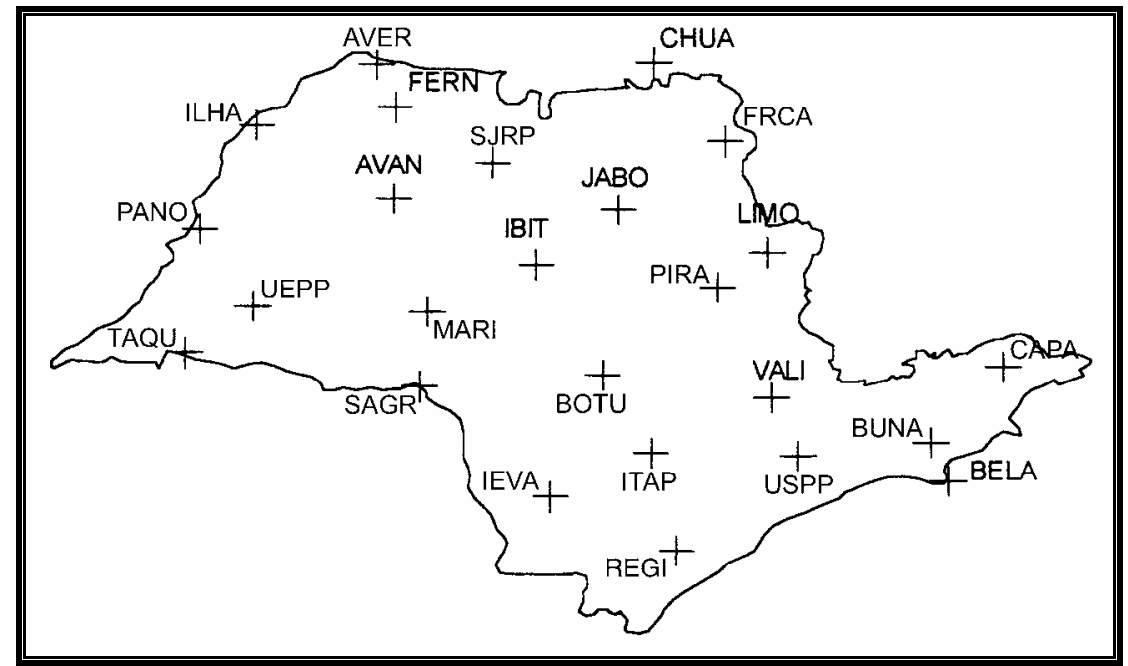

FGURA 08 - Loca lização das estações da rede GPS do Estado de São Paulo

A descrição das sessões de observações, realizadas em 1994, com a indicação do DIA, das estações observadas e a duração de cada sessão. Estes foram extraídos de SEGANTINE (1995) e são mostrados na Tabela 08. 
TABEAA 08 - Descrição das sessões de observação

\begin{tabular}{ccc}
\hline \hline DIA & Estações obsenvadas (nome abreviado) & $\begin{array}{c}\text { Tempo de } \\
\text { obsenvação (h) }\end{array}$ \\
\hline 069 & USPP PIRA BELA BUNA VAU & 5 \\
070 & USPP PIRA LMO FRCA BELA BUNA VAU & 8 \\
071 & PIRA LMO FRCA & 8 \\
072 & CHUÁ AVER SJ RP J ABO PIRA LMO FRCA & 8 \\
073 & CHUÁ SJ RP JABO & 8 \\
074 & CHUÁ AVER SJ RP J ABO FERN AVAN IBIT & 8 \\
075 & AVAN FERN IBIT & 8 \\
076 & UEPP FERN AVAN IBIT TAQU SAGR ILHA & 8 \\
327 & VAU BELA BUNA CAPA & 6 \\
328 & USPP VALI CAPA REGI & 6 \\
329 & ITAP VAU REGI IEVA & 6 \\
332 & UEPP SAGR ITAP IEVA BOTU & 6 \\
333 & UEPP IBIT SAGR BOTU MARI & 6 \\
334 & ILHA IBT MARI PANO & 6 \\
335 & UEPP TAQU SAGR MARI PANO & 6 \\
337 & CHUA UEPP USPP & 6 \\
\hline \hline
\end{tabular}

Fonte: SEGANTINE (1995).

\section{2 - Escolha dos Pontos de Injunção}

Como pontos de injunção, deve-se procurar escolher pontos relevantes para a área em que se está trabalhando ou pontos que façam parte de redes geodésicas, que sejam oficiais e tenham sido estabelecidos por instituições ou grupos que tenham confiabilidade no meio geodésico.

Na elaboração da estratégia proposta foram considerados como pontos de injunção (ponto cujas coordenadas são considera das fixas e sem erros):

$\triangle$ Vértice CHUA: vértice fundamental da triangulação do Sistema Geodésico Brasileiro. A estação CHUA está localizada em uma chapada, $18,1 \mathrm{~km}$ a oeste da cidade de Uberaba-MG. As coordenadas deste ponto, referentes ao WGS - 84 foram obtidas diretamente do Banco de Dados do IBGE, e são apresentadasna TABELA 09: 
TABEA 09 - Coordenadas do Vértice CHUA

\begin{tabular}{lc}
\hline \hline \multicolumn{2}{c}{ WGS- 84 } \\
\hline Coordenadas Geodésicas & Coordenadas Cartesianas \\
\hline$\varphi=-19^{\circ} 45^{\prime} 43,34588^{\prime \prime}$ & $X=4010548,44 \mathrm{~m}$ \\
$\lambda=-48^{\circ} 06^{\prime} 05,67317^{\prime \prime}$ & $Y=4470076,61 \mathrm{~m}$ \\
$\mathrm{~h}=754,150 \mathrm{~m}$ & $\mathrm{Z}=-2143179,02 \mathrm{~m}$ \\
\hline \hline
\end{tabular}

Fonte: Banco de Dados do IBGE

$\triangle$ Estação Cachoeira Paulista (CAPA): esta estação foi ocupada em 1995, pelas campanhas de observação definidas no projeto SIRGAS. Foi utiliza do o mesmo pilar construído para a rede GPS do Estado de São Paulo. As observações ocorreram durante 10 dias, com receptor Trimble SST4000 de dupla freqüência. As coordenadas desta estação, referentes a o ITRF94, obtidas de SIRG AS - Relatório Final (1997) e referentes ao WGS84 e são apresentadas na TABELA 10:

TABELA 10 - Coordenadas da Estação Cachoeira Paulista - SIRG AS

\begin{tabular}{lcc}
\hline \multicolumn{2}{c}{ ITRF94* } & WGS84** \\
\hline Coordenadas Cartesianas & Sigma (m) & Coordenadas Cartesianas \\
\hline$X=4164684,609 m$ & 0.004 & $X=4164684,614 m$ \\
$Y=-4162401,036 m$ & 0.004 & $Y=-4162401,031 \mathrm{~m}$ \\
$Z=-2445011,067 \mathrm{~m}$ & 0.004 & $Z=-2445011,073 \mathrm{~m}$ \\
\hline
\end{tabular}

*Fonte: SIRGAS - Relatório Final - IBGE (1997).

**Fonte: Resulta do de transforma ções rea liza das pa ra este trabalho.

$\triangle$ Estação Presidente Prudente (UEPP): esta estação, ta mbém foi ocupada em 1995, pelas campanhas de observação definidas no projeto SIRGAS. Foi utiliza do o mesmo pilar construído para o a rede GPS do Estado de São Paulo. As observações ocorreram durante 10 dias, com receptor Trimble SST4000 de dupla freqüência. As coordenadas desta estação, referentes ao IRRF94, obtidas de SIRGAS - Relatório Final (1997) e referentes a o WGS-84 e são a presentadas na TABELA 11. A inc lusão desta estação como injunção oc orreu na fase de ajustamento.: 
TABEA 11 - Coordena das da Estação Presidente Prudente - SIRG AS

\begin{tabular}{lcc}
\hline \hline \multicolumn{2}{c}{ ITRF94* } & WGS84** \\
\hline Coordenadas Cartesianas & Sigma (m) & Coordenadas Cartesianas \\
\hline$X=3687624,310 \mathrm{~m}$ & 0.003 & $X=3687624,315 \mathrm{~m}$ \\
$Y=-4620818,571 \mathrm{~m}$ & 0.004 & $Y=-4620818,565 \mathrm{~m}$ \\
$Z=-2386880,407 \mathrm{~m}$ & 0.004 & $Z=-2386880,413 \mathrm{~m}$ \\
\hline \hline
\end{tabular}

* Fonte: SIRGAS - Relatório Final - IBGE (1997).

**Fonte: Resultado de transforma ções rea lizadas para este trabalho.

\section{3 - Escolha dos Vetores para a Composição da Estratégia de Processamento}

Um dos objetivos deste trabalho é a verificação da influência de processamento de dados com vetores de tamanhos sensivelmente diferentes e de processamento de dados com vetores de comprimentos menores e mais semelhantes possíveis, a fim de conseguir condições a tmosféric as menos heterog ênea s nas extremida des dos vetores.

Para a escolha dosvetorestomaram-se necessárias:

[1] A visualização gráfic a de todos os dos dados GPS existentes, ou seja, dos vetores, entre as estações, observados em 1994 e processados por SEG ANTINE (1995) e

$\mathbb{E}$ A escolha das estações que seriam consideradas como injunção: CHUA e CAPA.

Assim, partiu-se para a construção gráfica da rede constituída em 1994. Sobre mapas com as estações da rede GPS do Estado de São Paulo, desenhou-se, separadamente, para cada uma das 16 sessões, todos os vetores observados, anotando-se os respectivos comprimentos. São mostrados, a seguir, dois exemplos das construções gráficas rea liza das. 
Nas FIGURAS 9 e 10 estão ilustrados todos o vetores observados independentes (coloridos) e apenas parte dos vetores dependentes (em linhas pretas tracejadas), que foram processados. Nas TABELAS 12 e 13, a baixo, estão descritos estes vetores e seus comprimentos.

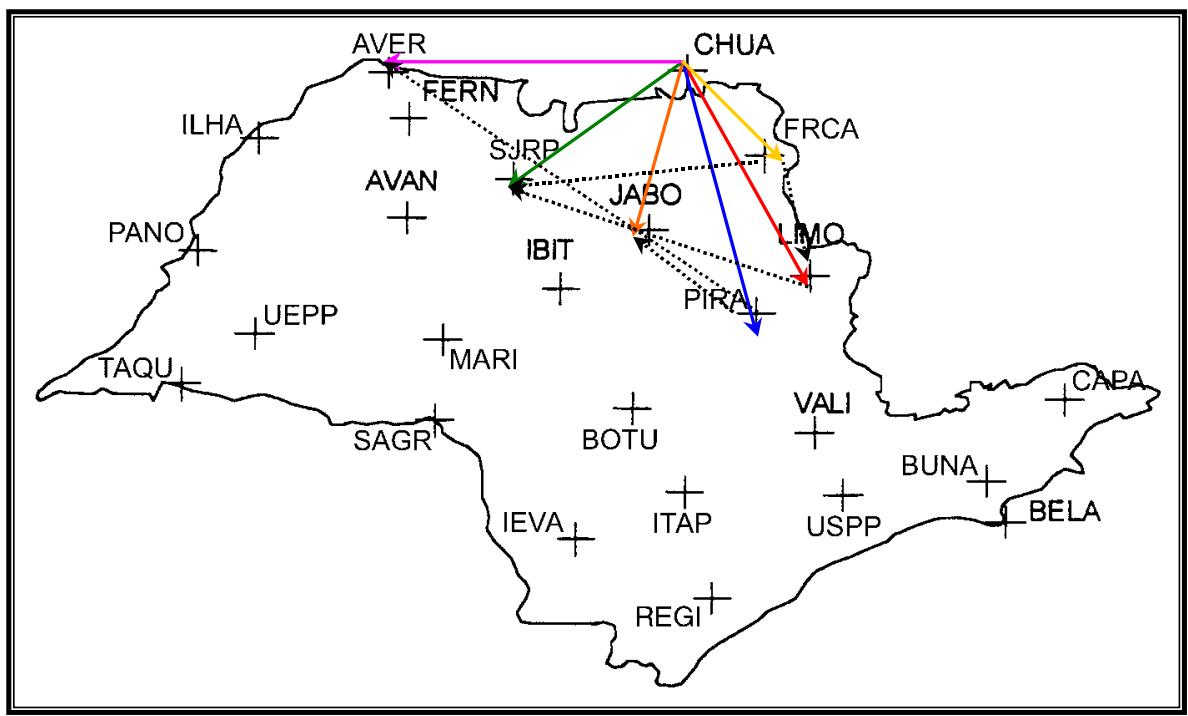

RGURA 09 - Construção gráfica original dos vetores observados na sessão do DIA 072

TABEA 12 - Descrição dos vetores observadose proc essa dos (DIA 072)

\begin{tabular}{cc}
\hline \hline Vetor & $\begin{array}{c}\text { Comprimento } \\
\text { aproximado (km) }\end{array}$ \\
\hline CHUA - FRCA & 117 \\
CHUA - PIRA & 253 \\
CHUA - UMO & 235 \\
CHUA - SJ RP & 173 \\
CHUA - AVER & 234 \\
UMO - SJ RP & 160 \\
AVER - UMO & 213 \\
AVER - J ABO & 127 \\
FRCA - AVER & 215 \\
FRCA - SJ RP & 160
\end{tabular}

TABEA 12 - Descrição dos vetores observa dose processa dos (DIA 072)

$\begin{array}{cc}\text { FRCA - J ABO } & 120 \\ \text { FRCA - LMO } & 122 \\ \text { PIRA - UMO } & 58 \\ \text { JABO - LMO } & 138\end{array}$




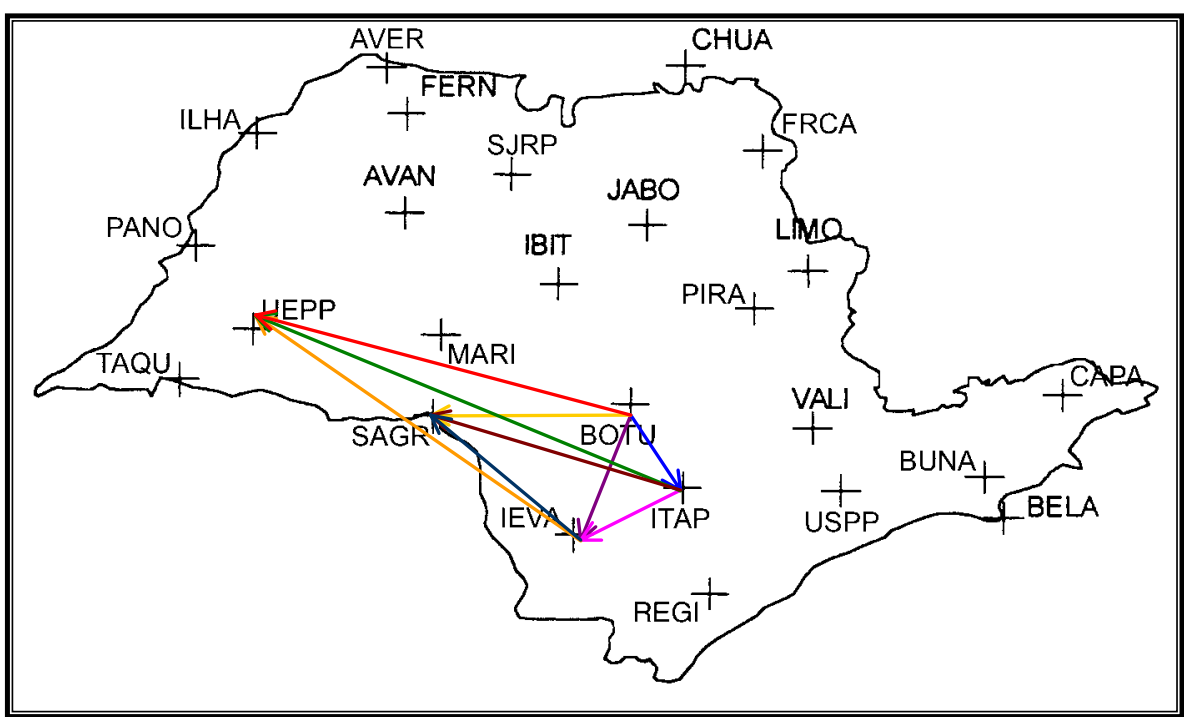

FGURA 10- Construção gráfic a orig inal dos vetores observados na sessão do

DIA 332

TABEA 13 - Descrição dos vetores observa dose processa dos (DIA 332)

\begin{tabular}{cc}
\hline \hline Vetor & $\begin{array}{c}\text { Comprimento } \\
\text { aproximado (km) }\end{array}$ \\
\hline BOTU - UEPP & 316 \\
ITAP - UEPP & 382 \\
IEVA - UEPPO & 329 \\
SAG R - UEPP & 169 \\
SAGR - IEVA & 162 \\
SAG - ITAP & 215 \\
SAGR - BOTU & 162 \\
IEVA - BOTU & 134 \\
ITAP - BOTU & 91 \\
ITAP - IEVA & 100 \\
\hline
\end{tabular}

Paralelamente à construção gráfica original das sessões de observação da rede, foi realizada uma análise, a o nível de planejamento das sessões de observação, para a elaboração da estratégia proposta neste trabalho, ou seja, com vetores de comprimentos menores possíveis. 


\section{4 - Análise ao Nível de Planejamento das Sessões de Observação}

Observou-se que apesar de os vinte e quatro pontos da rede GPS do Estado de São Paulo estarem distantes entre si na ordem de aproximadamente 100 a $160 \mathrm{~km}$ (considerando-os em disposição adjacente); grande parte das observações foram realizadas entre pontos espaça dos de $150 \mathrm{~km}$ até $382 \mathrm{~km}$ (UEPP-IEVA). Algumas sessões possuem $70 \%$ de observações de linhas bases com comprimentos maiores que $160 \mathrm{~km}$. É o caso das sessões DIA 334, DIA 333, DIA 076.

Ainda, observando a disposição das estações da rede, os vetores ma is curtos ocorreriam, em maioria, somente entre estações adjacentes. E sabendo-se que quanto menor a distância entre dois pontos observados simultaneamente, com GPS, menos heterogêneas são as condições atmosféricas; adotou-se, então, como o melhor comprimento máximo para os vetores, comprimentos da ordem de $150 \mathrm{~km}$.

Assim, iniciou-se a elaboração da estratégia proposta de processamento, com vetores de comprimentos $\leq 150 \mathrm{~km}$, a partir das construções gráficas orig ina is.

Nas FIGURAS 11 e 12 estão ilustra dos dois exemplos das construções gráficas, das sessões, para a elaboração da estratégia proposta neste trabalho. Nelas, estão ilustrados os vetores independentes e dependentes, escolhidos de a cordo com os critérios a presenta dos a cima. Nas TABELAS 13 e 14 estão descritos estes vetorese seus comprimentos.

Para proporcionar melhor visualização das análises realizadas das construções gráficas originais, a té se chegar nas construções gráficas da estratégia proposta, nas FIGURAS 11 e 12 estão ilustra das as mesma sessões, DIA 072 e DIA 332, das FIGURAS 09 e 10. O mesmo ocorre nas TABELAS 14 e 15. 


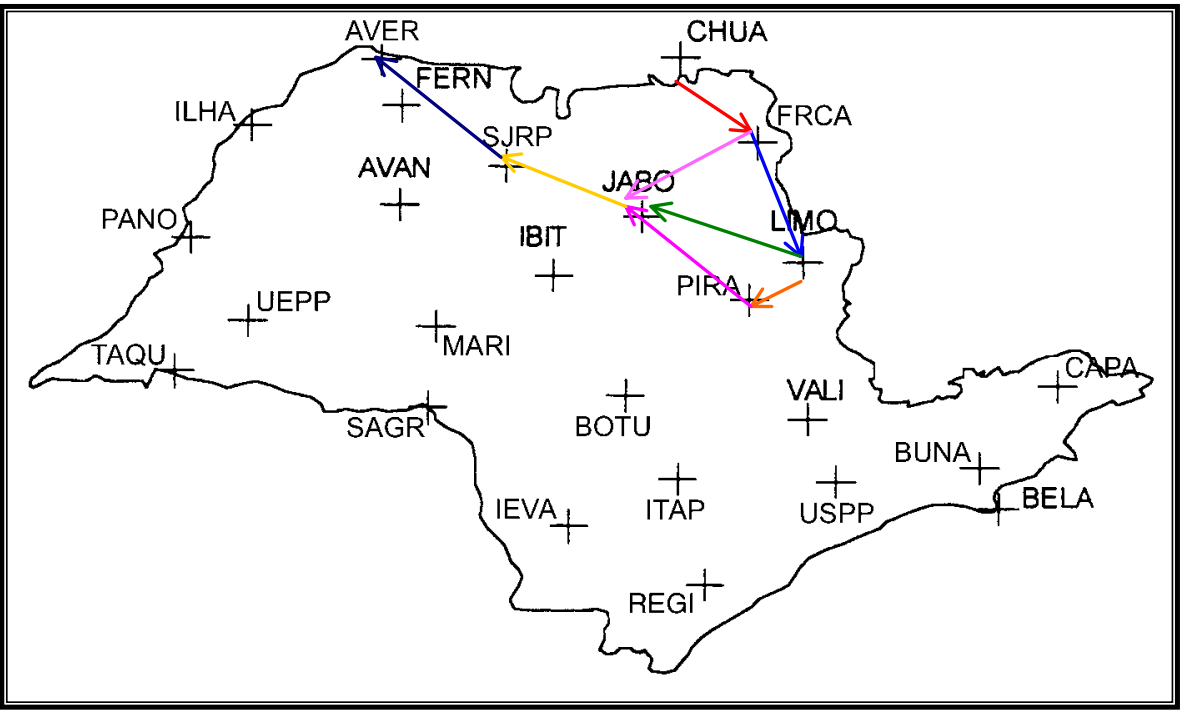

FGURA 11 - Construção gráfic a final da sessão DIA 072 (a partir da FIG URA 09)

TABEA 14 - Descrição dos vetores observa dos esc olhidos (DIA 072)

\begin{tabular}{cc}
\hline \hline Vetor & $\begin{array}{c}\text { Comprimento } \\
\text { aproximado (km) }\end{array}$ \\
\hline CHUA - FRCA & 117 \\
JABO - FRCA & 119 \\
J ABO - SJ RP & 122 \\
FRCA - UMO & 122 \\
SJ RP - AVER & 146 \\
UMO - PIRA & 58 \\
PIRA - JABO & 119 \\
J ABO - LIMO & 138 \\
\hline \hline
\end{tabular}

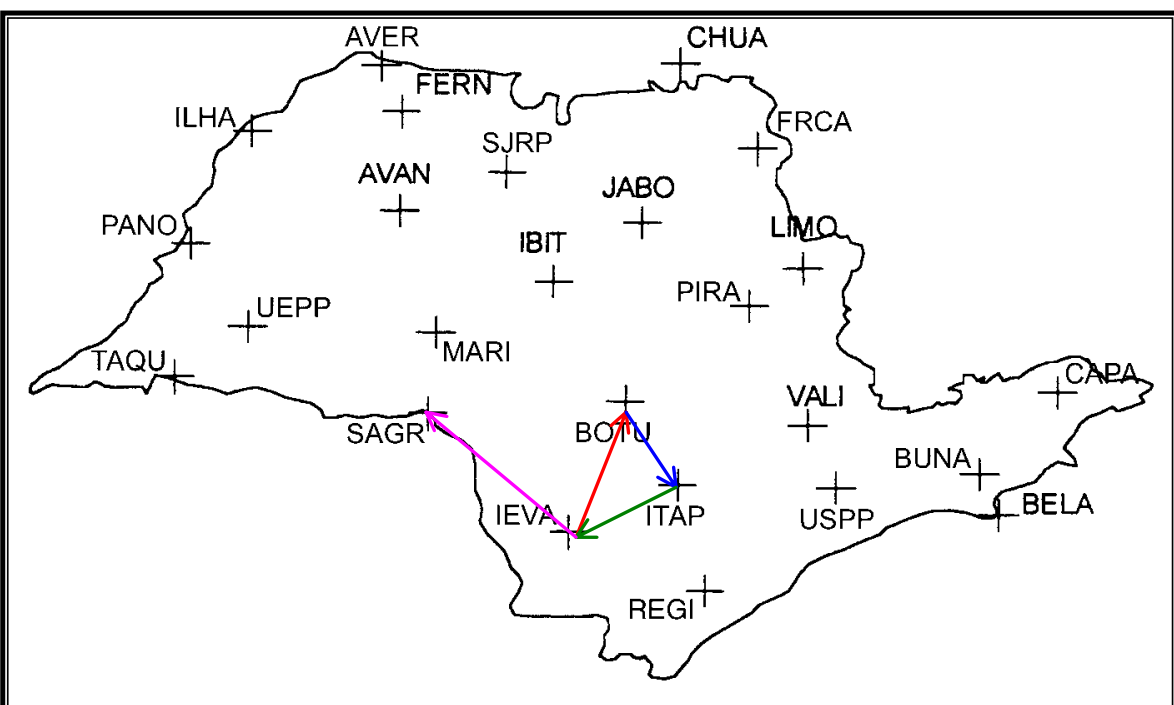

FGURA 12 - Construção gráfic a final da sessão DIA 332 (a partir da FIG URA 10) 
TABEA 15 - Desc rição dos vetores observados escolhid os

\begin{tabular}{cc}
\hline \hline Vetor & $\begin{array}{c}\text { Comprimento } \\
\text { aproximado (km) }\end{array}$ \\
\hline BOTU - ITAP & 91 \\
IEVA - BOTU & 134 \\
ITAP - IEVA & 100 \\
IEVA - SAGR & 162 \\
\hline \hline
\end{tabular}

No entanto, a nova estratégia para processamento, com vetores de comprimentos $\leq 150 \mathrm{~km}$, foi uma tarefa laboriosa, que exigiu longo tempo para a nálise.

Da análise das construções gráficas, das sessões de observação, realizou-se três pré-construções gráficas, a té se chegar na configuração final da estratégia proposta apresentada e detalhada no item 9.5, adiante.

Ainda assim, para a ligação de todos os pontos da rede, obedecendo aos critérios de observação propostos por SEEBER (1993), foi necessária a inclusão de cinco vetores com comprimentos maiores que 150km: CHUA-J ABO -164km, IEVA-SAGR -162km, BOTU-MARI -168km, SAGRBOTU -162km, e SAGR-UEPP -168km, mesmo partindo-se de dois pontos de injunção mínima, VT-CHUA e CAPA.

Ressalta-se, também ,que o processamento da configuração original de rede, apresentado por SEGANTINE (1995) envolve 160 vetores (dependentes e independentes) e o de FONSECA J r. (1996) envolve 98 vetores independentes, além dos dependentes; ao passo que a estratégia proposta envolve 66 vetores. 


\subsection{1 - Observações sobre as sessões determinadas em 1994}

As observa ções a presenta das a seguir, extraídas das a ná lises gráficas das sessões de obsenação realizadas em 1994, foram diagnosticadas, baseadas nos conhecimentos adquiridos das pesquisas bibliográficas e poderiam se utilizadas da época da observação, ter resultado em uma melhor distribuição das estações e conseqüentemente, melhores sessões de observação.

[D] DIA 072 - a maioria dos vetores que partem da injunção CHUA são maiores que $150 \mathrm{~km}$, neste, caso, verifica-se que a escolha de localidades mais próximas de CHUA, permitiria uma melhor configuração de observações entre as estações;

DIA 076 - poderia ter sido ma is bem planejada, observando as estações PANO e MARI, o que diminuiria o comprimentos de vetores maiores que $150 \mathrm{~km}$;

DIA 328 - poderiam ter sido observa das as estações BUNA, BELA e ITAP, o que diminuiria os comprimentos dos vetores e permitiria melhor configuração de observação das estações observadas;

Da DIA 332 - poderia ter sido observada a estação MARI, a o invés de UEPP, o que diminuiria de maneira considerável os comprimentos dos vetores observados;

Dd DIA 334 - apresenta-se apenas com duas linhas bases observadas menores que $150 \mathrm{~km}$, e as dema is maiores que $218 \mathrm{~km}$.

Assim, a falta de um planejamento minucioso, detalhando-se as linhas bases antes da realização das observações, mostra que pode-se realizar sessões além das necessánias, o que implica em desperdício de tempo e de recursos. 


\section{5 - Apresentação da Estratégia Proposta}

A estratégia utilizada neste trabalho para processamento dos dados da rede GPS do Estado de São Paulo possui, então:

Sessenta e seis vetores, sendo cinco com comprimentos maiores que 150 $\mathrm{km}$;

$\checkmark$ Dois pontos de injunção: VT-CHUA e CAPA (Cachoeira Paulista);

$\checkmark$ Dois sentidos de caminhamento para processamento dos vetores: um partindo de VT-CHUA e um partindo de CAPA (Cachoeira Paulista);

TABEA 16 - Sessões que fazem parte da estratégia proposta.

\begin{tabular}{|c|c|}
\hline DIA & $\begin{array}{l}\text { Estações Observadas } \\
\text { CHUA como injunção mínima }\end{array}$ \\
\hline $\begin{array}{l}071 \\
072 \\
073 \\
074 \\
075 \\
076\end{array}$ & $\begin{array}{c}\text { LMO PIRA FRCA } \\
\text { CHUA FRCA S RP UMO AVER PIRA JABO } \\
\text { CHUÁ JABO SJ RP } \\
\text { JABO IBIT SJ RP AVAN FERN } \\
\text { AVAN IBIT } \\
\text { IBIT AVAN ILHA FERN }\end{array}$ \\
\hline & CAPA como injunção mínima \\
\hline $\begin{array}{l}069 \\
070 \\
076 \\
327 \\
328 \\
329 \\
332 \\
333 \\
334 \\
335\end{array}$ & $\begin{array}{c}\text { BELA BUNA USPP VAU } \\
\text { BUNA BELA VAU USPP } \\
\text { SAGR UEPP TAQU } \\
\text { CAPA BELA BUNA USPP VAU } \\
\text { VAU USPP REGI } \\
\text { VALI REGI ITAP IEVA } \\
\text { IEVA BOTU ITAP SAGR } \\
\text { SAGR BOTU MARI UEPP } \\
\text { PANO ILHA } \\
\text { SAGR MARI UEPP TAQU PANO }\end{array}$ \\
\hline
\end{tabular}

A FIG URA 13 ilustra, de modo geral, os dois pontos de injunção e os sentidos de caminhamento para processamento dos vetores. 


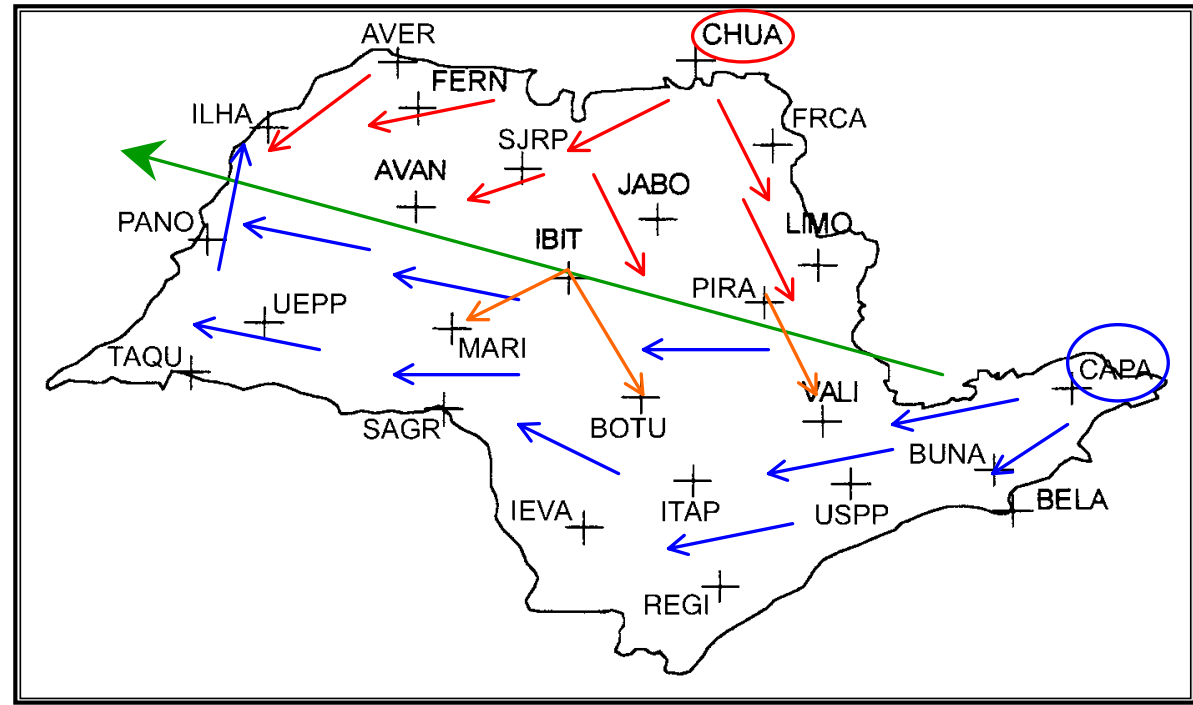

FGURA 13 - Construção gráfica geral dos sentidos de caminhamento para processamento dos vetores

Da análise da FIGURA 13, observou-se a formação de duas redes. A ligação entre elas, inicia Imente, era realizada pelo vetor PANO-ILHA. Foram inseridos, então, os vetores PIRA-VAL, IBIT-BOTU e IBIT-MARI, para dar a rede maior rigidez.

Nas TABELAS 17 até 22, encontram-se descritos os vetores do sentido de caminhamento que parte de CHUA e na ordem em que as sessões foram utiliza das.

TABEA 17 - Vetores a partir de CHUA, na sessão do DIA 073

\begin{tabular}{cc}
\hline \hline & DIA 073 \\
\hline De $\rightarrow$ Para & Comprimento (km) \\
\hline CHUA - JABO & 164 \\
JABO - SJ RP & 122 \\
\hline
\end{tabular}


TABEA 18 - Vetores a partir de CHUA, na sessão do DIA 072

\begin{tabular}{cc}
\hline \hline \multicolumn{2}{c}{ DIA 072 } \\
\hline De $\rightarrow$ Para & Comprimento (km) \\
\hline CHUA - FRCA & 117 \\
J ABO - FRCA & 119 \\
JABO - SJ RP & 112 \\
FRCA - LMO & 122 \\
SJ RP - AVER & 146 \\
UMO - PIRA & 58 \\
PIRA - J ABO & 138 \\
JABO -LMO & 119 \\
\hline \hline
\end{tabular}

TABEA 19 - Vetores a partir de CHUA, na sessão do DIA 071

\begin{tabular}{cc}
\hline \multicolumn{2}{c}{ DIA 071 } \\
\hline De $\rightarrow$ Para & Comprimento (km) \\
\hline PIRA - FRCA & 150 \\
FRCA - LMO & 122 \\
\hline \hline
\end{tabular}

TABEA 20 - Vetores a partir de CHUA, na sessão do DIA 074

\begin{tabular}{cc}
\hline \hline \multicolumn{2}{c}{ DIA 074 } \\
\hline De $\rightarrow$ Para & Comprimento (km) \\
\hline J ABO - IBIT & 93 \\
J ABO - SJ RP & 122 \\
SJ RP - IBIT & 114 \\
SJ RP - AVAN & 95 \\
SJ RP - FERN & 104 \\
SJ RP - AVER & 146 \\
FERN - AVER & 48 \\
FERN AVAN & 96 \\
AVAN - IBIT & 144 \\
AVAN - AVER & 133 \\
\hline \hline
\end{tabular}


TABEA 21 - Vetores a partir de CHUA, na sessão do DIA 075

\begin{tabular}{cc}
\hline \multicolumn{2}{c}{ DIA 075 } \\
\hline De $\rightarrow$ Para & Comprimento (km) \\
\hline AVAN - IBIT & 149 \\
\hline \hline
\end{tabular}

TABEA 22 - Vetores a partir de CHUA, na sessão do DIA 076

\begin{tabular}{cc}
\hline \hline \multicolumn{2}{c}{ DIA 076 } \\
\hline De $\rightarrow$ Para & Comprimento (km) \\
\hline IBIT- AVAN & 144 \\
AVAN - FERN & 96 \\
AVAN - ILHA & 150 \\
FERN - ILHA & 128 \\
\hline
\end{tabular}

Nas TABELAS 23 até 32 encontram-se descritos os vetores do sentido de caminhamento que parte de CAPA e na ordem em que as sessões foram utiliza das.

TABEA 23 - Vetores a partir de CAPA, na sessão do DIA 327

\begin{tabular}{cc}
\hline \multicolumn{2}{c}{ DIA 327} \\
\hline De $\rightarrow$ Para & Comprimento (km) \\
\hline CAPA - BELA & 128 \\
CAPA - BUNA & 102 \\
BUNA - BELA & 48 \\
BUNA - VAU & 148 \\
\hline
\end{tabular}

TABEA 24 - Vetores a partir de CAPA, na sessão do DIA 069

\begin{tabular}{cc}
\hline \multicolumn{2}{c}{ DIA 069 } \\
\hline De $\rightarrow$ Para & Comprimento (km) \\
\hline BELA - BUNA & 48 \\
BELA - USPP & 17 \\
BUNA - USPP & 148 \\
BUNA - VAL & 148 \\
USPP - VAU & 65 \\
PIRA - VAL & 125 \\
\hline
\end{tabular}


CAPÍTULO 8 - ELABORAÇÃO DA CONFIG URAÇÃO VETORIAL PARA ASESTRATÉG IASDE PROCESSAMENTO

TABEA 25 - Vetores a partir de CAPA, na sessão do DIA 070

\begin{tabular}{cc}
\hline \hline \multicolumn{2}{c}{ DIA 070 } \\
\hline De $\rightarrow$ Para & Comprimento (km) \\
\hline BUNA - BELA & 49 \\
BUNA - USPP & 117 \\
BUNA - VAப & 148 \\
BELA - USPP & 143 \\
USPP - VAU & 65 \\
\hline \hline
\end{tabular}

TABEA 26 - Vetores a partir de CAPA, na sessão do DIA 328

\begin{tabular}{cc}
\hline \hline \multicolumn{2}{c}{ DIA 328 } \\
\hline De $\rightarrow$ Para & Comprimento (km) \\
\hline VAU - USPP & 65 \\
VAU - REGI & 180 \\
USPP - REGI & 146 \\
\hline
\end{tabular}

TABEA 27 - Vetores a partir de CAPA, na sessão do DIA 329

\begin{tabular}{cc}
\hline \hline \multicolumn{2}{c}{ DIA 329} \\
\hline De $\rightarrow$ Para & Comprimento (km) \\
\hline VAU - REGI & 122 \\
VAU - ITAP & 180 \\
REG I - IEVA & 124 \\
REGI - ITAP & 103 \\
ITAP - IEVA & 99 \\
\hline
\end{tabular}

TABEA 28 - Vetores a partir de CAPA, na sessão do DIA 332

\begin{tabular}{cc}
\hline \multicolumn{2}{c}{ DIA 332 } \\
\hline De $\rightarrow$ Para & Comprimento $(\mathrm{km})$ \\
\hline IEVA - BOTU & 134 \\
BOTU - ITAP & 91 \\
ITAP - IEVA & 100 \\
IEVA - SAGR & 162 \\
\hline
\end{tabular}


TABEA 29 - Vetores a partir de CAPA, na sessão do DIA 333

\begin{tabular}{cc}
\hline \hline \multicolumn{2}{c}{ DIA 333 } \\
\hline De $\rightarrow$ Para & Comprimento (km) \\
\hline SAGR - BOTU & 162 \\
BOTU - MARI & 168 \\
MARI - SAGR & 79 \\
IBIT - BOTU & 130 \\
IBIT - MARI & 108 \\
\hline
\end{tabular}

TABEA 30 - Vetores a partir de CAPA, na sessão do DIA 076

\begin{tabular}{cc}
\hline \multicolumn{2}{c}{ DIA 076 } \\
\hline De $\rightarrow$ Para & Comprimento (km) \\
\hline SAG R - UEPP & 168 \\
UEPP - TAQU & 78 \\
\hline
\end{tabular}

TABEA 31 - Vetores a partir de CAPA, na sessão do DIA 335

\begin{tabular}{cc}
\hline \multicolumn{2}{c}{ DIA 335} \\
\hline De $\rightarrow$ Para & Comprimento (km) \\
\hline SAGR - MARI & 79 \\
MARI - UEPP & 150 \\
UEPP - TAQU & 78 \\
UEPP - PANO & 93 \\
TAQU - PANO & 130 \\
\hline
\end{tabular}

TABEA 32 - Vetores a partir de CAPA, na sessão do DIA 334

\begin{tabular}{cc}
\hline \multicolumn{2}{c}{ DIA 334 } \\
\hline De $\rightarrow$ Para & Comprimento (km) \\
\hline PANO - ILHA & 122 \\
\hline \hline
\end{tabular}


Na FIGURA 14, está ilustrada a construção gráfica vetorial da estratégia de processamento proposta neste trabalho.

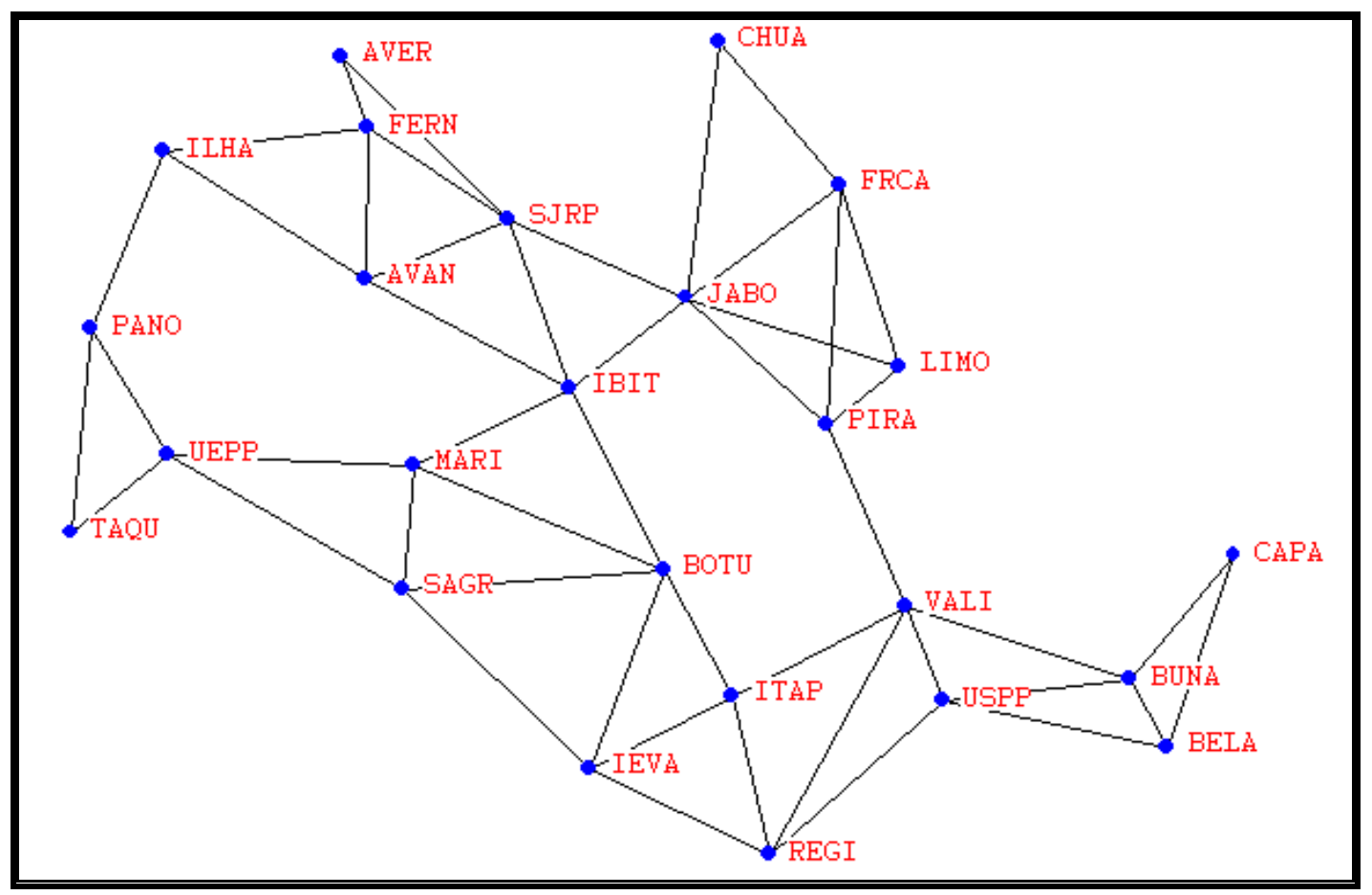

FGURA 14 - Construção gráfic a vetorial da estratégia de processamento proposta 


\section{CAPÍTULO 9}

\section{ESTRATÉGIAS DE PROCESSAMENTOS}

"A vita lida de se revela não a penas na capacidade de persistir, mas também na de começartudo

de novo."

Franc is Sc ott Fitzgerald (1896-1940), Escritor a meric a no.

\section{Sumário detalhado do Capítulo 9}

9 - Introdução

9.1. - Estratégia de Processamento 1

9.2 - Estratégia de Processamento 2 78

9.3 - Estratégia de Processamento 3 79

9.4 - Estratégia de Processamento 4 80 


\section{9 - Introdução}

Para atingir os objetivos deste trabalho, então, foram elaboradas quatro estratégias de processamento, baseadas na disposição vetorial apresentada no CAPÍTULO 8 , ou seja, vetores com comprimentos $\leq 150 \mathrm{~km}$ entre as estações.

As quatro estratégias apresentam em comum as seguintes características:

Processamento com dois pontos de injunção mínima: VT-CHUA e CAPA (Cachoeira Paulista);

Sistema de referência WG S-84;

> Processamento utilizando a combinação linear entre as observações em L1 e L2, conhecida como ionospheric free-combination, com o propósito de reduzir os efeitos ionosféricos e a combinação linear conhecida como wide-lane;

> Opção pornão fixara ambigüidade devido ao comprimento doslados.

\section{1. - Estratégia de Processamento 1}

Caracteriza-se por:

I Processamento dos dados considerando o tempo total das observações. Na TABELA 33 são a presentadas as sessões consideradas, em ordem de processamento, a duração das observações e tempo inicial e final considerados para processamento;

$\because$ Processamento com dados meteorológicos reais medidos, ao invés dos valorespadrão do software;

Proc essa mento utiliza nd o efemérid es prec isa s disponibiliza das pelo IGS. 
TABELA 33 - Dura ção das sessões de obsenvação, tempo inicial e final de processamento para a estratégia 1

\begin{tabular}{|c|c|c|c|c|}
\hline DOY & Estações Obsenvadas & $\begin{array}{c}\text { Tempo de } \\
\text { obsenvação (h) }\end{array}$ & $\begin{array}{c}\text { Tempo } \\
\text { inicial } \\
\text { (h min s) }\end{array}$ & $\begin{array}{c}\text { Tempo } \\
\text { final } \\
\text { (h min s) }\end{array}$ \\
\hline \multicolumn{5}{|c|}{ CHUA como injunção mínima } \\
\hline 073 & CHUÁ J ABO SJ RP & 8 & $11: 50: 00$ & 19:50:00 \\
\hline 072 & CHUÁ FRCA SJ RP UMO AVER PIRA JABO & 8 & 11:55:00 & 19:55:00 \\
\hline 071 & UMO PIRA FRCA & 8 & 11:55:00 & 19:55:00 \\
\hline 074 & JABO IBIT SJ RP AVAN FERN & 8 & 12:05:00 & 19:55:00 \\
\hline 075 & AVAN IBIT & 8 & 12:05:00 & 19:55:00 \\
\hline 076 & IBIT AVAN ILHA FERN & 8 & 12:08:00 & 19:40:00 \\
\hline \multicolumn{5}{|c|}{ CAPA como injunção mínima } \\
\hline 327 & CAPA BELA BUNA USPP VAU & 6 & 10:40:00 & $16: 20: 00$ \\
\hline 069 & BELA BUNA USPP VAL & 5 & 15:10:00 & 19:50:00 \\
\hline 070 & BUNA BELA VAU USPP & 8 & 12:10:00 & 19:50:00 \\
\hline 328 & VAU USPP REGI & 6 & 10:38:00 & $16: 20: 00$ \\
\hline 329 & VAU REGI ITAP IEVA & 6 & 10:55:00 & $15: 30: 00$ \\
\hline 332 & IEVA BOTU ITAP SAGR & 6 & 10:35:00 & $15: 30: 00$ \\
\hline 333 & SAGR BOTU MARI UEPP & 6 & 10:35:00 & $13: 45: 00$ \\
\hline 076 & SAGR UEPP TAQU & 8 & $12: 10: 00$ & 19:00:00 \\
\hline 335 & SAGR MARI UEPP TAQU PANO & 6 & 10:40:00 & $15: 40: 00$ \\
\hline 334 & PANO ILHA & 6 & 10:45:00 & $15: 45: 00$ \\
\hline
\end{tabular}

\section{2 - Estratégia de Processamento 2}

Caracteriza-se por:

- Processamento dos dados considerando apenas duas horas e trinta minutos do tempo total de duração das sessões. Na TABELA 34 são apresentados as sessões consideradas, em ordem de processamento e o tempo inicial e final considerados para processamento;

$\because$ Processamento com dados meteorológicos reais medidos, ao invés dos valorespadrão do software;

Processa mento utilizando efemérides prec isas disponibiliza das pelo IGS. 
TABELA 34 - Dura ção das sessões de obsenvação, tempo inicial e final de proc essa mento

\begin{tabular}{|c|c|c|c|c|}
\hline DOY & Estações Obsenvadas & $\begin{array}{c}\text { Tempo de } \\
\text { obsenvação } \\
\text { considerado (h) }\end{array}$ & $\begin{array}{c}\text { Tempo } \\
\text { inicial } \\
\text { (h min s) }\end{array}$ & $\begin{array}{c}\text { Tempo } \\
\text { final } \\
\text { (h min s) }\end{array}$ \\
\hline \multicolumn{5}{|c|}{ CHUA como injunção mínima } \\
\hline 073 & CHUÁ JABO SJ RP & $2: 30$ & $13: 00: 00$ & $15: 30: 00$ \\
\hline 072 & CHUÁ FRCA SJRP UMO AVER PIRA JABO & $2: 30$ & 13:00:00 & 15:30:00 \\
\hline 071 & UMO PIRA FRCA & $2: 30$ & 13:00:00 & 15:30:00 \\
\hline 074 & JABO IBIT SJ RP AVAN FERN & $2: 30$ & 13:00:00 & $15: 30: 00$ \\
\hline 075 & AVAN IBIT & $2: 30$ & 13:00:00 & 15:30:00 \\
\hline 076 & IBIT AVAN ILHA FERN & $2: 30$ & 13:00:00 & 15:30:00 \\
\hline \multicolumn{5}{|c|}{ CAPA como injunção mínima } \\
\hline 327 & CAPA BELA BUNA USPP VAU & $2: 30$ & $13: 30: 00$ & $16: 00: 00$ \\
\hline 069 & BELA BUNA USPP VAU & $2: 30$ & $15: 30: 00$ & 18:00:00 \\
\hline 070 & BUNA BELA VAL USPP & $2: 30$ & $15: 30: 00$ & 18:00:00 \\
\hline 328 & VAU USPP REGI & $2: 30$ & $10: 40: 00$ & 13:10:00 \\
\hline 329 & VAU REGI ITAP IEVA & $2: 30$ & 11:00:00 & $14: 30: 00$ \\
\hline 332 & IEVA BOTU ITAP SAGR & $2: 30$ & 11:00:00 & $14: 30: 00$ \\
\hline 333 & SAGR BOTU MARI UEPP & $2: 30$ & 10:35:00 & 13:05:00 \\
\hline 076 & SAGR UEPP TAQU & $2: 30$ & $12: 10: 00$ & $14: 30: 00$ \\
\hline 335 & SAGR MARI UEPP TAQU PANO & $2: 30$ & $10: 45: 00$ & 13:00:00 \\
\hline 334 & PANO ILHA & $2: 30$ & $10: 45: 00$ & $13: 00: 00$ \\
\hline
\end{tabular}

\section{3 - Estratégia de Processamento 3}

\section{Caracteriza-se por:}

I] Processamento dos dados considerando apenas duas horas e trinta minutos do tempo total de duração das sessões. Na TABELA 34 são apresentados as sessões consideradas e o tempo inicial e final considerados para processamento (os mesmos da estratégia 2);

" Processa mento com os valores meteorológicos padrão do software;

[D] Processa mento utiliza nd o efemérides prec isa s disponibiliza das pelo IGS. 


\section{4 - Estratégia de Processamento 4}

Caracteriza-se por:

[. Processamento dos dados considerando apenas duas horas e trinta minutos do tempo total de duração das sessões. Na TABELA 34 são apresentados as sessões consideradas e o tempo inicial e final considerados para processamento (os mesmos da estra tégia 2 e 3);

$\because$ Processamento com dados meteorológicos medidos, ao invés dos valorespadrão do software;

[ㅁ] Processamento utiliza ndo efemérides tra nsmitidas no processamento. 


\section{CAPÍTULO 10}

\section{RECURSOS NECESSÁRIOS PARA OS PROCESSAMENTOS}

" À medida que o conhecimento aumenta, o espanto se aprofunda "

Charles Morgan (1894-1958), Escritor inglês.

\section{Sumário detalhado do Capitulo 10}

10.1 - Programas Computacionais para Processamentos 82

10.1.1 - Considerações sobre os programas 83

10.2 - Dados Meteorológicos 84

10.3 - Dados de Efemérides Precisas 87

10.4 - Dados de Efemérides Transmitidas 89 


\section{1 - Programas Computacionais para Processamentos}

Ressalta-se que a escolha dos programas a seguir, justificou-se não só por se tratar de um projeto que envolve processar os dados GPS de uma rede geodésica de alta precisão, mas também, porque considerando as distâncias médias entre as estações da Rede GPS do Estado de São Paulo, só faz sentido a utilização de programas, que permitem combinações linea res com as duas portadoras L1 e L2.

Determinou-se a utilização dos seguintes programas:

[1 OMNI v4.0: programa científico composto por uma série de 50 sub programas para processamento de dados coletados dos satélites GPS, pelos receptores. A versão 4.0 foi desenvolvida sob a coordenação de MADER et al. (1994) e de HILLA (1994). HILLA (1999) informou que esta é a mais recente versão do OMNI e funciona perfeitamente, em computador com sistema operacional DO S26. Está disponível na Intemet, no endereço eletrônico ftp://www.ngs.noaa.gov/pub/omni/update.

[. SK Leica Static Kinematic Software v2.3: programa comercial que permite o processamento de dados GPS envolvendo as duas portadoras L1 e L2, desde que se possua a chave que o habilite para tal. Esta versão requer a mbiente Windows.

[. PRISMA Software v2.0 da Ashtech: ta mbém um programa comercial que permite realizar processamento de dados GPS envolvendo as duas portadoras L1 e L2, desde que se possua a chave que o habilite para tal. Esta versão requer ambiente Windows.

${ }^{26}$ DOS: Disk Operating System 


\subsection{1 - Considerações sobre os programas}

Optou-se, inicialmente, pela utilização do programa OMNI v4.0, que sendo c ientífic o, permitiu a quisição de conhec imentos puros e rea is sobre os comportamentos dos dados das portadoras L1 e L2.

Através do próprio OMNI v4.0 foram gerados todos os arquivos de dados no formato RINEX, de todas as sessões de observação, a partir dos dados brutos do receptor TRIMBLE 4000 SST.

Partiu-se, então, para a utilização dos programas SKI e PRISMA. Porém, encontrou-se incompatibilidades nesses programas, no momento das leituras de a lguns a rquivos RINEX gera dos pelo programa OMNI v4.0.

Na tentativa de solucionar este problema para o programa PRISMA, testou-se, primeiramente, usar o conversor intemo de arquivos RINEX do PRISMA. Este conversor transforma a rquivos RINEX de padrão TRIMBLF para padrão Ashtech. No entanto, a incompatibilidade persistiu. Então, partiu-se para a utilização do programa BERNESE GPS Software v1.1, para gerar, novamente, os arquivos RINEX. Os arquivos gerados através do BERNESE também não foram lidos corretamente pelo programa PRISMA. Assim, em virtude da impossibilidade de despender mais tempo para solucionar essa inc ompatibilidade, optou-se por não utiliza reste programa.

Para o SKI, verific ou-se, que os a rquivos RINEX, gerados pelo OMNI, e que a presentavam erros de leitura, quando foram gerados novamente pelo OMNI, mas em ambiente Windows e em seguida inseridos no SKI, passaram a serem lidos sem problema. Uma possível explicação para este ac ontec imento, pode residir no fato de que os a rquivos RINEX gera dos pelo OMNI e inseridos no SKI haviam sido gerados em um computador com sistema operacional DOS., gerando, talvez, alguma incompatibilidade. Ainda, o erro de leitura ocorreu no a rquivo de orbita is. 
E sendo a solução para a utilização do SKI, a necessidade de gerar novamente, os arquivos RINEX em ambiente Windows, através do próprio OMNI v4.0, optou-se por não utilizar este programa também.

Assim, para os processamento, foi utilizado somente, o programa OMNI v4.0.

É importante lembrar que os arquivos RINEX, tendo padrão universal, os problemas relatados a cima não deveriam ter ocomido, ou seja, os dados da rede, de receptor TRIMBLF 4000 SST, quando em formato RINEX, deveriam ter sido aceitos sem problemas pelos programas SKI, da Leica e PRISMA, da Ashtech.

Ainda, o fato de o programa PRISMA ter conversor intemo de padrão de arquivos, sugere a idéia de que cada fabricante, provavelmente, ao incluir ou excluir linhas nos cabeçalhos dos arquivos de navegação e orbitais, acabam dando caráter personalizado a estes arquivos, descaracterizando, portanto, o padrão universal dos arquivos RINEX.

No entanto, antes de qualquer afimação conclusiva, ressalta-se, a necessidade de investigações ma is profundas sobre este problema.

\section{2 - Dados Meteorológicos}

De acordo com os objetivos propostos, pretende-se verificar a influência de dados meteorológico (temperatura, pressão e umidade) rea is no processamento de linhas bases longas. Para esta investigação, então, será realiza do o processamento dos dados da rede GPS do Estado de São Paulo, utiliza ndo dados meteorológic os rea is reg istra dos nos dias e loca is em que cada sessão de observação foi realizada.

A busca por estes dados foi realizada junto ao escritório do IBGE de São Carlos e na biblioteca central da EESC-USP27 (observações de mapas

${ }^{27}$ EESC -USP: Esc ola de Engenharia de São Carlos - Universidade de São Paulo 
de iso ietas do esta do) e solic ita ções a o CPTEC/INPE28, CEAPLA ${ }^{29}$, IAG/USP30 e DAEE ${ }^{31}$. Entretanto, a coleta destes dados, foi possível somente junto ao INMET $^{32}$ e ao IAC ${ }^{33}$.

Esperava-se, a través destes dois Institutos, ter acesso a um banco de dados que tomasse possível reconstituir a representação, mais fiel possível, das condições meteorológicas, durante as sessões.

Para tal, seria ideal:

[D] Obter valores de temperatura de hora em hora durante as sessões de observações, para só, então, calcular um valor de temperatura médio para as sessões;

Obter valores de umidade absoluta ou dados que pemitissem calculála.

Entretanto, isto não foi possível. De acordo com informações destes dois institutos, havia dados de temperatura média diária (INMET e IAC), temperatura média mensal (INMET), umidade média mensal (INMET), precipitação diária (IAC) e pressão atmosférica média mensal (INMET). E a inda, ambos os institutos não possuíam dados meteorológicos de todas as cidades solicitadas.

Foi decidido, então, utilizar dados de temperatura média diária, umidade média mensale pressão atmosférica média mensal.

Através do INMET se conseguiu dados de temperatura média diária $\left(\mathrm{em}{ }^{\circ} \mathrm{C}\right)$, pressão atmosférica média mensal (em $\mathrm{mb}$ ) e umidade média mensal (em \%) das cidades de São Paulo, Presidente Prudente e de Uberaba.

\footnotetext{
${ }^{28}$ C PTEC/INPE: Centro de Previsão de Tempo e Estudos Climáticos/Instituto de Pesquisas Espa cias

29 CEAPLA: Centro de Análise e Planejamento Ambiental

30 IAG: Instituto Astronômico e Geofísico da USP

31 DAEE: Departamento de Águase Energia Elétrica

32 INMET: Instituto Nacional de Meteorologia

33 IAC: Instituto Agronômico de Campinas
} 
Junto ao IAC se obteve os dados de temperaturas máximas e mínimas diárias (em ${ }^{\circ} \mathrm{C}$ ) e precipitação diária (em $\mathrm{mm}$ ), para quase todasas loc a lida de solic ita das.

Como foram obtidos valores de pressão atmosféricas de apenas três estações (São Paulo, Presidente Prudente e de Uberaba) das vinte e cinco solicitadas, decidiu-se, através de sugestão do Prof. Antônio Marozzi Righetto ${ }^{34}$, calcular os valores de pressão que faltavam, por meio das altitudes das localidades, considerando a atmosfera padrão.

Numa atmosfera padrão em que se encontra o ar seco com mesma composição química em todas as altitudes, pressão e temperatura a o nível do mar igual a $1013 \mathrm{mb}$ e $15^{\circ} \mathrm{C}$, respectivamente, obtêm-se, da equação hidrostátic a e da lei dos gases (OCCHIPINTI, 1989):

$$
p=1013,2 \cdot\left(1-\frac{0,0065 \cdot z}{288}\right)^{5,256}, \text { onde }
$$

p é a pressão atmosférica em mb $\left(1 \mathrm{~atm}=1.01325 \times 10^{-3} \mathrm{mb}\right) \mathrm{e}$ z é a altitude em m (RIG UETTO, 1998). p é a pressão a tmosféric a em mb $\left(1 \mathrm{~atm}=1.01325 \times 10^{-3} \mathrm{mb}\right) \mathrm{e}$ z é a altitude em m (RIG UETTO, 1998).

Assim, obteve-se, para todas as localidades, onde se encontram os pontos da rede, os valores de pressão atmosférica. Os valores das altitudes para a slocalidades dos pontos foram obtidos a través do IBGE.

Os valores de umidade, também foram obtidos apenas para três estações (São Paulo, Presidente Prudente e de Uberaba). O Professor Righetto, a inda, sugeriu a adoção de valores de umidade de $50 \%$ quando não havia registro de precipitação no dia da observação e de $75 \%$ quando havia registro de precipitação. Mas enfatizou, que tais considerações são grosseiras.

34 Professor Titular do Departamento de Hidráulica e Saneamento da Escola de Engenharia de São Carlos - USP 
No ANEXO B encontram-se as TABELAS de 82 até 96 , com os dados meteorológicos fomecidos pelo INMET e pelo IAC, utilizados para processamentos dos dados GPS no programa OMNI V4.0, de todas as sessões consideradas.

\section{3 - Dados de Efemérides Precisas}

As efemérides precisas para o processamento dos dados da rede GPS foram obtidas junto a o IGS. Encontram-se exemplificadas no ANEXO C.

Através do endereço ftp://igscb.jpl.nasa.gov/igscb/product/0739/, por exemplo, copiou-se os arquivos das efemérides de cada dia da semana, no caso, semana 0739, que estão em formato SP3.

Assim, foram copiados e utilizados arquivos de efemérides das seguintes semanas e dias em que ocorreram as observações em 1994, apresentados na TABELA 35, a seguir. O calendário GPS e o correspondente gregoriano foram obtidos no endereço eletrônico http://www.noaa.gov/CORS/gpscal94.html. 
TABELA 35 - Semana GPS, DOY e data

\begin{tabular}{ccc}
\hline Semana GPS & DOY & Data \\
\hline 069 & $10 / 03 / 94$ \\
0739 & 071 & $11 / 03 / 94$ \\
& 072 & $12 / 03 / 94$ \\
& 073 & $14 / 03 / 94$ \\
& 074 & $15 / 03 / 94$ \\
& 075 & $16 / 03 / 94$ \\
& 076 & $17 / 03 / 94$ \\
\hline 0776 & 327 & $23 / 11 / 94$ \\
& 328 & $24 / 11 / 94$ \\
& 329 & $25 / 11 / 94$ \\
& 332 & $28 / 11 / 94$ \\
& 334 & $30 / 11 / 94$ \\
\hline \hline 077 & 335 & $01 / 12 / 94$ \\
\hline \hline
\end{tabular}

Fonte: http://www.noaa.gov/CORS/gpscal94.html

Como o programa OMNI v4.0 requer arquivos de efemérides no forma to SP1, realiza ram-se as seguintes tra nforma ções dos a rquivos obtidos em formato SP3:

$[$ Utilizou-se, primeiramente, o programa SP3-EF18: o arquivo em formato SP3 foi renomeado para SP3ASC Il e a execução do programa gerou um arquivo binánio, EF18BIN;

[. Em seguida, utilizou-se o programa EF18-SP1: durante a execução fomeceu-se ao programa os seguintes dados relativos às efemérides, nas respectivas ordens:

11 Start Time e Stop Time, na configuração: (ano_mês_dia_h_min_s);

Intervalo de tempo de coleta de dados pelo arquivo SP3, em segundos: no caso, 900.0 s, que corresponde a quinze minutos;

[Dal Escolha dos satélites: como se optou por dados de todos os sa télites, digitou-se -1. Caso sejam desejados alguns satélites, deve-se digitar, inicialmente, a quantia de satélites desejados e em seguida, o número de cada sa télite; 
O programa retoma, então, o arquivo de efeméride no formato SP1 com o nome SPIASCII, que foi renomeado com a extensão *.eph.

\section{4 - Dados de Efemérides Transmitidas}

As efemérides transmitidas foram obtidas a partir do próprio a rquivo de dados de navegação, em formato RINEX, a partir dos dados origina is em formato binário. Encontram-se, também, exemplificadas no ANEXO C. 


\section{CAPÍTULO 11}

\section{PROCESSAMENTOS}

"A coisa mais bonita que podemos

experimentar é o misterioso. "

Albert Einstein (1879-1955.),

Físic o a lemão

\section{Sumário detalhado do Capitulo 11}

11.1 - Considerações sobre os Critérios do Programa para Realização dos Processamentos

11.2 - Intervenções Realizadas Manualmente no Processamento 92

11.3 - Resultados dos Processamentos 97

11.3.1 - Coordenadas preliminares das estações para o ajustamento 97

11.3.2 - Valores das diferenças em relação aos eixos cartesianos X, Y e Z dos vetores processados 97 
Foram realizados, então, os quatro processamentos dos dados GPS, de acordo com as quatro estra tégias descritas no CAPÍTULO 9.

É importante ressaltar que o OMNIv4.0, pemite escolher o tipo da antena do receptor usada, para inserir no processamento, offsets das variações dos centros de fase da antena, em relação às portadoras L1 e L2.

\section{1 - Considerações sobre os Critérios do Programa para Realização dos Processamentos}

O programa OMNI v4.0, na solução à priori, detecta e corige perdas de cic los das portadoras, a tra vés de diversas iterações. Depois de corrigidas todas as perdas de ciclo, em L1, o programa realiza as correções das perdas de ciclosem L2, a tra vés da combinação ionospheric-free de L1 e L2.

A precisão das medidas, usualmente, a plicadas em levantamentos e na Geodésia é analisada através do desvio padrão $\sigma$, também chamado de RMS, root mean square error. O RMS de uma simples diferença de fase depende do comprimento da linha base observada, tempo de observação e distúrbios ionosféricos.

No resultado do processamento, será observado o valor do RMS a posteriori, das linhas bases processadas. O manual do OMNI v4.0 sugere que para linhas bases maiores que $100 \mathrm{~km}$, o usuário obtenha valor de RMS igual ou inferior a $0.030 \mathrm{~m}$. SEGANTINE (1999) relata que a experiência mostra que para linhas bases longas processadas com efemérides precisas, um valor considerado muito bom para RMS é da ordem de $0.05 \mathrm{~m}$.

Ressalta-se que nos processamentos das linhas base das estratégias propostas, conseguiu-se, trabalhando-se sobre os dados observados, valores de desvio padrão de ordem dez vezes menor que $0.05 \mathrm{~m}$. 


\section{2 - Intervenções Realizadas Manualmente no Processamento}

Antes da realização do processamento, para todos os dias em que havia sessões de observação, verificou-se a quantidade de épocas registradas para cada satélite. Isto foi possível através do arquivo 'Sumário'. Há um exemplo deste arquivo no ANEXO D.

Realizou-se, então, a exclusão dos satélites com quantidade de épocas registradas inferior a $15 \%$ do total (desde que o número mínimo de satélites remanescentes fosse igual ou superior a quatro, o que ocorreu com folga). A exclusão garante diminuição dos efeitos de refração e multicaminhamento de sina is de sa télites de baixa elevação. A TABELA com os satélites excluídos, sob esse critério, em cada sessão, encontra-se no APÊNDICE I.

Durante o processamento, verificou-se que os dados coletados em 1994 apresentavam grande número de perdas de ciclo. E no processamento de algumas sessões ocorreu que o próprio programa, apesar de ter detectado as perdas, não conseguiu eliminá-las, impedindo a fina lização do processamento.

Duas soluções para este problema foram levadas em consideração e aplicadas no processamento:

1. Em algumas sessões, solucionou-se este problema excluindo os satélites que estavam com dados muitos ruins. Realizou-se, então, diversas combina ções de sa télites a té encontrar uma que permitisse a realização completa do processamento. Em alguns casos, a identificação foi possível graficamente. Na FIGURA 15 pode-se visualizar a identificação do satélite com dados ruins, através da ocorrência dos valores '81001700.00'. O valor-9999.00, por sua vez, significa .ausência de dados coletados. 


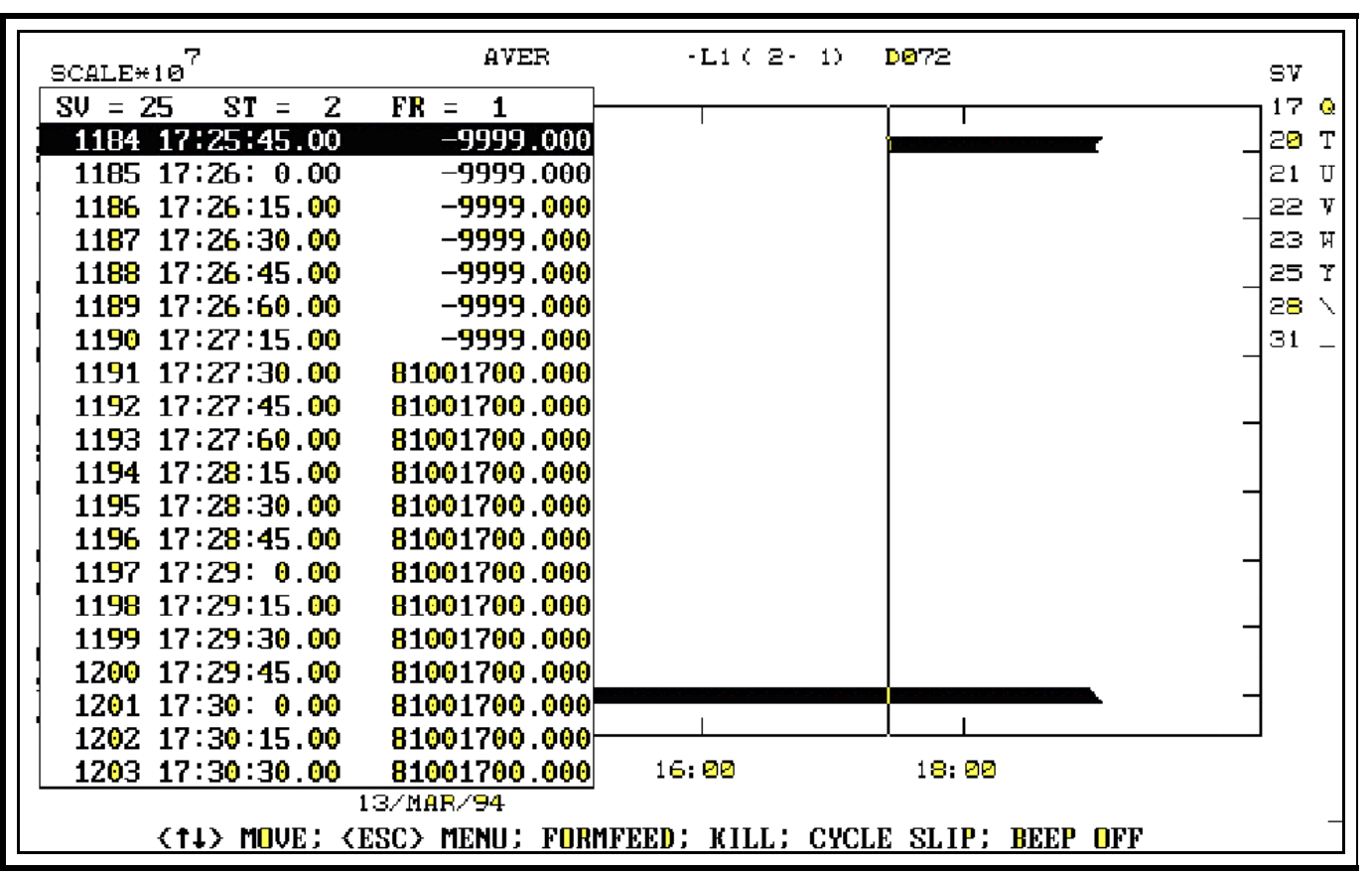

FGURA 15 - Exemplo de sa télite com dado ruim

2. Para outras sessões foi necessária a exclusão da parte ruim dos dados dos sa télites.

Foram considerados dados ruins os dados dos satélites que ocorriam fora da faixa de concentração da maior parte dos resíduos dos sa télites e também os que se apresentavam com configuração extremamente espalha da e muitos outliers.

Ressalta-se, que nos do is casos menciona dos a cima, sempre houve a preocupação de verificar se o período de observação permanecia com no mínimo dados de quatro satélites. E ainda, de anotar cuidadosamente, os sa télites e o período em que ocomiam dados ruins.

Nas FIGURAS 16 e 17 pode-se visualizar, através de gráficos dos resíduos gerados pela solução a posteriori versus peńodo de observação, os dados originais dos satélites e os mesmos dados após correções (através das exclusões), respectivamente. O mesmo ocorre com as FIG URAS 19 e 20. 
As FIG URAS 16 e 17 foram extraídas dos processamentos realizados para a sessão do DOY 335.

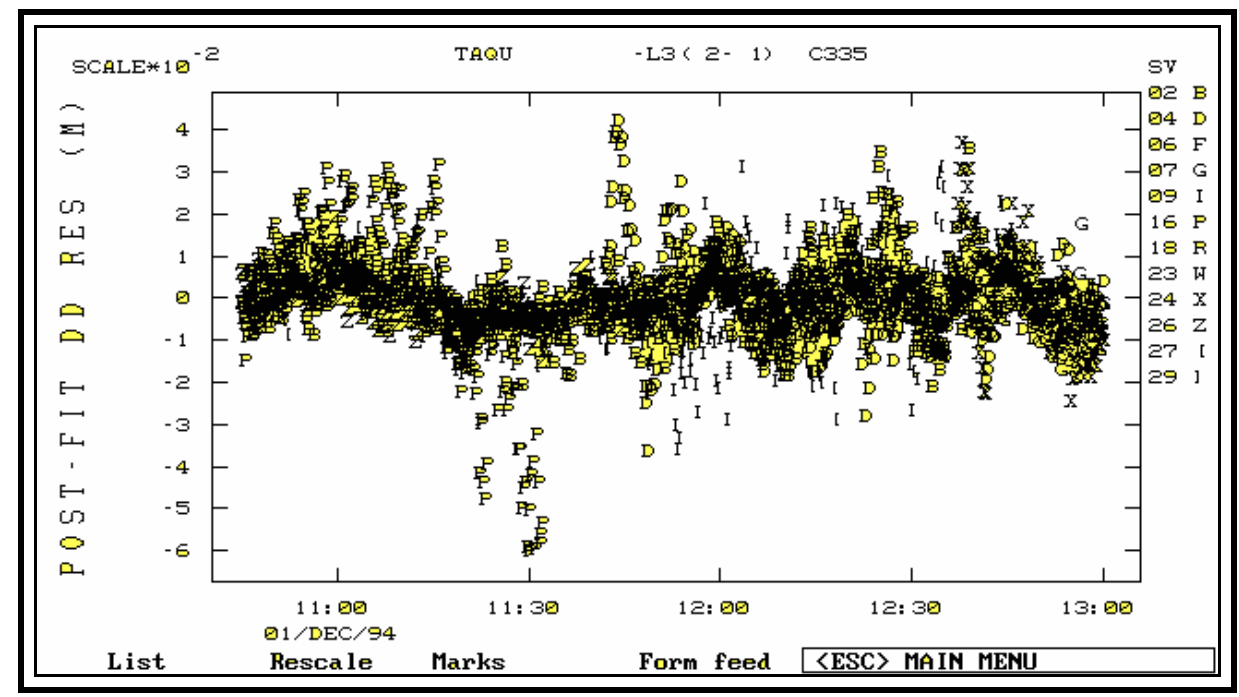

FGURA 16 - Dados dos sa télites sem correção - Taqua russu - DOY 335

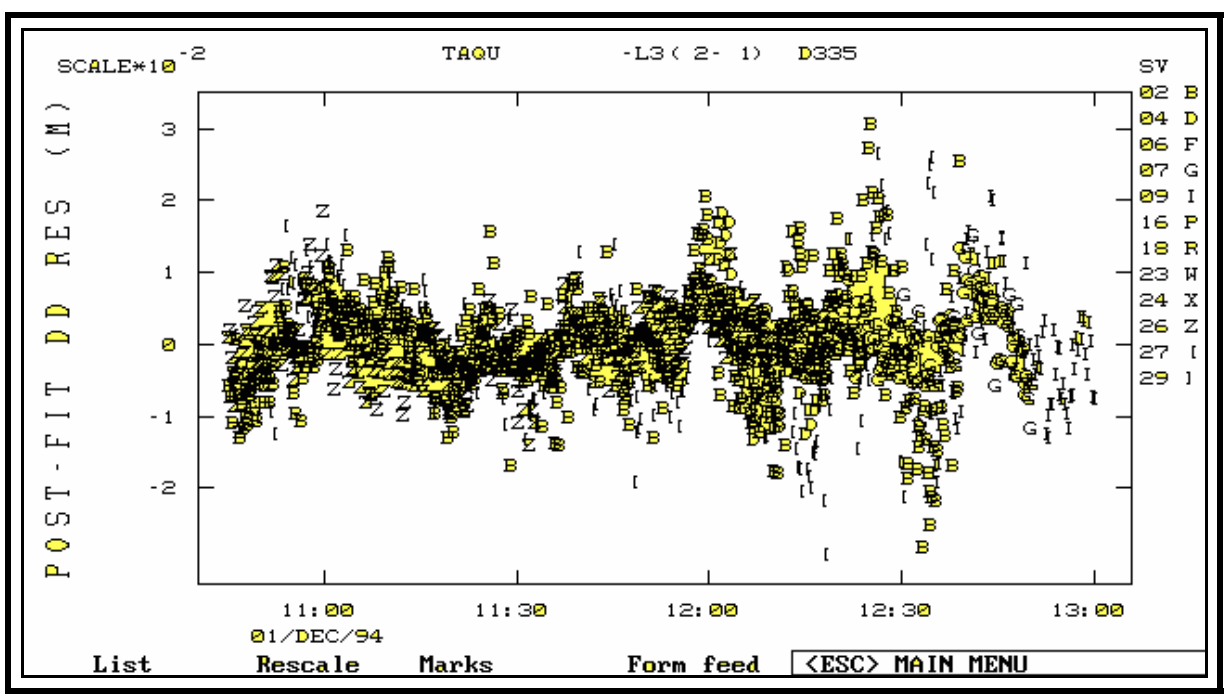

FGURA 17 - Da dos dos sa télites a pós correções ma nua is - Ta qua russu - DOY 335 
As FIGURAS 18 e 19 foram extraídas dos processamento realizados para a sessão do DOY 069.

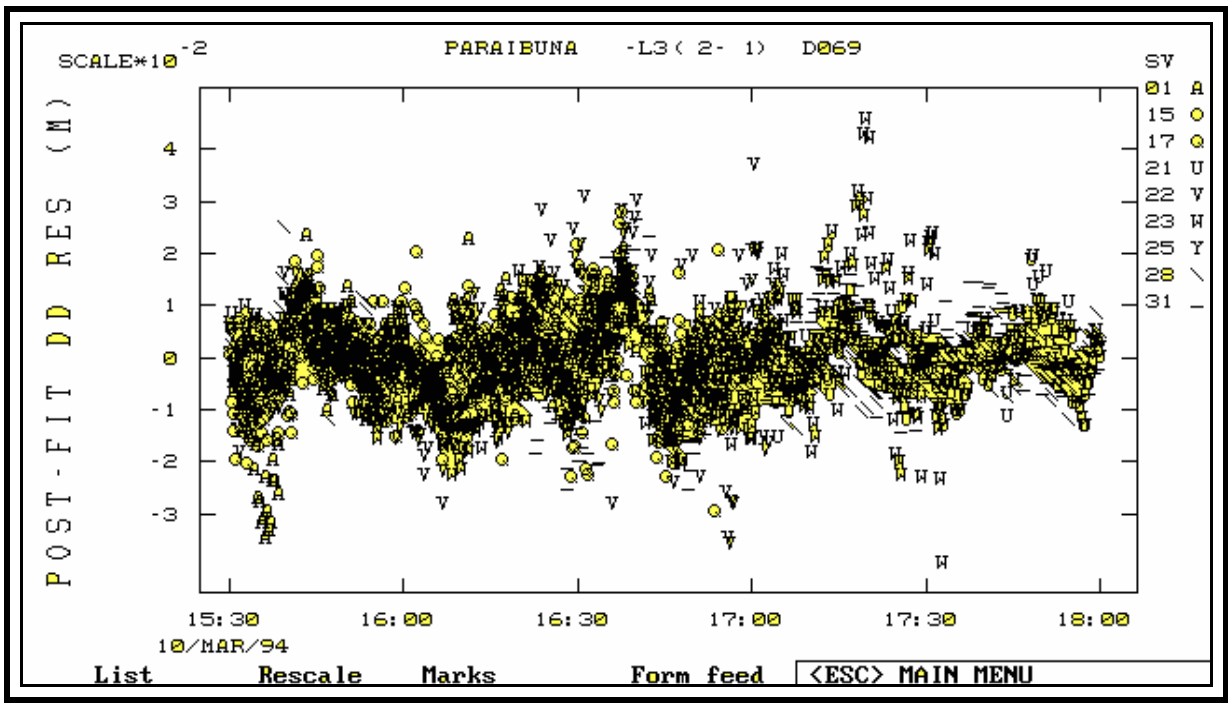

FGURA 18 - Da dos dos satélites sem correção - Pa ra ibuna - DOY 069

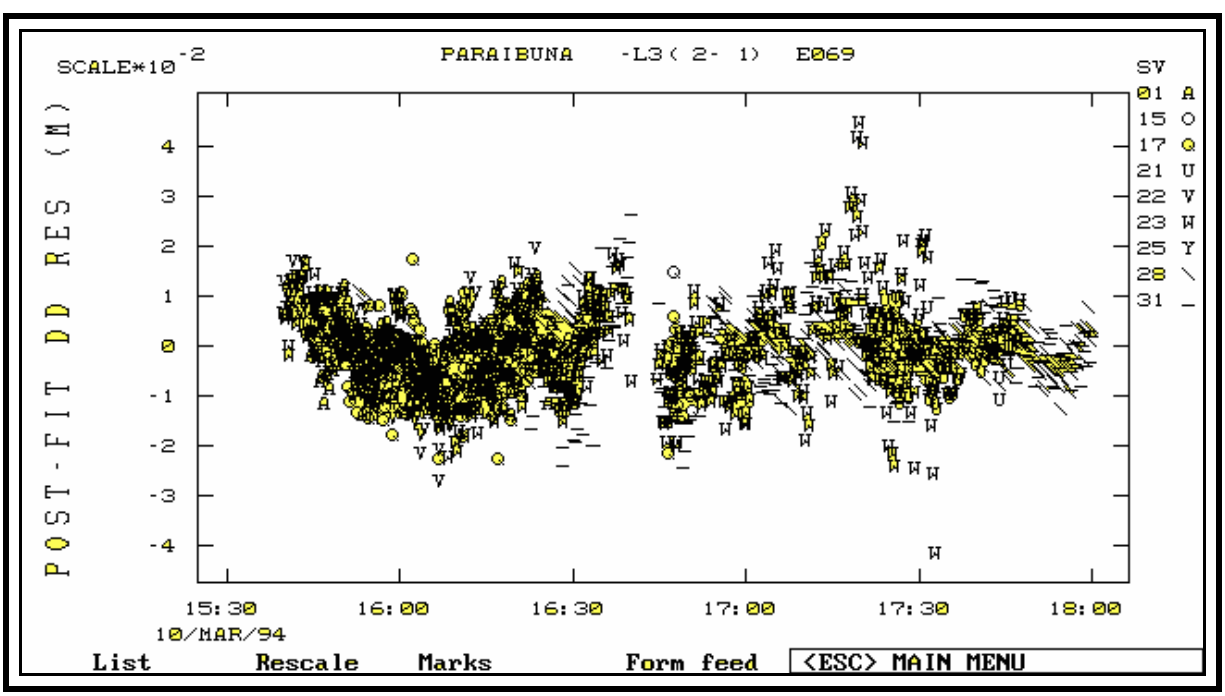

FGURA 19 - Da dos dos satélites a pós correções ma nua is- Pa ra ibuna - DOY 069 
Na FIGURA 20 pode ser observada ocorência de perdas de ciclo no sinal captado pela antena receptora.

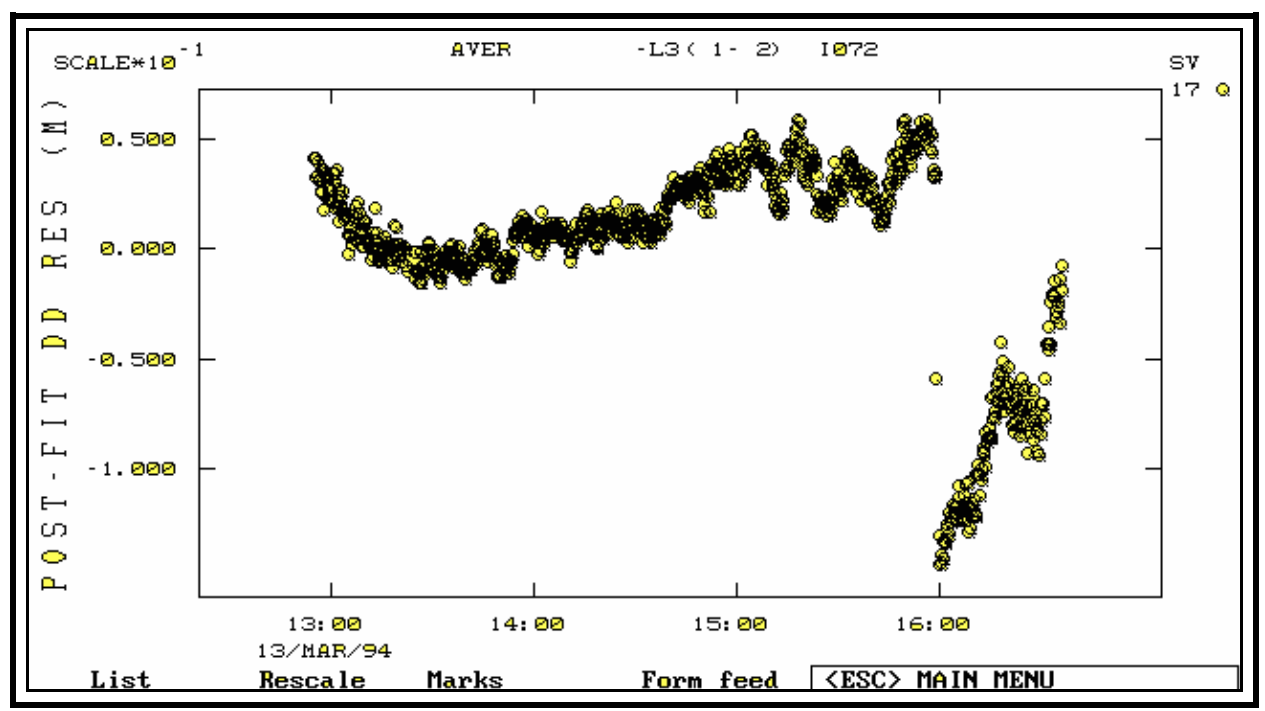

FGURA 20 - Exemplo de ocorência de perdas de ciclos

Os fatos acima citados foram observados durante o processamento da estratégia com o tempo total das obsenvações, realizada primeiro, bem como no processamento das três estratégias com o tempo de 2:30h, rea liza das posteriomente.

Estas últimas tiveram seus períodos escolhidos a partir de anotações feitas no processamento da estratégia com tempo total. Foram escolhidos os períodos cujos dados a presentavam-se melhores. Ainda assim, registrouse grande número de perdas de ciclos. Mas, pode-se observar que a eliminação das perdas de ciclos ocorreu de maneira mais rápida, seja através do programa ou através das intervenções manuais. $E$ de maneira geral, então, os processamentos foram ma is rá pidos. 


\section{3 - Resultados dos Processamentos}

\subsection{1 - Coordenadas preliminares das estações para o ajustamento}

As coordenadas cartesianas preliminares foram obtidas dos processamentos da rede GPS, realizados pela autora, a partir da seqüência de vetores deteminadas no item 8.5.

Partindo-se de CHUA, por exemplo, cujas coordenadas são conhecidas, foi-se processando vetores entre as estações e anotando-se em planilha Excel as coordenadas, na medida em que eram obtidas e calculando-se a média. E os valores médios obtidos, então, passavam a serem usados como coordenadas preliminares para os vetores subseqüentes dependentes.

Assim, termina do o processamento, o último valor médio obtido, para cada estação, gerou a coordenada preliminar para o ajustamento.

No ANEXO E encontram-se as quatro TABELAS com os valores das coordenadas preliminares para ajustamento, obtidas para cada uma das quatro estratégias elaboradas.

\subsection{2 - Valores das diferenças em relação aos eixos cartesianos $\mathrm{X}$, $\mathrm{Y}$ e $\mathrm{Z}$ dos vetores processados}

Os resultados de maior importância para a realização do ajustamento são os valores das diferenças em relação a os eixos cartesianos $\mathrm{X}, \mathrm{Y}$ e $\mathrm{Z}$, dos vetores processa dos, ou seja, $\Delta \mathrm{X}, \Delta \mathrm{Y}$ e $\Delta \mathrm{Z}$

Estes valores, resultantes da estratégias de processamento 1 estão apresentadosno ANEXO F. 
Os valores resultantes das estra tégias de processamentos 2, 3 e 4 não estão apresentados, pois implic ariam em mais três tabelas com sessenta e seis vetores cada, sendo demasiado extensa a listagem de todos. 


\section{CAPÍTULO 12}

\section{AJUSTAMENTOS}

"Os melhores médicos do mundo são: a dra. Dieta, a dra. Tranqüilida de e a dra.

Alegria."

J onathan Swift (1667-1745),

Escritor irlandês

\section{Sumário detalhado do Capitulo 12}

12.1 - Programas Computacionais 100

12.2 - Resultados dos Ajustamentos 102

12.2.1 - Resultados dos ajustamentos da estratégia com tempo total 102

12.2.1.1 - Estratégia 1 - Injunções mínimas CHUA e CAPA 102

12.2.1.2 - Estratégia 1.1 - Injunções mínimas CAPA e UEPP 104

12.2.2 - Resultados dos ajustamentos das estratégia com 2:30h 106

12.2.2.1 - Estratégia 2 - Injunções mínimas CHUA e CAPA 106

12.2.2.2 - Estratégia 3 - Injunções mínimas CHUA e CAPA 108

12.2.2.3 - Estratégia 4 - Injunções mínima s CHUA e CAPA 110 
Utilizando-se os resultados dos processamentos, partiu-se para a realização dos ajustamentos das quatro estratégias de proc essamentos.

Inicialmente determinou-se realizar os ajustamentos nos seguintes programas descritos, brevemente, abaixo.

\section{1 - Programas Computacionais}

[] STAR*NET PLUS - GPS Intemational Least Squares Survey Adjustment Program V5.0: é operado em DOS -Disk Operating System- e suporta dados de diferentes receptores, inclusive dos receptores Trimble, série 4000 SST que foram utilizados para a implantação da rede geodésica do Esta do de São Paulo.

[. COWMBUS - Geodetic Network Adjustment Software: programa comercial.

[. PRISMA Software v2.0 da Ashtech: é um programa comercial que permite realizar processamento e ajustamento dos dados.

De posse dos dados processados pelo OMNI v4.0, utilizou-se inicialmente o programa STAR NET PLUS. No entanto, no momento da entrada dos pontos considerados como injunção, CHUA e CAPA, inic ia Imente, verific ou-se a possibilidade de apenas entrar com um valor de zona UTM, ou de CHUA (Meridiano Central: -510) ou de CAPA (Meridiano Central: $\left.-45^{\circ}\right)$.

Disto concluiu-se que o programa não pemite ajustamento de áreas c uja extensão ultrapasse ma is de $3^{\circ}$ a leste do Meridiano Central ou ma is de 3o a oeste do mesmo.

O que foi confirmado, através do seguinte teste: realizou-se o ajustamento considerando apenas CHUA como ponto de injunção. Os 
valores de coordenadas ajustadas retomadas pelo programa estavam totalmente distorcidos, com valores de altura geométrica variando de $1300 \mathrm{~m}$ a $3500 \mathrm{~m}$.

Partiu-se, então para tentativa de realização do ajustamento no PRISMA. O que não foi possível devido ao fato de não se possuir os manuais e conseqüentemente, as informações necessária para a elaboração do arquivo em formato texto, com os dados para ajustamento.

O mesmo problema ocorreu com o SKI, quando da tentativa de ajustamento, que também foi investigado, apesar de inicialmente, não ter sido proposto nesta etapa de ajustamento.

Fina Imente, partiu-se para a utilização do Columbus. Este programa permite rea lizar o ajustamento sobre diversos elipsóides, entre eles o WGS 84. Ainda, de acordo com o manual do usuário, o número de pontos a serem ajustados é ilimitado. Assim, de posse do manual, foi possível elaborar o arquivo com os dados necessários para ajustamento. Este arquivo foi elaborado através do próprio programa. Há a opção de poder ser digitado fora do programa, em outro editor de texto e posteriomente, lido pelo programa.

Os dados de entrada constituíam-se das coordenadas preliminares das estações (apresentadas no item 11.3.1), dos valores das diferenças em relação a os eixos cartesianos $X, Y$ e $Z$, dos vetores processa dos, ou seja, $\Delta X$, $\Delta Y$ e $\Delta Z$ (apresentados no item 11.3.2) e os respectivos valores das variâncias. 


\section{2 - Resultados dos Ajustamentos}

Para se chegar aos resultados de ajustamentos apresentados a seguir, foram realizados aproximadamente trinta ajustamentos, em média seis para cada estratégia, com diferentes combinações de vetores.

Por combinações de vetores, realizada, deve-se entender a exclusão de determinados vetores com valor de desvio padrão alto, apontados pelo programa. A ordem de exclusão desses vetores foi determinante para se chegar aos melhores resultados de ajustamentos. Esta ordem de exclusão, no entanto, constituiu-se de diversas combinações entre os vetores apontados, para então, finalmente, chegar à exclusão dos vetores que, realmente, proporcionariam o melhor resultado. Esta tarefa foi extremamente laboriosa.

\subsection{1 - Resultados dos ajustamentos da estratégia com tempo total}

\subsubsection{1 - Estratégia 1 - Injunções mínimas CHUA e CAPA}

$\mathrm{Na}$ TABELA 36, apresenta-se os resultados do ajustamento da estratégia 1 (tempo total de observação, efemérides precisas e valores atmosféric os reais), em coordenadas geográfic as geodésicas referentes a o sistema WG 84.

As estações consideradas como injunção mínima foram CHUA e CAPA.

A visualização das elipses de erros e os valores obtidos para os semieixos maiore menor, encontram-se no CAPÍtULO 13. 
TABELA 36 - Resultados do ajustamento da Estratégia 1, a presentadosem coordenadas geodésicas (WGS 84)

\begin{tabular}{|c|c|c|c|}
\hline Estação & Latitude & Longitude & $\begin{array}{c}\mathbf{h} \\
(\mathbf{m})\end{array}$ \\
\hline AVAN & -21007' $19.295^{\prime \prime}$ & $\begin{array}{llll}-50^{\circ} & 12^{\prime} & 07.966 "\end{array}$ & 345.301 \\
\hline AVER & $-19^{\circ} 50^{\prime} 31.826^{\prime \prime}$ & $-50^{\circ} \quad 20^{\prime} 05.7561^{\prime \prime}$ & 388.798 \\
\hline BEA & $-23^{\circ} 47^{\prime} 33.444^{\prime \prime}$ & -45021'31.307" & 55.089 \\
\hline BOTU & $-22^{\circ} 48^{\prime} 17.251^{\prime \prime}$ & $-48^{\circ} 25^{\prime} 38.750^{\prime \prime}$ & 745.487 \\
\hline BUNA & $-23^{\circ} 24^{\prime} 41.188^{\prime \prime}$ & $-45^{\circ} 35^{\prime} 37.105^{\prime \prime}$ & 717.636 \\
\hline CAPA & $-22^{\circ} 41^{\prime} 13.061^{\prime \prime}$ & -440 $59^{\prime} 03.435^{\prime \prime}$ & 620.302 \\
\hline CHUA & -19o $45^{\prime} 43.346^{\prime \prime}$ & $-48^{\circ} 06^{\prime} 05.673^{\prime \prime}$ & 754.148 \\
\hline ERN & $-20^{\circ} 15^{\prime} 08.866^{\prime \prime}$ & $-50^{\circ} 11^{\prime} 00.6264^{\prime \prime}$ & 426.444 \\
\hline RCA & $-20^{\circ} 34^{\prime} 54.872^{\prime \prime}$ & $-47^{\circ} 22^{\prime} 51.420^{\prime \prime}$ & 1003.984 \\
\hline IBIT & $-21^{\circ} 45^{\prime} 17.713^{\prime \prime}$ & $-48^{\circ} 59^{\prime} 33.932^{\prime \prime}$ & 401.267 \\
\hline IEVA & -230 $56^{\prime} 39.041^{\prime \prime}$ & $-48^{\circ} 52^{\prime} 50.880^{\prime \prime}$ & 707.121 \\
\hline IUHA & $-20^{\circ} 22^{\prime} 16.370^{\prime \prime}$ & -51'23'52.409" & 322.390 \\
\hline ITAP & $-23^{\circ} 31^{\prime} 45.606^{\prime \prime}$ & $-48^{\circ} 00^{\prime} 35.490^{\prime \prime}$ & 746.898 \\
\hline JABO & $-21^{\circ} 14^{\prime} 06.597^{\prime \prime}$ & $-48^{\circ} 17^{\prime} 10.963^{\prime \prime}$ & 604.878 \\
\hline UMO & -210 $37^{\prime} 30.592^{\prime \prime}$ & -470 01'04.8291" & 578.798 \\
\hline MAR & $-22^{\circ} 11^{\prime} 42.907^{\prime \prime}$ & $-49^{\circ} 55^{\prime} 39.639^{\prime \prime}$ & 637.576 \\
\hline PANO & $-21^{\circ} 23^{\prime} 03.193^{\prime \prime}$ & $-51^{\circ} 50^{\prime} 58.669^{\prime \prime}$ & 333.266 \\
\hline PIRA & $-21^{\circ} 57^{\prime} 54.333^{\prime \prime}$ & $-47^{\circ} 26^{\prime} 35.651^{\prime \prime}$ & 599.432 \\
\hline REGI & -240 $26^{\prime} 31.757^{\prime \prime}$ & $-47^{\circ} 46^{\prime} 58.620^{\prime \prime}$ & 44.433 \\
\hline SAGR & $-22^{\circ} 54^{\prime} 16.098^{\prime \prime}$ & $\begin{array}{lll}-50^{\circ} & 00^{\prime} & 06.818^{\prime \prime}\end{array}$ & 386.841 \\
\hline SJ RP & $-20^{\circ} \quad 47^{\prime} 04.771^{\prime \prime}$ & $-49^{\circ} 21^{\prime} 29.440^{\prime \prime}$ & 519.742 \\
\hline TAQU & $-22^{\circ} 33^{\prime} 04.548^{\prime \prime}$ & $-52^{\circ} 00^{\prime} 14.419^{\prime \prime}$ & 288.502 \\
\hline UEPP & $-22^{\circ} 07^{\prime} 11.661^{\prime \prime}$ & -51'24'30.691" & 429.247 \\
\hline USPP & -23० $33^{\prime} 03.0467^{\prime \prime}$ & $-46^{\circ} 43^{\prime} 53.666^{\prime \prime}$ & 718.346 \\
\hline VAU & $-23^{\circ} 00^{\prime} \quad 06.158^{\prime \prime}$ & $-46^{\circ} 57^{\prime} 57.954^{\prime \prime}$ & 856.968 \\
\hline
\end{tabular}

A FIGURA 21, apresenta a configuração gráfica final da rede para a estratégia 1 . 


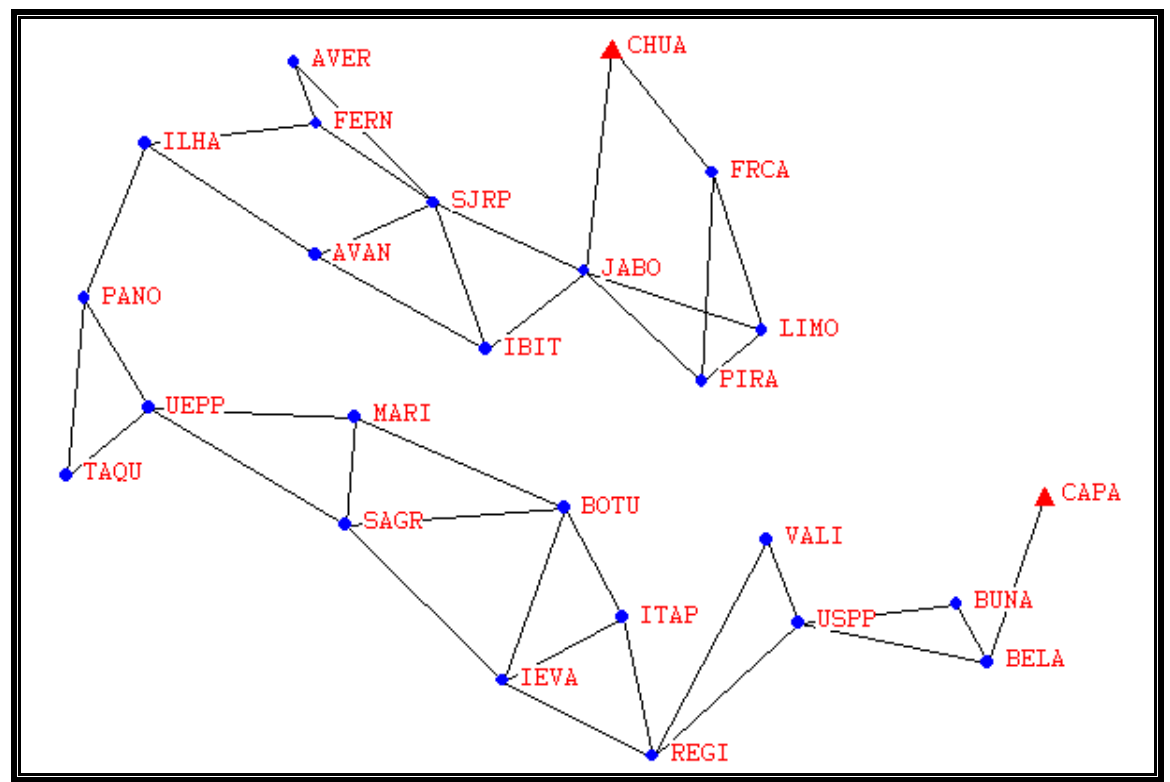

RGURA 21 - Configuração gráfic a vetorial da rede para a Estra tégia 1 - Injunções CHUA e CAPA -

\subsubsection{2 - Estratégia 1.1 - Injunções mínimas CAPA e UEPP}

$\mathrm{Na}$ TABELA 37, apresenta-se os resultados do ajustamento da mesma estratégia 1, mas com as estações CAPA e UEPP consideradas como injunção mínima, denominada, então, de estratégia 1.1 .

Os resultados são apresentados em coordenadas geográficas geodésicas, referentes a o sistema WGS 84.

A visualização das elipses de erros e os valores obtidos para os semieixos maiore menor, encontram-se no CAPÍTULO 13. 
TABEA 37 - Resulta dos do a justa mento da Estra tégia 1.1, a presenta dos em coordenadas geodésicas (WGS 84).

\begin{tabular}{|c|c|c|c|}
\hline Estação & Latitude & Longitude & $\begin{array}{c}\mathrm{h} \\
(\mathbf{m})\end{array}$ \\
\hline AVAN & $-21^{\circ} 07^{\prime} 19.288^{\prime \prime}$ & $\begin{array}{lll}-50^{\circ} & 12^{\prime} & 07.991 "\end{array}$ & 346.719 \\
\hline AVER & -190 $50^{\prime} 31.814^{\prime \prime}$ & $\begin{array}{lll}-50^{\circ} 20^{\prime} & 05.780^{\prime \prime}\end{array}$ & 390.213 \\
\hline BELA & -23047'33.450" & $-45^{\circ} 21^{\prime} 31.308^{\prime \prime}$ & 55.128 \\
\hline BOTU & $-22^{\circ} 48^{\prime} 17.252^{\prime \prime}$ & $-48^{\circ} 25^{\prime} 38.767^{\prime \prime}$ & 745.645 \\
\hline BUNA & $-23^{\circ} 24^{\prime} 41.193^{\prime \prime \prime}$ & $-45^{\circ} 35^{\prime} 37.108^{\prime \prime}$ & 717.889 \\
\hline CAPA & $-22^{\circ} 41^{\prime} 13.061^{\prime \prime}$ & $-44^{\circ} 59^{\prime} 03.435^{\prime \prime}$ & 620.302 \\
\hline CHUA & $-19045^{\prime} 43.334^{\prime \prime}$ & $-48^{\circ} 06^{\prime} 05.689 "$ & 755.547 \\
\hline FRN & $-20^{\circ} 15^{\prime} 08.856^{\prime \prime}$ & $-50^{\circ} 11^{\prime} 00.650^{\prime \prime}$ & 427.867 \\
\hline RCA & $-20^{\circ} 34^{\prime} 54.863^{\prime \prime}$ & $-47022^{\prime} 51.433^{\prime \prime}$ & 1005.373 \\
\hline IBIT & $-21^{\circ} 45^{\prime} 17.709^{\prime \prime}$ & $-48^{\circ} 59^{\prime} 33.952^{\prime \prime}$ & 402.665 \\
\hline IEVA & -230 $56^{\prime} 39.047^{\prime \prime}$ & $-48^{\circ} 52^{\prime} 50.899^{\prime \prime}$ & 707.283 \\
\hline IUHA & $-20^{\circ} 22^{\prime} 16.359^{\prime \prime}$ & $-51^{\circ} 23^{\prime} 52.438^{\prime \prime}$ & 323.844 \\
\hline ITAP & $-23^{\circ} 31^{\prime} 45.611^{\prime \prime}$ & $-48^{\circ} 00^{\prime} 35.505^{\prime \prime}$ & 747.047 \\
\hline JABO & $-21^{\circ} 14^{\prime} 06.591^{\prime \prime}$ & $-48^{\circ} 17^{\prime} 10.979 "$ & 606.272 \\
\hline பMO & $-21^{\circ} 37^{\prime} 30.588^{\prime \prime}$ & $-47^{\circ} 01^{\prime} 04.841 "$ & 580.180 \\
\hline MAR & $-22^{\circ} 11^{\prime} 42.905^{\prime \prime}$ & $-49^{\circ} 55^{\prime} 39.664^{\prime \prime}$ & 637.735 \\
\hline PANO & $-21^{\circ} 23^{\prime} 03.188^{\prime \prime}$ & $-51^{\circ} 50^{\prime} 58.699^{\prime \prime}$ & 334.796 \\
\hline PIRA & $-21^{\circ} 57^{\prime} 54.331^{\prime \prime}$ & $-47026^{\prime} 35.664^{\prime \prime}$ & 600.816 \\
\hline REGI & $-24^{\circ} 26^{\prime} 31.766^{\prime \prime}$ & $-47^{\circ} 46^{\prime} 58.633^{\prime \prime}$ & 44.598 \\
\hline SAGR & $-22^{\circ} 54^{\prime} 16.099^{\prime \prime}$ & 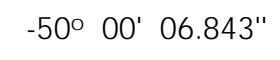 & 387.012 \\
\hline $\mathbf{S P P}$ & $\begin{array}{llll}-20^{\circ} & 47^{\prime} 04.762^{\prime \prime}\end{array}$ & $-49^{\circ} 21^{\prime} 29.460^{\prime \prime}$ & 521.150 \\
\hline TAQU & $-22^{\circ} 33^{\prime} 04.548^{\prime \prime}$ & $\begin{array}{llll}-52^{\circ} 00^{\prime} & 14.451^{\prime \prime}\end{array}$ & 290.132 \\
\hline UEPP & $-22^{\circ} 07^{\prime} 11.659^{\prime \prime}$ & $-51^{\circ} 24^{\prime} 30.721^{\prime \prime}$ & 430.946 \\
\hline USPP & -230 $33^{\prime} 03.051^{\prime \prime}$ & - $46^{\circ} 43^{\prime} 53.674^{\prime \prime}$ & 718.500 \\
\hline VAU & 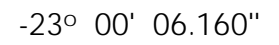 & $-46^{\circ} 57^{\prime} 57.963 "$ & 857.133 \\
\hline
\end{tabular}

A FIG URA 22, a presenta a configuração gráfica final da rede para a estratégia 1.1. 


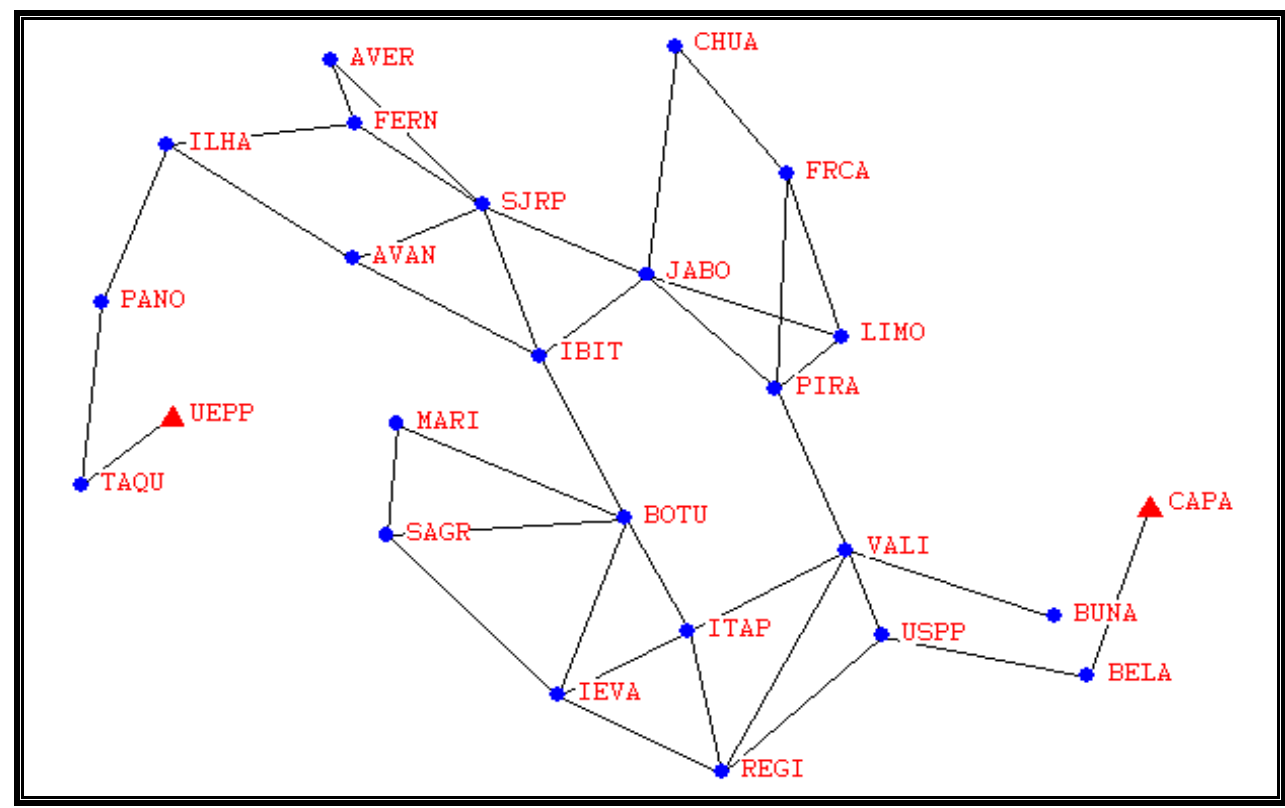

FGURA 22 - Configuração gráfic a vetorial da rede para a Estratégia 1.1

\subsection{2 - Resultados dos ajustamentos das estratégia com 2:30h}

\subsubsection{1 - Estratégia 2 - Injunções mínimas CHUA e CAPA}

Proc essa da com efemérides prec isa se va lores a tmosféric os rea is.

$\mathrm{Na}$ TABELA 38, apresenta-se os resultados do ajustamento da estratégia 2. Os resultados são a presentados em coordenadas geográficas geodésic as referentes a o sistema WG S84.

A visualização das elipses de erros e os valores obtidos para os semieixos maiore menor, encontram-se no CAPÍTULO 13. 
TABELA 38 - Resultados do ajustamento da Estratégia 2, a presentadosem coordenadas geodésicas (WGS 84)

\begin{tabular}{|c|c|c|c|}
\hline Estação & Latitude & Longitude & $\mathbf{h}$ \\
\hline AVAN & $\begin{array}{llll}21^{\circ} & 07^{\prime} 19.299^{\prime \prime}\end{array}$ & $\begin{array}{llll}-50^{\circ} & 12^{\prime} & 07.974 "\end{array}$ & 345.258 \\
\hline AVER & $-19^{\circ} 50^{\prime} 31.825^{\prime \prime}$ & $-50^{\circ} 20^{\prime} 05.763^{\prime \prime}$ & 388.747 \\
\hline BEA & $-23^{\circ} 47^{\prime} 33.449^{\prime \prime}$ & $-45^{\circ} 21^{\prime} 31.315^{\prime \prime}$ & 54.933 \\
\hline ВOTU & $-22^{\circ} 48^{\prime} 17.263^{\prime \prime}$ & $-48^{\circ} 25^{\prime} 38.750^{\prime \prime}$ & 744.394 \\
\hline BUNA & $-23^{\circ} 24^{\prime} 41.192^{\prime \prime}$ & $-45^{\circ} 35^{\prime} 37.115^{\prime \prime}$ & 717.496 \\
\hline CAPA & $-22^{\circ} 41^{\prime} 13.060^{\prime \prime}$ & -440 $59^{\prime} 03.434^{\prime \prime}$ & 620.302 \\
\hline CHUA & $-19 \circ 45^{\prime} 43.345^{\prime \prime}$ & $-48^{\circ} 06^{\prime} 05.673^{\prime \prime}$ & 754.148 \\
\hline FERN & $\begin{array}{lll}-20^{\circ} & 15^{\prime} 08.867^{\prime \prime}\end{array}$ & $-50^{\circ} 11^{\prime} 00.633^{\prime \prime}$ & 426.331 \\
\hline RCA & $-20^{\circ} 34^{\prime} 54.874^{\prime \prime}$ & -470 $22^{\prime} 51.419 "$ & 1003.962 \\
\hline IBIT & $-21^{\circ} 45^{\prime} 17.719^{\prime \prime}$ & -48 $58^{\prime} 33.937^{\prime \prime}$ & 401.182 \\
\hline IEVA & $-23^{\circ} 56^{\prime} 39.057^{\prime \prime}$ & $-48^{\circ} 52^{\prime} 50.882^{\prime \prime}$ & 705.971 \\
\hline IUHA & $-20^{\circ} 22^{\prime} 16.372^{\prime \prime}$ & $-51^{\circ} 23^{\prime} 52.421^{\prime \prime}$ & 322.250 \\
\hline ITAP & $-23^{\circ} 31^{\prime} 45.621^{\prime \prime}$ & $-48^{\circ} 00^{\prime} 35.489^{\prime \prime}$ & 745.764 \\
\hline JABO & $-21^{\circ} 14^{\prime} 06.601^{\prime \prime}$ & $-48^{\circ} 17^{\prime} 10.964^{\prime \prime}$ & 604.816 \\
\hline UMO & $-21^{\circ} 37^{\prime} 30.598^{\prime \prime}$ & 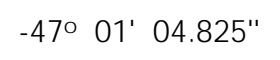 & 578.755 \\
\hline MAR & $-22^{\circ} 11^{\prime} 42.916^{\prime \prime}$ & -49o $55^{\prime} 39.644^{\prime \prime}$ & 636.448 \\
\hline PANO & $\begin{array}{lll}-21^{\circ} & 23^{\prime} 03.200^{\prime \prime}\end{array}$ & $-51^{\circ} 50^{\prime} 58.682^{\prime \prime}$ & 332.137 \\
\hline PIRA & $-21^{\circ} 57^{\prime} 54.341^{\prime \prime}$ & $-47026^{\prime} 35.649^{\prime \prime}$ & 599.384 \\
\hline REGI & $-24^{\circ} 26^{\prime} 31.776^{\prime \prime}$ & $-47046^{\prime} 58.618^{\prime \prime}$ & 43.294 \\
\hline SAGR & $-22^{\circ} 54^{\prime} 16.110^{\prime \prime}$ & 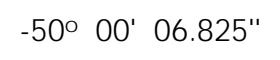 & 385.652 \\
\hline $\mathbf{S} \mathbf{R P}$ & $\begin{array}{llll}-20^{\circ} & 47^{\prime} & 04.774^{\prime \prime}\end{array}$ & $-49^{\circ} 21^{\prime} 29.445^{\prime \prime}$ & 519.658 \\
\hline TAQU & $-22^{\circ} 33^{\prime} 04.559^{\prime \prime}$ & $\begin{array}{llll}-52^{\circ} & 00^{\prime} & 14.434^{\prime \prime}\end{array}$ & 287.291 \\
\hline UEPP & $-22^{\circ} 07^{\prime} 11.670^{\prime \prime}$ & $-51^{\circ} 24^{\prime} 30.704^{\prime \prime}$ & 428.009 \\
\hline USPP & $-23^{\circ} 33^{\prime} 03.062^{\prime \prime}$ & $-46^{\circ} 43^{\prime} 53.656^{\prime \prime}$ & 717.435 \\
\hline VAU & -230 $03^{\prime} 06.171 "$ & $-46^{\circ} 57^{\prime} 57.947^{\prime \prime}$ & 855.844 \\
\hline
\end{tabular}

A FIG URA 23, apresenta a configuração gráfica final da rede para a estra tégia 2. 


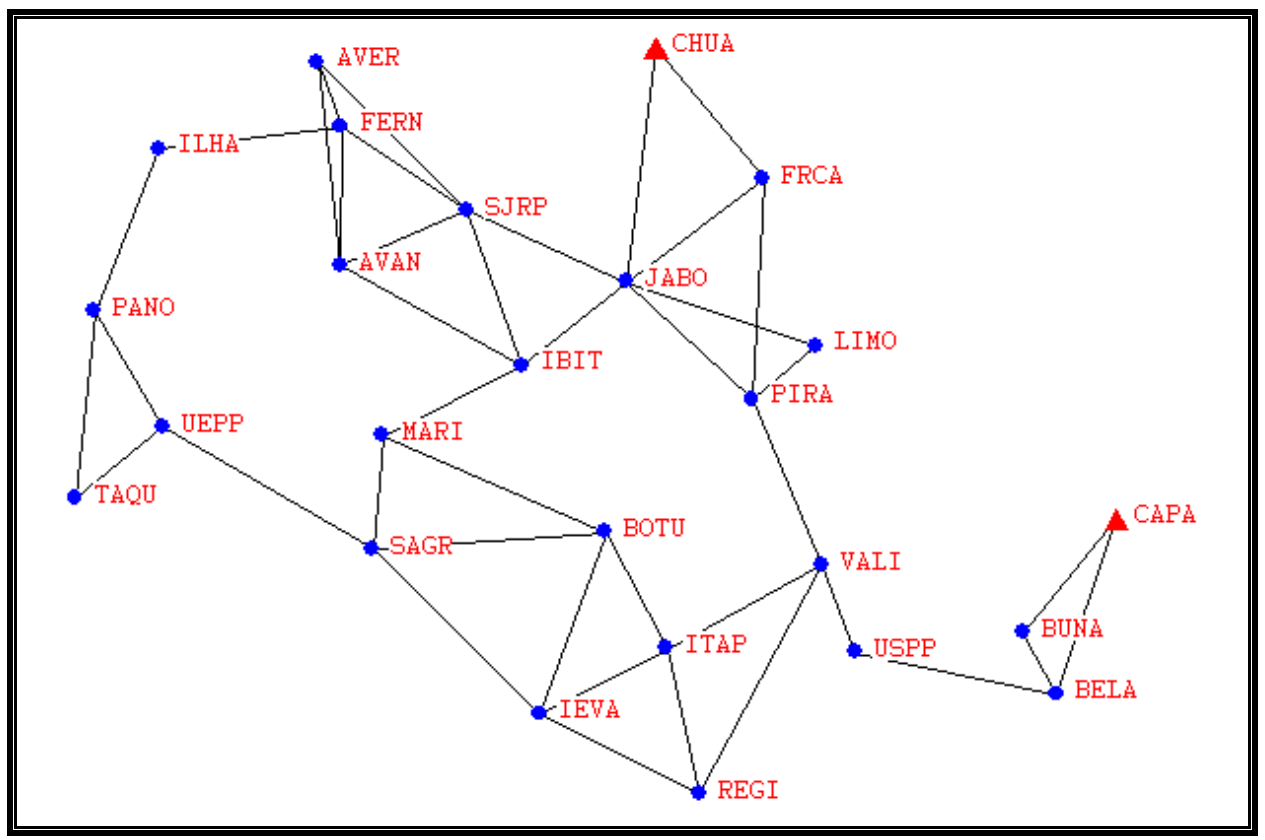

RGURA 23 - Configuração gráfic a vetorial da rede para a Estratégia 2

\subsubsection{2 - Estratégia 3 - Injunções mínimas CHUA e CAPA}

Processada com efemérides precisas e valores do default do OMNI v4.0.

$\mathrm{Na}$ TABELA 39, apresenta-se os resultados do ajustamento da estratégia 3. Os resultados são a presentados em coordenadas geográficas geodésicas, referentes a o sistema WGS 84.

A visualização das elipses de erros e os valores obtidos para os semieixos maiore menor, encontram-se no CAPÍtULO 13. 
TABELA 39 - Resultados do ajustamento da Estratégia 3, a presentados em coordenadas geodésicas (WGS 84)

\begin{tabular}{|c|c|c|c|}
\hline Estação & Latitude & Longitude & $\begin{array}{c}\mathrm{h} \\
\text { (m) }\end{array}$ \\
\hline AVAN & $-21^{\circ} 07^{\prime} 19.295^{\prime \prime}$ & $\begin{array}{llll}-50^{\circ} & 12^{\prime} & 07.969^{\prime \prime}\end{array}$ & 346.965 \\
\hline AVER & -190 $50^{\prime}$ '31.825 & $\begin{array}{lll}-50^{\circ} & 20^{\prime} & 05.759^{\prime \prime}\end{array}$ & 388.666 \\
\hline BELA & $-23^{\circ} 47^{\prime} 33.445^{\prime \prime}$ & $-45^{\circ} 21^{\prime} 31.308^{\prime \prime}$ & 55.382 \\
\hline ВОTU & $-22^{\circ} 48^{\prime} 17.252^{\prime \prime}$ & $-48^{\circ} 25^{\prime} 38.751^{\prime \prime}$ & 745.980 \\
\hline BUNA & $-23^{\circ} 24^{\prime} 41.189 "$ & $-45^{\circ} 35^{\prime} 37.107^{\prime \prime}$ & 718.000 \\
\hline CAPA & $-22^{\circ} 41^{\prime} 13.060^{\prime \prime}$ & -440 59' $03.434^{\prime \prime}$ & 620.302 \\
\hline CHUA & $-19^{\circ} 45^{\prime} 43.345^{\prime \prime}$ & $-48^{\circ} 06^{\prime} 05.673^{\prime \prime}$ & 754.148 \\
\hline FER & $-20^{\circ} 15^{\prime} 08.867^{\prime \prime}$ & $-50^{\circ} 11^{\prime} 00.628^{\prime \prime}$ & 428.055 \\
\hline RCA & $-20^{\circ} 34^{\prime} 54.871^{\prime \prime}$ & $-47^{\circ} 22^{\prime} 51.422^{\prime \prime}$ & 1003.987 \\
\hline IBIT & $-21^{\circ} 45^{\prime} 17.713^{\prime \prime}$ & $-48^{\circ} 59^{\prime} 33.937^{\prime \prime}$ & 402.902 \\
\hline IEVA & -230 $56^{\prime} 39.044^{\prime \prime}$ & $-48^{\circ} 52^{\prime} 50.881^{\prime \prime}$ & 707.513 \\
\hline ILHA & $-20^{\circ} 22^{\prime} 16.371 "$ & $-51^{\circ} 23^{\prime} 52.411^{\prime \prime}$ & 324.010 \\
\hline ITAP & $-23^{\circ} 31^{\prime} 45.607^{\prime \prime}$ & $-48^{\circ} 00^{\prime} 35.491^{\prime \prime}$ & 747.288 \\
\hline JABO & $-21^{\circ} 14^{\prime} 06.597^{\prime \prime}$ & $-48^{\circ} 17^{\prime} 10.964^{\prime \prime}$ & 604.791 \\
\hline பMO & $-21^{\circ} 37^{\prime} 30.592^{\prime \prime}$ & $-47 \circ 01^{\prime} 04.830^{\prime \prime}$ & 578.765 \\
\hline MAR & $-22^{\circ} 11^{\prime} 42.907^{\prime \prime}$ & $-49^{\circ} 55^{\prime} 39.640^{\prime \prime}$ & 638.073 \\
\hline PANO & $-21^{\circ} 23^{\prime} 03.194^{\prime \prime}$ & $-51^{\circ} 50^{\prime} 58.670^{\prime \prime}$ & 333.745 \\
\hline PIRA & $-21^{\circ} 57^{\prime} 54.334^{\prime \prime}$ & $-47^{\circ} 26^{\prime} 35.652^{\prime \prime}$ & 599.391 \\
\hline REGI & $-24^{\circ} 26^{\prime} 31.758^{\prime \prime}$ & $-47^{\circ} 46^{\prime} 58.622^{\prime \prime}$ & 44.833 \\
\hline SAGR & $-22^{\circ} 54^{\prime} 16.098^{\prime \prime}$ & $-50^{\circ} 00^{\prime} 06.819^{\prime \prime}$ & 387.303 \\
\hline $\mathbf{S} \mathbf{R P}$ & $-20^{\circ} \quad 47^{\prime} 04.771 "$ & $-49^{\circ} 21^{\prime} 29.443^{\prime \prime}$ & 519.613 \\
\hline TAQU & $-22^{\circ} 33^{\prime} 04.549^{\prime \prime}$ & $-52^{\circ} 00^{\prime} 14.419^{\prime \prime}$ & 288.912 \\
\hline UEPP & $-22^{\circ} 07^{\prime} 11.662^{\prime \prime}$ & 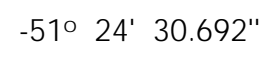 & 429.679 \\
\hline USPP & $-23^{\circ} 33^{\prime} 03.047^{\prime \prime}$ & $-46^{\circ} 43^{\prime} 53.668^{\prime \prime}$ & 718.764 \\
\hline VAU & $-23^{\circ} 00^{\prime} 06.159^{\prime \prime}$ & $-46^{\circ} 57^{\prime} 57.955^{\prime \prime}$ & 857.367 \\
\hline
\end{tabular}

A FIGURA 24, apresenta a configuração gráfica final da rede para a estratégia 3. 


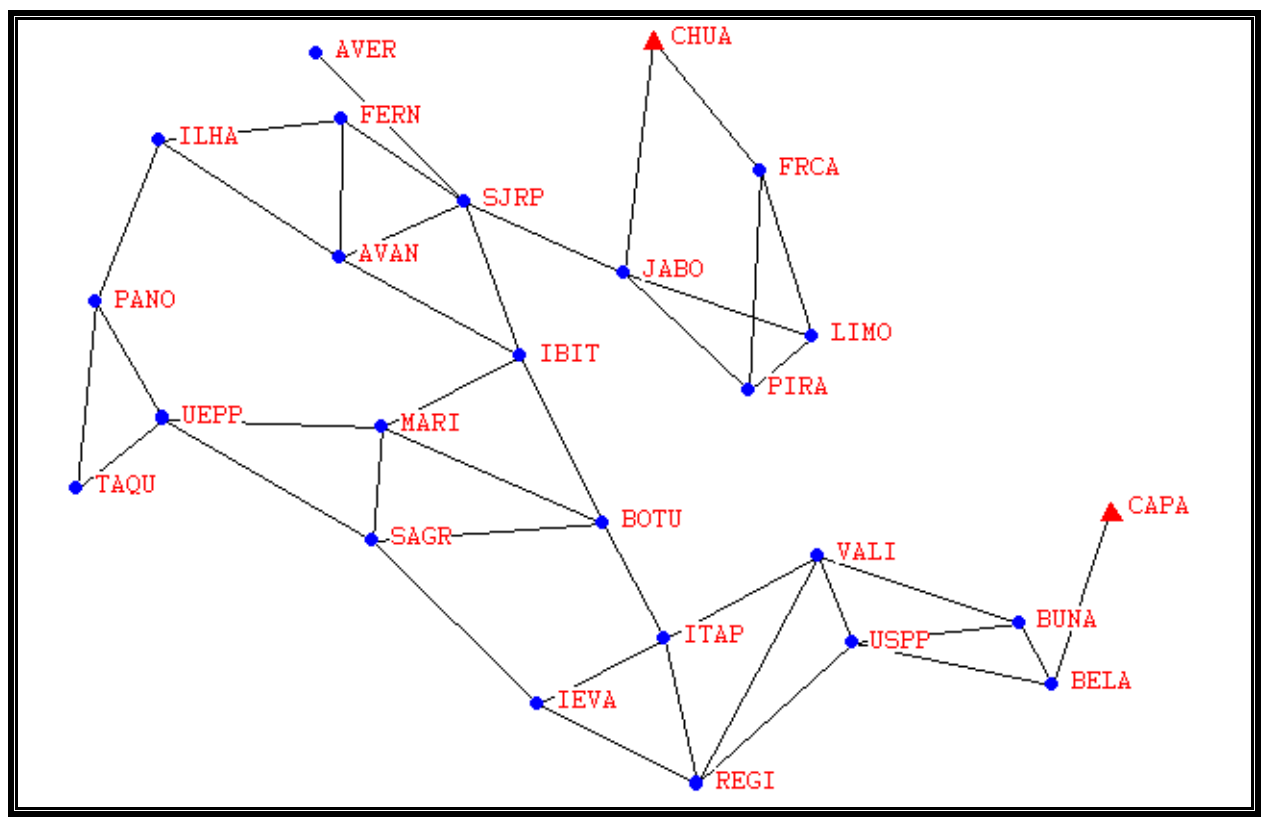

HGURA 24 - Configura ção gráfica vetorial da rede para a Estra tégia 3

\subsubsection{3 - Estratégia 4 - Injunções mínimas CHUA e CAPA}

Processa da com efemérides transmitidas e valores a tmosféric os rea is, no OMNI v4.0.

$\mathrm{Na}$ TABELA 40 apresenta-se os resultados do ajustamento da estra tégia 4.

Os resultados são apresentados em coordenadas geográficas geodésic as, referentes a o sistema WGS 84.

A visualização das elipses de erros e os valores obtidos para os semieixos maiore menor, encontram-se no CAPÍTULO 13. 
TABELA 40 - Resultados do ajustamento da Estratégia 4, a presenta dos em coordenadas geodésicas (WGS 84).

\begin{tabular}{|c|c|c|c|}
\hline Estação & Latitude & Longitude & $\begin{array}{l}\text { h } \\
\text { (m) }\end{array}$ \\
\hline AVAN & "210 $07^{\circ} 19.291^{\prime \prime}$ & $\begin{array}{lll}-50^{\circ} & 12^{\prime} 07.960^{\prime \prime}\end{array}$ & 346.781 \\
\hline AVER & -190 $50^{\prime} 31.824^{\prime \prime}$ & -50'20 $20^{\prime} 05.751^{\prime \prime}$ & 388.621 \\
\hline BEA & "230 $473.431^{\prime \prime}$ & $-45^{\circ} 21^{\prime} 31.315^{\prime \prime}$ & 55.425 \\
\hline BOTU & $-22^{\circ} 48^{\prime} 17.242^{\prime \prime}$ & $-48^{\circ} 25^{\prime} 38.749^{\prime \prime}$ & 745.844 \\
\hline BUNA & -230 $24^{\prime} 41.177^{\prime \prime}$ & $-45^{\circ} 35^{\prime} 37.111^{\prime \prime}$ & 718.158 \\
\hline CAPA & $-22^{\circ} 41^{\prime} 13.060^{\prime \prime}$ & -440 $59^{\prime} 03.434^{\prime \prime}$ & 620.302 \\
\hline CHUA & $-19^{\circ} \quad 45^{\prime} 43.345^{\prime \prime}$ & -48 $06^{\prime}$ 05.673" & 754.148 \\
\hline FERN & -20 $10^{\prime} 08.867^{\prime \prime}$ & $\begin{array}{lll}-50^{\circ} & 11^{\prime} 00.622^{\prime \prime}\end{array}$ & 427.740 \\
\hline FCA & $-20^{\circ} 34^{\prime} 54.869^{\prime \prime}$ & $-47^{\circ} 22^{\prime} 51.430^{\prime \prime}$ & 1003.743 \\
\hline IBIT & $\begin{array}{llll}-21^{\circ} & 45^{\prime} & 17.706^{\prime \prime}\end{array}$ & $-48^{\circ} 59^{\prime} 33.933^{\prime \prime}$ & 402.720 \\
\hline IEVA & $-23^{\circ} 56^{\prime} 39.029^{\prime \prime}$ & $-48^{\circ} 52^{\prime} 50.885^{\prime \prime}$ & 707.632 \\
\hline IUHA & $-20^{\circ} 22^{\prime} 16.369^{\prime \prime}$ & -510 $23^{\circ} 52.399^{\prime \prime}$ & 323.858 \\
\hline ITAP & -23 $31^{\prime} 45.597^{\prime \prime}$ & $\begin{array}{lll}-48^{\circ} & 00^{\prime} 35.493^{\prime \prime}\end{array}$ & 747.427 \\
\hline JABO & -210 $14^{\prime} 06.592^{\prime \prime}$ & -48 $18^{\prime} 17^{\prime} 10.970$ & 604.644 \\
\hline LMO & י"210 $37^{\prime} 30.587^{\prime \prime}$ & -470 $01^{\prime} 04.846^{\prime \prime}$ & 578.460 \\
\hline MARI & $-22^{\circ} 11^{\prime} 42.900^{\prime \prime}$ & $-49^{\circ} 55^{\prime} 39.639^{\prime \prime}$ & 637.907 \\
\hline PANO & -210 $23^{\prime} 03.190^{\prime \prime}$ & $-51^{\circ} 50^{\prime} 58.664^{\prime \prime}$ & 333.762 \\
\hline PIRA & "210 57'54.328' & -47026'35.667" & 599.047 \\
\hline REG I & $-24^{\circ} 26^{\prime} 31.744^{\prime \prime}$ & $-47^{\circ} \quad 46^{\prime} 58.626^{\prime \prime}$ & 44.977 \\
\hline SAGR & $-22^{\circ} 54^{\prime} 16.088^{\prime \prime}$ & $\begin{array}{lll}-50^{\circ} & 00^{\prime} & 06.821^{\prime \prime}\end{array}$ & 387.195 \\
\hline S RP & -20 & -49o $21^{\prime} 29.439^{\prime \prime}$ & 519.537 \\
\hline TAQU & -220 $33^{\prime} 04.541^{\prime \prime}$ & $\begin{array}{lll}-52^{\circ} 00^{\prime} & 14.417^{\prime \prime}\end{array}$ & 288.807 \\
\hline UEPP & "22007' $11.655^{\prime \prime}$ & $-51^{\circ} 24^{\prime} 30.690^{\prime \prime}$ & 429.631 \\
\hline USPP & -230 33'03.035" & -460 $43^{\prime} 53.670^{\prime \prime}$ & 718.866 \\
\hline VAU & -230 $03^{\prime}$ '06.150" & "46 $56^{\circ} 57.955^{\prime \prime}$ & 857.522 \\
\hline
\end{tabular}

A FIGURA 25, apresenta a configuração gráfica final da rede para a estra tégia 4. 


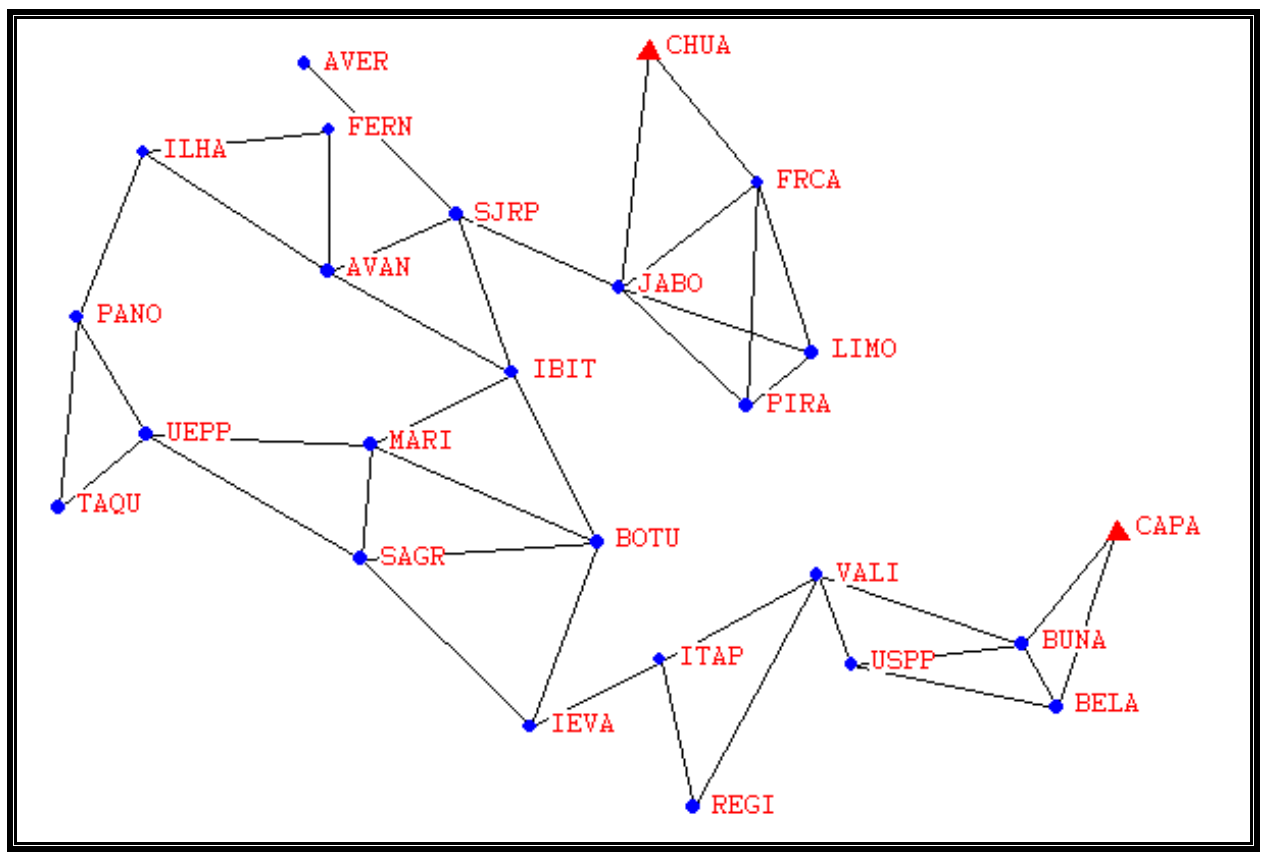

RGURA 25 - Configuração gráfic a vetorial da rede para a Estra tégia 4 


\section{CAPÍTULO 13}

\section{ELÍPSES DE ERROS}

"Há grandes homens que fazem com que todos se sintam pequenos. Maso verdadeiro grande homem é aquele que fazcom que todos se sintam

grandes. "

Gilbert Keith Chesterton (1874-1936), Escritoringlês.

\section{Sumário detalhado do Capitulo 13}

13.1 - Elipses de Erros da Estratégia 1

13.2 - Elipses de Erros da Estratégia 1.1

13.3 - Elipses de Erros da Estratégia 2

13.4 - Elipses de Erros da Estratégia 3 


\section{1 - Elipses de Erros da Estratégia 1}

A FIG URA 26 ilustra as elipses de erros do ajustamento da Estra tégia 1, e a TABELA 41 a presenta os valores para os semi-eixos e para a altura. 
TABEA 41 - Va lores do Semi-Eixos Ma ior e Menor e Altura, das elipses - Estratégia 1

\begin{tabular}{|c|c|c|c|}
\hline Estação & $\begin{array}{l}\text { Semi-eixo } \\
\text { Maior } \\
\text { (m) }\end{array}$ & $\begin{array}{l}\text { Semi-eixo } \\
\text { Menor } \\
\text { (m) }\end{array}$ & $\begin{array}{c}\text { Altura } \\
\text { (m) }\end{array}$ \\
\hline$\overline{\text { AVAN }}$ & 0.072 & 0.024 & 0.027 \\
\hline AVER & 0.079 & 0.032 & 0.039 \\
\hline BELA & 0.068 & $\odot .049$ & 0.048 \\
\hline BOTU & 0.102 & 0.051 & 0.060 \\
\hline BUNA & 0.074 & 0.047 & 0.053 \\
\hline CAPA & 0.000 & 0.000 & 0.000 \\
\hline CHUA & 0.000 & $\odot .000$ & 0.000 \\
\hline FERN & 0.073 & 0.025 & 0.034 \\
\hline FRCA & 0.035 & 0.024 & $\odot .022$ \\
\hline IBIT & 0.059 & $\odot .029$ & 0.024 \\
\hline IEVA & 0.115 & 0.055 & 0.058 \\
\hline ILHA & 0.102 & $\odot .028$ & 0.037 \\
\hline ITAP & $\odot .099$ & $\odot .055$ & 0.058 \\
\hline JABO & ๑. 039 & $\odot .023$ & 0.018 \\
\hline LIMO & 0.056 & $\odot .028$ & $\odot .023$ \\
\hline MARI & 0.120 & $\odot .049$ & $\odot .06 \odot$ \\
\hline PANO & 0.141 & 0.044 & 0.056 \\
\hline PIRA & ๑. 059 & $\odot .029$ & $\odot .022$ \\
\hline REGI & 0.104 & 0.054 & 0.055 \\
\hline SAGR & 0.125 & 0.049 & 0.059 \\
\hline SJRP & 0.050 & 0.021 & 0.023 \\
\hline TAQU & 0.157 & 0.055 & 0.065 \\
\hline UEPP & 0.142 & 0.048 & $\odot .059$ \\
\hline USPP & 0.082 & 0.047 & 0.053 \\
\hline VALI & $\odot .083$ & $\odot .044$ & 0.055 \\
\hline
\end{tabular}




\section{2 - Elipses de Erros da Estratégia 1.1}

A FIGURA 27 ilustra as elipses de erros do ajustamento da Estra tégia

1.1, e a TABELA 42 a presenta os valores para os semi-eixos e para a altura. 
TABEA 42 - Va lores do Semi-Eixos Ma ior e Menor e Altura, das elipses da Estratégia 1.1

\begin{tabular}{|c|c|c|c|}
\hline Estação & $\begin{array}{l}\text { Semi-eixo } \\
\text { Maior } \\
\text { (m) }\end{array}$ & $\begin{array}{l}\text { Semi-eixo } \\
\text { Menor } \\
\text { (m) }\end{array}$ & $\begin{array}{l}\text { Altura } \\
\text { (m) }\end{array}$ \\
\hline$\overline{\text { AVAN }}$ & 0.144 & 0.092 & 0.092 \\
\hline AVER & 0.165 & 0.114 & $\odot .097$ \\
\hline BELA & $\odot . \odot 97$ & 0.064 & $\odot .07 \odot$ \\
\hline BOTU & 0.130 & 0.068 & $\odot . \odot 86$ \\
\hline BUNA & 0.135 & 0.075 & $\odot .097$ \\
\hline CAPA & 0.000 & 0.000 & $\odot .000$ \\
\hline CHUA & 0.138 & 0.123 & 0.097 \\
\hline FERN & 0.150 & 0.107 & 0.094 \\
\hline FRCA & 0.135 & 0.101 & 0.096 \\
\hline IBIT & 0.125 & $\odot .083$ & $\odot .091$ \\
\hline IEVA & 0.145 & 0.068 & $\odot .084$ \\
\hline ILHA & 0.168 & $\odot .095$ & $\odot .091$ \\
\hline ITAP & 0.127 & $\odot .065$ & ๑.๑83 \\
\hline JABO & 0.122 & $\odot .092$ & $\odot .093$ \\
\hline LIMO & 0.133 & $\odot .082$ & $\odot . \odot 96$ \\
\hline MARI & 0.170 & ๑. 083 & $\odot . \odot 95$ \\
\hline PANO & 0.126 & $\odot .071$ & $\odot .078$ \\
\hline PIRA & 0.128 & $\odot . \odot 79$ & $\odot .095$ \\
\hline REGI & 0.130 & 0.073 & $\odot .082$ \\
\hline SAGR & 0.168 & 0.072 & $\odot .088$ \\
\hline SJRP & 0.130 & 0.102 & $\odot .092$ \\
\hline TAQU & 0.065 & 0.032 & 0.039 \\
\hline UEPP & 0.000 & 0.000 & $\odot .0 \odot \odot$ \\
\hline USPP & 0.110 & 0.059 & $\odot .079$ \\
\hline VALI & 0.112 & $\odot .059$ & ๑.๑81 \\
\hline
\end{tabular}




\section{3 - Elipses de Erros da Estratégia 2}

A FIG URA 28 ilustra as elipses de erros do ajustamento da Estra tégia 2, e a TABELA 43 a presenta os valores para os semi-eixos e para a altura. 
TABEA 43 - Va lores do Semi-Eixos Ma ior e Menor e Altura, das elipses - Estratégia 2

\begin{tabular}{|c|c|c|c|}
\hline Estação & $\begin{array}{l}\text { Semi-eixo } \\
\text { Maior } \\
\text { (m) }\end{array}$ & $\begin{array}{l}\text { Semi-eixo } \\
\text { Menor } \\
(\mathrm{m})\end{array}$ & $\begin{array}{c}\text { Altura } \\
\text { (m) }\end{array}$ \\
\hline AVAN & 0.139 & $\odot .037$ & $\odot . \odot 44$ \\
\hline AVER & 0.131 & 0.033 & $\odot . \odot 49$ \\
\hline BELA & 0.071 & $\odot .043$ & $\odot .033$ \\
\hline BOTU & 0.159 & 0.102 & $\odot . \odot 77$ \\
\hline BUNA & 0.064 & $\odot .04 \odot$ & $\odot .036$ \\
\hline CAPA & $\odot . \odot \odot \odot$ & $\odot . \odot \odot \odot$ & $\odot . \odot \odot \odot$ \\
\hline CHUA & $\odot . \odot \odot \odot$ & $\odot . \odot \odot \odot$ & $\odot . \odot \odot \odot$ \\
\hline FERN & 0.124 & $\odot .031$ & $\odot . \odot 45$ \\
\hline FRCA & 0.067 & 0.044 & $\odot .038$ \\
\hline IBIT & 0.119 & $\odot .051$ & $\odot .043$ \\
\hline IEVA & 0.216 & $\odot . \odot 99$ & $\odot . \odot 75$ \\
\hline ILHA & 0.194 & 0.063 & $\odot . \odot 72$ \\
\hline ITAP & 0.189 & 0.103 & $\odot . \odot 76$ \\
\hline JABO & 0.081 & $\odot .046$ & $\odot .034$ \\
\hline LIMO & 0.115 & 0.062 & $\odot . \odot 47$ \\
\hline MARI & 0.171 & $\odot .075$ & $\odot . \odot 7 \odot$ \\
\hline PANO & 0.228 & $\odot .067$ & $\odot . \odot 80$ \\
\hline PIRA & 0.120 & 0.054 & $\odot .038$ \\
\hline REGI & 0.235 & 0.104 & $\odot . \odot 75$ \\
\hline SAGR & 0.196 & ๑. 085 & $\odot . \odot 75$ \\
\hline SJRP & 0.097 & $\odot .033$ & $\odot . \odot 4 \odot$ \\
\hline TAQU & 0.257 & 0.077 & ๑.๑81 \\
\hline UEPP & 0.222 & $\odot .071$ & $\odot .077$ \\
\hline USPP & 0.259 & 0.178 & 0.175 \\
\hline VALI & 0.171 & 0.103 & $\odot .077$ \\
\hline
\end{tabular}




\section{4 - Elipses de Erros da Estratégia 3}

A FIG URA 29 ilustra as elipses de erros do ajustamento da Estra tégia 3, e a TABELA 44 a presenta os valores para os semi-eixos e para a altura. 
TABEA 44 - Va lores do Semi-Eixos Maior e Menor e Altura, das elipses - Estratégia 3

\begin{tabular}{|c|c|c|c|}
\hline Estação & $\begin{array}{l}\text { Semi-eixo } \\
\text { Maior } \\
\text { (m) }\end{array}$ & $\begin{array}{l}\text { Semi-eixo } \\
\text { Menor } \\
\text { (m) }\end{array}$ & $\begin{array}{c}\text { Altura } \\
\text { (m) }\end{array}$ \\
\hline AVAN & $\odot .148$ & $\odot .049$ & 0.072 \\
\hline AVER & 0.132 & $\odot .044$ & $\odot . \odot 65$ \\
\hline BELA & 0.167 & 0.105 & $\odot . \odot 92$ \\
\hline BOTU & 0.137 & $\odot . \odot 97$ & $\odot . \odot 85$ \\
\hline BUNA & 0.159 & 0.112 & $\odot . \odot 97$ \\
\hline CAPA & $\odot .0 \odot \odot$ & $\odot . \odot \odot \odot$ & $\odot . \odot \odot \odot$ \\
\hline CHUA & $\odot . \odot \odot \odot$ & $\odot . \odot \odot \odot$ & $\odot . \odot \odot \odot$ \\
\hline FERN & 0.144 & $\odot .048$ & $\odot . \odot 75$ \\
\hline FRCA & 0.082 & $\odot . \odot 49$ & $\odot .058$ \\
\hline IBIT & 0.128 & $\odot .068$ & $\odot . \odot 73$ \\
\hline IEVA & 0.174 & 0.106 & $\odot . \odot 88$ \\
\hline ILHA & 0.186 & $\odot .059$ & $\odot . \odot 83$ \\
\hline ITAP & 0.147 & 0.112 & $\odot . \odot 88$ \\
\hline JABO & $\odot .07 \odot$ & $\odot . \odot 49$ & $\odot .041$ \\
\hline LIMO & $\odot .095$ & $\odot .071$ & $\odot .056$ \\
\hline MARI & 0.162 & $\odot .076$ & $\odot . \odot 85$ \\
\hline PANO & 0.208 & $\odot .066$ & $\odot . \odot 87$ \\
\hline PIRA & $\odot .095$ & $\odot .072$ & $\odot .051$ \\
\hline REGI & 0.176 & 0.117 & $\odot . \odot 88$ \\
\hline SAGR & 0.175 & $\odot .084$ & $\odot .085$ \\
\hline SJRP & 0.103 & $\odot .04 \odot$ & $\odot .056$ \\
\hline TAQU & 0.228 & $\odot .074$ & $\odot . \odot 88$ \\
\hline UEPP & 0.203 & $\odot . \odot 7 \odot$ & $\odot . \odot 86$ \\
\hline USPP & 0.140 & $\odot .122$ & $\odot . \odot 94$ \\
\hline VALI & 0.125 & 0.120 & ๑.092 \\
\hline
\end{tabular}




\section{4 - Elipses de Erros da Estratégia 4}

A FIG URA 30 ilustra as elipses de erros do ajustamento da Estra tégia 4, e a TABELA 45 a presenta os valores para os semi-eixos e para a altura. 
TABEA 45 - Va lores do Semi-Eixos Ma ior e Menor e Altura, das elipses - Estratégia 4

\begin{tabular}{|c|c|c|c|}
\hline Estação & $\begin{array}{l}\text { Semi-eixo } \\
\text { Maior } \\
\text { (m) }\end{array}$ & $\begin{array}{l}\text { Semi-eixo } \\
\text { Menor } \\
\text { (m) }\end{array}$ & $\begin{array}{c}\text { Altura } \\
\text { (m) }\end{array}$ \\
\hline AVAN & 0.462 & 0.175 & $\odot .265$ \\
\hline AVER & $\odot .392$ & $\odot .159$ & $\odot .220$ \\
\hline BELA & $\odot .514$ & 0.338 & 0.340 \\
\hline BOTU & $\odot .430$ & $\odot .278$ & $\odot .294$ \\
\hline BUNA & $\odot .493$ & ๑. 312 & $\odot .334$ \\
\hline CAPA & $\odot . \odot \odot \odot$ & $\odot . \odot \odot \odot$ & $\odot . \odot \odot \odot$ \\
\hline CHUA & $\odot . \odot \odot \odot$ & $\odot . \odot \odot \odot$ & $\odot . \odot \odot \odot$ \\
\hline FERN & 0.465 & $\odot .183$ & $\odot .278$ \\
\hline FRCA & $\odot .233$ & 0.133 & $\odot .166$ \\
\hline IBIT & 0.403 & $\odot .205$ & $\odot .261$ \\
\hline IEVA & 0.481 & $\odot .325$ & $\odot .297$ \\
\hline ILHA & $\odot .580$ & $\odot .209$ & $\odot .306$ \\
\hline ITAP & $\odot .435$ & $\odot .327$ & $\odot .305$ \\
\hline JABO & $\odot .256$ & $\odot .169$ & $\odot .180$ \\
\hline LIMO & $\odot .293$ & $\odot .220$ & $\odot .199$ \\
\hline MARI & $\odot .484$ & $\odot .221$ & $\odot .287$ \\
\hline PANO & 0.636 & 0.240 & $\odot .325$ \\
\hline PIRA & 0.283 & ๑. 249 & $\odot .200$ \\
\hline REGI & 0.463 & 0.406 & 0.323 \\
\hline SAGR & 0.510 & $\odot .253$ & $\odot .291$ \\
\hline SJRP & 0.315 & 0.141 & $\odot .195$ \\
\hline TAQU & 0.662 & $\odot .243$ & ๑. 315 \\
\hline UEPP & 0.600 & $\odot .230$ & $\odot .308$ \\
\hline USPP & $\odot .483$ & $\odot .339$ & $\odot .349$ \\
\hline VALI & 0.433 & 0.292 & ๑. 317 \\
\hline
\end{tabular}




\section{CAPÍTULO 14}

\section{ANÁLISES DOS AJUSTAMENTOS}

"O que querque você seja capazde

fazer, ou imagina sercapaz,

comece. Ousadia contém

gênio, podere magia."

Johann Wolfgang von Goethe

(1749-1832),

Poeta a lemão

\section{Sumário detalhado do Capítulo 14}

14.1 - Análise 1 - Verificação da Suficiência de Sessões com 2:30 horas de Observação

14.2 - Análise 2 - Verificação da Influência da utilização de valores atmosféricos reais

14.3 - Análise 3 - Verificação da Influência da utilização de efemérides precisas e das transmitidas

14.4 - Análise 4 - Verificação da Influência de vetores maiores que $150 \mathrm{~km}$ processadas em conjunto com vetores menores que $150 \mathrm{~km}$.

14.5 - Análise 5 - Comparação das Coordenadas obtidas dos Ajustamentos realizados com Diferentes Injunções

14.5.1 - Comparações das coordenadas de CAPA 159

14.5.2 - Comparações das coordenadas de UEPP 160

14.5.3 - Comparações das coordenadas do Vértice CHUA 161 
A análise dos ajustamentos das quatro estratégias de processamentos, em relação aos objetivos propostos, estão apresentadas abaixo. Como parâmetro de comparação entre os resultados obtidos, utiliza ra m-se os seguintes c ritérios sugerid os por SEG ANTINE:

橉 O valor do erro médio das elipses de erros, calculado através da média dos erros obtidos para o semi-eixo maior, semi-eixo menor e altura. Elevou-se todos estes três temos ao quadrado e extraiu-se a raiz quadrada.

erromédio das elípses $=\sqrt{\text { semi }- \text { eixomaior }^{2}+\text { semi }- \text { eixomenor }^{2}+\text { altura }^{2}} \mathrm{e}$

O valor da variância a posteriori do ajustamento.

Estes valores estão a presentados na TABELA 46, com a indicação da estratégia, entre parênteses o tempo de observação e as injunções.

Para as estratégias de duas horas e trinta minutos de dados observados, há a indicação sobre as efemérides e os dados meteorológic os, para facilitar a distinção e comparação.

TABEA 46 - Valores dos emos médios das elipses e variâncias a posteriori

\begin{tabular}{|c|c|c|}
\hline $\begin{array}{l}\text { Descrição da estratégia } \\
\text { ajustada }\end{array}$ & Variância a posteriori & $\begin{array}{l}\text { Erro médio das elipses } \\
\qquad(\mathrm{mm})\end{array}$ \\
\hline Estratégia 1 (total) - CHUA - CAPA & 9,8 & 100 \\
\hline Estratégia 1 (total) - CAPA - UEPP & 13,7 & 160 \\
\hline $\begin{array}{l}\text { Estratégia } 2 \text { (2:30h) - CHUA - CAPA / Efemérides } \\
\text { precisase valores atmosféric os reais }\end{array}$ & 10,0 & 150 \\
\hline $\begin{array}{l}\text { Estratégia } 3(2: 30 h) \text { - CHUA - CAPA / Efemérides } \\
\text { precisase valores atmosféric os do default }\end{array}$ & 12,5 & 170 \\
\hline $\begin{array}{l}\text { Estratégia } 4 \text { (2:30h) - CHUA - CAPA / Efemérides } \\
\text { transmitidase valores atmosféric os. rea is }\end{array}$ & 81,0 & 500 \\
\hline
\end{tabular}

São apresentadas, também, comparações gráficas dos resultados dos a justamentos, entre as estra tégias a na lisa das. 
As comparações gráficas, a presentadas a seguir, constituem-se das diferenças, deltas, entre a parte inteira das coordenadas UTM (nas direções N, E e altura) e as mesmas coordenadas consideradas em sua forma real, com três casas decimais. Assim, é possível visualizar melhor o que representam as discrepâncias entre os valores de variância a posteriori, das estratégias comparadas, bem como entre os valores dos emos médios das elipses, também entre as estratégias comparadas. Ainda, quando a parte inteira das coordenadas UTM apresentou diferenças no último algarismo, antes da parte decimal, tomou-se como referência a parte inteira da coordenada de maiorvalor.

As transformações de coordenadas geográficas geodésicas em coordenadas UTM foram realizadas do programa GeoBase VB50 versão 1.1.4 - Transformador de coordenadas, da empresa Base Aerofotogrametria e Projetos S.A.

Essa compa rações foram rea liza das com as coordenadas de alguns pontos escolhidos estrategicamente. Foram escolhidos o ponto USPP, que é muito utiliza do e outros como o de Valinhos, Marília, Registro, Ilha Solteira e São J osé do Rio Preto, cobrindo as diversas regiões da rede GPS do Estado de São Paulo. Ainda, optou-se por não a presentar as comparações gráficas de todos os pontos das redes, entre as estratégias elaboradas, por se tomar uma apresentação demasiado extensa.

Assim, cada representação gráfica está acompanhada da respectiva tabela com as coordenadas do ponto, obtida nas estratégias, comparadas entre si. 


\section{1 - Análise 1 - Verificação da Suficiência de Sessões com 2:30 horas de Observação}

Serão analisados os valores obtidos para as variâncias a posteriori e dos errosmédio das elipses da estratégia 1 - CHUA e CAPA e da estratégia 2 - CHUA e CAPA.

Como pode ser observado na TABELA 47, ocorreram discrepâncias pequenas entre esses valores, sendo que entre os valores de erros médio das elipses, as discrepâncias foram de $50 \mathrm{~mm}(5 \mathrm{~cm})$ entre as duas estratégias.

TABEAA 47 - Estratégia 1 e estratégia 2

\begin{tabular}{|c|c|c|}
\hline $\begin{array}{l}\text { Desc rição da estratégia } \\
\text { Ajustada }\end{array}$ & Variância a posterioni & $\begin{array}{l}\text { Ero médio das elipses } \\
\qquad(\mathrm{mm})\end{array}$ \\
\hline $\begin{array}{l}\text { Estratégia } 1 \text { (total) - CHUA - CAPA / Efemérides } \\
\text { precisase Valores a tmosféric os rea is }\end{array}$ & 9,8 & 100 \\
\hline $\begin{array}{l}\text { Estratégia } 2 \text { (2:30h) - CHUA - CAPA / Efemérides } \\
\text { precisase Valores atmosféric os rea is }\end{array}$ & 10,0 & 150 \\
\hline
\end{tabular}

Assim, fica provado, que quando da elaboração das estratégia para observação dos vetores da rede GPS do Estado de São Paulo, em 1994, não havia necessidade de sessões com 6 ou 8 horas de observação. Sessões com a penas 2:30h fomeceriam resulta dos tota Imente favoráveis.

Isto, também pode reafirmar a confiabilidade das propostas existentes hoje, de realizar sessões com apenas uma hora de observação, como as propostas do JPL. Se em 1994, duas horas e meia mostraram-se suficientes, hoje, com satélites mais sofisticados e em maior quantidade, provavelmente seriam obtidos resultados bons com menos horas de observação.

A seguir, são apresentadas as TABELAS com as coordenadas dos pontos que serão comparados, em UTM, e a visualização gráfica das diferenças (deltas), explic adas a nteriomente. 
TABEAA 48 - Coordena das UTM do Ponto USP-SP

\begin{tabular}{|c|c|c|c|c|c|c|}
\hline \multicolumn{7}{|c|}{ Coordenadas UTM } \\
\hline Descrição/ Ponto & Norte (m) & Este (m) & h (m) & $\begin{array}{c}\text { DEITA E } \\
\text { (mm) }\end{array}$ & $\begin{array}{c}\text { DETA N } \\
\text { (mm) }\end{array}$ & $\begin{array}{c}\text { DETA } \\
(\mathbf{m m})\end{array}$ \\
\hline Estratégia 1 - USP - SP & 7394432.244 & 323255.446 & 718.346 & 446 & 244 & 346 \\
\hline Estratégia 2 - USP - SP & 7394431.740 & 323255.742 & 717.435 & 742 & -260 & -565 \\
\hline
\end{tabular}

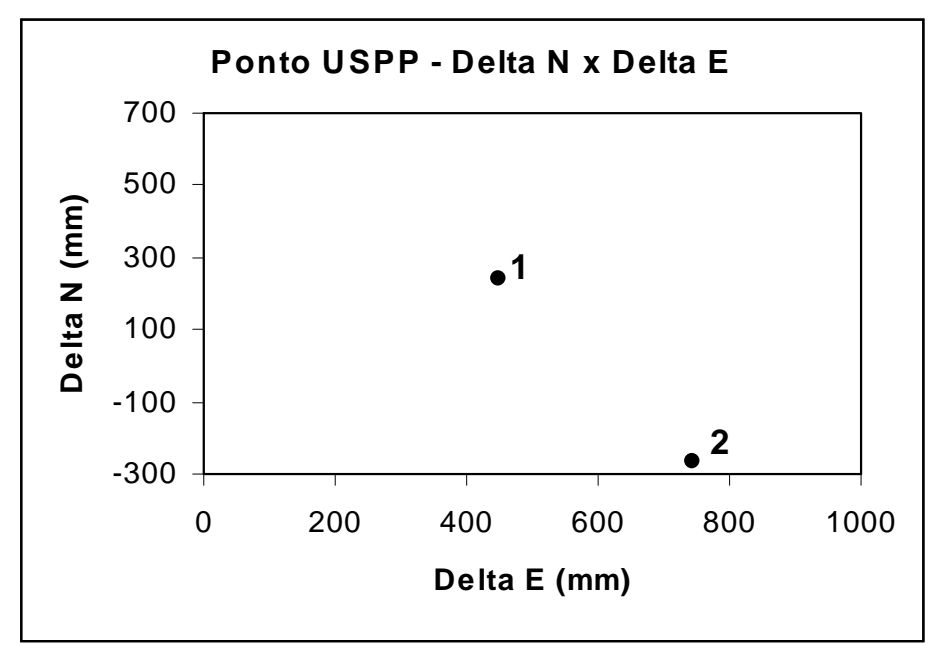

FGURA 31 - G ráfico dos va lores das diferença s obtidas nas Direções N e E do ponto USPP

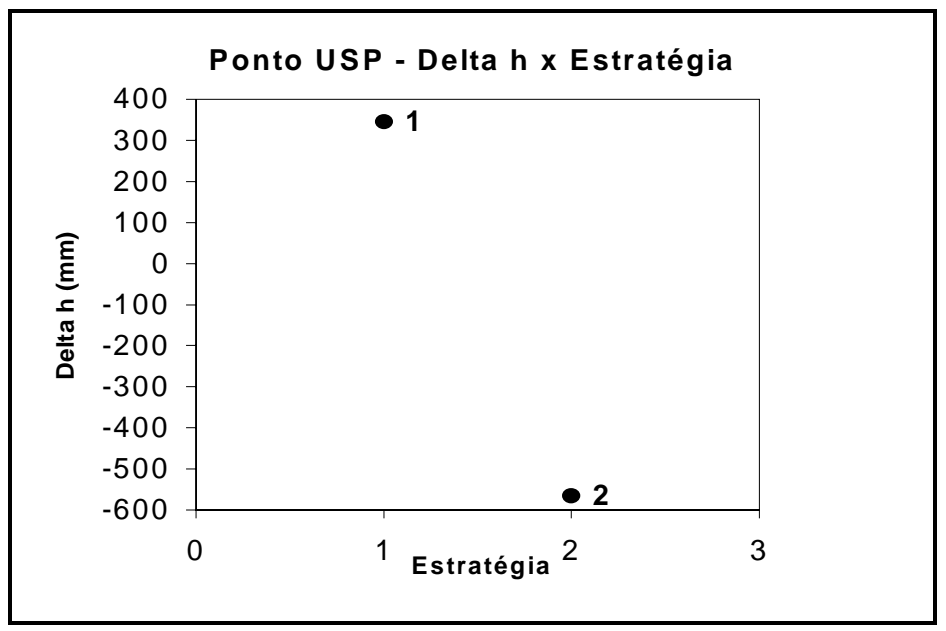

FGURA 32 - Gráfic o dos va lores das diferenças das alturas do ponto USPP 
TABEA 49 - Coordena das UTM do Ponto Valinhos

\begin{tabular}{lllcccc}
\hline \hline \multicolumn{7}{c}{ Coordenadas UTM } \\
\hline Descrição/ Ponto & Norte $(\mathbf{m})$ & Este $(\mathbf{m})$ & $\mathbf{h}(\mathbf{m})$ & $\begin{array}{c}\text { DEITA E } \\
(\mathbf{m m})\end{array}$ & $\begin{array}{c}\text { DEITA N } \\
(\mathbf{m m})\end{array}$ & $\begin{array}{c}\text { DEIA H } \\
(\mathbf{m m})\end{array}$ \\
\hline Estratégia 1 - VAU & 7454939.490 & 298486.122 & 856.969 & 122 & 490 & 968 \\
Estratégia 2 - VAU & 7454939.075 & 298486.299 & 855.844 & 299 & 75 & -156 \\
\hline \hline
\end{tabular}

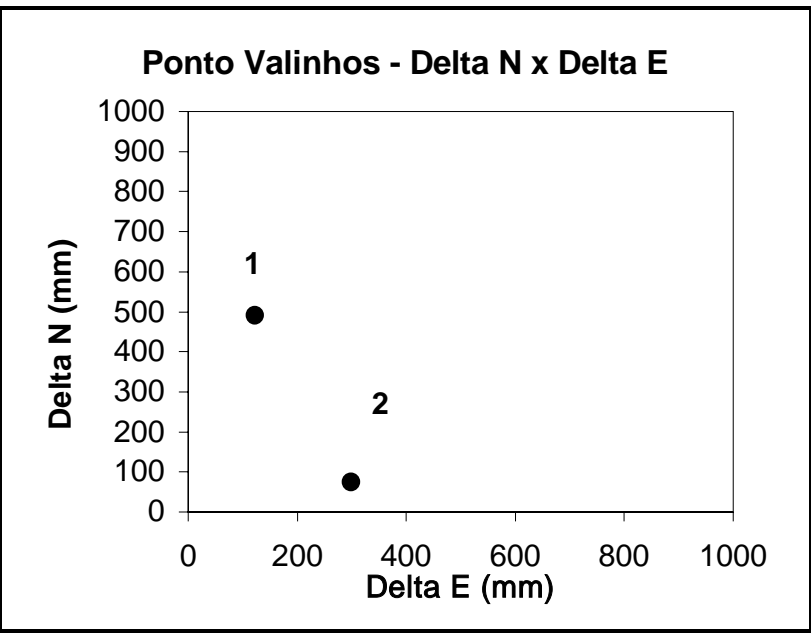

FGURA 33 - Gráfico dos va lores das diferenças obtidas nas Direções N e E do ponto VAU

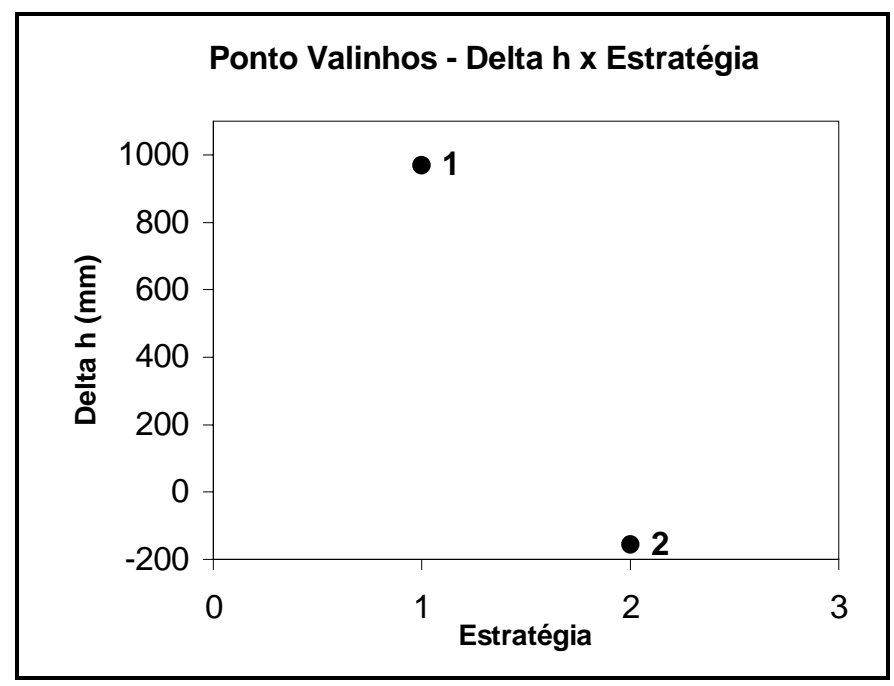

RGURA 34 - Gráfico dos valores das diferenças das alturas do ponto VAU 
TABEA 50 - Coordenadas UTM do Ponto Marília

\begin{tabular}{cclcccc}
\hline \hline \multicolumn{7}{c}{ Coordenadas UTM } \\
\hline Descrição/ Ponto & Norte (m) & Este (m) & h(m) & $\begin{array}{c}\text { DELTA E } \\
(\mathbf{m m})\end{array}$ & $\begin{array}{c}\text { DELTA N } \\
(\mathbf{m m})\end{array}$ & $\begin{array}{c}\text { DETA H } \\
\text { (mm) }\end{array}$ \\
\hline Estratégia 1 - Manlia & 7545170.342 & 610538.515 & 637.576 & 515 & 342 & 576 \\
Estratégia 2 - Manlia & 7545170.043 & 610538.371 & 636.448 & 370 & 43 & -552 \\
\hline \hline
\end{tabular}

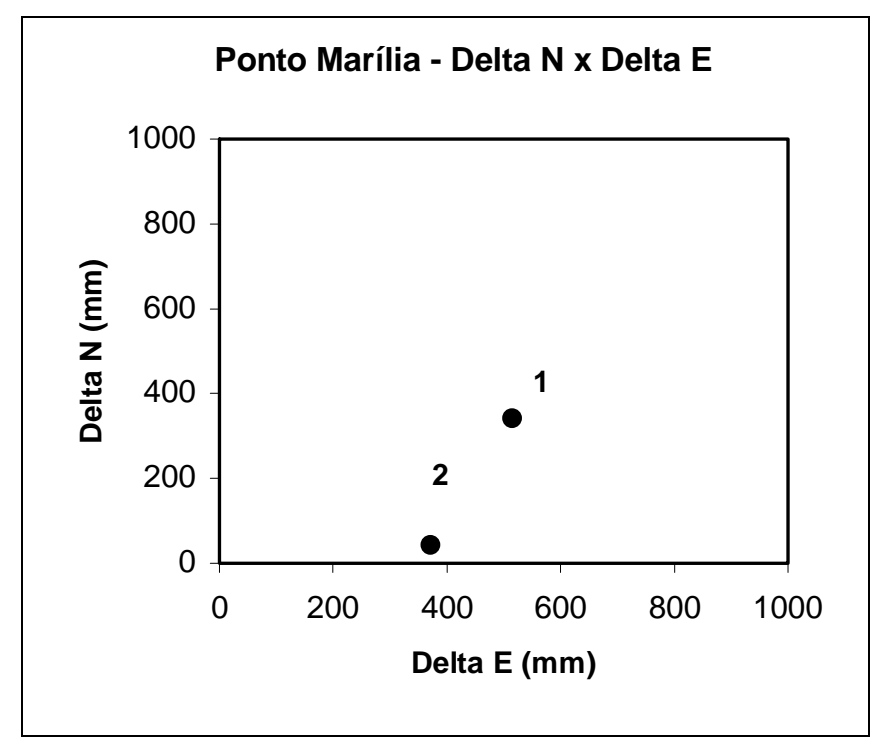

RGURA 35 - Gráfic o dos va lores das diferenç as obtidas nas Direções N e E do ponto MARI

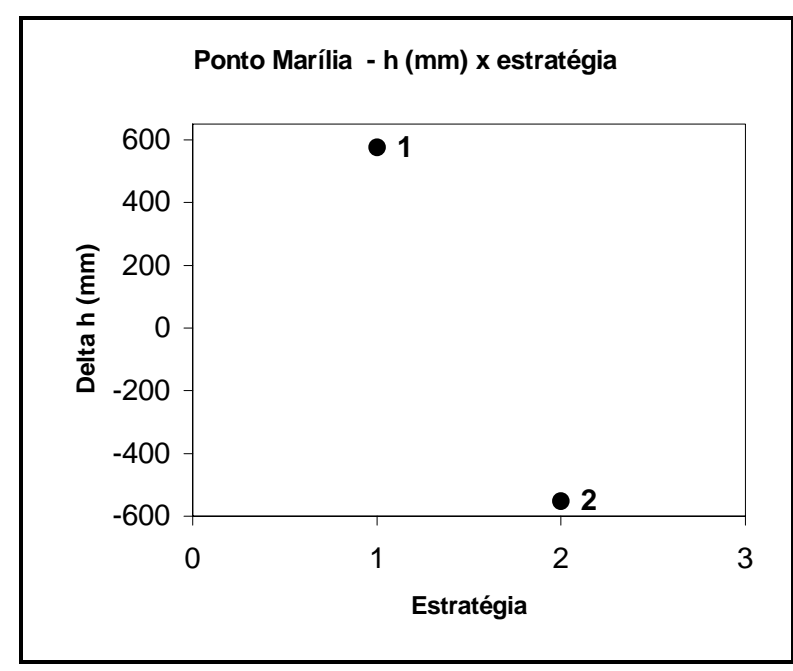

FGURA 36- G ráfico dos va lores das diferenças das alturas do ponto MARI 
TABEA 51 - Coordenadas UTM do Ponto llha Solteira

\begin{tabular}{|c|c|c|c|c|c|c|}
\hline \multicolumn{7}{|c|}{ Coordenadas UTM } \\
\hline Descrição/Ponto & Norte (m) & Este (m) & $h(\mathbf{m})$ & $\begin{array}{c}\text { DEITA E } \\
\text { (mm) }\end{array}$ & $\begin{array}{c}\text { DELTA N } \\
\text { (mm) }\end{array}$ & $\begin{array}{c}\begin{array}{c}\text { DELTA H } \\
(\mathrm{mm})\end{array} \\
\end{array}$ \\
\hline Estratégia 1 - ILHA & 7747389.136 & 458476.658 & 322.390 & 658 & 136 & 390 \\
\hline Estratégia 2 - ILHA & 7747389.027 & 458476.315 & 322.250 & 314 & 27 & 250 \\
\hline
\end{tabular}

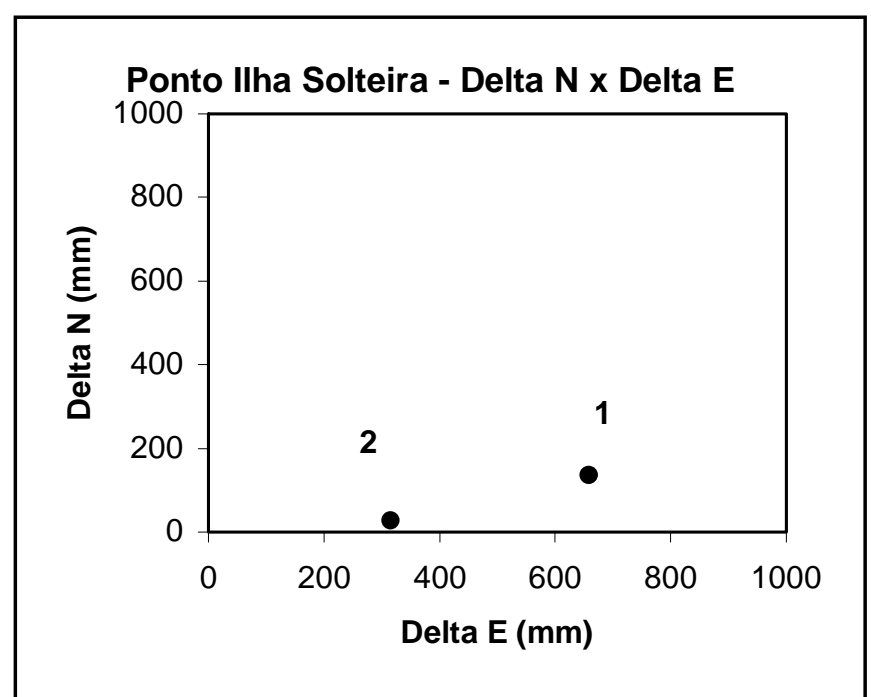

FGURA 37 - G ráfico dos va lores das diferenç a s obtidas nas Direções N e E do ponto ILHA

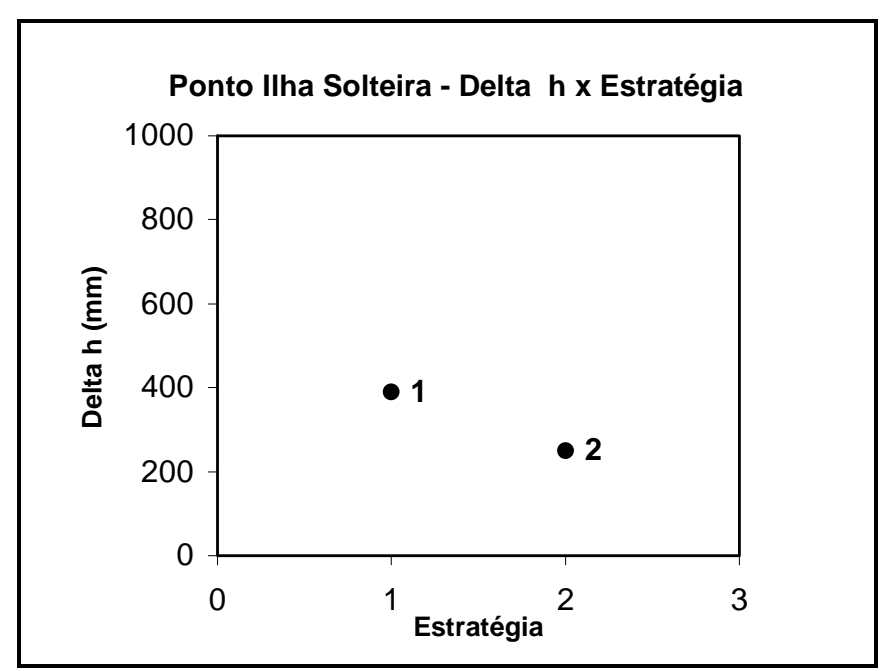

FGURA 38 - Gráfic o dos va lores das diferenças das alturas do ponto ILHA 
TABELA 52 - Coordena das UTM do Ponto São J osé do Rio Preto

\begin{tabular}{|c|c|c|c|c|c|c|}
\hline \multicolumn{7}{|c|}{ Coordenadas UIM } \\
\hline Descrição/ Ponto & Norte (m) & Este (m) & $h(\mathbf{m})$ & $\begin{array}{c}\text { DELTA E } \\
\text { (mm) }\end{array}$ & $\begin{array}{c}\text { DELTA N } \\
\text { (mm) }\end{array}$ & $\begin{array}{c}\text { DELTA H } \\
\text { (mm) }\end{array}$ \\
\hline $\begin{array}{l}\text { Estratégia } 1 \text { - S. J .do } \\
\text { R. Preto }\end{array}$ & 7700815.461 & 670893.791 & 519.742 & 791 & 461 & 742 \\
\hline $\begin{array}{l}\text { Estratégia } 2 \text { - S. J .do } \\
\text { R. Preto }\end{array}$ & 7700815.351 & 670893.620 & 519.658 & 620 & 351 & 658 \\
\hline
\end{tabular}

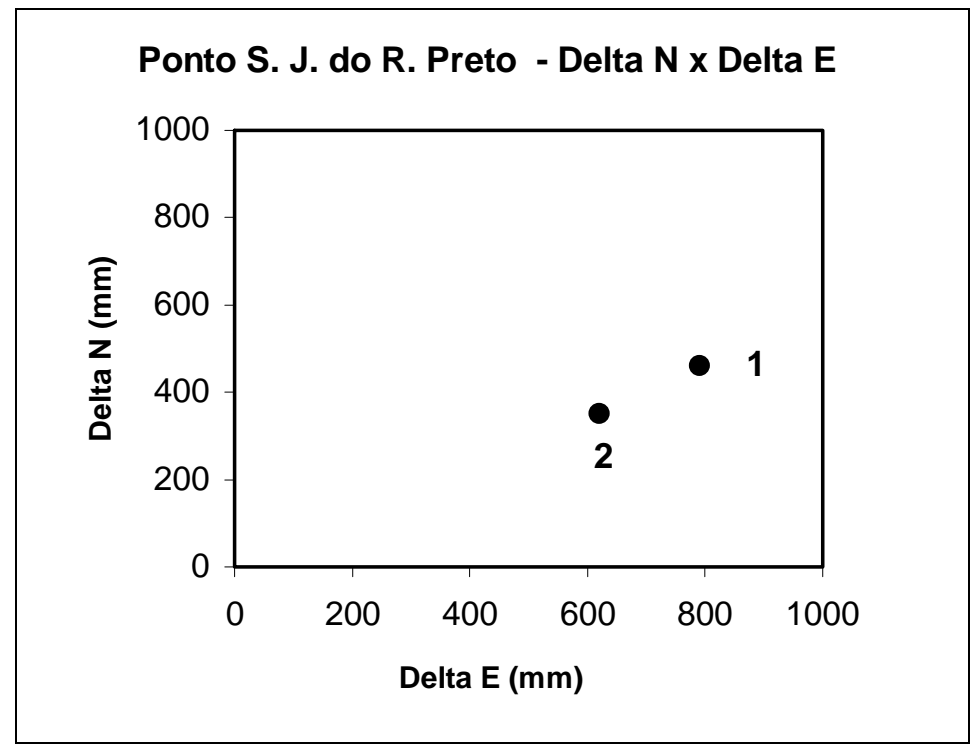

FGURA 39 - G ráfico dos va lores das diferenç as obtidas nas Direções N e E do ponto SJ RP

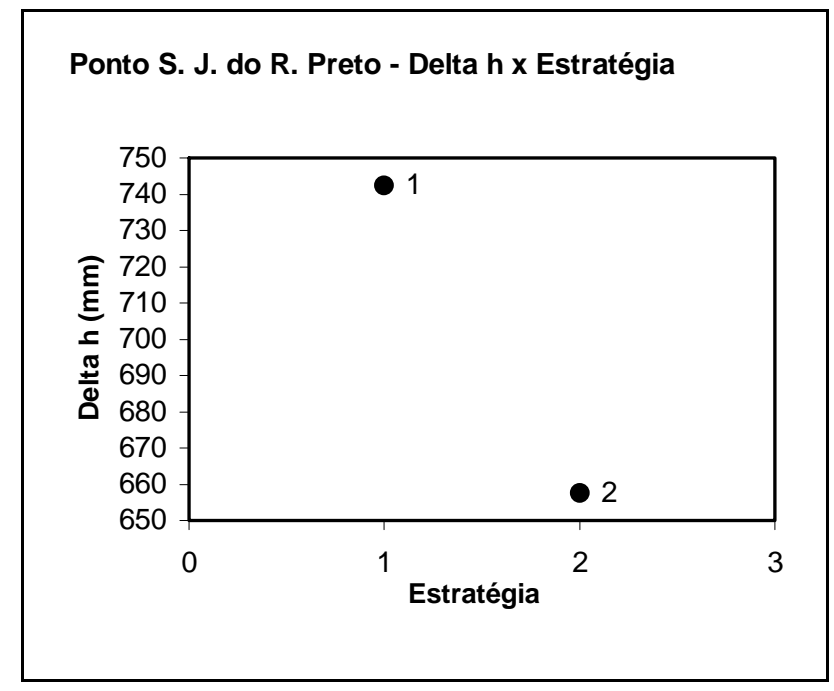

FGURA 40 - Gráfic o dos va lores das diferenças das alturas do ponto SJ RP 
TABEA 53 - Coordenadas UTM do Ponto Registro

\begin{tabular}{|c|c|c|c|c|c|c|}
\hline \multicolumn{7}{|c|}{ Coordenadas UTM } \\
\hline Desc rição/ Ponto & Norte (m) & Este (m) & $h(\mathbf{m})$ & $\begin{array}{c}\text { DELTA E } \\
(\mathrm{mm})\end{array}$ & $\begin{array}{c}\text { DEITA N } \\
(\mathrm{mm})\end{array}$ & $\begin{array}{c}\begin{array}{c}\text { DETA H H } \\
(\mathrm{mm})\end{array} \\
\end{array}$ \\
\hline Estratégia 1- REGI & 7293982.528 & 217845.199 & 44.433 & 199 & 528 & 433 \\
\hline Estratégia 2- REGI & 7293981.940 & 217845.275 & 43.294 & 275 & -60 & -706 \\
\hline
\end{tabular}

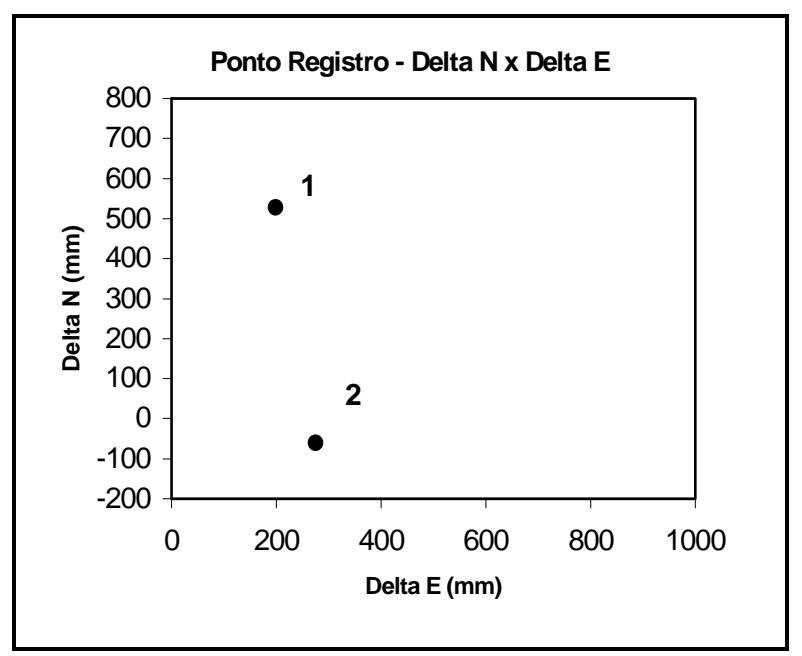

FGURA 41 - Gráfico dos va lores das diferença sobtidas nas Direções N e E do ponto REGI

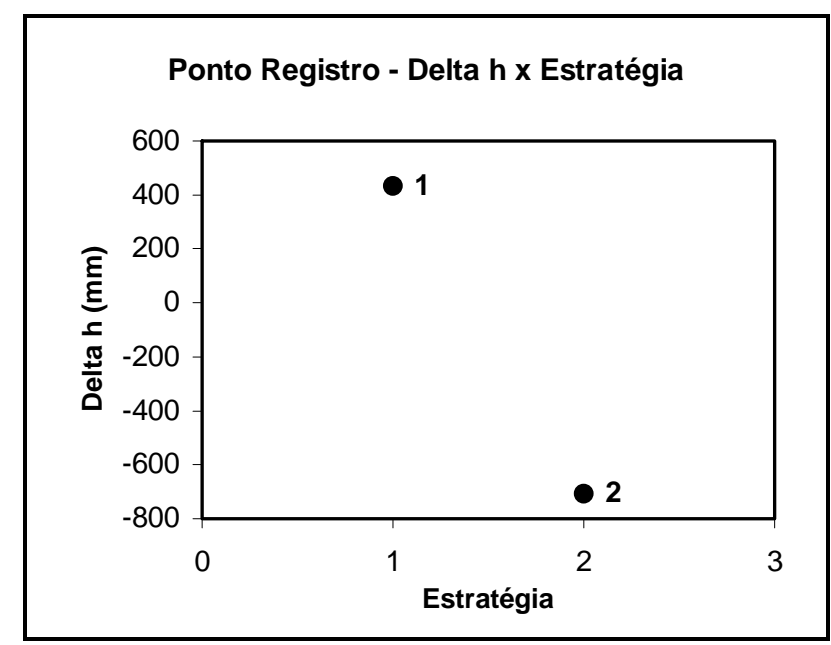

FG URA 42 - Grá fic o dos va lores das diferenças das alturas do ponto REGI 


\section{2 - Análise 2 - Verificação da Influência da utilização de valores atmosféricos reais}

Serão analisados os valores obtidos para as variâncias a posteriori e dos erros médio das elipses da estra tégia 2 - CHUA e CAPA e da estratégia 3 - CHUA e CAPA.

Como pode ser observado na TABELA 54, o valor da estratégia 2 são ligeiramente melhores que os obtidos para a estratégia 3, indicando que utilização dos valores de temperatura, umidade e pressão no processamento, resultam em valores ajustados melhores, quando da utilização de valores do defaltut do próprio software.

TABEA 54 - Estra tégia 2 e estratégia 3

\begin{tabular}{lcc}
\hline \multicolumn{1}{c}{$\begin{array}{c}\text { Descrição da estratégia } \\
\text { ajustada }\end{array}$} & Variância a posterion & $\begin{array}{c}\text { Ero médio das elipses } \\
\text { (mm) }\end{array}$ \\
\hline $\begin{array}{l}\text { Estratégia } 2 \text { (2:30h) - CHUA - CAPA / Efemérides } \\
\text { precisas e Valores atmosféricos reais }\end{array}$ & 10,0 & 150 \\
$\begin{array}{l}\text { Estratégia } 3 \text { (2:30h) - CHUA - CAPA / Efemérides } \\
\text { precisas e valores atmosféricos do default }\end{array}$ & 12,5 & 170 \\
\hline \hline
\end{tabular}

A diferença, nos erros méd ios das elipses, a pesar de pequenas, $20 \mathrm{~mm}$ $(2 \mathrm{~cm})$, ocorrem, não são nulas. Assim, em trabalhos que se deseja grande precisão, como rede geodésicas de alta precisão, sugere-se, sempre, a rea lização de coleta dos dados meteorológicos.

A seguir, são apresentadas as TABELAS com as coordenadas dos pontos que serão comparados, em UTM, as respectivas diferenças e em seguida a visualização gráfica destas diferenças. 
TABEA 55 - Coordena das UTM do USP - SP

\begin{tabular}{ccccccc}
\hline \multicolumn{7}{c}{ Coordenadas UTM } \\
\hline Descrição/ Ponto & Norte (m) & Este (m) & $\mathbf{h}(\mathbf{m})$ & $\begin{array}{c}\text { DETA E } \\
(\mathbf{m m})\end{array}$ & $\begin{array}{c}\text { DETA N } \\
(\mathbf{m m})\end{array}$ & $\begin{array}{c}\text { DELTA H } \\
\text { (mm) }\end{array}$ \\
\hline Estratégia 2 / USP - SP & 7394431.740 & 323255.742 & 717.435 & 742 & -260 & -565 \\
Estratégia 3 / USP - SP & 7394432.197 & 323255.400 & 718.764 & 400 & 197 & 764 \\
\hline \hline
\end{tabular}

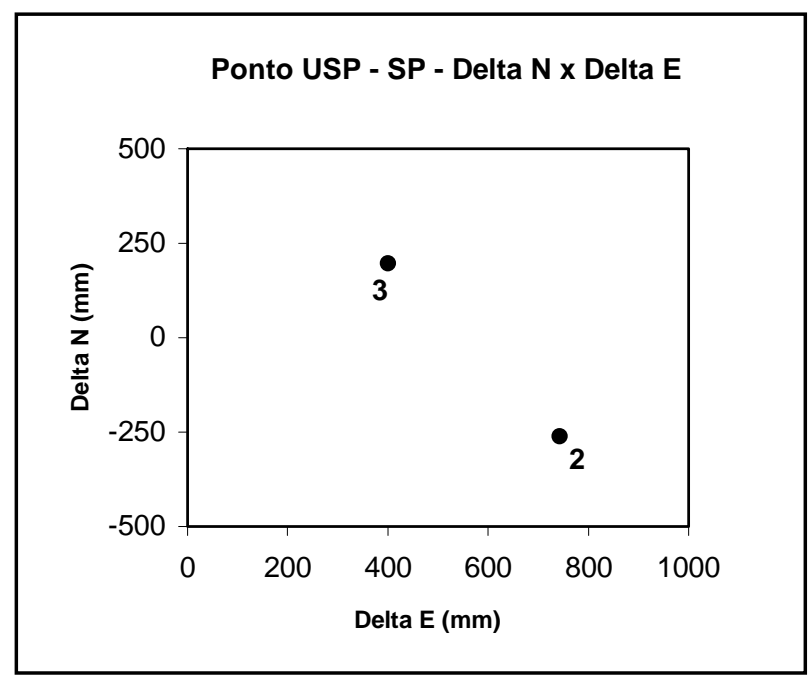

FGURA 43 - Gráfico dos va lores das diferenças obtidas nas Direções N e E do ponto USP - SP

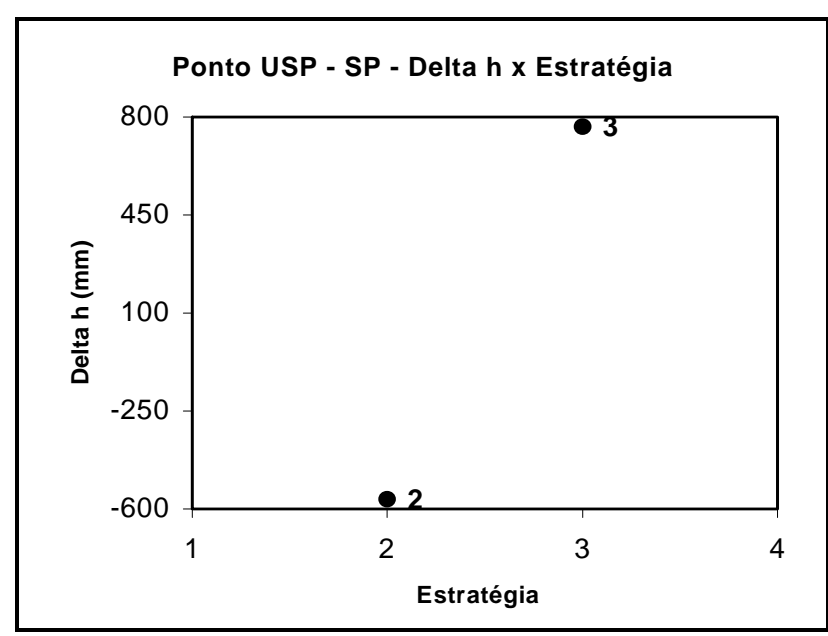

FGURA 44 - Gráfic o dos va lores das diferenças das alturas do ponto REG I 
TABEA 56 - Coordenadas UTM do Ponto Va linhos

\begin{tabular}{ccccccc}
\hline \multicolumn{7}{c}{ Coordenadas UTM } \\
\hline Descrição/ Ponto & Norte $\mathbf{( m )}$ & Este $\mathbf{( m )}$ & $\mathbf{h}(\mathbf{m})$ & $\begin{array}{c}\text { DELTA E } \\
(\mathbf{m m})\end{array}$ & $\begin{array}{c}\text { DELTA N } \\
(\mathbf{m m})\end{array}$ & $\begin{array}{c}\text { DETA H } \\
\text { (mm) }\end{array}$ \\
\hline Estratégia 2 / Valinhos & 7454939.075 & 298486.299 & 855.844 & 299 & 75 & -1156 \\
Estratégia 3 / Valinhos & 7454939.443 & 298486.077 & 857.367 & 77 & 443 & 366 \\
\hline \hline
\end{tabular}

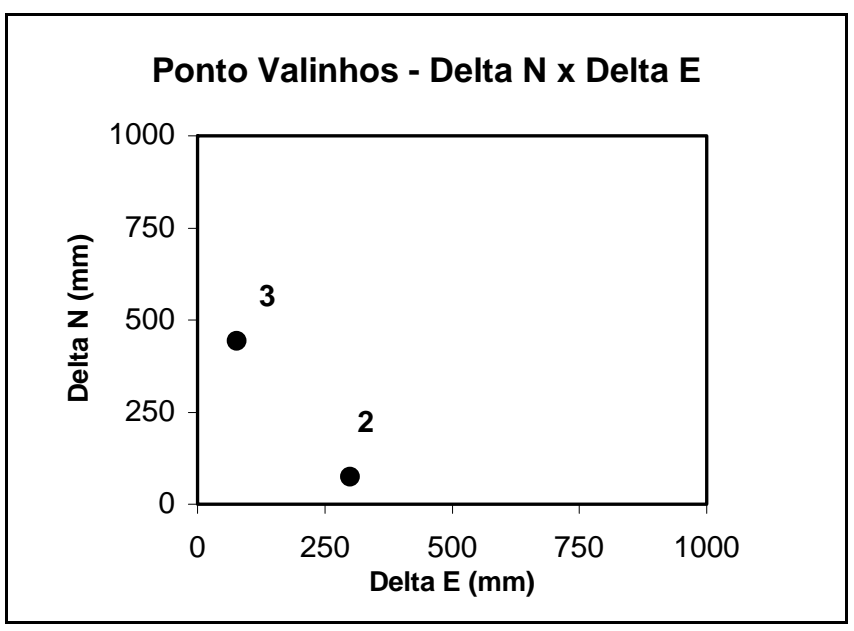

FGURA 45 - G ráfico dos va lores das diferença s obtidas nas Direções N e E do ponto VAU

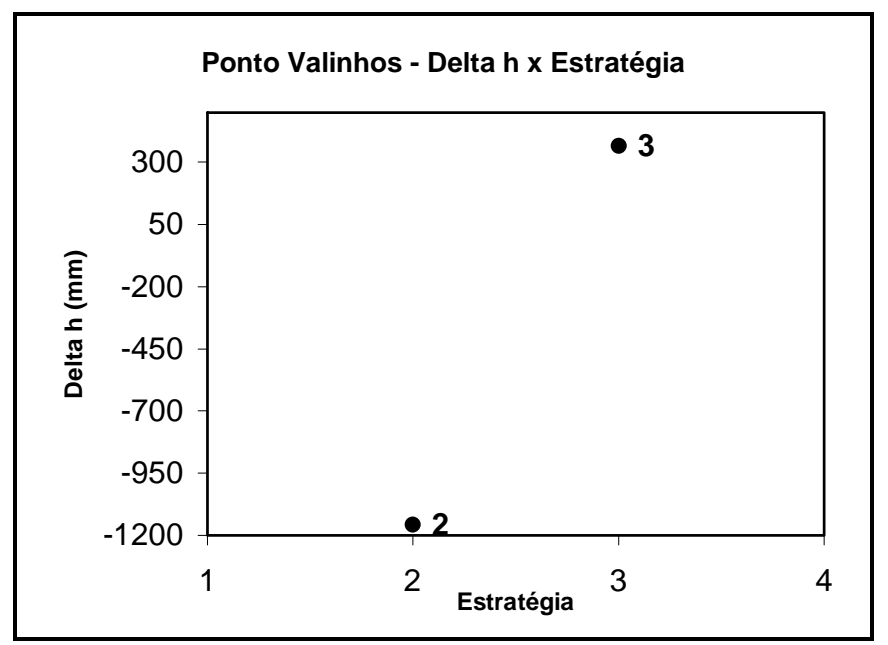

FGURA 46 - Grá fic o dos va lores das diferenças das alturas do ponto VAU 
TABEA 57 - Coordenadas UTM do Ponto Marília

\begin{tabular}{ccccccc}
\hline \multicolumn{7}{c}{ Coordenadas UTM } \\
\hline Descrição/ Ponto & Norte (m) & Este (m) & $\mathbf{h}(\mathbf{m})$ & $\begin{array}{c}\text { DELTA E } \\
\text { (mm) }\end{array}$ & $\begin{array}{c}\text { DELTA N } \\
\text { (mm) }\end{array}$ & $\begin{array}{c}\text { DEETA H } \\
\text { (mm) }\end{array}$ \\
\hline Estratégia 2 / Mańlia & 7545170.043 & 610538.371 & 636.448 & 370 & 43 & -1552 \\
Estratégia 3 / Manilia & 7545170.315 & 610538.471 & 638.073 & 471 & 315 & 73 \\
\hline \hline
\end{tabular}

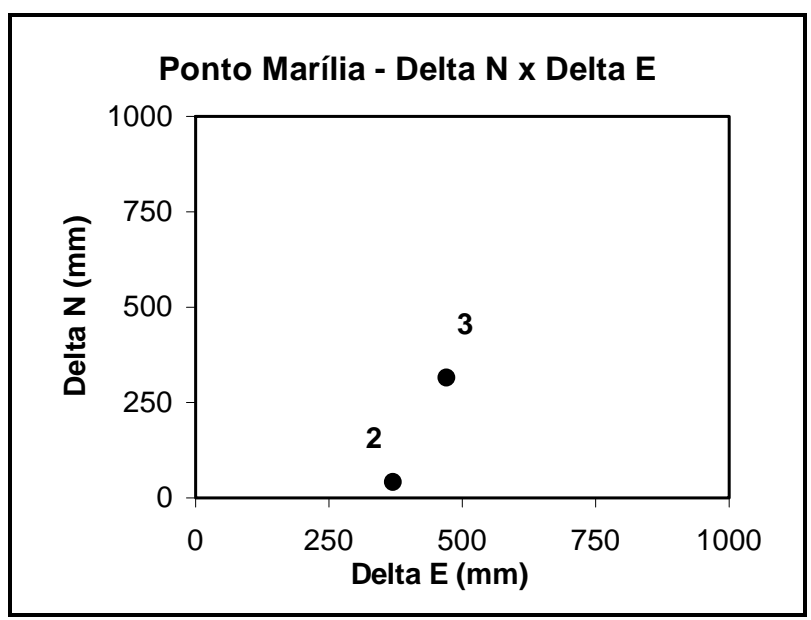

FGURA 47 - G ráfico dos va lores das diferença s obtidas nas Direções N e E do ponto MARI

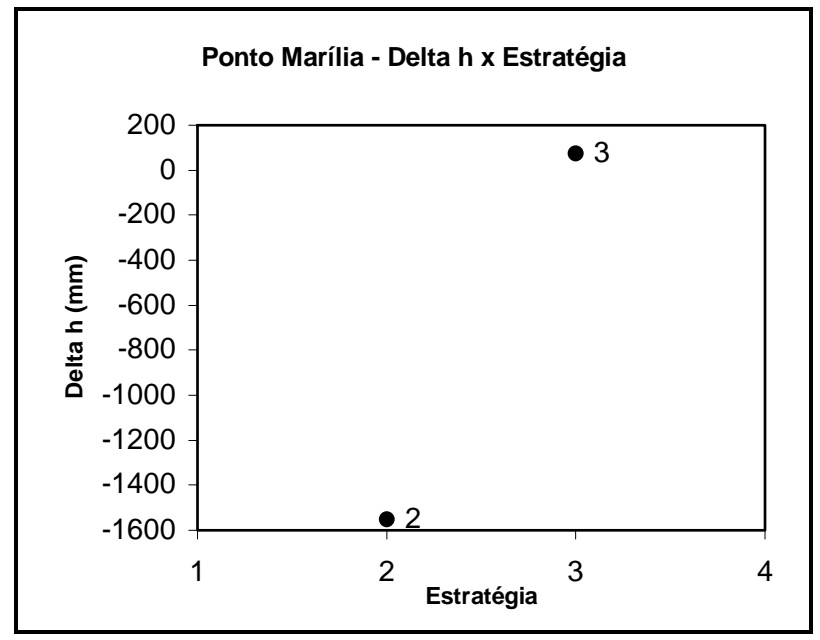

RGURA 48 - Gráfic o dos va lores das diferenç as das alturas do ponto MARI 
TABEA 58- Coordenadas UTM do Ponto llha Solteira

\begin{tabular}{|c|c|c|c|c|c|c|}
\hline \multicolumn{7}{|c|}{ Coordenadas UTM } \\
\hline Descrição/ Ponto & Norte (m) & Este (m) & $h(m)$ & $\begin{array}{c}\text { DELTA E } \\
(\mathrm{mm})\end{array}$ & $\begin{array}{c}\text { DELTA N } \\
(\mathrm{mm})\end{array}$ & $\begin{array}{c}\text { DEITA H } \\
(\mathrm{mm})\end{array}$ \\
\hline Estratégia 2 / Ilha & 7747389.027 & 458476.315 & 322.250 & 314 & 27 & -1750 \\
\hline Estratégia 3 / Ilha & 7747389.070 & 458476.596 & 324.010 & 596 & 70 & 10 \\
\hline
\end{tabular}

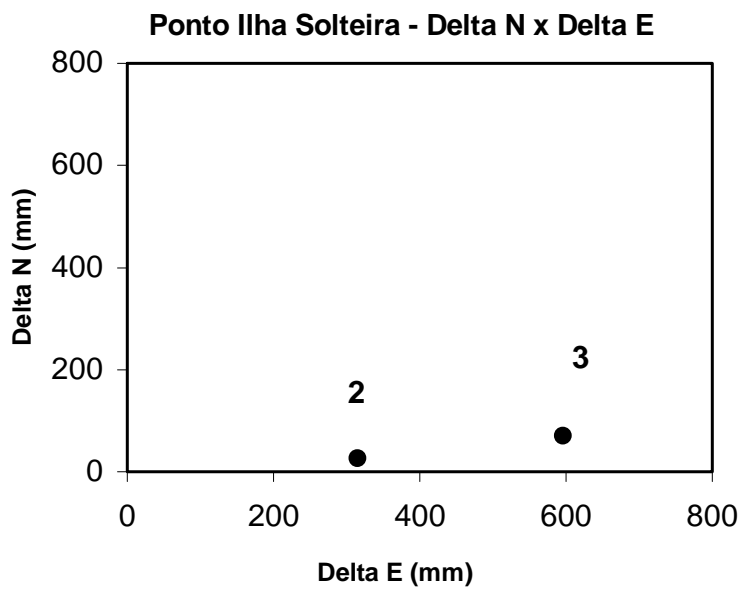

FGURA 49 - Grá fic o dos va lores das diferenç as obtidas nas Direções N e E do ponto ILHA

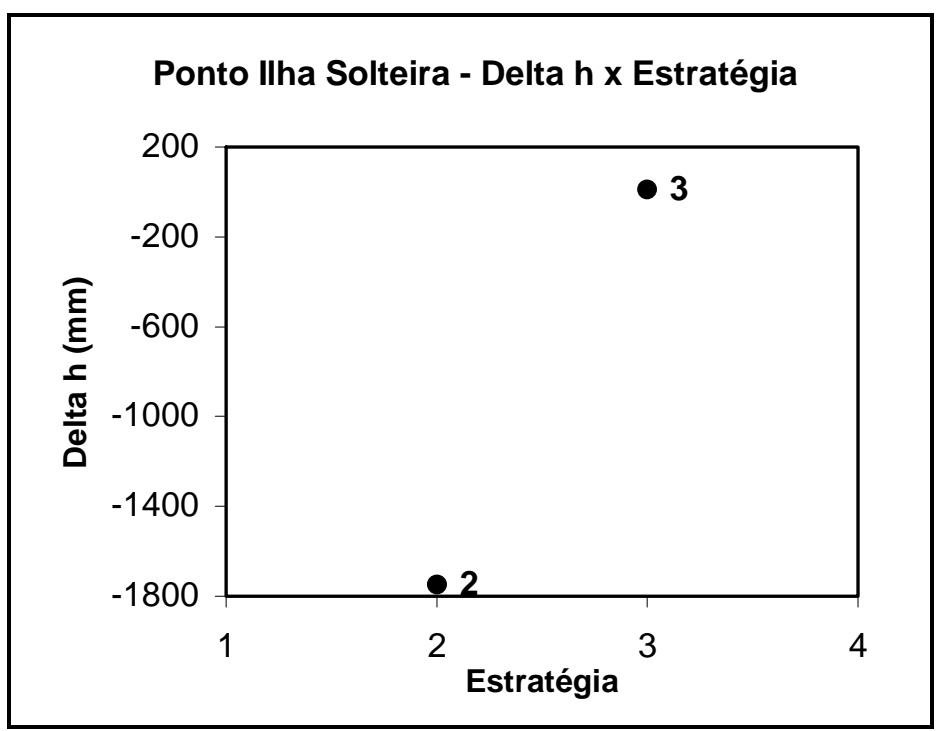

FGURA 50 - Gráfic o dos va lores das diferenç as das alturas do ponto ILHA 
TABeAA 59- Coordenadas UTM do Ponto São J osé do Rio Preto

\begin{tabular}{lcccccc}
\hline \multicolumn{7}{c}{ Coordenadas UTM } \\
\hline \multicolumn{1}{c}{ Descrição/Ponto } & Norte (m) & Este (m) & h(m) & $\begin{array}{c}\text { DELTA E } \\
\text { (mm) }\end{array}$ & $\begin{array}{c}\text { DELTA N } \\
\text { (mm) }\end{array}$ & $\begin{array}{c}\text { DELTA H } \\
\text { (mm) }\end{array}$ \\
\hline $\begin{array}{l}\text { Estratégia 2 / S. J. do } \\
\text { R. Preto }\end{array}$ & 7700815.351 & 670893.620 & 519.658 & 620 & 351 & 658 \\
$\begin{array}{l}\text { Estratégia 3/ S. J. do } \\
\text { R. Preto }\end{array}$ & 7700815.443 & 670893.688 & 519.622 & 688 & 443 & 622 \\
\hline \hline
\end{tabular}

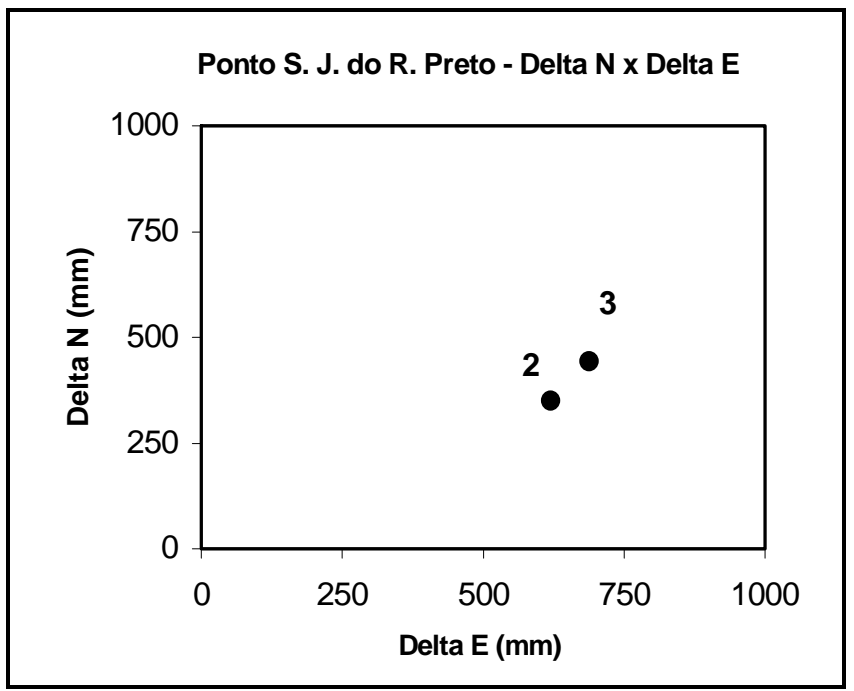

FGURA 51 - G ráfico dos va lores das diferença sobtidas nas Direções N e E do ponto SJ RP

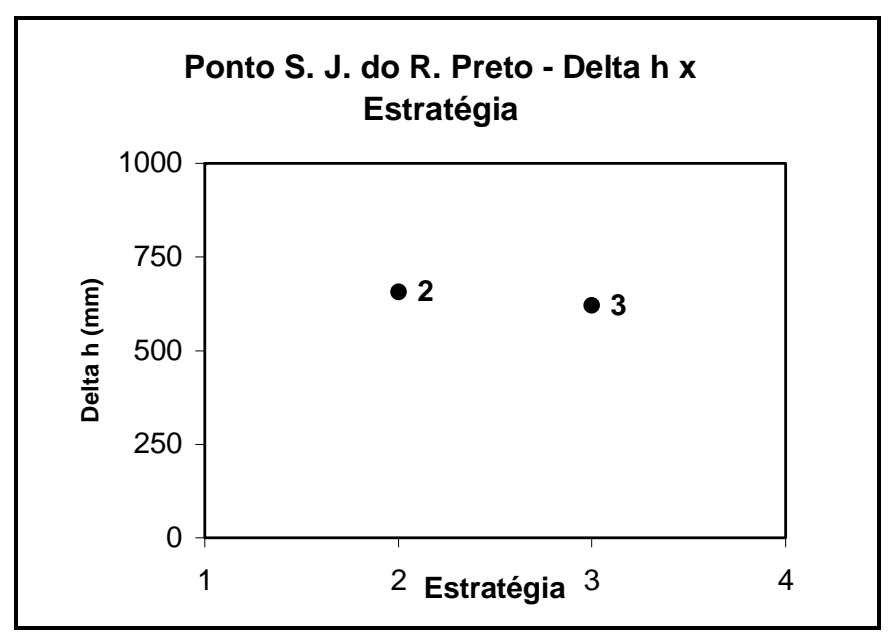

FGURA 52 - Gráfic o dos va lores das diferenças das alturas do ponto SJ RP 
TABEA 60 - Coordenadas UTM do Ponto Registro

\begin{tabular}{|c|c|c|c|c|c|c|}
\hline \multicolumn{7}{|c|}{ Coordenadas UTM } \\
\hline Descrição/ Ponto & Norte (m) & Este (m) & $h(m)$ & $\begin{array}{c}\text { DELTA E } \\
(\mathrm{mm})\end{array}$ & $\begin{array}{c}\text { DELTA N } \\
(\mathrm{mm})\end{array}$ & $\begin{array}{c}\text { DELTA H } \\
(\mathrm{mm})\end{array}$ \\
\hline Estratégia 2 / REGI & 7293981.940 & 217845.275 & 43.294 & 275 & 940 & 294 \\
\hline Estratégia 3 / REGI & 7293982.496 & 217845.15 & 44.833 & 149 & 1496 & 1833 \\
\hline
\end{tabular}

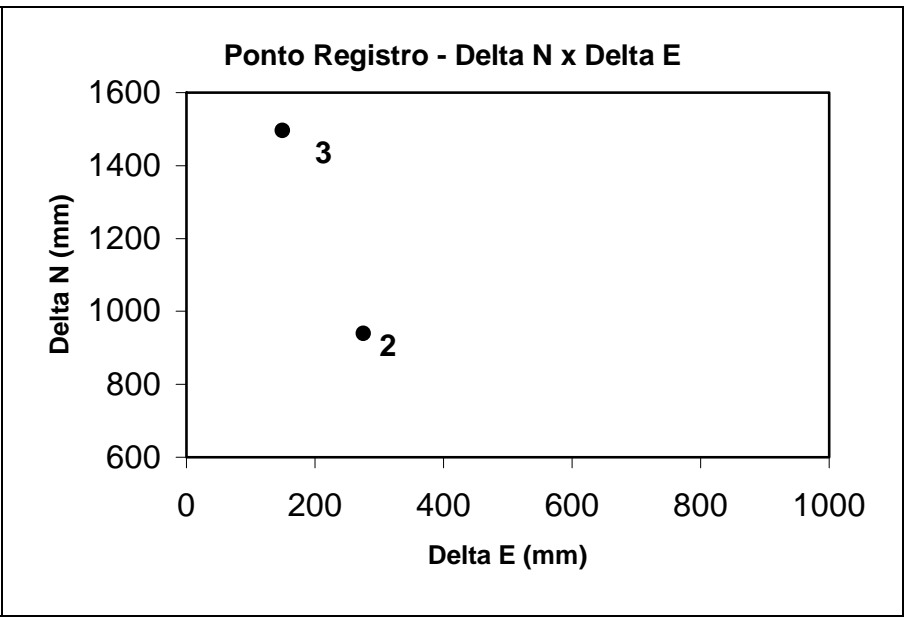

FGURA 53 - G rá fico dos va lores das diferenç as obtidas nas Direções N e E do ponto REG I

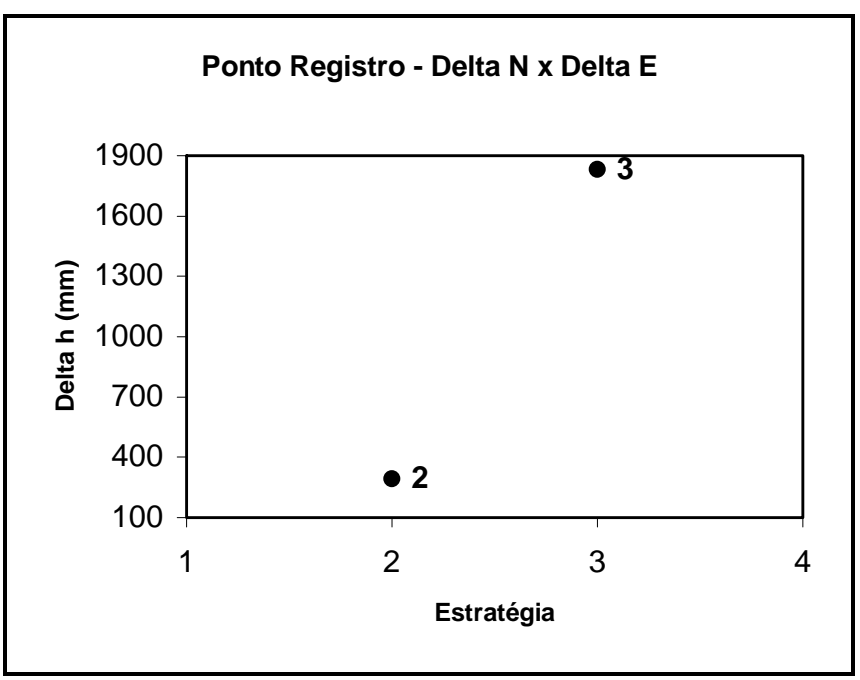

RGURA 54 - G rá fic o dos va lores da s diferenç as das alturas do ponto REG I 


\section{3 - Análise 3 - Verificação da Influência da utilização de efemérides precisas e das transmitidas}

Serão ana lisados os valores obtidos para as variâncias a posteriori e dos emos médio das elipses da estra tégia 2 - CHUA e CAPA e da estratégia 4 - CHUA e CAPA.

Como pode ser observada na TABELA 61, a grande discrepância entre os valores de variância e erro médio das elipses, da estratégia 2 e os da estratégia 4, indicam a necessidade de utilização de efemérides precisas em trabalhos que se deseja grande precisão e principalmente, envolvem distância longas.

TABEA 61 - Comparação Estratégia 2 e Estra tégia 4

\begin{tabular}{|c|c|c|}
\hline $\begin{array}{l}\text { Descrição da estratégia } \\
\text { ajustada }\end{array}$ & Variância a posteriori & $\begin{array}{l}\text { Erro médio das elipses } \\
\qquad(\mathrm{mm})\end{array}$ \\
\hline $\begin{array}{l}\text { Estratégia } 2 \text { (2:30h) - CHUA - CAPA / Efemérides } \\
\text { precisase Valores atmosféricos rea is }\end{array}$ & 10,0 & 120 \\
\hline $\begin{array}{l}\text { Estratégia } 4 \text { (2:30h) - CHUA - CAPA / Efemérides } \\
\text { transmitidas e valores a tmosféric os. rea is }\end{array}$ & 81,0 & 500 \\
\hline
\end{tabular}

A seguir, são apresentadas as tabelas com as coordenadas dos pontos que serão comparados, em UTM, as respectivas diferenças e em seguida a visualização gráfica destas diferenças. 
TABELA 62 - Coordenadas UTM do Ponto USP -SP

\begin{tabular}{ccccccc}
\hline \hline \multicolumn{7}{c}{ Coordenadas UTM } \\
\hline Desc rição/ Ponto & Norte (m) & Este (m) & $\mathbf{h}(\mathbf{m})$ & $\begin{array}{c}\text { DELTA E } \\
(\mathbf{m m})\end{array}$ & $\begin{array}{c}\text { DEITA N } \\
(\mathbf{m m})\end{array}$ & $\begin{array}{c}\text { DELTA H } \\
(\mathbf{m m})\end{array}$ \\
\hline Estratégia 2 / USP- SP & 7394431.740 & 323255.742 & 717.435 & 742 & -260 & -565 \\
Estratégia 4 / USP- SP & 7394432.566 & 323255.317 & 718.866 & 317 & 566 & 866 \\
\hline \hline
\end{tabular}

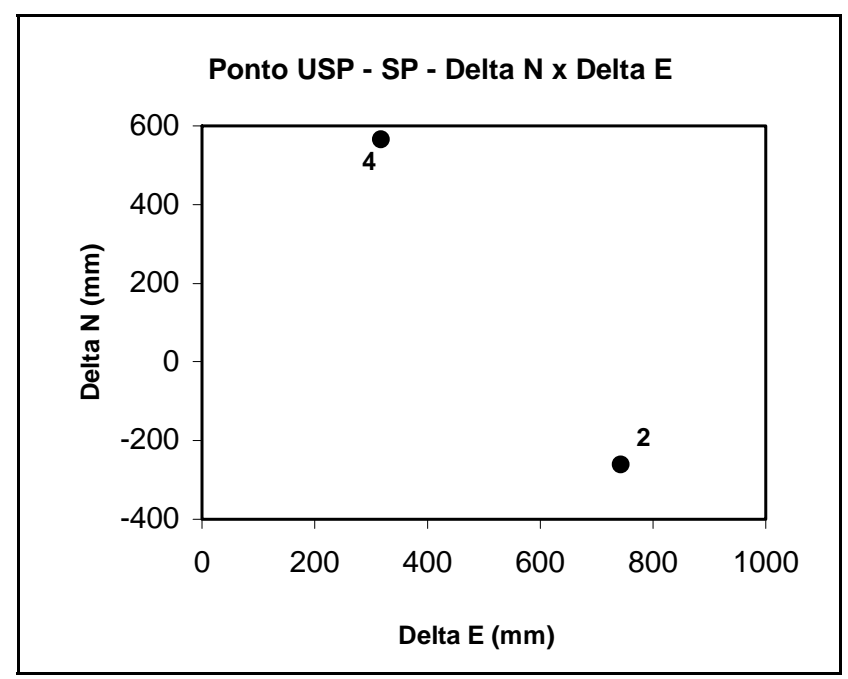

FGURA 55 - G ráfico dos va lores das diferença s obtidas nas Direções N e E do ponto USPP

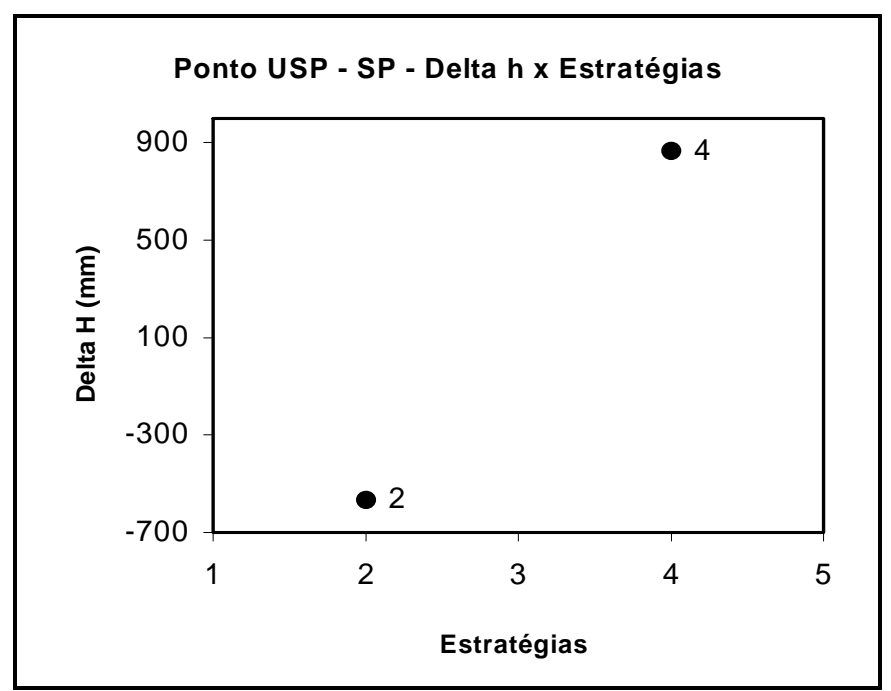

FG URA 56 - Gráfic o dos va lores das diferenças das alturas do ponto USPP 
TABEA 63 - Coordenadas UTM do Ponto VAU

\begin{tabular}{ccccccc}
\hline \hline \multicolumn{7}{c}{ Coordenadas UTM } \\
\hline Desc rição/ Ponto & Norte (m) & Este (m) & h(m) & $\begin{array}{c}\text { DELTA E } \\
(\mathbf{m m})\end{array}$ & $\begin{array}{c}\text { DElTA N } \\
(\mathbf{m m})\end{array}$ & $\begin{array}{c}\text { DELTA H } \\
(\mathbf{m m})\end{array}$ \\
\hline Estratégia 2 / Valinhos & 7454939.075 & 298486.299 & 855.844 & 299 & 75 & -1156 \\
Estratégia 4/ Valinhos & 7454939.727 & 298486.064 & 857.522 & 64 & 727 & 522 \\
\hline \hline
\end{tabular}

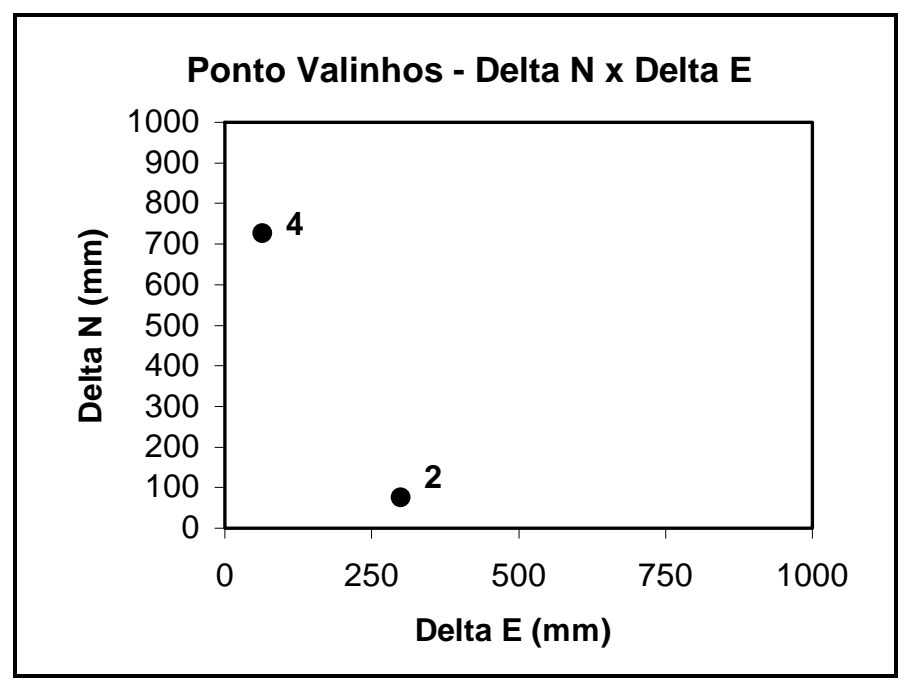

RGURA 57 - G ráfico dos va lores das diferenças obtidas nas Direções $\mathrm{N}$ e E do ponto VAL

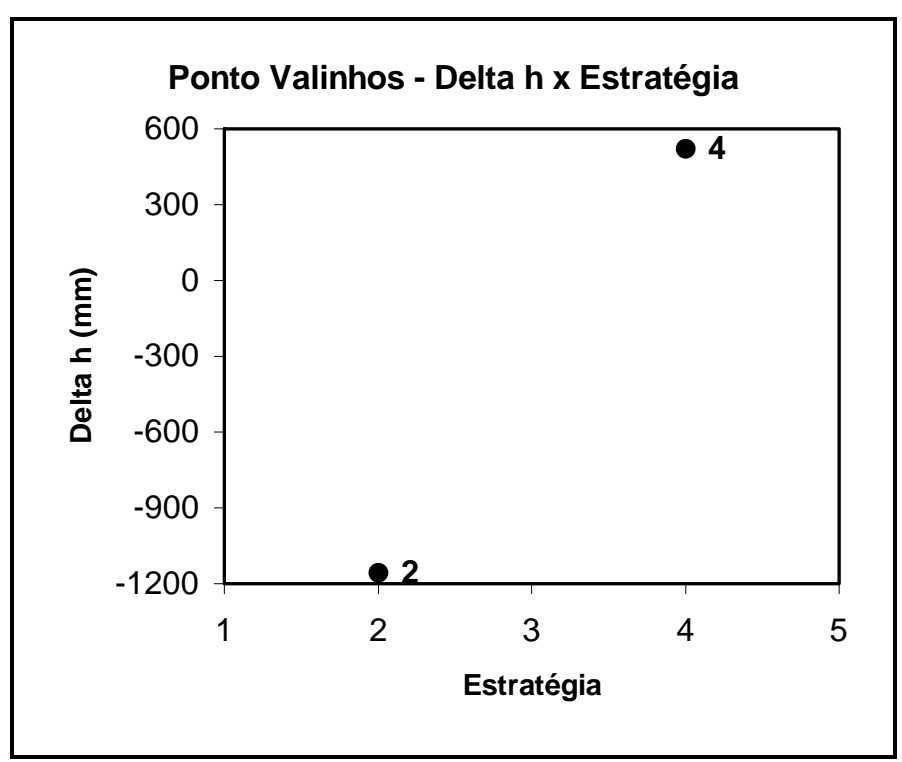

FG URA 58 - Grá fic o dos va lores das diferenças das alturas do ponto VAU 
TABEA 64- Coordenadas UTM do Ponto MARI

\begin{tabular}{|c|c|c|c|c|c|c|}
\hline \multicolumn{7}{|c|}{ Coordenadas UTM } \\
\hline Descrição/ Ponto & Norte (m) & Este (m) & $h(m)$ & $\begin{array}{c}\text { DELTA E } \\
(\mathrm{mm})\end{array}$ & $\begin{array}{c}\text { DELTA N } \\
\text { (mm) }\end{array}$ & $\begin{array}{c}\text { DELTA H } \\
\text { (mm) }\end{array}$ \\
\hline Estratégia 2 / Manlia & 7545170.043 & 610538.371 & 636.448 & 370 & 43 & -552 \\
\hline Estratégia 4 / Manlia & 7545170.558 & 610538.501 & 637.907 & 501 & 558 & 907 \\
\hline
\end{tabular}

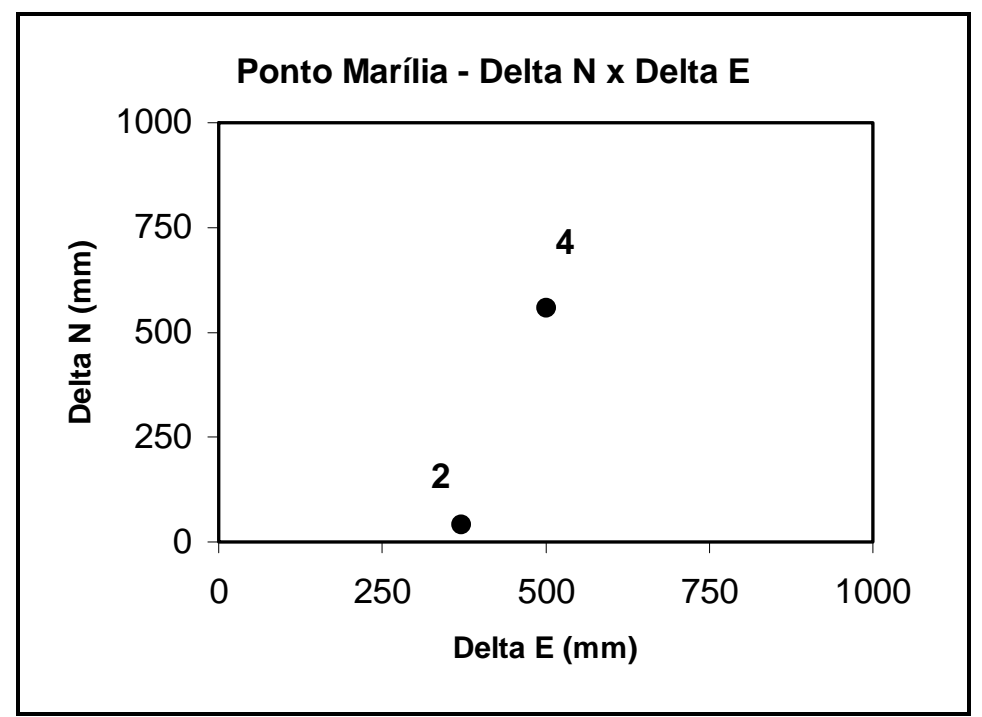

RGURA 59 - G ráfico dos va lores das diferenças obtidas nas Direções N e E do ponto MARI

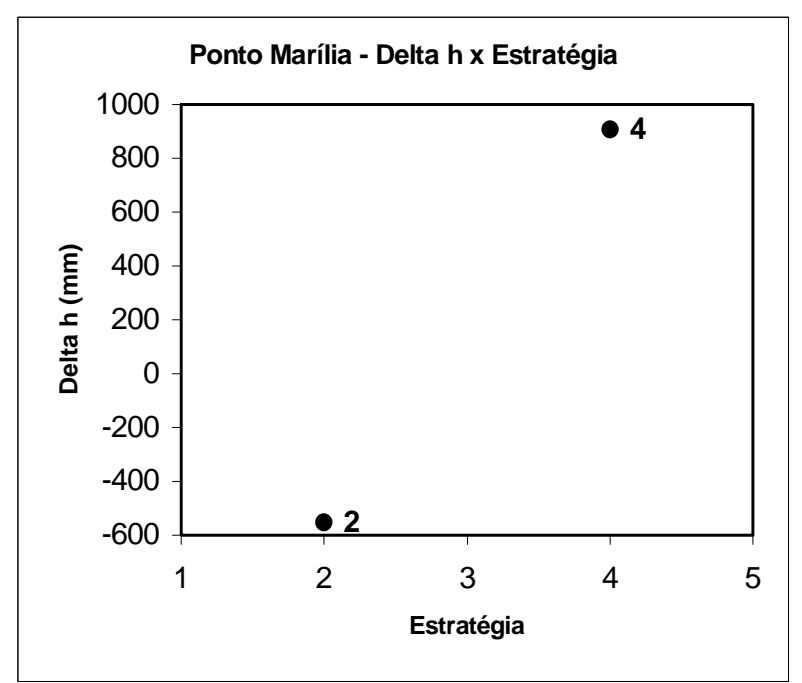

FG URA 60 - G rá fic o dos va lores das diferenças das alturas do ponto MARI 
TABEA 65 - Coordenadas UTM do Ponto ILHA

\begin{tabular}{lcccccc}
\hline \multicolumn{1}{c}{ Coordenadas UTM } & & & \\
\hline \multicolumn{1}{c}{ Descrição/ Ponto } & Norte (m) & Este (m) & h(m) & $\begin{array}{c}\text { DELTA E } \\
(\mathbf{m m})\end{array}$ & $\begin{array}{c}\text { DELTA N } \\
(\mathbf{m m})\end{array}$ & $\begin{array}{c}\text { DELTA H } \\
(\mathbf{m m})\end{array}$ \\
\hline Estratégia 2 / Ilha & 7747389.027 & 458476.315 & 322.250 & 314 & 27 & -750 \\
Estratégia 4 / llha & 7747389.110 & 458476.929 & 323.858 & 929 & 110 & 858 \\
\hline \hline
\end{tabular}

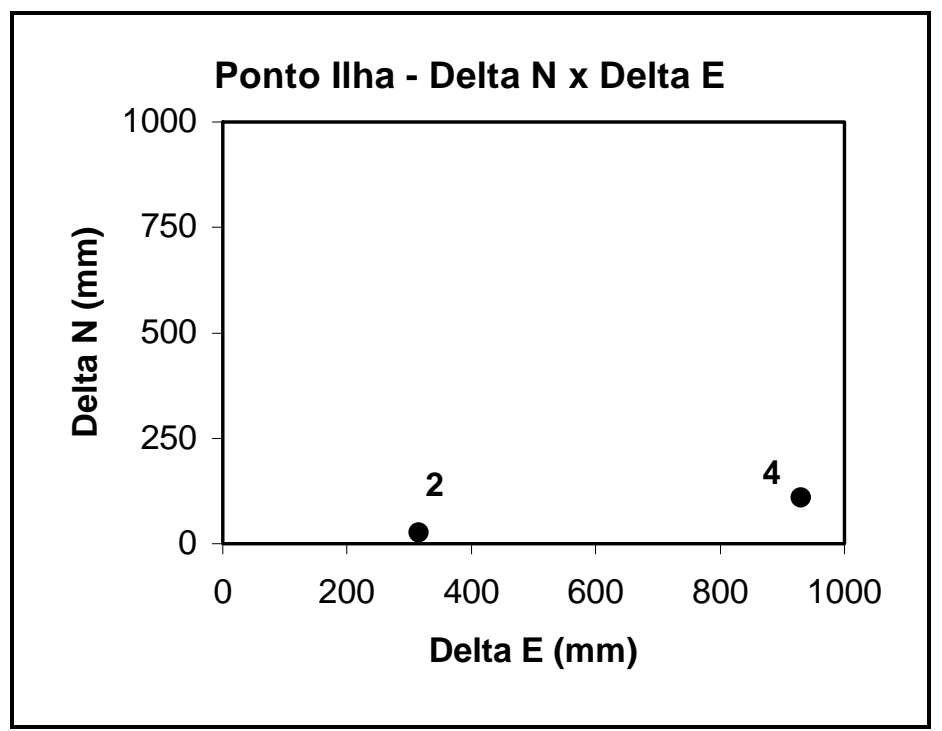

FGURA 61 - G ráfico dos va lores das diferença s obtidas nas Direções N e E do ponto ILHA

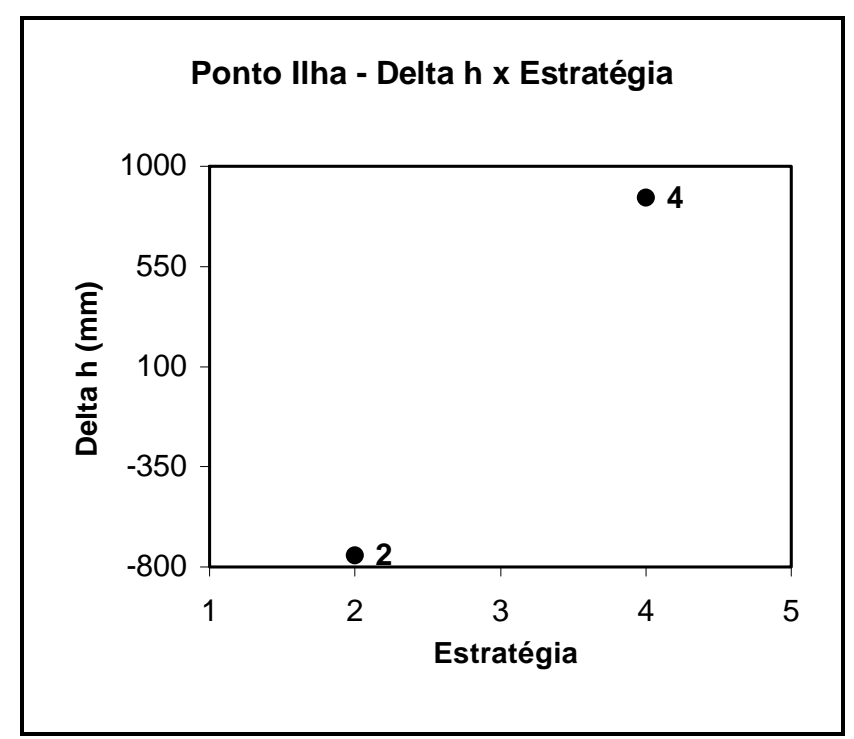

FG URA 62 - Gráfic o dos va lores das diferenças das alturas do ponto ILHA 
TABEA 66 - Coordenadas UTM do Ponto SJ RP

\begin{tabular}{lcccccc}
\hline \multicolumn{1}{c}{ Coordenadas UTM } \\
\hline \multicolumn{1}{c}{ Descrição/ Ponto } & Norte (m) & Este (m) & h(m) & $\begin{array}{c}\text { DELTA E } \\
(\mathbf{m m})\end{array}$ & $\begin{array}{c}\text { DELTA N } \\
(\mathbf{m m})\end{array}$ & $\begin{array}{c}\text { DELTA H } \\
(\mathbf{m m})\end{array}$ \\
\hline $\begin{array}{l}\text { Estratégia 2 / S. J. do R. } \\
\text { Preto }\end{array}$ & 7700815.351 & 670893.620 & 519.658 & 620 & 351 & 658 \\
$\begin{array}{l}\text { Estratégia 4 / S. J. do R } \\
\text { Preto }\end{array}$ & 7700815.557 & 670893.801 & 519.537 & 801 & 557 & 537 \\
\hline \hline
\end{tabular}

Ponto S. J. do R. Preto - Delta N x Delta E

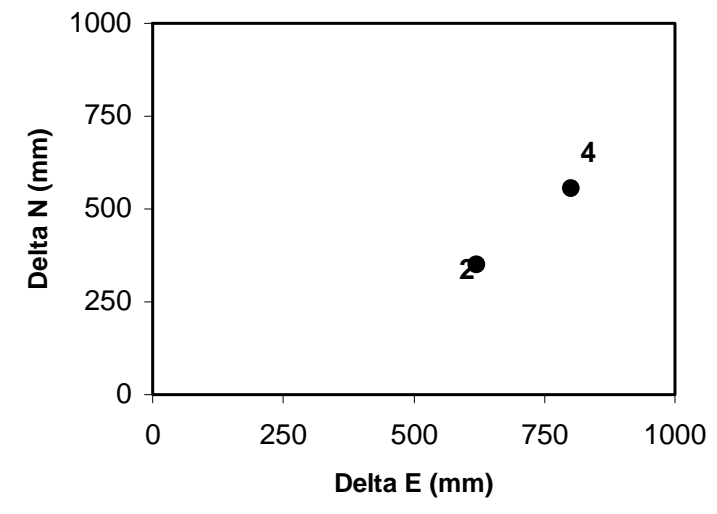

FGURA 63 - G ráfico dos va lores das diferença s obtidas nas Direções N e E do ponto SJ RP

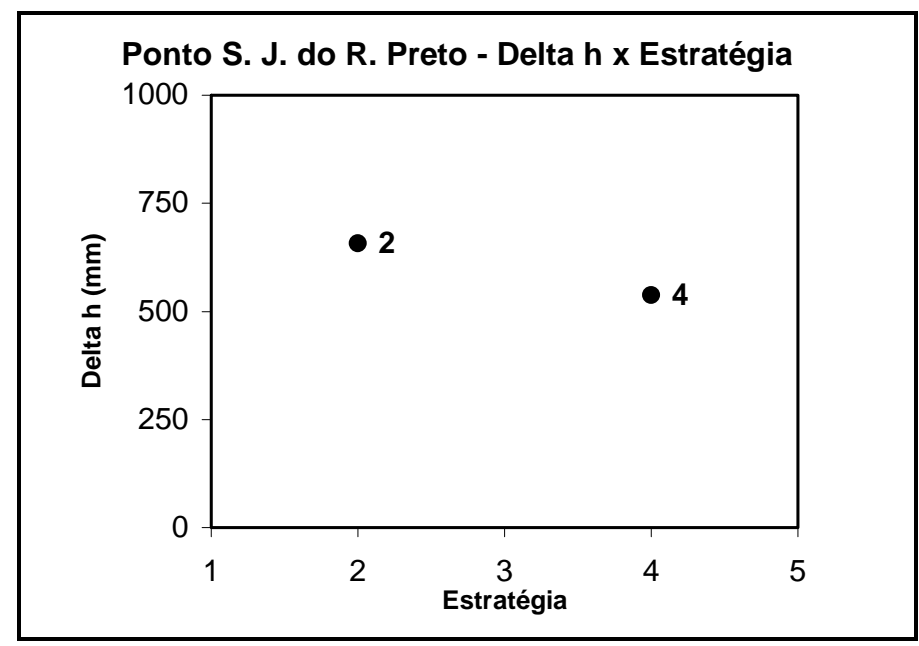

FGURA 64 - Gráfic o dos va lores das diferenças das alturas do ponto SJ RP 
TABEA 67 - Coordenadas UTM do Ponto REGI

\begin{tabular}{lcccccc}
\hline \multicolumn{7}{c}{ Coordenadas UTM } \\
\hline Descrição/ Ponto & Norte (m) & Este (m) & $\mathbf{h}(\mathbf{m})$ & $\begin{array}{c}\text { DELTA E } \\
\text { (mm) }\end{array}$ & $\begin{array}{c}\text { DELTA N } \\
\text { (mm) }\end{array}$ & $\begin{array}{c}\text { DELTA H } \\
\text { (mm) }\end{array}$ \\
\hline Estratégia 2 / REGI & 7293981.940 & 217845.275 & 43.294 & 275 & 940 & 294 \\
Estratégia 4 / REGI & 7293982.911 & 217845.017 & 44.977 & 17 & 1911 & 1977 \\
\hline \hline
\end{tabular}

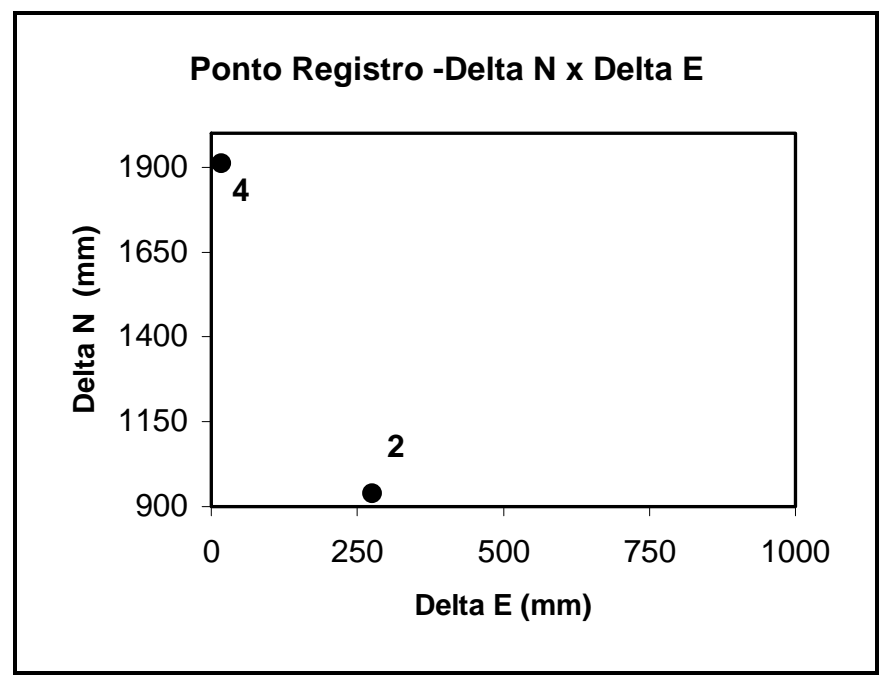

FGURA 65 - G ráfico dos va lores das diferenças obtidas nas Direções N e E do ponto REGI

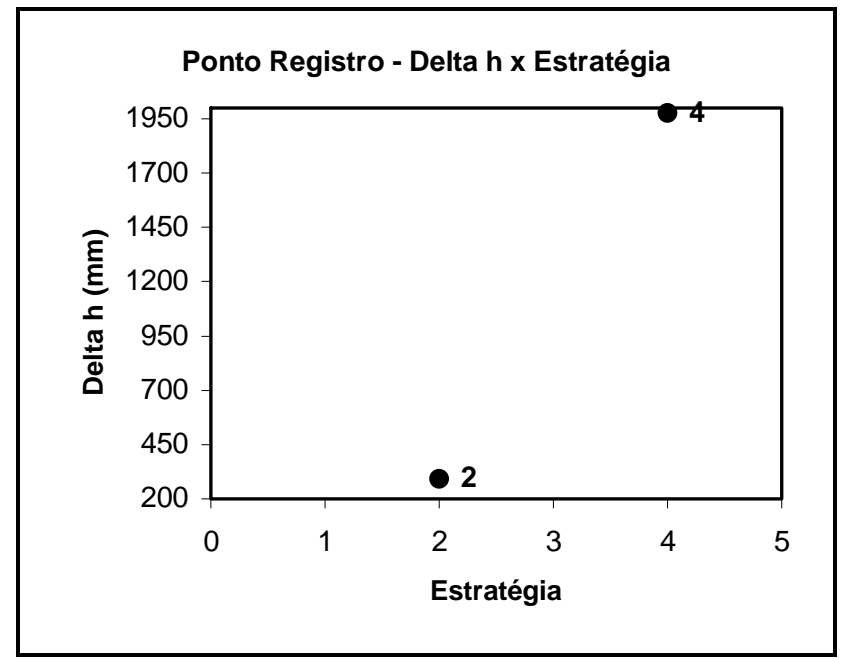

FGURA 66 - Gráfic o dos va lo res das diferenças das alturas do ponto REG I 


\section{4 - Análise 4 - Verificação da Influência de vetores maiores que $150 \mathrm{~km}$ processadas em conjunto com vetores menores que $150 \mathrm{~km}$}

Esta verificação será realizada através da comparação dos valores das coordenadas ajustadas de alguns pontos, em UTM, da estratégia 1 , com os valores obtidos por SEG ANTINE (1995), por FONSECA J r. (1996) e os resultados publicados pelo IBGE.

SEGANTINE (1995) realizou o processamento de todos os vetores observados, com diversos comprimentos, incluindo vetores de até, aproximadamente, $500 \mathrm{~km}$ (USPP - UEPP), considerando CHUA como injunção. O mesmo foi realizado pelo IBGE. FONSECA (1996), por sua vez, processou vetores entre BUNA e Fortaleza (estação da rede IGS), entre FRCA e Kourou (estação da rede IGS, localizada na Guiana) e outros, considerando CHUA como injunção.

A descrição da estratégia 1 , com todos os vetores encontra-se em 9.1.

A seguir, são apresentadas as tabelas com as coordenadas dos pontos que serão comparados, em UTM, as respectivas diferenças e em seguida a visualização gráfica destas diferenças.

Nos gráficos, os valores do IBGE estão representados pela letra I, os obtidos por FONSECA J r. estão representados pela letra $\mathrm{F}$ e os obtidos por SEGANTINE estão representados pela letra $S$.

As coordenadas de todas as estações da rede, apresentadas por SEGANTINE (1995), FONSECA J r. (1996) e as oficias divulgadas pelo IBGE estão apresentadas no ANEXO G. 
TABELA 68 - Coordena das UTM do Ponto USP -SP

\begin{tabular}{lcccccc}
\hline \multicolumn{7}{c}{ Coordenadas UTM } \\
\hline \multicolumn{1}{c}{ Descrição/ Ponto } & Norte (m) & Este (m) & h(m) & $\begin{array}{c}\text { DELTA E } \\
\text { (mm) }\end{array}$ & $\begin{array}{c}\text { DELTA N } \\
\text { (mm) }\end{array}$ & $\begin{array}{c}\text { DELTA H } \\
\text { (mm) }\end{array}$ \\
\hline Estratégia 1 / USP - SP & 7394432.244 & 323255.446 & 718.346 & 446 & 244 & 346 \\
IBGE / USP - SP & 7394431.893 & 323255.801 & 718.203 & 801 & -107 & 203 \\
FONSECA J R. / USP - SP & 7394431.895 & 323255.734 & 718.345 & 733 & -105 & 345 \\
SEGANTINE / USP. SP & 7394431.892 & 323255.669 & 718.314 & 669 & -108 & 314 \\
\hline \hline
\end{tabular}

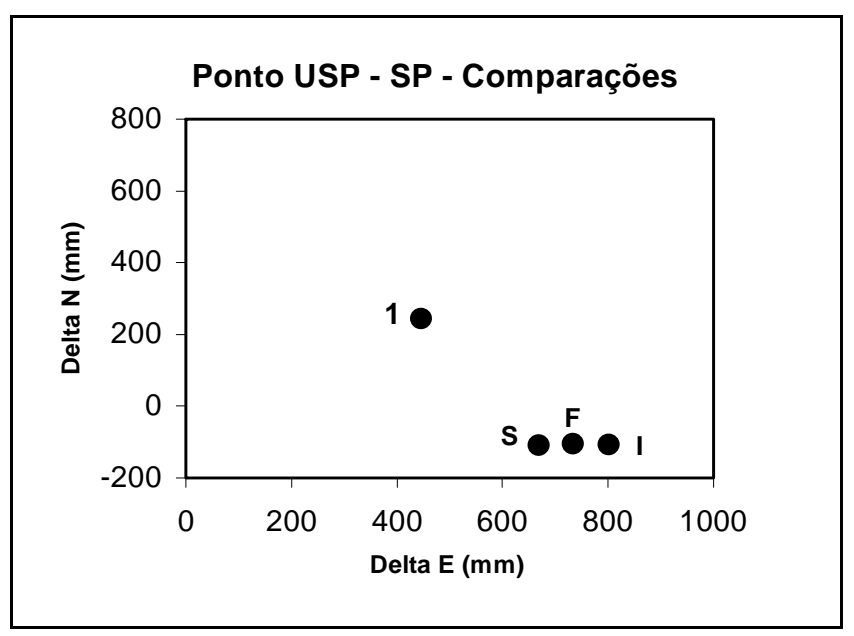

FGURA 67 - G ráfico dos va lores das diferença s obtidas nas Direções N e E do ponto USPP

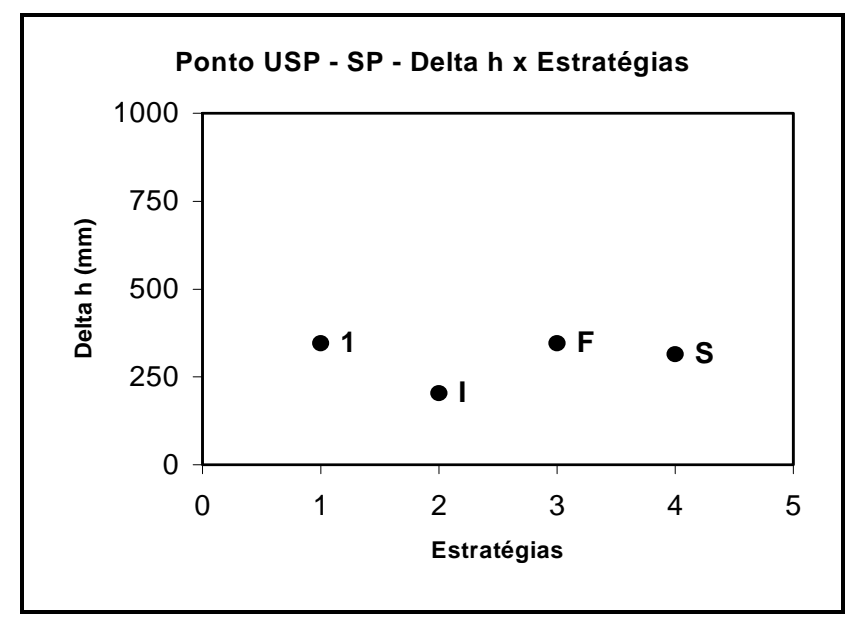

FGURA 68 - Gráfic o dos va lores das diferenças das alturas do ponto USPP 
TABEA 69 - Coordena das UTM do Ponto Valinhos

\begin{tabular}{lcccccc}
\hline \multicolumn{1}{c}{ Coordenadas UTM } & & & \\
\hline \multicolumn{1}{c}{ Descrição/ Ponto } & Norte $(\mathbf{m})$ & Este $(\mathbf{m})$ & $\mathbf{h}(\mathbf{m})$ & $\begin{array}{c}\text { DELTA E } \\
(\mathbf{m m})\end{array}$ & $\begin{array}{c}\text { DELTA N } \\
(\mathbf{m m})\end{array}$ & $\begin{array}{c}\text { DELTA H } \\
(\mathbf{m m})\end{array}$ \\
\hline Estratégia 1 / Valinhos & 7454939.490 & 298486.122 & 856.969 & 122 & 490 & 968 \\
IBGE / Valinhos & 7454939.193 & 298486.420 & 856.934 & 420 & 193 & 934 \\
FONSECA J R. / Valinhos & 7454939.202 & 298486.372 & 857.041 & 372 & 202 & 1041 \\
SEGANTINE / Valinhos & 7454939.204 & 298486.292 & 857.005 & 292 & 204 & 1005 \\
\hline \hline
\end{tabular}

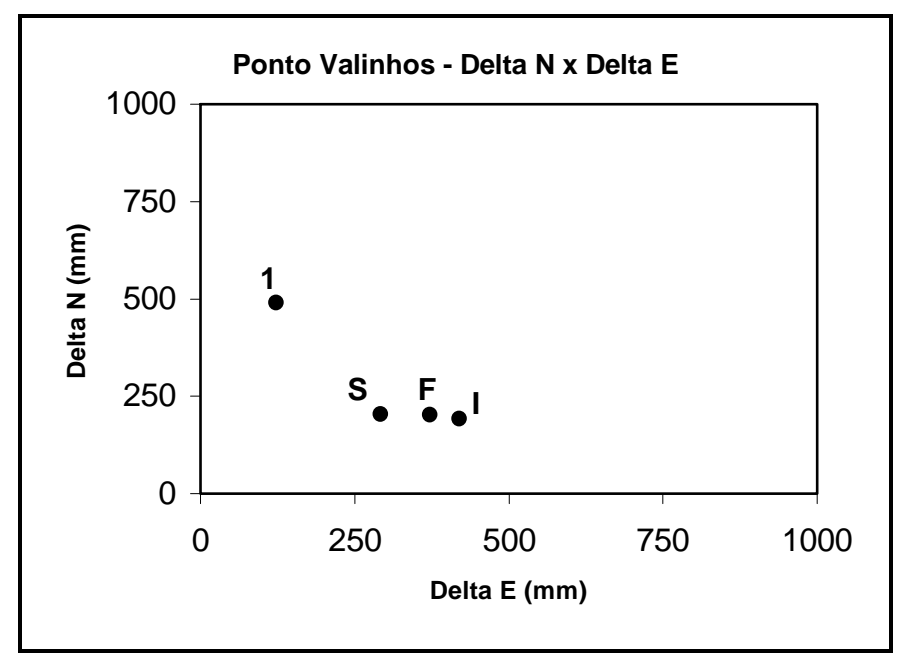

RGURA 69 - G ráfico dos va lores das diferenças obtidas nas Direções N e E do ponto VAU

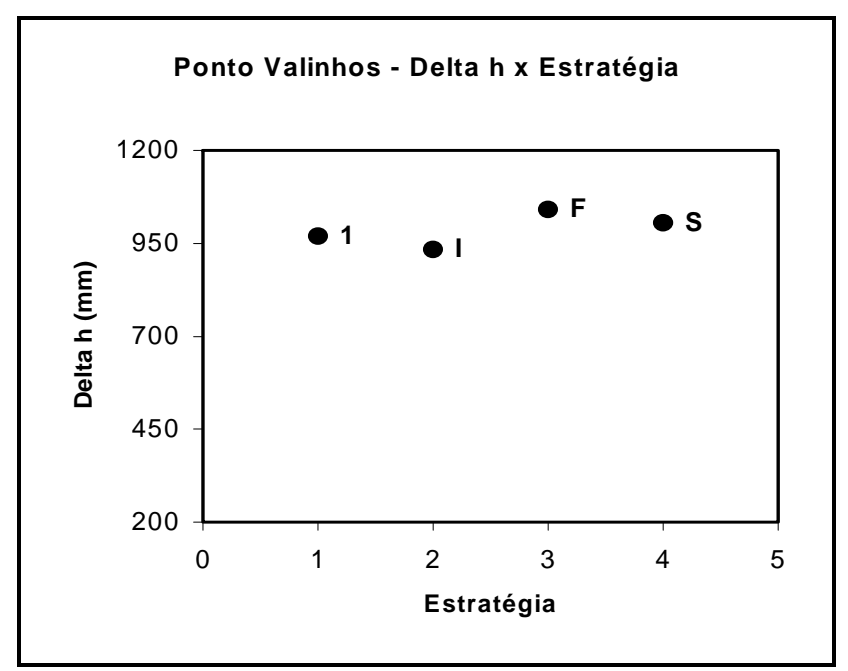

FG URA 70 - Gráfic o dos va lores das diferenças das alturas do ponto VAU 
TABEA 70 - Coordenadas UTM do Ponto Marília

\begin{tabular}{|c|c|c|c|c|c|c|}
\hline \multicolumn{7}{|c|}{ Coordenadas UTM } \\
\hline Descrição/ Ponto & Norte (m) & Este (m) & $h(m)$ & $\begin{array}{c}\text { DEITA E } \\
\text { (mm) }\end{array}$ & $\begin{array}{c}\text { DELTA N } \\
\text { (mm) }\end{array}$ & $\begin{array}{c}\text { DELTA H } \\
\text { (mm) }\end{array}$ \\
\hline Estratégia 1 / Manilia & 7545170.342 & 610538.515 & 637.576 & 515 & 342 & 576 \\
\hline IBGE / Manilia & 7545170.150 & 610538.474 & 637.470 & 474 & 150 & 470 \\
\hline FONSECA J R. / Manilia & 7545170.137 & 610538.404 & 637.549 & 404 & 137 & 549 \\
\hline SEGANTINE / Manlia & 7545170.132 & 610538.412 & 637.488 & 412 & 132 & 488 \\
\hline
\end{tabular}

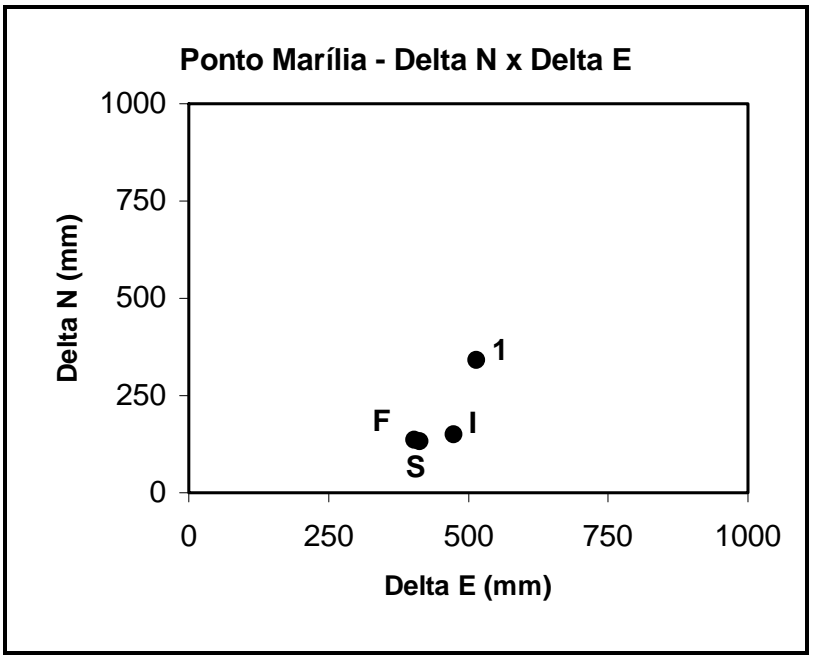

FGURA 71 - G ráfico dos va lores das diferenç as obtidas nas Direções $\mathrm{N}$ e E do ponto MARI

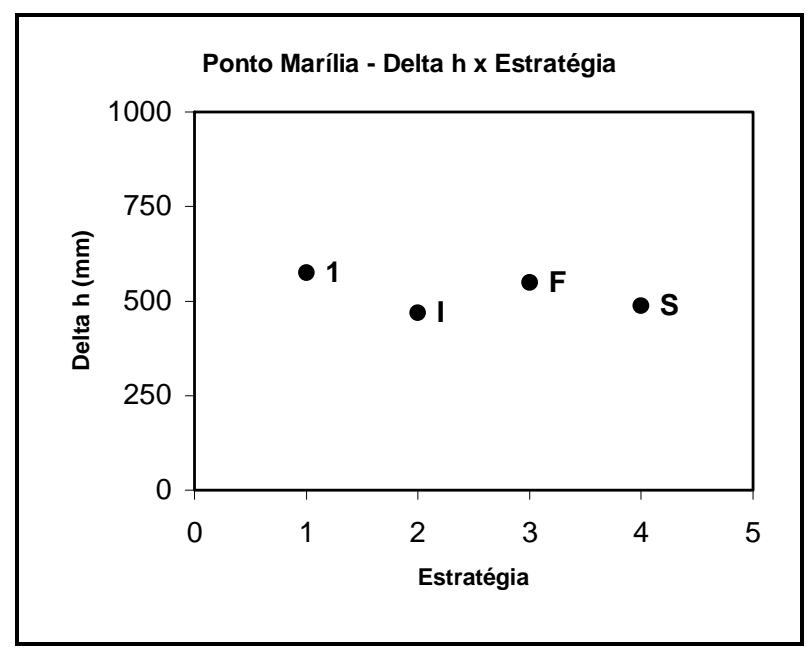

RGURA 72 - Gráfic o dos va lores das diferenças das alturas do ponto VAU 
TABEA 71 - Coordenadas UTM do Ponto llha Solteira

\begin{tabular}{lcccccc}
\hline \multicolumn{7}{c}{ Coordenadas UTM } \\
\hline \multicolumn{1}{c}{ Descrição/ Ponto } & Norte (m) & Este (m) & h(m) & $\begin{array}{c}\text { DELTA E } \\
\text { (mm) }\end{array}$ & $\begin{array}{c}\text { DELTA N } \\
\text { (mm) }\end{array}$ & $\begin{array}{c}\text { DELTA H } \\
\text { (mm) }\end{array}$ \\
\hline Estratégia 1 / Ilha & 7747389.136 & 458476.658 & 322.390 & 658 & 136 & -610 \\
IBGE / Ilha & 7747389.096 & 458476.489 & 323.452 & 489 & 96 & 452 \\
FONSECA J R. / Ilha & 7747389.070 & 458476.434 & 323.554 & 434 & 70 & 554 \\
SEGANTINE / Ilha & 7747389.078 & 458476.372 & 323.530 & 372 & 78 & 530 \\
\hline \hline
\end{tabular}

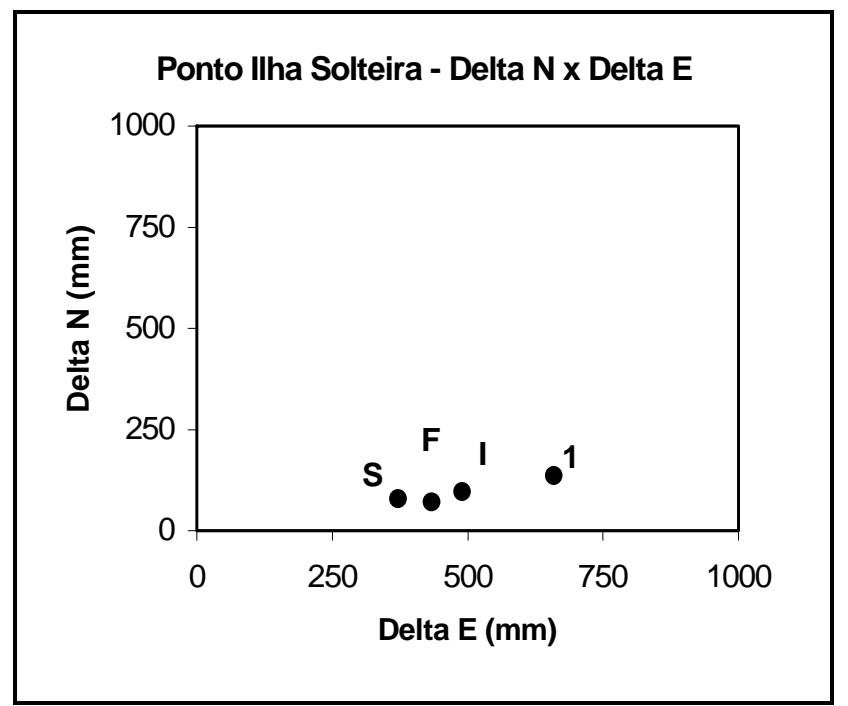

FGURA 73 - G ráfico dos va lores das diferença s obtidas nas Direções N e E do ponto IUHA

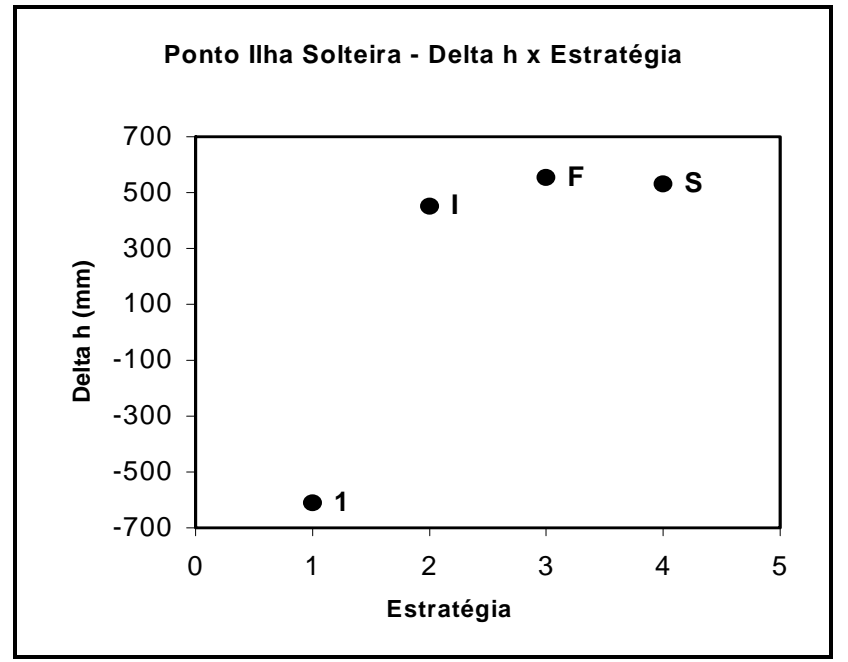

RGURA 74 - Gráfic o dos va lores das diferenças das alturas do ponto ILHA 
TABEAA 72 - Coordena das UTM do Ponto São J osé do Rio Preto

\begin{tabular}{lcccccc}
\hline \multicolumn{7}{c}{ Coordenadas UTM } \\
\hline \multicolumn{1}{c}{ Descrição/ Ponto } & Norte (m) & Este (m) & h(m) & $\begin{array}{c}\text { DELTA E } \\
(\mathbf{m m})\end{array}$ & $\begin{array}{c}\text { DELTA N } \\
(\mathbf{m m})\end{array}$ & $\begin{array}{c}\text { DELTA H } \\
\text { (mm) }\end{array}$ \\
\hline $\begin{array}{l}\text { Estratégia 1 / S. J. do R. } \\
\text { Preto }\end{array}$ & 7700815.461 & 670893.791 & 519.742 & 791 & 461 & -258 \\
IBGE / S. J. do R. Preto & 7700815.397 & 670893.727 & 520.850 & 727 & 397 & 850 \\
$\begin{array}{l}\text { FONSECA J R. / S. J. do } \\
\text { R. Preto }\end{array}$ & 7700815.381 & 670893.687 & 520.933 & 687 & 381 & 933 \\
$\begin{array}{l}\text { SEGANTINE / S. J. do R. } \\
\text { Preto }\end{array}$ & 7700815.384 & 670893.666 & 521.083 & 666 & 384 & 1083 \\
\hline \hline
\end{tabular}

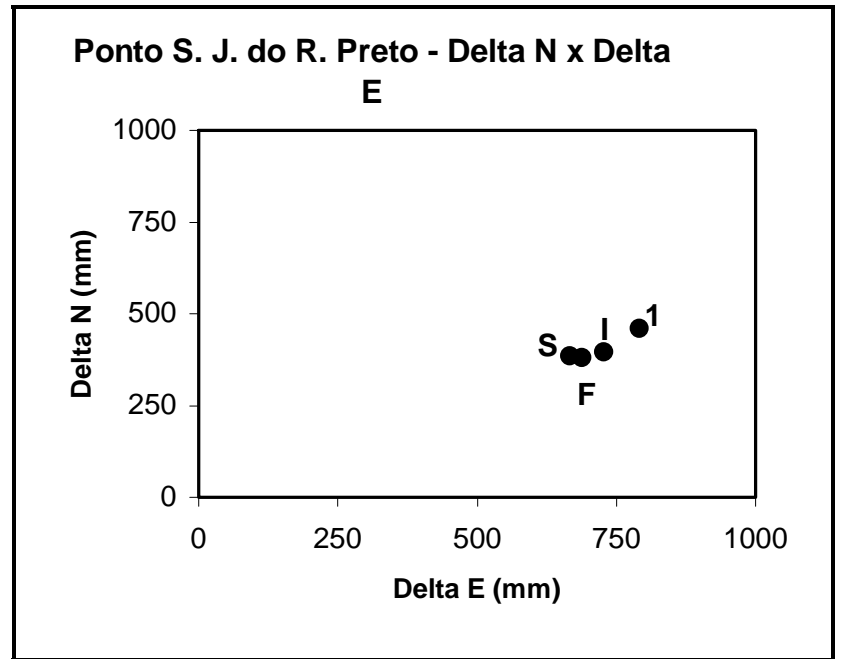

FGURA 75 - G ráfico dos va lores das diferenças obtidas nas Direções N e E do ponto SJ RP

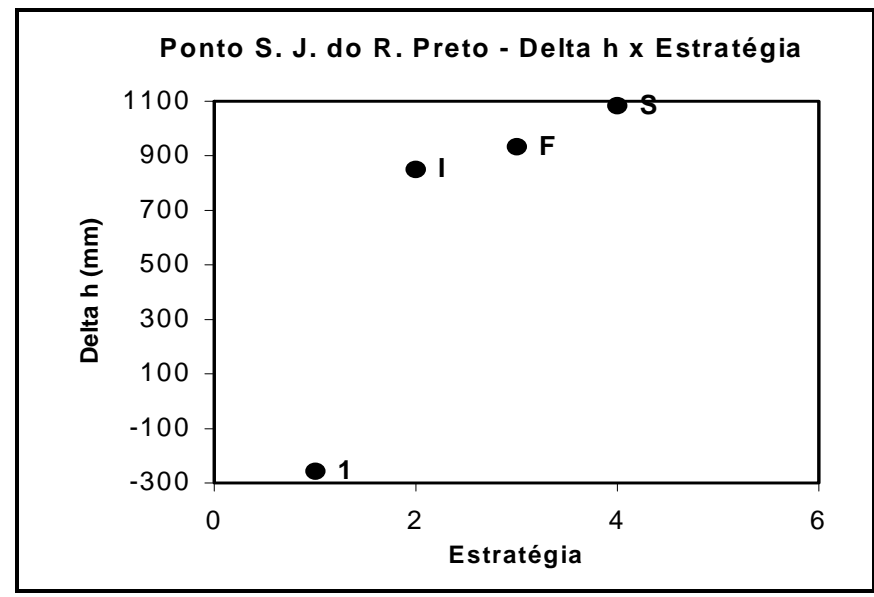

FGURA 76 - G ráfico dos valores das diferenças das alturas do ponto SJ RP 
TABEA 73 - Coordenadas UTM do Ponto Registro

\begin{tabular}{lccccccc}
\hline \multicolumn{7}{c}{ Coordenadas UTM } \\
\hline \multicolumn{1}{c}{ Desc rição/ Ponto } & Norte (m) & Este (m) & $\mathbf{h}(\mathbf{m})$ & $\begin{array}{c}\text { DELTA E } \\
(\mathbf{m m})\end{array}$ & $\begin{array}{c}\text { DEETA N } \\
(\mathbf{m m})\end{array}$ & $\begin{array}{c}\text { DEITA H } \\
(\mathbf{m m})\end{array}$ \\
\hline Estratégia 1 / Registro & 7293982.528 & 217845.199 & 44.433 & 199 & 528 & 433 \\
IBGE / Registro & 7293982.098 & 217845.409 & 44.282 & 409 & 98 & 282 \\
FONSECA J R. / Registro & 7293982.089 & 217845.340 & 44.460 & 340 & 89 & 459 \\
SEGANTINE / Registro & 7293982.077 & 217845.310 & 44.332 & 310 & 77 & 332 \\
\hline \hline
\end{tabular}

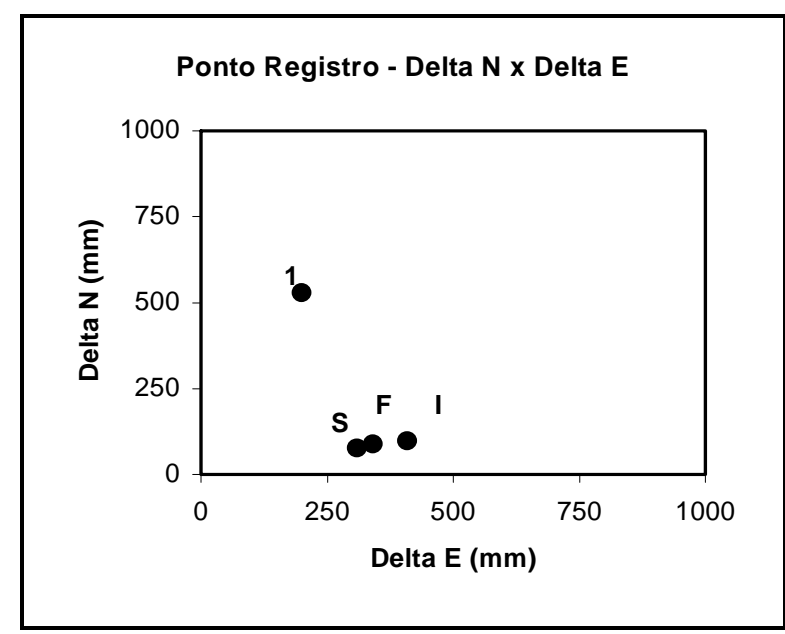

FGURA 77 - G ráfico dos va lores das diferença s obtidas nas Direções N e E do ponto REGI

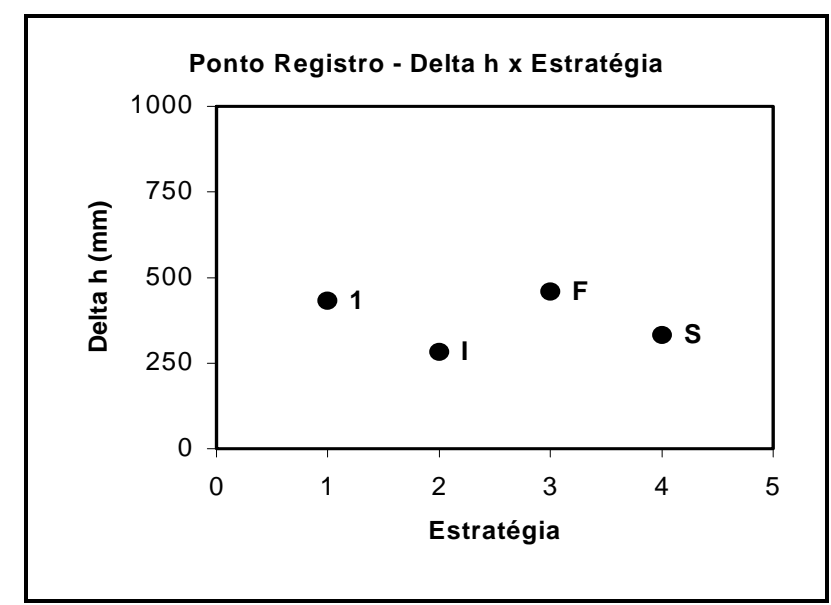

RGURA 78 - Gráfic o dos va lores das diferenças das alturas do ponto REG I 
Ainda, não se conseguiu junto ao $\mathrm{IBGE}$, os valores de variância a posteriori do ajustamento realizados por seu corpo técnico. FONSECA J r. (1996) nada relata, também, a respeito. Somente SEG ANTINE (1995), publica os valores obtidos em seu ajustamento, da estratégia nomeada de MP1. Este valor está apresentado na TABELA 74, abaixo, junto com o obtido do ajustamento da estratégia 1 .

TABEA 74 - Valores de variância a posteriori da estratégia 1

\begin{tabular}{|c|c|}
\hline $\begin{array}{l}\text { Descrição da estratégia } \\
\text { Ajustada }\end{array}$ & Variância a posterioni \\
\hline $\begin{array}{l}\text { Estratégia } 1 \text { (total) - CHUA - CAPA / Efemérides } \\
\text { precisas IGS e Valores atmosféric os rea is }\end{array}$ & 9,8 \\
\hline $\begin{array}{l}\text { Solução SEGANTINE (1995) - CHUA / Efemérides } \\
\text { precisas NGSe Valores atmosféric os default }\end{array}$ & 10,7 \\
\hline
\end{tabular}

Também, não se conseguiu junto ao IBGE os valores das elipses de erros e SEG ANTINE (1995) e FONSECA J r. (1996) nada relatam a respeito. 


\section{5 - Análise 5 - Comparação das Coordenadas obtidas dos Ajustamentos realizados com Diferentes Injunções}

Realizou-se o ajustamento da estratégia 1 de duas maneiras:

$\checkmark$ Na primeira, considerou-se CHUA e CAPA como injunções (estratégia 1) e

$\checkmark \mathrm{Na}$ segunda, considerou-se CAPA e UEPP como injunções (estratégia 1.1).

Em ambas considerou-se o tempo total de observação, efemérides precisase valores atmosféric os rea is.

Na TABELA 75, a seguir, são apresentados os valores obtidos para a variância a posteriori e o erro médio daselipses.

TABEA 75 - Comparação Estra tégia 1 e Estra tégia 1.1

\begin{tabular}{lcc}
\hline \multicolumn{1}{c}{$\begin{array}{c}\text { Descrição da estratégia } \\
\text { ajustada }\end{array}$} & Variância a posteriori & $\begin{array}{c}\text { Eno médio das elipses } \\
\text { (mm) }\end{array}$ \\
\hline $\begin{array}{l}\text { Estratégia 1 (total) - } \\
\text { CHUA (IBG E) - CAPA (SIRGAS) }\end{array}$ & 9,8 & 100 \\
Estratégia 1.1 (total) - & 13,7 & 160 \\
CAPA (SIRG AS) - UEPP (SIRGAS) & & \\
\hline \hline
\end{tabular}

A seguir, são apresentadas as tabelas com as coordenadas dos pontos que serão comparados, em UTM, as respectivas diferenças e em seguida a visualização gráfica destas diferenças. 
TABEIA 76 - Coordenadas UTM do ponto USP - SP

\begin{tabular}{lcccccc}
\hline \hline \multicolumn{7}{c}{ Coordenadas UTM } \\
\hline Desc rição/ Ponto & Norte $\mathbf{( m )}$ & Este $\mathbf{( m )}$ & $\mathbf{h}(\mathbf{m})$ & $\begin{array}{c}\text { DEITA E } \\
(\mathbf{m m})\end{array}$ & $\begin{array}{c}\text { DEITA N } \\
(\mathbf{m m})\end{array}$ & $\begin{array}{c}\text { DElTA H } \\
(\mathbf{m m})\end{array}$ \\
\hline $\begin{array}{l}\text { Estratégia 1 - CHUA - } \\
\text { CAPA }\end{array}$ & 7394432.244 & 323255.446 & 718.346 & 446 & 244 & 346 \\
$\begin{array}{l}\text { Estratégia 1.1 - CAPA - } \\
\text { UEPP }\end{array}$ & 7394432.087 & 323255.228 & 718.500 & 228 & 87 & 500 \\
\hline \hline
\end{tabular}

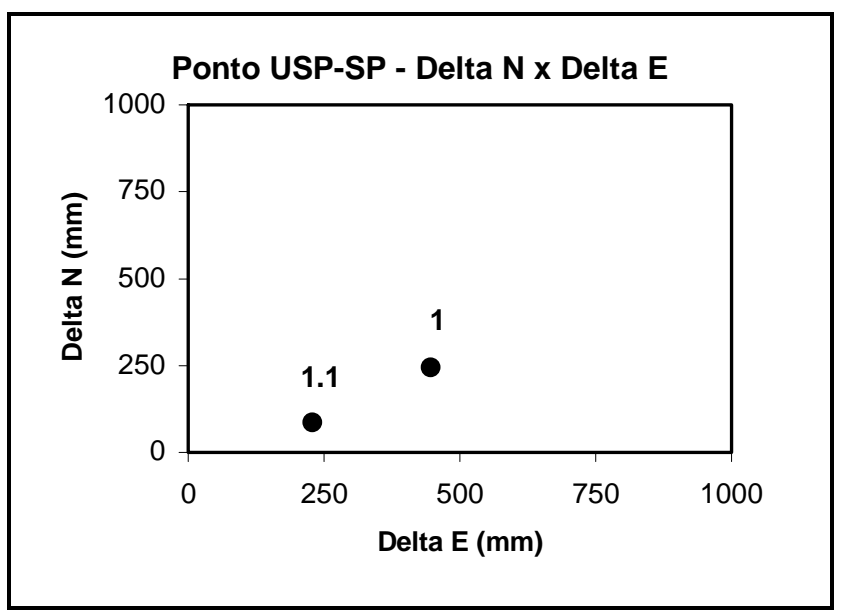

FGURA 79 - G ráfico dos va lores das diferença s obtidas nas Direções N e E do ponto USP - SP

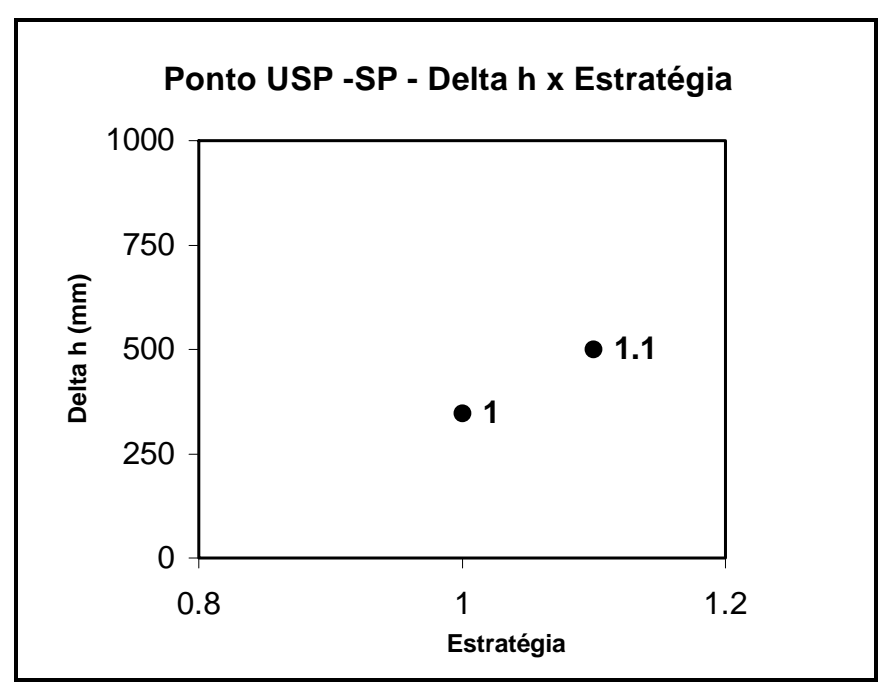

FG URA 80 - Gráfic o dos va lores das diferenças das a lturas do ponto USP - SP 
TABEA 77 - Coordenadas UTM do ponto VAU

\begin{tabular}{lcccccc}
\hline \multicolumn{7}{c}{ Coordenadas UTM } \\
\hline Descrição/ Ponto & Norte $(\mathbf{m})$ & Este $(\mathbf{m})$ & $\mathbf{h}(\mathbf{m})$ & $\begin{array}{c}\text { DEITA E } \\
(\mathbf{m m})\end{array}$ & $\begin{array}{c}\text { DETA N } \\
(\mathbf{m m})\end{array}$ & $\begin{array}{c}\text { DETA H } \\
(\mathbf{m m})\end{array}$ \\
\hline $\begin{array}{l}\text { Estratégia 1 - CHUA - } \\
\text { CAPA }\end{array}$ & 7454939.490 & 298486.122 & 856.969 & 1122 & 490 & -32 \\
$\begin{array}{l}\text { Estratégia 1.1 - CAPA - } \\
\text { UEPP }\end{array}$ & 7454939.413 & 298485.862 & 857.133 & 862 & 413 & 133 \\
\hline \hline
\end{tabular}

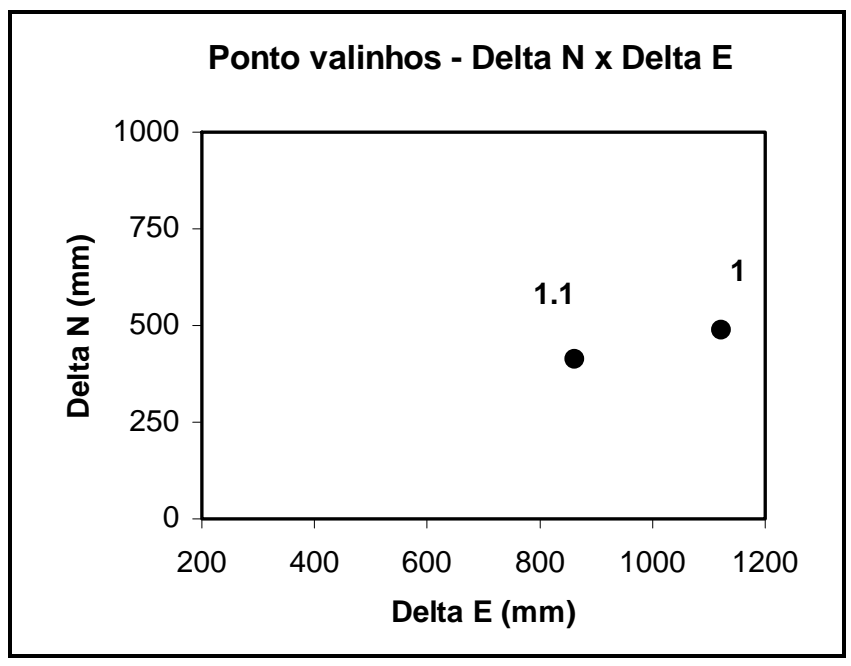

FGURA 81 - G ráfico dos va lores das diferenç as obtidas nas Direções $\mathrm{N}$ e E do ponto VAU

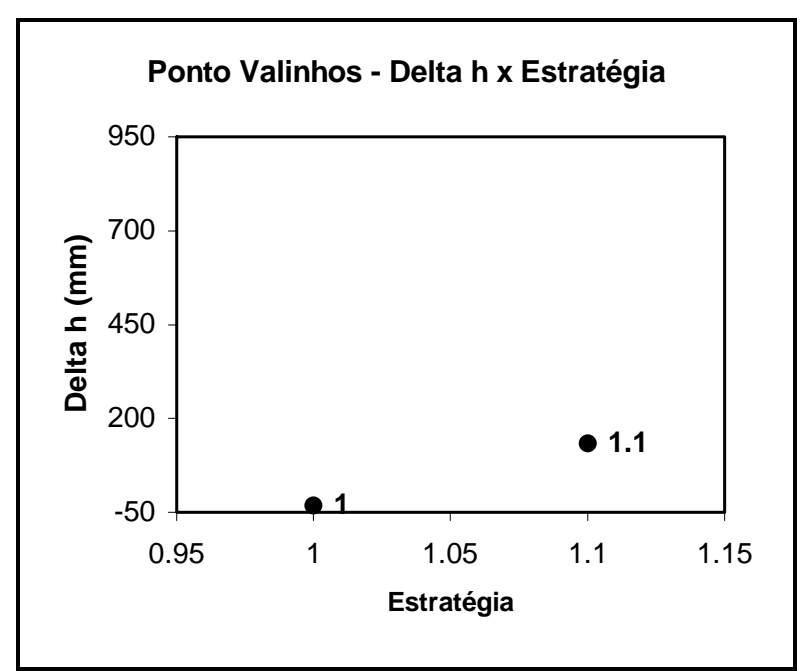

RG URA 82 - Gráfic o dos va lores das diferenças das alturas do ponto VAU 
TABELA 78 - Coordenadas UTM do ponto Marília

\begin{tabular}{lcccccc}
\hline \hline \multicolumn{7}{c}{ Coordenadas UTM } \\
\hline Desc rição/ Ponto & Norte (m) & Este (m) & h(m) & $\begin{array}{c}\text { DETA E } \\
(\mathbf{m m})\end{array}$ & $\begin{array}{c}\text { DETA N } \\
(\mathbf{m m})\end{array}$ & $\begin{array}{c}\text { DETA H } \\
(\mathbf{m m})\end{array}$ \\
\hline $\begin{array}{l}\text { Estratégia 1 - CHUA - } \\
\text { CAPA }\end{array}$ & 7545170.342 & 610538.515 & 637.576 & 1515 & 342 & 576 \\
$\begin{array}{l}\text { Estratégia 1.1 - CAPA - } \\
\text { UEPP }\end{array}$ & 7545170.412 & 610537.813 & 637.735 & 813 & 412 & 735 \\
\hline \hline
\end{tabular}

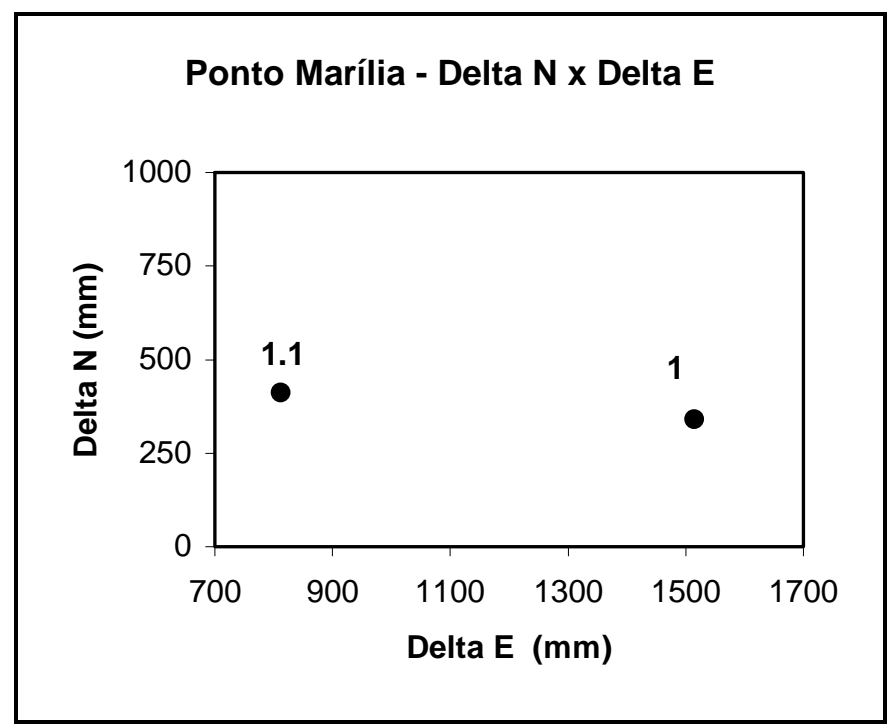

FGURA 83- Gráfico dos valores das diferenç as obtidas nas Direções N e E do ponto MARI

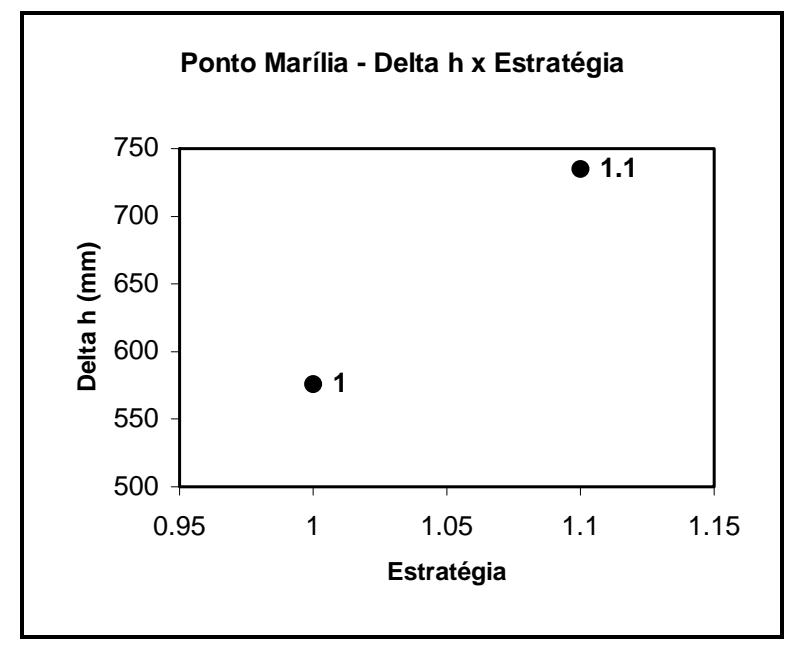

RGURA 84 - Gráfic o dos va lores das diferenças das alturas do ponto MARI 
Realizou-se, também, as seguintes comparações entre as coordenadas das estações consideradas como injunção:

\subsection{1 - Comparações das coordenadas de CAPA}

A seguir, são a presentadas as ta belas com as coordenadas do ponto Cachoeira Paulista obtidas de SIRGAS, IBGE, SEGANTINE (1995) e FONSECA J r. (1996), em UTM, as respectivas diferenças e em seguida a visualização gráfic a destas diferenças.

TABEA 79- Coordenadas UTM do ponto Cachoeira Paulista

\begin{tabular}{|c|c|c|c|c|c|c|}
\hline \multicolumn{7}{|c|}{ Coordenadas UTM } \\
\hline Descrição/ Ponto & Norte (m) & Este (m) & $h(\mathbf{m})$ & $\begin{array}{c}\text { DElTA E } \\
\text { (mm) }\end{array}$ & $\begin{array}{c}\text { DETA N } \\
\text { (mm) }\end{array}$ & $\begin{array}{c}\text { DELTA H } \\
(\mathrm{mm})\end{array}$ \\
\hline CAPA (SIRGAS) & 7491132.763 & 501613.934 & 620.302 & 934 & 763 & 302 \\
\hline CAPA (IBGE) & 7491132.526 & 501614.612 & 620.492 & 1611 & 526 & 492 \\
\hline CAPA (FONSECA) & 7491132.561 & 501614.508 & 620.505 & 1508 & 561 & 505 \\
\hline CAPA (SEGANTINE) & 7491132.556 & 501614.604 & 620.349 & 1604 & 556 & 349 \\
\hline
\end{tabular}

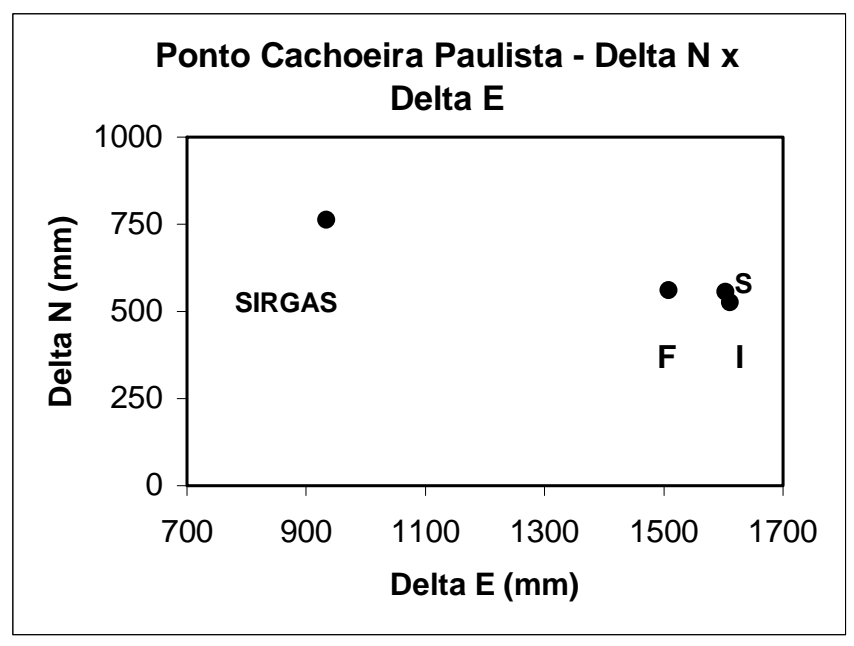

RGURA 85- Gráfico dos valores das diferenç as obtidas nas Direções N e E do ponto CAPA 


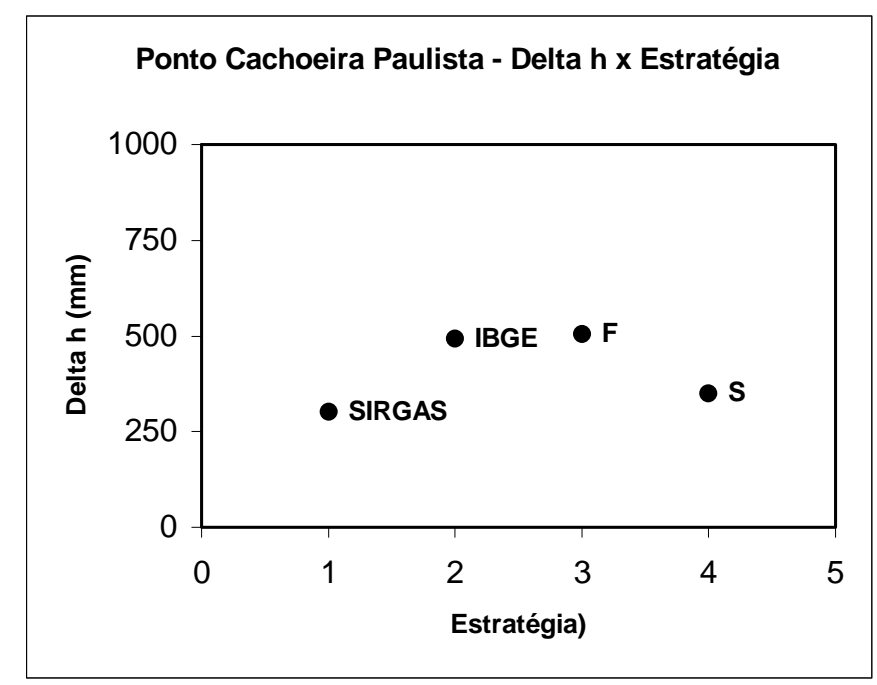

FGURA 86 - Gráfic o dos va lores das diferenças das alturas do ponto CAPA

\subsection{2 - Comparações das coordenadas de UEPP}

Da Estratégia 1 (injunções CHUA (IBGE) e CAPA (SIRGAS)), comparouse os valores das coordenadas obtidas para o ponto UEPP, com os valores do IBG E, FONSECA J r. e SEG ANTINE.

TABEIA 80 - Coordenadas UTM do ponto UEPP

\begin{tabular}{|c|c|c|c|c|c|c|}
\hline \multicolumn{7}{|c|}{ Coordenadas UTM } \\
\hline Descrição/ Ponto & Norte (m) & Este (m) & $h(m)$ & $\begin{array}{c}\text { DELTA E } \\
(\mathrm{mm}) \\
\end{array}$ & $\begin{array}{c}\text { DETA N } \\
(\mathrm{mm})\end{array}$ & $\begin{array}{c}\text { DELTA H } \\
(\mathrm{mm})\end{array}$ \\
\hline Estratégia 1 & 7553844.490 & 457866.962 & 429.247 & 962 & 490 & -753 \\
\hline UEPP (SIRGAS) & 7553844.532 & 457866.090 & 430.946 & 90 & 532 & 946 \\
\hline UEPP (IBG E) & 7553844.312 & 457866.738 & 431.037 & 737 & 312 & 1037 \\
\hline UEPP (SEG ANTINE) & 7553844.291 & 457866.673 & 431.081 & 673 & 291 & 1081 \\
\hline UEPP (FONSECA J r.) & 7553844.298 & 457866.675 & 431.064 & 675 & 298 & 1064 \\
\hline
\end{tabular}




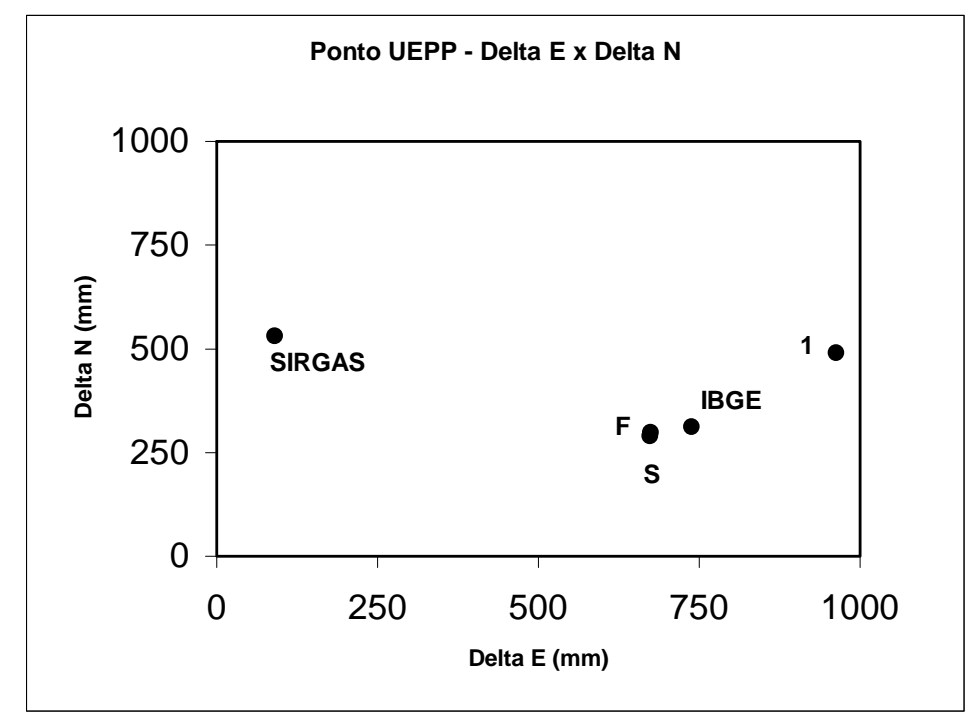

FGURA 87 - Gráfico dos va lores das diferenças obtidas nas Direções N e E do ponto UEPP

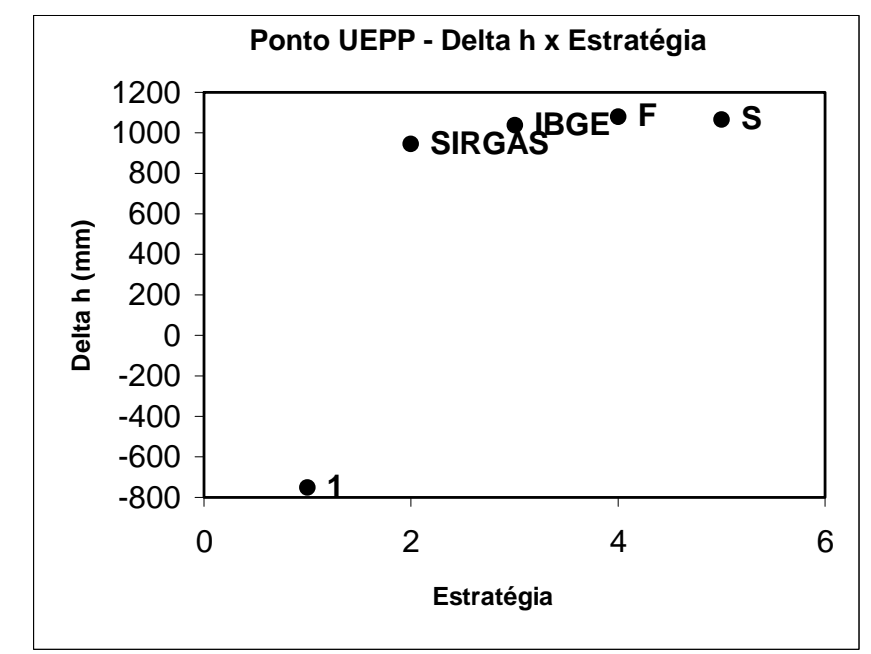

FG URA 88 - Gráfic o dos va lores das diferenças das alturas do ponto UEPP

\subsection{3 - Comparações das coordenadas do Vértice CHUA}

Da Estratégia 1.1 (injunções CAPA (SIRGAS) e UEPP (SIRGAS)), comparou-se os valores das coordenadas obtidas para o vértice CHUA, com os valores do IBGE. 
TABEA 81 - Coordena das UTM do Vértice CHUA

\begin{tabular}{lcccccc}
\hline \hline Coordenadas UTM \\
\hline Descrição/Ponto & Norte $(\mathbf{m})$ & Este $(\mathbf{m})$ & $\mathbf{h}(\mathbf{m})$ & $\begin{array}{c}\text { DELTA E } \\
(\mathbf{m m})\end{array}$ & $\begin{array}{c}\text { DELTA N } \\
(\mathbf{m m})\end{array}$ & $\begin{array}{c}\text { DELTA H } \\
(\mathbf{m m})\end{array}$ \\
\hline CHUA (IBG E) & 7812251.730 & 803743.927 & 754.148 & 927 & 730 & -852 \\
Estratégia 1.1 & 7812252.113 & 803743.476 & 755.547 & 476 & 1112 & 547 \\
\hline \hline
\end{tabular}

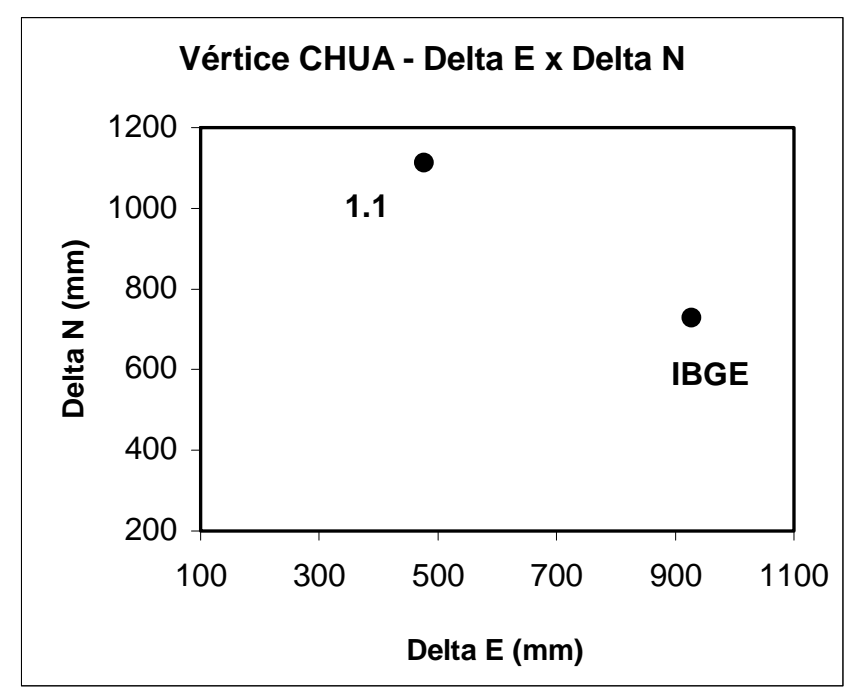

FGURA 89 - G ráfico dos va lores das diferenças obtidas nas Direções N e E do ponto Vértice CHUA

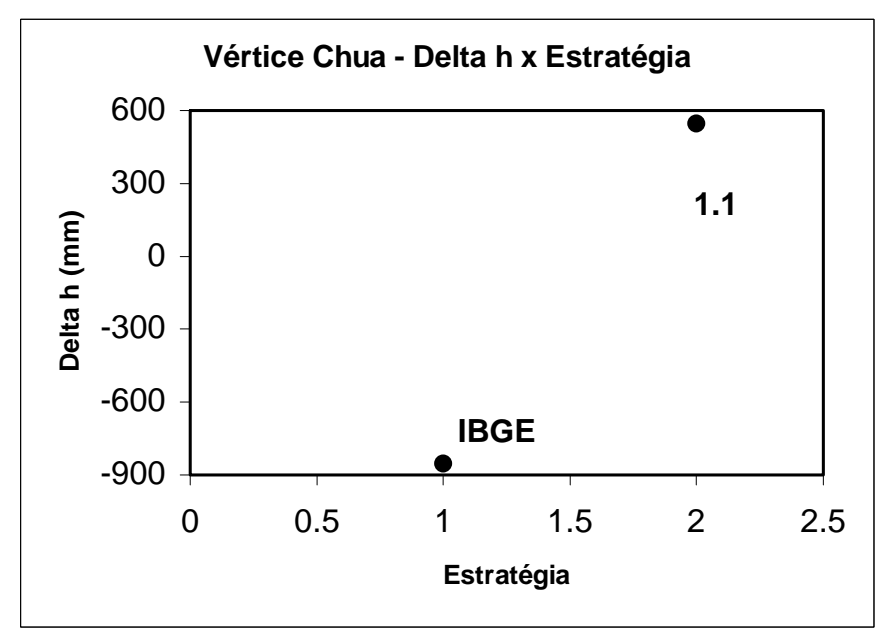

FG URA 90 - Grá fic o dos va lores das diferenças das alturas do ponto Vértice CHUA 


\section{CAPÍTULO 15}

\section{CONCLUSÕES E \\ RECOMENDAÇÕES}

"A c iência está sempre errada. Nunca se resolve um problema sem criar outros dez."

George Bemard Shaw

\section{Sumário detalhado do Capitulo 15}

15.1- Conclusões sobre o Programa de Processamento 164

15.2 - Conclusões sobre os programas de ajustamento 165

15.3 - Conclusões sobre a qualidade dos dados coletados em 1994 _ 166

15.4 - Conclusões sobre o Ajustamento das Estratégias 1 e 2 166

15.5 - Conclusões sobre os Ajustamentos das Estratégias 2 e 3 167

15.6 - Conclusões sobre os ajustamentos das estratégias 2 e 4 168

15.7 - Conclusões sobre os ajustamentos para verificação da influência de vetores maiores que $150 \mathrm{~km}$ processadas em conjunto com vetores menores que $150 \mathrm{~km}$.

15.8 - Conclusões sobre os Ajustamentos das Estratégias 1 e 1.1 169

15.8.1 - Conclusões sobre comparações das coordenadas de CAPA 169 
Baseando-se nos estudos, nos resultados obtidos e nas análises executadas neste trabalho, a presentam-se algumas conclusões para este trabalho:

\section{1- Conclusões sobre o Programa de Processamento}

O programa OMNI v4.0, usado para a realização dos processamentos, apesar de exigir iteração constante com o usuário é um programa excelente, no sentido que permite conhecer as influências dos satélites no processamento dos dados, verificar a qualidade dos sinais dos sa télites, bem como as respec tivas visua liza ções grá fic as;

$\checkmark$ O manual do programa, no entanto, é pobre nas explicações sobre os critérios e valores escolhidos para a realização das etapas dos processamentos a priori e a posterior para a portadora $L 1, L 2$ e a combinação L3;

$\checkmark$ A interface gráfica deste programa, apesar de ser em DOS, é muito agradável.

- Quanto ao programa comercial SKI, da Leica, nos processamentos que foram realizados, verificou-se que é um programa fácil de ser executado e com interface em a mbiente Windows agradável;

$\checkmark$ No entanto, como o programa realiza o processamento em uma única etapa, não foi possível saber quais os critérios intemos utiliza dos.

MQuanto ao programa comercia, PRISMA da Ashtech foi possível constatar que é um programa fácil de ser executado também. Em virtude dos problemas apresentados no item 10.1.1, não foi possível 
comparar os resultados que este programa geraria, com os obtidos pelo OMNI v4.0.

PDe acordo com o exposto no item 10.1.1, seria imprescindível que as empresas, evitassem inc luir ou excluir linhas nos cabeça lhos dos a rquivos de navegação e orbita is gerados por seus receptores, para não eliminar o caráter universal do forma to RINEX.

\section{2 - Conclusões sobre os programas de ajustamento}

- De acordo com o explicado em 12.1, não foi possível utilizar os programas comerciais SKI e PRISMA para ajustamento, sem ter sido realizado o processamento nos mesmos previamente. Isto, porque não havendo instruções disponíveis, não se pôde organizar um a rquivo, em formato texto, com a configuração dos dados de ajustamentos exigidos por esses programas.

O programa STAR NET PLUS não é indicado para ajustar pontos em áreas que ultrapassem $3^{\circ}$ a leste do Meridiano Central ou $3^{\circ}$ a oeste do mesmo.

- O programa COLUMBUS é fácil de ser executado. Requer iteração com o usuário para se obter o melhor resultado de ajustamento. O manual do usuário sugere os valores mínimos e condições que podem ser aceitas para uma resultado ser considerado o melhor;

$\checkmark$ No entanto, a iteração com o programa, para se chegar ao melhor resultado, é extremamente exaustiva: após cada combinação de vetores (explanada no item 11.1) é preciso verificar:

[D] se ela passa nos testes estatístic os do programa, a plicados para $X, Y$ e Z;

verific a r os va lores das elipses de erros;

verific a r os va lores do resíd uos nos va lores dos delta s a justa dos. 


\section{3 - Conclusões sobre a qualidade dos dados coletados em 1994}

Durante os processamentos, observou-se a ocorência de grande número de perdas de ciclos e outliers, o que exigiu a necessidade de inúmeras tentativas de eliminação estas perdas com os critérios do software e até mesmo manualmente, quando os critérios não eram suficiente. Estas correções tomaram esta etapa do processamento exaustiva.

Assim, pode se dizer que os dados coletados em 1994 são de qualidade ruim e comportamento não homogêneo, o que foi verificado pelos diferentes satélites que tiveram que ser exc luídos.

\section{4 - Conclusões sobre o Ajustamento das Estratégias 1 e 2}

A partir da análise das FIGURAS 31 a 42, do CAPÍTULO 14, conclui-se que o processamento das linhas bases com duas horas e trinta minutos é viável, revelando que não havia necessidade de sessões de observação com seis ou oito horas.

As diferenças observadas, da ordem de $1 \mathrm{~m}$ para a altura em alguns pontos e bem menores nas direções $\mathrm{N}$ e E podem ser resultantes de períodos com dados ruins, quando se considerou, no processamento, o período total de observação.

Já, o período de observação de duas horas e trinta minutos foi extraído do período em que se verificou menos ocorrência de perdas de ciclos, do período total, a presentando, portanto, dados com menos perdas de cic lose com comportamento geodésico mais homogêneo. 


\section{5 - Conclusões sobre os Ajustamentos das Estratégias 2 e 3}

A partir da análise das FIGURAS 43 a 54, do CAPÍTULO 14, observou-se que o processamento das linhas bases com valores meteorológicos do default do programa, apresentam diferenças de mais de $1 \mathrm{~m}$ no valor da altura, para a maioria dos pontos analisados, em relação aos obtidos de processamento com valores rea is.

Estes resultados são um forte indicativo que ocorrem diferenças nas coordenadas finais, quando se consideram todos os pontos ou extremidades dos vetores com os mesmos valores de temperatura, pressão e umidade, em relação à quando se aplica o valor real registrado nestes pontos. O que vem de encontro com o exposto por FABRI (1999) e DANA (1999), no item 5.5 deste trabalho.

Assim, partindo-se do princípio que para linhas bases maiores que $20 \mathrm{~km}$, as condições atmosféricas já não são consideradas as mesmas, há necessida de da realiza ção de medidas atmosféric as nas bases, bem como a inserção destes valores nos processa mentos.

Menciona-se, também, que assim como há necessidade da inserção dos valores meteorológicos reais nos processamento, há a necessidade, também, do desenvolvimento de modelos atmosféricos confiáveis para as diversa s regiões do Brasil.

Provavelmente, quando houver a combinação de uso, num processamento futuro, de um modelo atmosférico para o estado de São Paulo, por exemplo, juntamente com dados atmosféric os coletados in loco, os va lores obtidos para as coordena das fina is a justa das serão diferentes dos apresentados. 
Não se pode ignorar as limitações imposta pela atmosfera, à utilização do sistema GPS, quando a mesma não está modelada com parâmetros da região em que se está trabalhando.

\section{6 - Conclusões sobre os ajustamentos das estratégias 2 e 4}

A partir da análise das FIGURAS 55 a 66, do CAPÍTULO 14, observou-se que o processamento das linhas bases com efemérides transmitidas apresentam diferenças por volta de $1,5 \mathrm{~m}$ para a altura para a maioria dos pontos analisados; diferenças de ma is 0,60m na direção $\mathrm{N}$ e E para alguns dos pontos analisados, em relação aos obtidos de processamento com efemérides precisas.

Isto deixa claro que para trabalhos que envolvam linhas bases grandesé imprescindível a utilização de efemérides precisas.

\section{7 - Conclusões sobre os ajustamentos para verificação da influência de vetores maiores que $150 \mathrm{~km}$ processadas em conjunto com vetores menores que $150 \mathrm{~km}$.}

As diferenças encontradas, apresentadas nas TABELAS 68 a 73 e nas FIGURAS 67 a 78, no CAPÍTULO 14, podem evidenciar que a realização de processamento com vetores de comprimentos semelhantes, mas $\leq 150 \mathrm{~km}$, na disposição vetorial a presentada no item 9.5, com valores atmosféricos reais, geram resultados diferentes quando, os mesmos dados GPS são processados em conjunto com vetores de diversos tamanhos, variando de comprimentos entre $80 \mathrm{~km}$ e $390 \mathrm{~km}$ e sem a utilização de valores atmosféric os rea is.

Estes resultados mostram, também, que apesar do caráter da tecnologia GPS independer das distâncias entre as estações observadas (não requer intervisibilidade entre as estações), há necessidade de impor 
limites à estas distâncias, quando não se têm conhec imentos sufic ientes em relação à influência atmosférica, ou ainda, quando ela não está modelada para a região em que se está trabalhando.

\section{8 - Conclusões sobre os Ajustamentos das Estratégias 1 e 1.1}

A partir da análise das FIGURAS 79 a 84, do CAPÍTULO 14, observou-se que o processamento das linhas bases que constituem a rede, com as injunções CAPA e UEPP apresentam diferenças de coordenadas ajustadas por volta de $16 \mathrm{~cm}$ para a altura, para a maioria dos pontos analisados; diferenças de 20 a $70 \mathrm{~cm}$ na direção $E$ e diferenças de 10 a $15 \mathrm{~cm}$ na direção N para alguns dos pontos analisados, em relação aos obtidos de com as injunções CAPA e CHUA. Estas diferenças não são grandes, mas ocorrem.

Ainda, na tentativa de encontrar maiores explicações, se realizou as comparações das coordenadas das injunções utilizadas neste trabalho, e apresentadasa seguir.

\subsection{1 - Conclusões sobre comparações das coordenadas de CAPA}

As coordenadas de CAPA, obtidas de SIRGAS, diferem das do IBGE, SEGANTINE e FONSECA J r., da ordem de aproximadamente $60 \mathrm{~cm}$, na direção E e da ordem de aproximadamente, 24cm na direção N. Já, em relação à altura, as diferenças são de aproximadamente $10 \mathrm{~cm}$.

As coordenadas de UEPP, por sua vez, obtidas de SIRGAS, diferem das do IBGE, SEGANTINE e FONSECA J r., da ordem de aproximadamente $60 \mathrm{~cm}$, na direção $\mathrm{E}$ e da ordem de aproximadamente $20 \mathrm{~cm}$ na direção $\mathrm{N}$. Já, em relação à altura, as diferenças são de a proximadamente $9 \mathrm{~cm}$. 
Assim, CAPA e UEPP, obtidas de SIRGAS, apresentando diferenças semelhantes nas direções Ne E e na altura, em relação ao IBG E, verificou-se, se estas diferenças se mantinham em outros pontos. Através de comparações realizadas pelas FIGURAS 79 a 84 e pelas TABELAS 75 a 78, encontrou-se resposta positiva. No entanto, quando da mesma verificação para o vértice CHUA, em relação a o $\mathrm{IBGE}$, observou-se que este difere de $45 \mathrm{~cm}$ na direção $\mathrm{E}, 40 \mathrm{~cm}$ na direção $\mathrm{N}$ e $130 \mathrm{~cm}$ na altura. O que chamou atenção.

Da estratégia 1, com CHUA e CAPA como injunção, comparou-se as coordenadas obtidas para UEPP com as do IBGE e de SIRGAS, como ilustra do nas FIGURAS 87 e 88. As coordenadas de UEPP diferem, em relação ao IBGE de $23 \mathrm{~cm}$ na direção $\mathrm{E}, 48 \mathrm{~cm}$ na direção $\mathrm{N}$ e na altura $180 \mathrm{~cm}$. Em relação à SIRGAS, as diferenças são de $87 \mathrm{~cm}$ na direção $E, 4 c m$ na direção $\mathrm{N}$ e na altura $170 \mathrm{~cm}$.

Diante deste fato, pode-se concluir que as coordenadas do vértice CHUA precisam ser revistas.

Esta a firma ção vem em concordância com os relatos de SEG ANTINE (1995) e FONSECA J r. (1996). SEGANTINE, em seu trabalho, realizou inic ia Imente, o ajustamento considerando como fixos os pontos CHUA, USPP e UEPP, mas só chegou à valores de coordenadas para os demais pontos próximos aos divulgados pelo IBGE, quando ajustou a rede considerando apenas CHUA como ponto fixo. Relata ainda, a necessidade de verific ação das coordenadas do ponto USPP. FONSECA J r. por sua vez, cita que a realizou ajustamentos da rede considerando várias estações como fixas, mas apresenta como melhor resultado, o ajustamento com apenas CHUA fixo, que resultou nas coordenadas mais próximas do IBGE. Relata também a necessidade da verific ação das coordenadas do vértice CHUA, uma vez que encontrou diferenças entre as coordenadas oficiais do IBGE, deste vértice e as obtidas atra vés de testes que realizou, de 1044,53mm.

Diante das análises apresentadas, pode-se concluir que as coordenadas dos pontos da rede, estabelecidas pelo IBGE, a partir dos dados coletados nas campanhas rea liza das em 1994, a presenta problemas. Dos ajustamentos de redes realizados, esperava-se que independente do 
ponto que fosse considerado como fixo, desde que escolhido de estações oficiais, se encontrasse para os demais pontos (não fixos), coordenadas bem próximas. O que não ocorreu, não só neste trabalho, mas nos trabalhos de SEG ANTINE (1995) e FONSECA J r. (1996).

Assim, este trabalho, toma também, clara a necessidade de reocupação dos pontos da rede GPS do Estado de São Paulo. E esta necessidade é urgente, uma vez que as coordenadas do IBGE, sendo que as oficiais são as utilizadas por empresas e profissiona is autônomos, nos diversos tipos de trabalhos existentes na área de Geodésia, E ainda, sendo pequeno o número de pessoas atuantes na área, que realmente têm condições de desconfiar e questionar os resultados obtidos, acaba por geraruma propagação de emros e resultados de trabalhos distantes do real.

\section{9 - Recomendações}

Baseando-se nos conhecimentos e experiência adquirida na execução deste trabalho, a presenta-se, a seguir, a lgumas recomendações que podem serúteis em futuros projetos de pesquisa.

$\because$ Aprofundar pesquisas, no Brasil, dos efeitos atmosféricos sobre as observaçõescom GPS;

Desenvolver pesquisas com a objetivo de elaborar um modelo atmosférico para o Brasil, ou até mesmo para o Estado de São Paulo;

Na implantação de redes geodésicas:

deteminar pontos com distâncias entre si, que não ultrapassem, pelo menos $200 \mathrm{~km}$, devido às limitações impostas pela atmosfera e ao fato de não haver modelos atmosféricos desenvolvidos espec ia Imente para as regiões do Brasil;

coletardados atmosféric os dos pontos no dia da observação;

[L] escolher como pontos de injunção, estações que façam parte de projetos oficiais; 
elaborar sessões de observações entre os pontos adjacentes mais próximos, evitando, assim, vetores longos, e por outro lado, obter uma rede homogênea do ponto de vista geométrico;

$\checkmark \quad$ Utiliza r efemérides precisas do IGS. Estas envolvem da dos de estações de monitoramento no teritório brasileiro, permitindo calcular com maior prec isão as órbitas dos sa télites quando passam sobre o Brasil;

$\checkmark$ Antes de planejar e realizar observações com GPS, em linhas bases longas, verific ar o comportamento das atividades solares e previsões de explosões solares, o que pode serfeito, hoje, através da Intemet;

$\checkmark$ Realizar uma nova campanha de observação da rede GPS do Estado de São Paulo, sob a constelação atual de satélites, que tem maior número de satélites em relação à 1994;

$\checkmark$ Estabelecer pontos ma is próximos do vértice CHUA, para evitar as a tua is linhas bases de comprimentos da ordem de $230 \mathrm{~km}$ (CHUA - AVER), de $235 \mathrm{~km}$ (CHUA - LIMO), de 250km (C HUA - PIRA), de 173km (CHUA - SJ RP), etc;

$\checkmark$ Estabelecer mais um ponto na interseção do qua drilátero forma do pelas estações de ILHA, MARI, IBITE PANO, para ta mbém diminuir as distâncias dos vetores de observação entre as estações ILHA - MARI, de 253km; ILHA - IBIT, de 293km e PANO - MARI, de 218km;

$\checkmark$ Realizar campanhas para verificações das coordenadas do vértice CHUA;

$\checkmark$ Considerar como injunções, em próximos ajustamentos da rede GPS do estado de São Paulo, as estações de Cachoeira Paulista e Presidente Prudente, que fazem parte da rede SIRGAS;

$\checkmark$ Realizar coleta dos dados meteorológicos e incluí-los nos processamentos. 


\section{ANEXO A}

Transformação de Coordenadas ITRF94 para ITRF92

$X, Y, e Z$ săo as coordenadas em ITRF94,

$X S, Y S$ e ZS săo as coordenadas em outro sistema,

Coordenadas de Cachoeira Paulista no ITRF94, de acordo com o IBGE - SIRGAS:

Coordenadas em m:

$$
\begin{aligned}
& X:=4164684.609 \cdot 100 \\
& Y:=-4162401.036 \cdot 100 \\
& Z:=-2445011.067 \cdot 100
\end{aligned}
$$

$$
\begin{array}{lll}
\mathrm{Tl}:=0.8 & \mathrm{~T} 2:=0.2 & \mathrm{~T} 3:=-0.8 \\
\mathrm{R} 1:=0 & \mathrm{R} 2:=0 & \mathrm{R} 3:=0 \\
\mathrm{D}:=-0.08 \cdot 10^{-8} & &
\end{array}
$$

Coordenadas em cm:

$$
\begin{aligned}
& X=416468460.9 \\
& Y=-416240103.6 \\
& Z=-244501106.7
\end{aligned}
$$

$$
M:=\left[\begin{array}{ccc}
D & -R 3 & R 2 \\
R 3 & D & -R 1 \\
-R 2 & R 1 & D
\end{array}\right]
$$

ITRF92 $:=$ ITRF94 $+\mathrm{T}+\mathrm{M} \cdot \mathrm{ITRF} 94$ ITRF92 $=\left[\begin{array}{c}416468461.366825 \\ -416240103.067008 \\ -244501107.304399\end{array}\right] \mathrm{cm} \quad$ FITRF92 :=ITRF92.10 $0^{-2}$

$$
\text { Coordenadas de CAPA - ITRF92: FITRF92 }=\left[\begin{array}{c}
4164684.614 \\
-4162401.031 \\
-2445011.073
\end{array}\right] \mathrm{m}
$$

\section{Diferenças entre :}

$$
M=\left[\begin{array}{ccc}
-8 \cdot 10^{-10} & 0 & 0 \\
0 & -8 \cdot 10^{-10} & 0 \\
0 & 0 & -8 \cdot 10^{-10}
\end{array}\right]
$$

$$
\text { ITRF94 }- \text { ITRF92 }=\left[\begin{array}{c}
-0.467 \\
-0.533 \\
0.604
\end{array}\right] \mathrm{cm}
$$




\section{Transformação de Coordenadas ITRF94 para ITRF92}

$\mathrm{X}, \mathrm{Y}, \mathrm{e} Z$ são as coordenadas em ITRF94, $X S, Y S$ e ZS são as coordenadas em outro sistema,

Coordenadas de Presidente Prudente no ITRF94, de acordo com o IBGE - SIRGAS

Coordenadas em m:

$X:=3687624.310 \cdot 100$

$\mathrm{Y}:=-4620818.571 \cdot 100$

$Z:=-2386880.407 \cdot 100$
Coordenadas em cm:

$$
\begin{aligned}
& X=368762431 \\
& Y=-462081857.1 \\
& Z=-238688040.7
\end{aligned}
$$

$$
\begin{array}{rlr}
\text { T1 }:=0.8 & \mathrm{~T} 2:=0.2 & \mathrm{~T} 3:=-0.8 \\
\mathrm{R} 1:=0 & \mathrm{R} 2:=0 & \mathrm{R} 3:=0
\end{array}
$$

$$
\text { ITRF94: }:=\left[\begin{array}{l}
X \\
Y \\
Z
\end{array}\right]
$$

$$
\mathrm{T}:=\left[\begin{array}{c}
\mathrm{T} 1 \\
\mathrm{~T} 2 \\
\mathrm{~T} 3
\end{array}\right]
$$$$
M:=\left[\begin{array}{ccc}
D & -R 3 & R 2 \\
R 3 & D & -R 1 \\
-R 2 & R 1 & D
\end{array}\right]
$$

ITRF94 $=\left[\begin{array}{c}368762431 \\ -462081857.1 \\ -238688040.7\end{array}\right] \quad T=\left[\begin{array}{c}0.8 \\ 0.2 \\ -0.8\end{array}\right]$

ITRF92 :=ITRF94 + T + M-ITRF94

$$
M=\left[\begin{array}{ccc}
-8 \cdot 10^{-10} & 0 & 0 \\
0 & -8 \cdot 10^{-10} & 0 \\
0 & 0 & -8 \cdot 10^{-10}
\end{array}\right]
$$

ITRF92 $=\left[\begin{array}{c}368762431.50499 \\ -462081856.530335 \\ -238688041.30905\end{array}\right] \mathrm{cm} \quad$ FITRF92 $:=$ ITRF92 $\cdot 10^{-2}$

Coordenadas de UEPP- ITRF92: FITRF92 $=\left[\begin{array}{c}3687624.315 \\ -4620818.565 \\ -2386880.413\end{array}\right] \mathrm{m}$

\section{Diferenças entre :}




\section{ANEXO B}

A seguir encontram-se as TABELAS de dados meteorológicos fomecidos pelo INMETe pelo IAC, utilizados para processamentos dos dados GPS no programa OMNI V4.0.

TABEA 82 - Da dos Meteorológic os dos pontos observa dos no DOY 069

\begin{tabular}{ccccc}
\hline \hline Ponto & Nome & \multicolumn{3}{c}{ DOY 069- 10/ 03/ 1994 } \\
\hline \hline obsenvado & abreviado & $\begin{array}{c}\text { Temperatura. } \\
\text { Média Diária } \\
\text { ('C) }\end{array}$ & $\begin{array}{c}\text { Umidade } \\
\text { Média Mensal } \\
\text { (\%) }\end{array}$ & $\begin{array}{c}\text { Pressão } \\
\text { Média Mensal } \\
\text { (mb) }\end{array}$ \\
\hline 15 & USPP & 22,9 & 78 & 924,4 \\
05 & PIRA & 26,2 & 50 & 941,9 \\
16 & BELA & 25,0 & 50 & 1006,0 \\
17 & BUNA & 25,0 & 50 & 929,3 \\
18 & VAL & 24,8 & 50 & 913,5 \\
\hline \hline
\end{tabular}

TABEA 83- Dados Meteorológic os dos pontos observados no DOY 070

\begin{tabular}{ccccc}
\hline \hline \multirow{2}{*}{$\begin{array}{c}\text { Ponto } \\
\text { Obsenvado }\end{array}$} & Nome & \multicolumn{2}{c}{ DOY 070- 11/03/ 1994 } \\
\cline { 3 - 5 } & abreviado & $\begin{array}{c}\text { Temperatura. } \\
\text { Média Diária } \\
\text { (C) }\end{array}$ & $\begin{array}{c}\text { Umidade } \\
\text { Média Mensal } \\
\text { (\%) }\end{array}$ & $\begin{array}{c}\text { Média Messão } \\
\text { (mb) }\end{array}$ \\
\hline 015 & USPP & 22,2 & 78,0 & 924,4 \\
05 & PIRA & 25,4 & 50,0 & 941,9 \\
06 & UMO & 25,4 & 50,0 & 944,4 \\
07 & FRCA & 23,3 & 50,0 & 899,1 \\
16 & BELA & 25,0 & 50,0 & 1006,0 \\
17 & BUNA & 25,0 & 50,0 & 929,3 \\
18 & VALI & 23,6 & 50,0 & 913,5 \\
\hline \hline
\end{tabular}

TABEAA 84 - Dados Meteorológic os dos pontos observa dos no DOY 071

\begin{tabular}{|c|c|c|c|c|}
\hline \multicolumn{5}{|c|}{ DOY 071 - 12/03/ 1994} \\
\hline \multirow{2}{*}{$\begin{array}{c}\text { Ponto } \\
\text { obsenvado }\end{array}$} & \multirow{2}{*}{$\begin{array}{c}\text { Nome } \\
\text { abreviado }\end{array}$} & \multicolumn{3}{|c|}{ Dados Meteorológicos } \\
\hline & & $\begin{array}{l}\text { Temperatura. } \\
\text { Média Diánia } \\
\left({ }^{\circ} \mathrm{C}\right)\end{array}$ & $\begin{array}{c}\text { Umidade } \\
\text { Média Mensal } \\
\text { (\%) }\end{array}$ & $\begin{array}{c}\text { Pressão } \\
\text { Média Mensal } \\
\text { (mb) }\end{array}$ \\
\hline 05 & PIRA & 23,9 & 50 & 941,9 \\
\hline 06 & பMO & 24,1 & 50 & 944,4 \\
\hline 07 & FRCA & 23,6 & 50 & 899,1 \\
\hline
\end{tabular}


TABEA 85 - Dados Meteorológic os dos pontos observa dos no DOY 072

\begin{tabular}{|c|c|c|c|c|}
\hline \multicolumn{5}{|c|}{ DOY 072 - 13/ 03/ 1994} \\
\hline \multirow{2}{*}{$\begin{array}{c}\text { Ponto } \\
\text { Observados }\end{array}$} & \multirow{2}{*}{$\begin{array}{c}\text { Nome } \\
\text { abreviado }\end{array}$} & \multicolumn{3}{|c|}{ Dados Meteorológicos } \\
\hline & & $\begin{array}{l}\text { Temperatura. } \\
\text { Média Diária } \\
\left.\text { ( }{ }^{\circ} \mathrm{C}\right)\end{array}$ & $\begin{array}{c}\text { Umidade } \\
\text { Média Mensal } \\
(\%)\end{array}$ & $\begin{array}{c}\text { Pressão } \\
\text { Média Mensal } \\
\text { (mb) }\end{array}$ \\
\hline 01 & CHUA & 25,3 & 82 & 925,0 \\
\hline 02 & AVER & 25,0 & 50 & 966,2 \\
\hline 03 & SJ RP & 28,5 & 50 & 951,3 \\
\hline 04 & $\mathrm{JABO}$ & 23,3 & 50 & 941,4 \\
\hline 05 & PIRA & 24,0 & 50 & 941,9 \\
\hline 06 & பMO & 24,1 & 50 & 944,4 \\
\hline 07 & FRCA & 23,7 & 50 & 899,1 \\
\hline
\end{tabular}

TABEA 86- Da dos Meteorológic os dos pontos observados no DOY 073

\begin{tabular}{ccccc}
\hline \hline \multicolumn{5}{c}{ DOY 076- 14/03/1994 } \\
\hline \hline Ponto & Nome & \multicolumn{3}{c}{ Dados Meteorológic os } \\
\cline { 3 - 5 } & & $\begin{array}{c}\text { Temperatura. } \\
\text { Média Diána } \\
\text { ( } \mathbf{C} \text { ) }\end{array}$ & $\begin{array}{c}\text { Umidade } \\
\text { Média Mensal } \\
\text { (\%) }\end{array}$ & $\begin{array}{c}\text { Pressão } \\
\text { Média Mensal } \\
\text { (mb) }\end{array}$ \\
\hline 01 & CHUA & 26,3 & 82 & 925,0 \\
02 & AVER & 25,0 & 50 & 966,2 \\
03 & SJ RP & 27,0 & 50 & 951,3 \\
04 & JABO & 23,2 & 50 & 941,4 \\
\hline \hline
\end{tabular}

TABEAA 87 - Dados Meteorológic os dos pontos observa dos no DOY 074

\begin{tabular}{|c|c|c|c|c|}
\hline \multicolumn{5}{|c|}{ DOY 074 - 15/03/ 1994} \\
\hline \multirow{2}{*}{$\begin{array}{c}\text { Ponto } \\
\text { Obsenvado }\end{array}$} & \multirow{2}{*}{$\begin{array}{c}\text { Nome } \\
\text { abreviado }\end{array}$} & \multicolumn{3}{|c|}{ Dados Meteorológicos } \\
\hline & & $\begin{array}{l}\text { Temperatura. } \\
\text { Média Diária } \\
\text { (ํ) }\end{array}$ & $\begin{array}{c}\text { Umidade } \\
\text { Média Mensal } \\
\text { (\%) }\end{array}$ & $\begin{array}{c}\text { Pressão } \\
\text { Média Mensal } \\
\text { (mb) }\end{array}$ \\
\hline 01 & CHUA & 26,0 & 82 & 925,0 \\
\hline 02 & AVER & 25,0 & 50 & 966,2 \\
\hline 03 & SJ RP & 27,5 & 50 & 951,3 \\
\hline 04 & $\mathrm{~J} A B O$ & 24,3 & 50 & 941,4 \\
\hline 08 & FERN & 25,0 & 50 & 961,9 \\
\hline 09 & AVAN & 27,5 & 50 & 971,4 \\
\hline 10 & IBIT & 25,0 & 50 & 964,6 \\
\hline
\end{tabular}


TABEA 88 - Dados Meteorológic os dos pontos observa dos no DOY 075

\begin{tabular}{ccccc}
\hline \hline \multicolumn{5}{c}{ DOY 075 - 16/03/1994 } \\
\hline \hline Ponto & Nome & \multicolumn{3}{c}{ Dados Meteorológicos } \\
\cline { 3 - 5 } Obsenvado & Abrevido & $\begin{array}{c}\text { Temperatura. } \\
\text { Média Diánia } \\
\text { ( } \mathbf{C})\end{array}$ & $\begin{array}{c}\text { Umidade } \\
\text { Média Mensal } \\
(\%)\end{array}$ & $\begin{array}{c}\text { Pressão } \\
\text { Média Mensal } \\
\text { (mb) }\end{array}$ \\
\hline 08 & FERN & 25,0 & 50 & 961,9 \\
09 & AVAN & 27,5 & 70 & 971,4 \\
10 & IBIT & 25,0 & 50,0 & 964,6 \\
\hline \hline
\end{tabular}

TABEA 89 - Dados Meteorológic os dos pontos observa dos no DOY 076

\begin{tabular}{ccccc}
\hline \hline Ponto & \multicolumn{4}{c}{ DOY 076- 17/ 03/ 1994 } \\
\hline Obsenvdo & Nome & \multicolumn{3}{c}{ Dados Meteorológicos } \\
\cline { 3 - 5 } & Abreviado & $\begin{array}{c}\text { Temperatura. } \\
\text { Média Diánia } \\
\text { ('C) }\end{array}$ & $\begin{array}{c}\text { Umidade } \\
\text { Média Mensal } \\
\text { (\%) }\end{array}$ & $\begin{array}{c}\text { Pressão } \\
\text { Média Mensal } \\
\text { (mb) }\end{array}$ \\
\hline 11 & & 26,4 & 71 & 962,1 \\
08 & UEPP & 25,0 & 50 & 961,9 \\
09 & FERN & 27,7 & 50 & 971,4 \\
10 & AVAN & 25 & 50 & 964,6 \\
12 & IBIT & 25 & 50 & 972,0 \\
13 & TAQU & 25 & 50 & 967,0 \\
14 & SAGR & 25 & 50 & 971,0 \\
\hline \hline
\end{tabular}

TABEA 90 - Dados Meteorológic os dos pontos observa dos no DOY 327

\begin{tabular}{ccccc}
\hline \hline \multicolumn{1}{c}{ Ponto } & Nome & \multicolumn{3}{c}{ DOY 327 - 23/11/ 1994 } \\
\hline \hline Obsenvado & Abreviado & $\begin{array}{c}\text { Temperatura. } \\
\text { Média Diánia } \\
\left({ }^{\circ} \mathbf{C}\right)\end{array}$ & $\begin{array}{c}\text { Umidade } \\
\text { Média Mensal } \\
\text { (\%) }\end{array}$ & $\begin{array}{c}\text { Pressão } \\
\text { Média Mensal } \\
\text { (mb) }\end{array}$ \\
\hline 18 & VALI & 20,7 & 50 & 913,5 \\
16 & BELA & 25 & 50 & 1006,0 \\
17 & BUNA & 25 & 50 & 929,3 \\
19 & CAPA & 25 & 50 & 940,2 \\
\hline \hline
\end{tabular}


TABEA 91 - Dados Meteorológic os dos pontos observa dos no DOY 328

\begin{tabular}{ccccc}
\hline \hline & \multicolumn{4}{c}{ DOY 328 - 24/11/ 1994 } \\
\hline \hline Ponto & Nome & \multicolumn{3}{c}{ Dados Meteorológic os } \\
\cline { 3 - 5 } Obsenvado & abreviatura & $\begin{array}{c}\text { Temperatura. } \\
\text { Média Diária } \\
\left(\mathbf{\circ}^{\circ} \mathbf{C}\right)\end{array}$ & $\begin{array}{c}\text { Umidade } \\
\text { Média Mensal } \\
(\%)\end{array}$ & $\begin{array}{c}\text { Pressão } \\
\text { Média Mensal } \\
\text { (mb) }\end{array}$ \\
\hline 15 & USPP & 18,1 & 72 & 924,4 \\
18 & VALI & 21,2 & 70 & 913,5 \\
19 & CAPA & 25,0 & 50 & 940,2 \\
20 & REGI & 21,5 & 50 & 1007,5 \\
\hline \hline
\end{tabular}

TABEAA 92 - Dados Meteorológic os dos pontos observa dos no DOY 329

\begin{tabular}{|c|c|c|c|c|}
\hline \multicolumn{5}{|c|}{ DOY 329 - 25/11/ 1994} \\
\hline \multirow{2}{*}{$\begin{array}{c}\text { Ponto } \\
\text { Obsenvado }\end{array}$} & \multirow{2}{*}{$\begin{array}{c}\text { Nome } \\
\text { abreviado }\end{array}$} & \multicolumn{3}{|c|}{ Dados Meteorológicos } \\
\hline & & $\begin{array}{l}\text { Temperatura. } \\
\text { Média Diária } \\
\text { ('C) }\end{array}$ & $\begin{array}{c}\text { Umidade } \\
\text { Média Mensal } \\
\text { (\%) }\end{array}$ & $\begin{array}{c}\text { Pressão } \\
\text { Média Mensal } \\
\text { (mb) }\end{array}$ \\
\hline 21 & ITAP & 23,0 & 50 & 925,9 \\
\hline 18 & VALI & 25,0 & 50 & 913,5 \\
\hline 20 & REG I & 23,8 & 50 & 1007,5 \\
\hline 22 & IEVA & 22,5 & 50 & 930,7 \\
\hline
\end{tabular}

TABEA 93 - Dados Meteorológic os dos pontos observa dos no DOY 332

\begin{tabular}{|c|c|c|c|c|}
\hline \multicolumn{5}{|c|}{ DOY 332 - 28/ 11/ 1994} \\
\hline \multirow{2}{*}{$\begin{array}{c}\text { Ponto } \\
\text { Obsenado }\end{array}$} & \multirow{2}{*}{$\begin{array}{c}\text { Nome } \\
\text { abreviado }\end{array}$} & \multicolumn{3}{|c|}{ Dados Meteorológicos } \\
\hline & & $\begin{array}{l}\text { Temperatura. } \\
\text { Média Diária } \\
\left.\text { ( }{ }^{\circ} \mathrm{C}\right)\end{array}$ & $\begin{array}{c}\text { Umidade } \\
\text { Média Mensal } \\
(\%)\end{array}$ & $\begin{array}{c}\text { Pressão } \\
\text { Média Mensal } \\
\text { (mb) }\end{array}$ \\
\hline 11 & UEPP & 25,4 & 59 & 962,1 \\
\hline 13 & SAGR & 25,0 & 50 & 967,0 \\
\hline 21 & ITAP & 23,0 & 50 & 925,9 \\
\hline 22 & IEVA & 23,5 & 50 & 930,7 \\
\hline 23 & BOTU & 21,2 & 50 & 925,6 \\
\hline
\end{tabular}


TABEA 94 - Dados Meteorológic os dos pontos observa dos no DOY 333

\begin{tabular}{ccccc}
\hline \hline & & DOY 333- 29/ 11/1994 \\
\hline \hline Ponto & Nome & \multicolumn{3}{c}{ Dados Meteorológicos } \\
\cline { 3 - 5 } Obsenvado & abreviado & $\begin{array}{c}\text { Temperatura. } \\
\text { Média Diária } \\
\left({ }^{\circ} \mathbf{C}\right)\end{array}$ & $\begin{array}{c}\text { Umidade } \\
\text { Média Mensal } \\
(\text { \%) }\end{array}$ & $\begin{array}{c}\text { Pressão } \\
\text { Média Mensal } \\
\text { (mb) }\end{array}$ \\
\hline 11 & UEPP & 21,8 & 59 & 962,1 \\
10 & IBIT & 25,0 & 50 & 964,6 \\
13 & SAGR & 25 & 50 & 967,0 \\
23 & BOTU & 22,6 & 50 & 925,6 \\
24 & MARI & 22,5 & 50 & 938,1 \\
\hline \hline
\end{tabular}

TABEA 95 - Dados Meteorológic os dos pontos observa dos no DOY 334

\begin{tabular}{ccccc}
\hline \hline \multicolumn{5}{c}{ DOY 334 - 30/ 11/1994 } \\
\hline \hline Ponto & Nome & \multicolumn{3}{c}{ Dados Meteorológicos } \\
\cline { 3 - 5 } Obsenvados & Obsenvado & $\begin{array}{c}\text { Temperatura. } \\
\text { Média Diánia } \\
\text { (०C) }\end{array}$ & $\begin{array}{c}\text { Umidade } \\
\text { Média Mensal } \\
(\%)\end{array}$ & $\begin{array}{c}\text { Pressão } \\
\text { Média Mensal } \\
\text { (mb) }\end{array}$ \\
\hline 14 & ILHA & 25,1 & 50 & 971,0 \\
25 & PANO & 25 & 50 & $973,$. \\
\hline \hline
\end{tabular}

TABEAA 96 - Dados Meteorológic os dos pontos observa dos no DOY 335

\begin{tabular}{|c|c|c|c|c|}
\hline \multicolumn{5}{|c|}{ DOY 335 - 01/ 12/ 1994} \\
\hline \multirow{2}{*}{$\begin{array}{c}\text { Ponto } \\
\text { Obsenvado }\end{array}$} & \multirow{2}{*}{$\begin{array}{c}\text { Nome } \\
\text { Abreviado }\end{array}$} & \multicolumn{3}{|c|}{ Dados Meteorológicos } \\
\hline & & $\begin{array}{l}\text { Temperatura. } \\
\text { Média Diária } \\
\text { (०C) }\end{array}$ & $\begin{array}{c}\text { Umidade } \\
\text { Média Mensal } \\
\text { (\%) }\end{array}$ & $\begin{array}{c}\text { Pressão } \\
\text { Média Mensal } \\
\text { (mb) }\end{array}$ \\
\hline 11 & UEPP & 24,5 & 59 & 960,9 \\
\hline 12 & TAQU & 25,0 & 50 & 972 \\
\hline 13 & SAGR & 25,0 & 50 & 967 \\
\hline 24 & MARI & 23,0 & 50 & 938,1 \\
\hline 25 & PANO & 25,0 & 50 & 973,3 \\
\hline
\end{tabular}




\section{ANEXO C}

Há dois tipos de informações orbitais distintas, as efemérides transmitidas (pré determinadas) e as efemérides precisas, pós processadas (SEEBER, 1993).

\section{1 - Efemérides Transmitidas}

As efemérides transmitidas são sinais na forma de mensagem de navegação. São geradas pelo processo de integração orbital baseado em observações de 4 estações do OPNET35: Maine, Minnesota, Califómia, Hawaii. O cálculo é feito diariamente, duas vezes baseado em 36 horas de observação. Os dados orbita is são extrapolados para 36 horas e são carregados na memória do satélite pelas estações de controle terrestres (SEEBER, 1993).

NA FIG URA 91 está ilustra do um exemplo de parte de um arquivo de efemérides transmitidas.

\begin{tabular}{|c|c|c|c|c|c|c|c|}
\hline & & NAVIGATI & ON D & ATA & & RINEX & K VERSION / TYPE \\
\hline & & CIG & SNET & INFO CNTR & $98 / 11 / 20$ & $8: 51$ & PGM / RUN BY / DATE \\
\hline & $.1118 D-07$ & $.7451 D$ & $-\odot 8$ & $-.5960 \mathrm{D}-07$ & $-.5960 \mathrm{D}-07$ & & ION ALPHA \\
\hline & $.9011 \mathrm{D}+05$ & $.000 \odot \mathrm{D}$ & $+\odot \odot$ & $-.1966 D+06$ & $-.6554 D+05$ & & ION BETA \\
\hline & $\begin{array}{l}-.1862645149 \\
9\end{array}$ & $23 D-\odot 8$ & -.20 & $4281036531 D-13$ & $3 \quad 32768$ & -27 & $\begin{array}{l}\text { DELTA-UTC: } A \Theta, A 1, T, W \\
\text { LEAP SECONDS } \\
\text { END OF HEADER }\end{array}$ \\
\hline & $\begin{array}{lll}3 & 11 & 12\end{array}$ & .0 & & 7998๑371892D-๑4 & .1364242 & $1205266 \mathrm{D}-11$ & $.0 \odot \odot \odot \odot \odot \odot \odot \odot \odot \odot \odot D+\odot \odot$ \\
\hline & .1500000000 & $\odot \odot D+\odot 3$ & -.55 & 54375000 & .425803 & $3450710 D-08$ & -.189767 \\
\hline & -.2916902303 & $371 D-05$ & & 1349 & & $72 D-\odot 4$ & \\
\hline & $.4752000 \odot \odot \odot$ & $\odot \odot D+\odot 6$ & & $359730 s$ & .2 & $207 D+01$ & $D-07$ \\
\hline & .9608398326 & $67 D+00$ & & $59625000000 \mathrm{D}+03$ & $.141607 \varepsilon$ & $3875 D+01$ & -.78521 \\
\hline & -.5475228065 & $524 D-09$ & & 0000000 & .739 & $\odot \odot \odot \odot D+\odot 3$ & .00006 \\
\hline & .4000000000 & $00 D+01$ & .00 & 0000000 & .37 & $9846 D-08$ & 03 \\
\hline & .4748 & $00 D+06$ & & & & & \\
\hline & 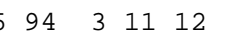 & .0 & .29 & $99797393382 D-\odot 4$ & .2046363 & $307899 D-11$ & $. \odot \odot \odot \odot \odot \odot \odot \odot \odot \odot \odot \odot \odot D+\odot \odot$ \\
\hline & .6600000000 & $0 \odot D+\odot 2$ & -.53 & $\odot \odot \odot \odot \odot D+\odot 2$ & & & \\
\hline & -.2961605787 & $729 D-05$ & & $25 D-02$ & .1165270 & $30536 D-04$ & .51 \\
\hline & $.4752000 \odot \odot \odot$ & $\odot \odot D+\odot 6$ & & 45058059695D-๑8 & .2753794 & $417484 D+01$ & -.46566128 \\
\hline & .9572782752 & $217 D+\odot \odot$ & & $\odot \odot \odot D+\odot 3$ & -.2314277 & $731122 D+01$ & -.79 \\
\hline & -.5243075538 & & & & .7390 & $000000 D+03$ & .00 \\
\hline & $.32000000 \odot \odot$ & $\odot \odot D+\odot 2$ & & 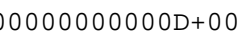 & .1396983 & $386192 D-08$ & $.660 \odot \odot \odot \odot \odot \odot \odot \odot \odot ०+\odot 2$ \\
\hline & & & & & & & \\
\hline
\end{tabular}

FIG URA 91 - Parte de um arquivo de efemérides transmitidas

\section{2 - Efemérides Precisas}

35 OPNET: Operational Network 
As órbitas precisas oficias dos satélites são produzidas pelo NSWC ${ }^{36} \mathrm{e}$ pela NIMA $^{37}$ e são baseadas nas observações de dados de diversas estações de controle terrestres. Atualmente, as efemérides precisas são calculadas por diversas instituições e estão disponíveis para os usuários atra vés da Intemet.

As efemérides precisas utilizadas neste trabalho foram obtidas junto ao IGS no formato chamado de SP3 e os programas para transformá-las para o formato SP1, bem como as instruções foram obtidos nos seguintes endereços eletrônicos, respec tiva mente: ftp://www.ngs.noaa.gov/cors/ utilities/Dos/ http://www.ngs.noaa.gov/GPS/Utilities/utility.doc.

No IGS, os dados de efemérides podem ser obtidas através do endereço ftp://igscb.jpl.nasa.gov/igscb/product. No NGS, podem ser obtidos a tra vés do endereço eletrônico ftp://www.ngs.noaa.gov/cors/dist.

São apresentados a seguir, partes de arquivos de diversos tipos de formatos de efemérides precisas.

\section{Formato SP1}

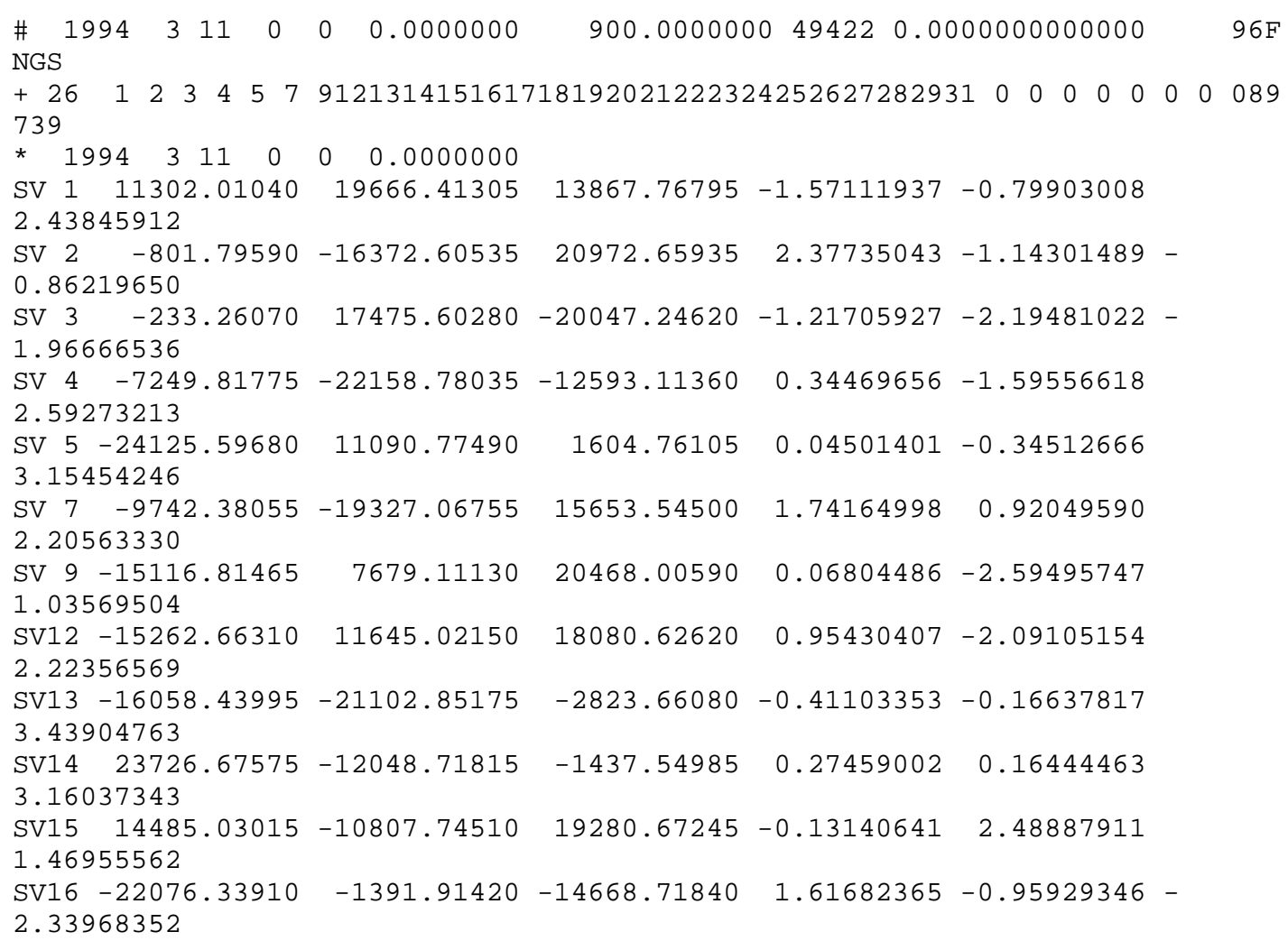

${ }^{36}$ NSWC: Naval Surface Warfare Center

37 NIMA: National Imagery and Mapping Agency 


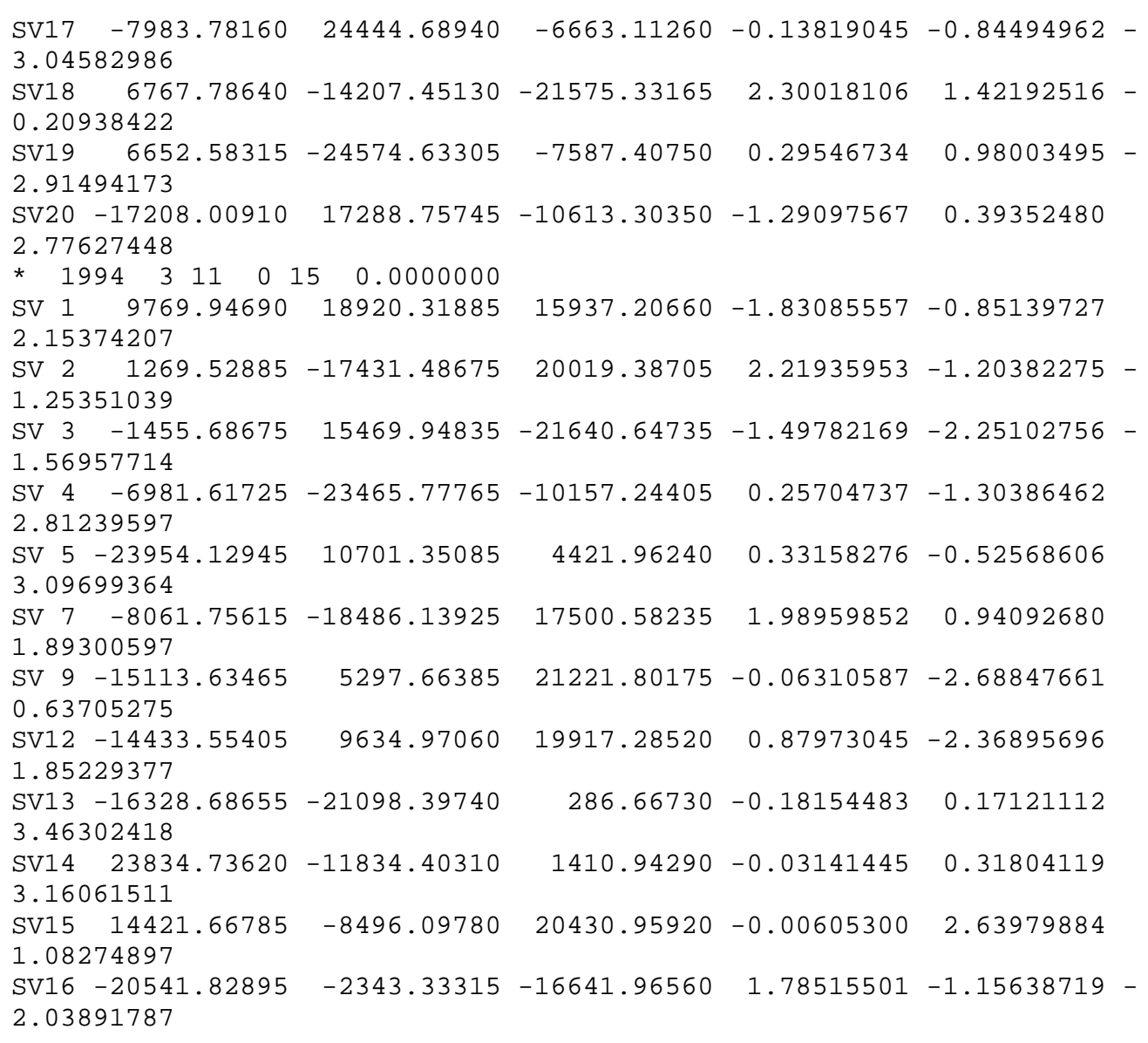

\section{Formato SP3 'P}

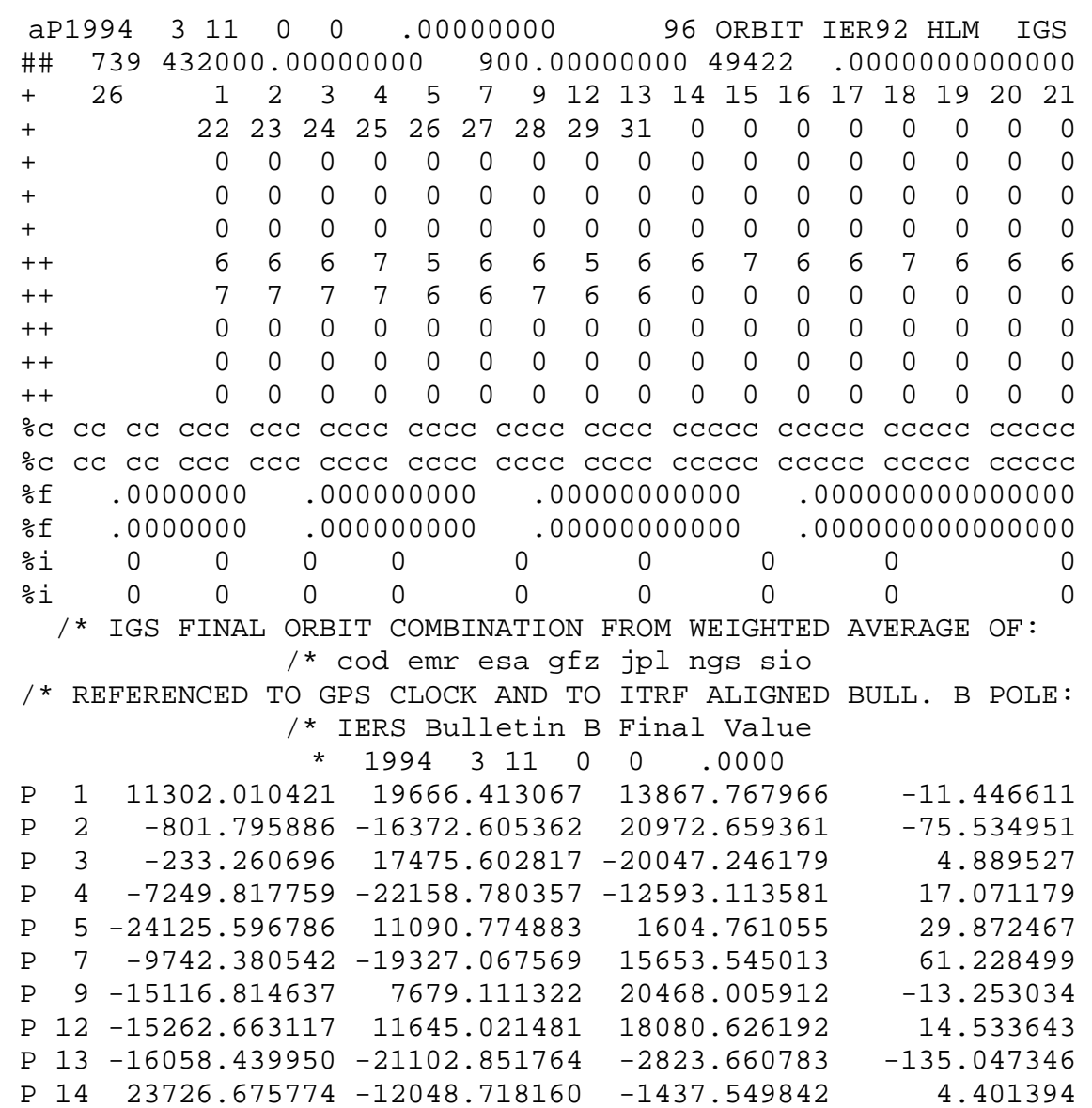




\begin{tabular}{|c|c|c|c|c|}
\hline & & & -10807.745094 & \\
\hline & & 39102 & -1391.914209 & $-14668 \cdot 718408$ \\
\hline & & 31583 & 24444.689397 & \\
\hline & & 6380 & -14207.451282 & \\
\hline & & 3174 & -24574.633055 & -7587 \\
\hline & & 9092 & & -10613 \\
\hline & & 625 & & \\
\hline & & & & \\
\hline & & & & \\
\hline & & & & \\
\hline & & & & \\
\hline & & 6635 & & \\
\hline & & & -2632 & \\
\hline & & & & \\
\hline & & & & \\
\hline & & & & \\
\hline & & & 1994311 & \\
\hline & 1 & & & \\
\hline & 2 & & -174 & \\
\hline & 3 & & & -21 \\
\hline & 4 & & -234 & -10 \\
\hline & 5 & -2395 & & \\
\hline & 7 & & -184 & \\
\hline & 9 & -1511 & & \\
\hline & 12 & $-14<$ & 0580 & 199 \\
\hline & & & -2109 & \\
\hline & & & -118 & \\
\hline & & & & \\
\hline & & .0 & (5) & 1. \\
\hline
\end{tabular}

66.628046

$-71.623691$

$-45.710277$

$-5.365846$

13.561208

47.926459

$-21.865495$

103.703478

4. 297977

8. 453685

$-4.282798$

$-44.150222$

21.958394

1. 313622

10.499655

80.430688

$-11.577067$

$-75.427337$

4.888493

17. 245992

29.907756

61.116115

$-13.411396$

14.532780

$-135.071082$

4. 357069

66.631058

$-71.579753$

\section{Formato SP3 'V'}

\begin{tabular}{|c|c|c|c|c|c|c|c|c|c|c|c|c|c|c|c|c|c|}
\hline \#aV1994 & \multirow{2}{*}{\multicolumn{2}{|c|}{$\begin{array}{r}8222 \\
160800\end{array}$}} & \multicolumn{2}{|c|}{$\odot 40$} & \multicolumn{4}{|c|}{$\odot .0 \odot \odot \odot \odot \odot \odot \odot$} & \multicolumn{3}{|c|}{47} & d & \multicolumn{2}{|c|}{ dTR92 } & \multicolumn{2}{|c|}{ FIT } & NGS \\
\hline \#\# 763 & & & & 000 & & 24 & 0. & $\odot \odot$ & $0 \odot$ & 0 & 495 & & 0.86 & 11 & 1111 & L11. & 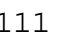 \\
\hline 25 & 1 & 2 & 4 & 5 & 6 & 7 & 9 & 12 & 14 & 15 & 16 & 17 & 18 & 19 & 20 & 21 & \\
\hline 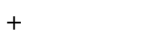 & 23 & 24 & 25 & 26 & 27 & 28 & 29 & 31 & $\odot$ & $\odot$ & $\odot$ & $\odot$ & $\odot$ & $\odot$ & $\odot$ & $\odot$ & \\
\hline+ & $\odot$ & $\odot$ & $\odot$ & $\odot$ & 0 & 0 & $\odot$ & $\odot$ & $\odot$ & $\odot$ & $\odot$ & $\odot$ & $\odot$ & $\odot$ & $\odot$ & $\odot$ & \\
\hline . & $\odot$ & $\odot$ & $\odot$ & $\odot$ & $\odot$ & $\odot$ & $\odot$ & $\odot$ & $\odot$ & $\odot$ & $\odot$ & $\odot$ & $\odot$ & $\odot$ & $\odot$ & $\odot$ & \\
\hline & $\odot$ & $\odot$ & $\odot$ & $\odot$ & $\odot$ & $\odot$ & $\odot$ & $\odot$ & $\odot$ & $\odot$ & $\odot$ & $\odot$ & $\odot$ & 0 & $\odot$ & 0 & \\
\hline+ & 5 & 6 & 6 & 5 & 6 & 6 & 5 & 5 & 5 & 5 & 6 & 5 & 5 & 5 & 5 & 5 & \\
\hline & 5 & 7 & 6 & 6 & 8 & 7 & 5 & 6 & $\odot$ & $\odot$ & $\odot$ & $\odot$ & $\odot$ & $\odot$ & $\odot$ & $\odot$ & \\
\hline & $\odot$ & $\odot$ & $\odot$ & $\odot$ & $\odot$ & $\odot$ & $\odot$ & $\odot$ & $\odot$ & $\odot$ & $\odot$ & $\odot$ & $\odot$ & $\odot$ & $\odot$ & $\odot$ & \\
\hline & $\odot$ & $\odot$ & $\odot$ & $\odot$ & $\odot$ & $\odot$ & $\odot$ & $\odot$ & $\odot$ & $\odot$ & $\odot$ & $\odot$ & $\odot$ & $\odot$ & $\odot$ & $\odot$ & \\
\hline & $\odot$ & $\odot$ & $\odot$ & $\odot$ & $\odot$ & $\odot$ & $\odot$ & $\odot$ & $\odot$ & $\odot$ & $\odot$ & 0 & $\odot$ & $\odot$ & $\odot$ & $\odot$ & \\
\hline
\end{tabular}

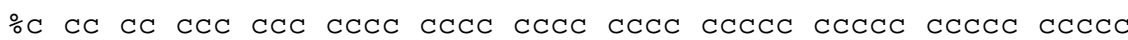

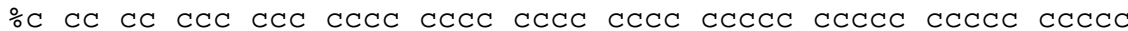
$\begin{array}{lllll}\% f & 0.0000000 & 0.000000000 & 0.00000000000 & 0.000000000000000\end{array}$

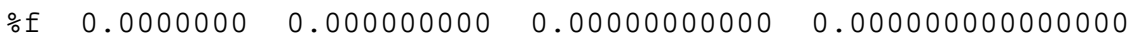

\begin{tabular}{|c|c|c|c|c|c|c|c|c|}
\hline & & & & & & & & \\
\hline$\% i$ & $\odot$ & $\odot$ & $\odot$ & $\odot$ & $\odot$ & $\odot$ & $\odot$ & $\odot$ \\
\hline$\%$ i & $\odot$ & 0 & $\odot$ & $\odot$ & $\odot$ & $\odot$ & $\odot$ & $\odot$ \\
\hline
\end{tabular}

* The NGS post-fit satellite positions have been combined /* with Broadcast ephemeris clock values at the epochs shown /* (Use these Broadcast clock values at your own risk.)

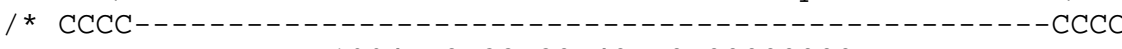

P $1-15041.238000-3055.847900-21565.680550$

V $12832.186081-27521.185484 \quad 1973.965959$

P $2 \quad 23869.334950 \quad 11146.051900 \quad-5050.436400$

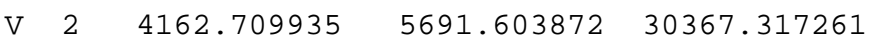

P $4 \quad 24250.758700 \quad-3536.972750 \quad-10203.363750$

$\begin{array}{lllll}\mathrm{V} & 4 & -10821.534577 & 7717.983969 & -28091.912138\end{array}$

P $5 \quad-544.817500-17351.846050-20026.692950$

$\begin{array}{lllll}\mathrm{V} & 5 & 21950.595956 & 13199.125789 & -12069.342692\end{array}$

P $6 \quad-5416.298150-23364.172050 \quad 11111.582450$

V $64114.350273-13817.911603-27426.905289$

P $7 \quad 14557.827350 \quad 5686.018100-21418.072450$

$\begin{array}{lllll}\mathrm{V} & 7 & -2179.172462 & 27280.440870 & 5457.018535\end{array}$

P $9 \quad 8911.431000-17937.389850 \quad-17333.674600$

$\begin{array}{llll}\mathrm{V} 920884.093502 & -7745.195191 & 18809.371497\end{array}$

$-40.355300$ $-44.114488$ $-108.906900$ $-0.102380$ 39.843800 $-0.054564$ 57.220300 $-0.010972$ 157.789800 $\odot .372575$ 697.447900 $-0.236559$ $-4.791900$ 2. 254773 


\begin{tabular}{|c|c|c|c|c|}
\hline$P$ & 12 & 9850 & $-12051.30980 \odot$ & \\
\hline$V$ & 12 & 27296.496208 & -2490.529773 & 1 \\
\hline$P$ & 14 & 5819.189750 & 19214.349200 & \\
\hline V & 14 & -18817.068110 & -11592.768942 & \\
\hline$P$ & 5 & $-7115.28140 \odot$ & 17327.758200 & -19 \\
\hline V & 5 & -22264.397470 & 8258.174455 & \\
\hline$P$ & 6 & 14555.189750 & -7457.115350 & 20952 \\
\hline V & 6 & 20801.133202 & 16525.170022 & -8572 \\
\hline$P$ & 17 & -12557.771200 & -10397.605200 & 20762.934 \\
\hline V & .7 & 24754.616507 & -10406.614514 & 9518. \\
\hline$P$ & 18 & 8195.516500 & $21703.00340 \odot$ & 12810 \\
\hline V & 18 & -3554.103611 & 16411.646626 & -25113. \\
\hline$P$ & 19 & 10833.212700 & 11994.003950 & 21085.722 \\
\hline V & 19 & -23693.964927 & 12666.294294 & $4951.952 \varepsilon$ \\
\hline $\mathrm{P}$ & 20 & -13218.216750 & -19351.394500 & -12679.387 \\
\hline V & 20 & 14483.900724 & 6828.478258 & -25801.2161 \\
\hline$P$ & 21 & -23814.346250 & - 9631.303150 & -7847.5837 \\
\hline V & 21 & -6670.898549 & -7402.945953 & 29217.0437 \\
\hline$P$ & 22 & - 19559.080950 & $2329.54410 \odot$ & 18030.4440 \\
\hline V & 22 & -18036.736484 & $-13828 \cdot 734780$ & -17493.4984 \\
\hline$P$ & 23 & -19012.633750 & -18194 . $17900 \odot$ & 4811.2092 \\
\hline V & 23 & 6173.775778 & 1425.551351 & 30767.5125 \\
\hline$P$ & 24 & 22914.680050 & -13019.206600 & 2692.1600 \\
\hline $\mathrm{V}$ & 24 & 4014 . 297353 & 860.229579 & -3189 \\
\hline$P$ & 25 & -24329.449250 & 4924.711550 & -9091.4302 \\
\hline
\end{tabular}

$-20.523200$

$\odot .815397$

6.408300

4.698226

109.593400

95.445542

$-74.639000$

$\odot .606526$

$-58.532800$

0.509295

$-2.125600$

$\odot .241834$

47.823700

$-0.062872$

144.561600

$\odot .262269$

$-2.322400$

$-1.366468$

148.603700

$-0.026829$

0.417300

$-0.238280$

768.464900

$-0.084506$

$-13.112700$

\section{Formato SP2}

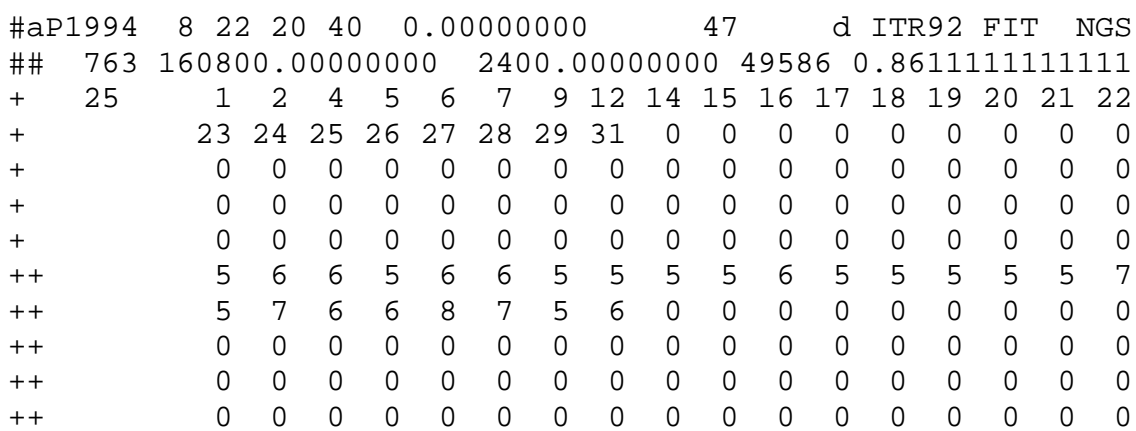

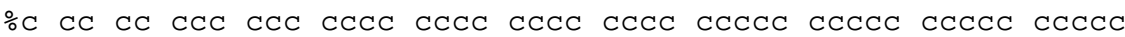

\% CC CC CCC CCC CCCC CCCC CCCC CCCC CCCCC CCCCC CCCCC CCCCC

$\begin{array}{lllll}\% f & 0.0000000 & 0.000000000 & 0.00000000000 & 0.000000000000000\end{array}$

$\begin{array}{lllll}\text { \% } & 0.0000000 & 0.000000000 & 0.0000000000000 & 0.000000000000000\end{array}$

$\begin{array}{llllllllll}\% i & \odot & \odot & \odot & \odot & \odot & \odot & \odot & 0 & 0 \\ \% \mathrm{i} & \odot & \odot & \odot & \odot & \odot & \odot & \odot & \odot & 0\end{array}$

/* The NGS post-fit satellite positions have been combined

/* with Broadcast ephemeris clock values at the epochs shown

$/^{*}$ (Use these Broadcast clock values at your own risk.)

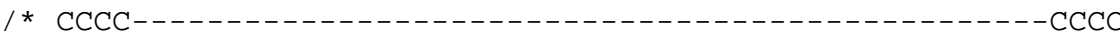

* $19948222040 \quad 0.00000000$

P $\quad \begin{array}{lllll}1 & -15041.237977 & -3055.847877 & -21565.680528\end{array}$

$\begin{array}{lllll}P & 2 & 23869.334938 & 11146.051908 & -5050.436382\end{array}$

$\begin{array}{lllll}P & 4 & 24250.758677 & -3536.972731 & -10203.363735\end{array}$

P $\quad 5 \quad-544.817481-17351.846065-20026.692944$

P $\quad 6 \quad-5416.298152 \quad-23364.172073 \quad 11111.582446$

$\begin{array}{lllll}P & 7 & 14557.827360 & 5686.018087 & -21418.072452\end{array}$

P $9 \quad 8911.430984-17937.389867 \quad-17333.674582$

$\begin{array}{lllll}\text { P } 12 & 9598.509872 & -12051.309800 & -21363.470253\end{array}$

$\begin{array}{lllll}P & 14 & 5819.189743 & 19214.349183 & -17327.045623\end{array}$

$\begin{array}{lllll}\text { P } 15 & -7115.281379 & 17327.758184 & -19081.523278\end{array}$

P $16 \quad 14555.189763 \quad-7457.115355 \quad 20952.403923$

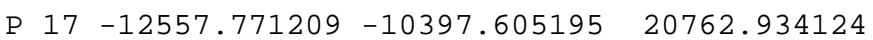

$\begin{array}{llll}\text { P } 18 & 8195.516490 & 21703.003387 & 12810.743234\end{array}$

$\begin{array}{llll}\text { P } 19 & 10833.212721 & 11994.003948 & 21085.722924\end{array}$

P $20-13218.216765-19351.394514-12679.387390$

$\begin{array}{llll}\text { P } 21 & -23814.346234 & -9631.303147 & -7847.583694\end{array}$

$\begin{array}{llrr}\text { P } 22 & -19559.080972 & 2329.544105 & 18030.444006\end{array}$

P $23-19012.633733-18194.179008 \quad 4811.209177$
$-40.355303$

$-108.906960$

39.843811

57.220332

157.789839

697.447904

$-4.791949$

$-20.523202$

6.408390

109.593460

$-74.639004$

$-58.532871$

$-2.125615$

47.823729

144.561641

$-2.322484$

148.603729

$\odot .417367$ 


\begin{tabular}{rrrrr}
$P$ & 24 & 22914.680032 & -13019.206597 & 2692.160056 \\
$P$ & 25 & -24329.449265 & 4924.711539 & -9091.430221 \\
$P$ & 26 & 8865.006772 & -22837.902689 & 10197.021861 \\
$P$ & 27 & 20662.199012 & 3020.844039 & 16423.188293 \\
$P$ & 28 & -12882.062463 & 15867.351073 & 17054.004974 \\
$P$ & 29 & 386.132444 & 26422.816540 & 2462.348121 \\
$P$ & 31 & -7285.230482 & 24106.916172 & 8028.350698 \\
\multicolumn{5}{c}{$*$} \\
$P$ & 1 & -14807.681972 & -9483.247963 & -19780.177337 \\
$P$ & 2 & 23978.127069 & 11932.908547 & 2391.531902 \\
$P$ & 4 & 20981.542980 & -1018.512380 & -16187.593622 \\
$P$ & 5 & 5194.435458 & -14408.128790 & -21642.270943
\end{tabular}

768.464964

$-13.112743$

$-10.827720$

40.464426

32.742237

16.696899

39.316615

$-40.360299$

$-108.912157$

39.846921

57.226151

A seguir, é apresentado um documento que permite a identificação de cada parâmetro que compõe o arquivo de efeméride precisa, no formato SP3, obtido no endereço ftp://igscb.jp/nasa.gov/igscb/data/format/sp3. Ainda, uma descrição com maiores explic ações sobre o formato SP3 pode ser encontrada no endereço ftp://igscb.jp/nasa.gov/igscb/data/format/sp3.docu.

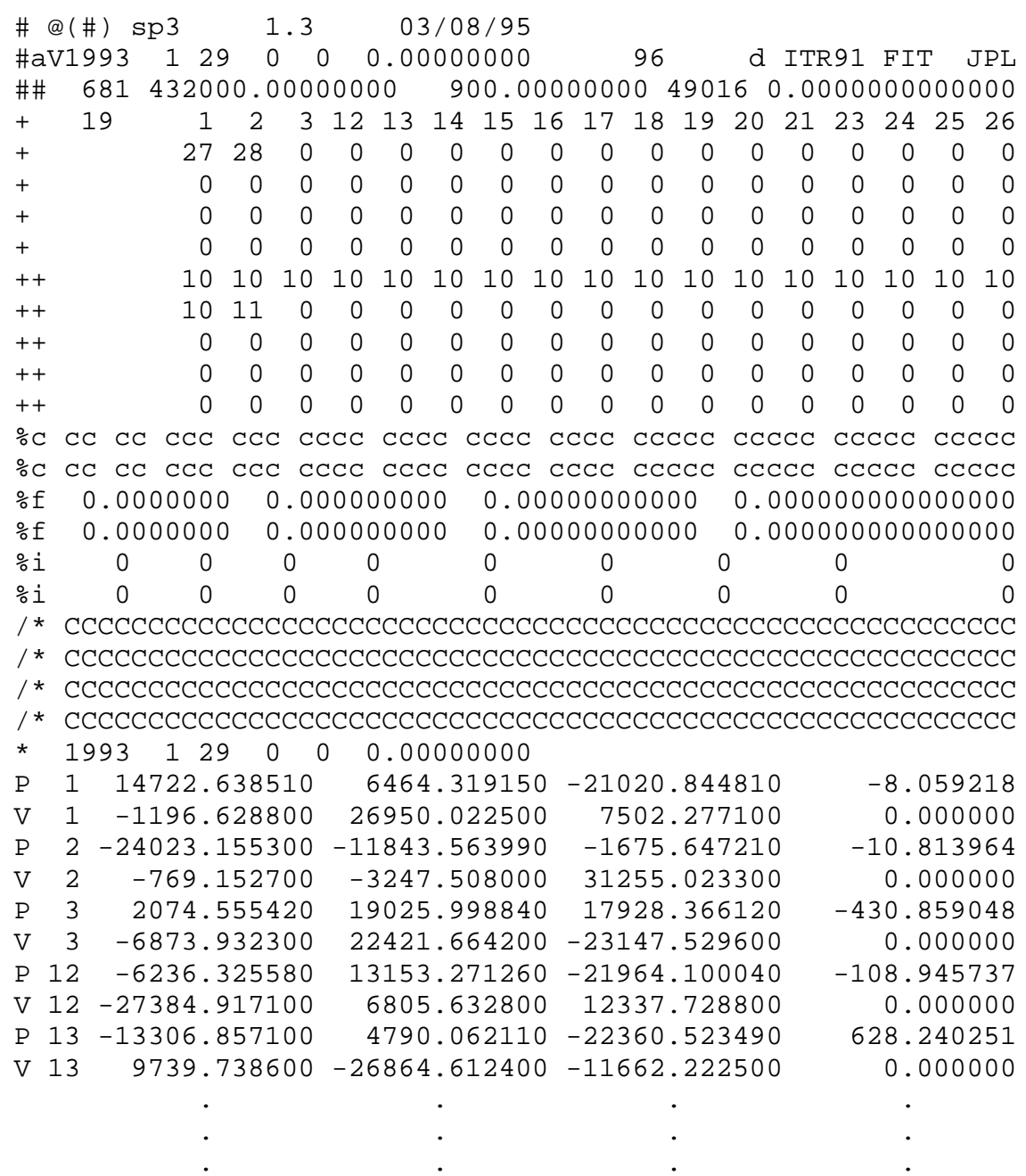




$\begin{array}{lrrrrr}\text { P } 27 & -19350.820260 & -4003.111190 & 17582.690790 & 14.651464 \\ \text { V } 27 & 19491.879100 & -11990.042400 & 18156.90440 \odot & 0.00000 \odot \\ \text { P } 28 & 13316.37850 \odot & -13959.644490 & 18317.660940 & 52.520005 \\ \text { V 28 } & 258.246400 & 23316.42080 \odot & 17208.92850 \odot & 0.0000 \odot \odot \\ \text { EOF } & & & & \end{array}$

SP3 LINE 1

$\operatorname{col} 1$

$\operatorname{col} 2$

col 3

col 4- 7

symbol

version id

col 9-10

$\mathrm{P} / \mathrm{V}$ mode flag

year start

month start

day of month start

hour start

col 15-16

minute start

col 18-19

second start

col 33-39

number of epochs

data used

coordinate system

orbit type

agency name

symbols

GPS week

seconds of week

epoch interval

mod. julian day start

fractional day

$\#$

a

1993

1

29

$-0$

$-0$

$-0.0000000 \odot$

d

ITR91

FIT

_JPL

SP3 LINE 2

col 1-

col 9-23

col 25-38

col 40-44

col 46-60

SP3 LINE 3

col 1- 2

symbols

number of satellites

sat \#1 id

sat \#2 id

\#\#

$-681$

432000. . 00000000

900.00000000

49016

0.0000000000000

col $5-$

$\operatorname{col} 10-12$

$\operatorname{col} 13-15$

$+$

$-1$

$\cdot$

col 58-60 sat \#17 id

$\_26$

SP3 LINES 4-7

col 1- 2 symbols

$\operatorname{col} 10-12$

col 13-15

$8(35,52,69)$ id

$+\frac{+}{27}$

$-28$

$\cdot$

$\operatorname{col} 58-60$

sat $\# 34(51,68,85)$ id

$-0$

SP3 LINES 8-12

$\operatorname{col} 1-2$
$\operatorname{col} 10-12$

symbols

sat $\# 1(18,35,52,69)$ acc $\quad 10$

col 13-15

sat \#2 $(19,36,53,70)$ acc

10
-10

$\cdot$

col 58-60 sat $\# 17(34,51,68,85)$ acc $\_10$

SP3 LINES 13-14

$\begin{array}{lrll}\text { col } & 1-2 & \text { symbols } & \% c \\ \text { col } & 4-5 & 2 \text { characters } & \text { cc } \\ \text { col } 7-8 & 2 \text { characters } & \text { cc } \\ \text { col } 10-12 & 3 \text { characters } & \text { ccc } \\ \text { col } 14-16 & 3 \text { characters } & \text { ccc } \\ \text { col } 18-21 & 4 \text { characters } & \text { cccc } \\ \text { col } 23-26 & 4 \text { characters } & \text { cccc } \\ \text { col } 28-31 & 4 \text { characters } & \text { cccc } \\ \text { col } 33-36 & 4 \text { characters } & \text { cccc } \\ \text { col } 38-42 & 5 \text { characters } & \text { cccc } \\ \text { col } 44-48 & 5 \text { characters } & \text { cccc } \\ \text { col } 50-54 & 5 \text { characters } & \text { cccc }\end{array}$


$\operatorname{col} 56-60 \quad 5$ characters cccc

SP3 LINES 15-16

col $1-2$ symbols \%f

col 4-13 10-column float

col 15-26 12-column float

col 28-41 14-column float

$-0.0000000$

$-0.000000 \odot \odot \odot$

col 43-60 18-column float

$-0.00000000000$

0.000000000000000

SP3 LINES 17-18

col 1- 2 symbols

col 4-7 4-column int

col 9-12 4-column int

col 14-17 4-column int

col 19-22 4-column int

col 24-29 6-column int

col 31-36 6-column int

col 38-43 6-column int

col 45-50 6-column int

col 52-60 9-column int

$\% i$

SP3 LINES 19-22

$\begin{array}{llll}\text { col } & 1-2 & \text { symbols } & /^{*} \\ \text { col } & 4-60 & \text { comment } & \text { CC...CC }\end{array}$

SP3 LINE 23 (epoch header record)

col 1- 2 symbols *

col $4-7$ year start $1 \overline{9} 93$

col 9-10 month start

col 12-13 day of month start $\overline{29}$

col 15-16 hour start -0

col 18-19 minute start -0

col 21-31 second start $\quad-0.0000000 \odot$

SP3 LINE 24 (position and clock record)

col 1 symbol $P$

col 2- 4 satellite id -1

col 5-18 X-coordinate $(\mathrm{km}) \quad$-14722.638510

col 19-32 y-coordinate $(\mathrm{km}) \quad 6464.319150$

col 33-46 z-coordinate $(\mathrm{km}) \quad-21020.844810$

col 47-60 clock (microsec) -

SP3 LINE 25 (velocity and clock record)

$\mathrm{col} 1$ symbol $\mathrm{V}$

col 2- 4 satellite id $x$ -

col 5-18 x-dot (decim/sec) - 1196.628800

col 19-32 y-dot (decim/sec) _26950.022500

col 33-46 z-dot (decim/sec) - 7502.277100

col 47-60 cl rate $(10 \mathrm{e}-4 \mathrm{msec} / \mathrm{sec})-0.000000$

SP3 LINE 22+numeps* (numsats+1)+1 (last line)

col $1-3$ symbols EOF. 
Exemplo de um arquivo Sumário.

STATION NAME: USP SP

PHASE \& PSEUDORANGE DATA FILE(S) INFO

BINARY INPUT FILE(S) : 16070701.DAT

ASCII OUTPUT FILE : USPP९70A.940

NAVIGATION MESSAGE FILE(S) INFO

BINARY INPUT FILE(S): 16070701. EPH

ASCII OUTPUT FILE : USPPO7@A.94N

OBSERVATION INFO

OBSERVING DATE : 1994/3/11

GPS WEEK \#

RECEIVER INITIALIZATION \& PRELIMINARY POSITION

LAT, ELON, HT(M) $\quad: \quad \begin{array}{llll} & -23.5506595 & -46.7313160 & 761.5590820\end{array}$

$\mathrm{X}, \mathrm{Y}, \mathrm{Z}$

NORTH, EAST, UP (M)

4010195.634

$-4260178.989$

$-2533044.658$

$000 \quad .000 \quad .069$

$\operatorname{TEMP}(\mathrm{C}), \operatorname{PRES}(M B), \operatorname{HUM}(\%)$

NAVIGATION SOFTWARE VER

15.000

4.81

SIGNAL SOFTWARE VERSION : 1.15

980.000

75.000

TRACKING SUMMARY:

SV

START TIME

STOP TIME

\#OBS \#REJ

1 94/ 3/11 15: 1: .01 (486060.01) 94/ 3/11 20: 4:30.04 (504270.04) 1215

5 94/ 3/11 11:59:45.00 (475185.00) 94/ 3/11 13:11:15.01 (479475.01) 287

14 94/ 3/11 18:58:15.03 (500295.03) 94/3/11 20:4:30.04 (504270.04) 266

15 94/ 3/11 18:12:45.03 (497565.03) 94/ 3/11 20: 4:30.04 (504270.04) 448

16 94/ 3/11 11:59:45.00 (475185.00) 94/3/11 13:6:45.00 (479205.01) 269

17 94/3/11 11:59:45.00 (475185.00) 94/3/11 17: 4:45.02 (493485.02) 1221

20 94/ 3/11 11:59:45.00 (475185.00) 94/ 3/11 14:29:15.01 (484155.01) 599

21 94/3/11 13:11:15.01 (479475.01) 94/3/11 19:35:30.04 (502530.04) 1538

22 94/ 3/11 13:16:45.01 (479805.01) 94/ 3/11 17: 5:45.03 (493545.03) 917

23 94/ 3/11 11:59:45.00 (475185.00) 94/ 3/11 17:29:30.03 (494970.03) 1320

25 94/ 3/11 11:59:45.00 (475185.00) 94/ 3/11 20:4:30.04 (504270.04) 839

26 94/ 3/11 13:56:30.01 (482190.01) 94/ 3/11 14:12: .01 (483120.01) 63

28 94/ 3/11 14:46:45.01 (485205.01) 94/3/11 19:46:45.04 (503205.04) 1201

29 94/ 3/11 19:19:45.03 (501585.04) 94/3/11 20: 4:30.04 (504270.04) 180

31 94/ 3/11 16:14:30.02 (490470.02) 94/ 3/11 20: 4:30.04 (504270.04) 921

TRACKING START TIME: 94/ 3/11 16:14:30.02 (475185.00)

STOP TIME: $94 / 3 / 11$ 20: 4:30.04 $(504270.04)$

\# OF EPOCHS : 1940

\# OF SATELLITES TRACKED : 15 


\section{ANEXO E}

As coordenadas preliminares para a Estratégia 1, com as seguintes caracteństica:

$\checkmark$ injunções VT-CHUA e CAPA,

$\checkmark$ valores atmosféricos reais,

$\checkmark$ efeméridesprecisas,

$\checkmark$ tempo total de obsenação, estão a presentadas na TABELA 97.

TABELA 97 - Coordenadas prelimina res para a Estratégia 1

\begin{tabular}{|c|c|c|c|}
\hline ESTAÇÃO & $X(m)$ & $\mathbf{Y}(\mathbf{m})$ & $\mathbf{Z}(\mathrm{m})$ \\
\hline AVAN & 3810096.804 & -4573379.606 & -2284127.532 \\
\hline AVER & 3831167.203 & -4620392.303 & -2151402.361 \\
\hline BELA & 4103079.534 & -4154778.183 & -2557306.246 \\
\hline BOTU & 3903909.173 & -4401321.075 & -2457094.497 \\
\hline BUNA & 4098261.350 & -4184077.861 & -2518883.831 \\
\hline CAPA & 4164684.614 & -4162401.031 & -2445011.073 \\
\hline CHUA & 4010548.440 & -4470076.610 & -2143179.020 \\
\hline FERN & 3833416.831 & -4598317.902 & -2194086.836 \\
\hline PRCA & 4045413.897 & -4396419.837 & -2228473.677 \\
\hline IBIT & 3889007.398 & -4472649.603 & -2349378.810 \\
\hline IEVA & 3836011.324 & -4394329.043 & -2572920.989 \\
\hline IHHA & 3732193.398 & -4674885.455 & -2206380.672 \\
\hline ITAP & 3914761.763 & -4349288.224 & -2530873.372 \\
\hline JABO & 3958010.971 & -4440248.391 & -2295902.832 \\
\hline பMO & 4044554.153 & -4339987.201 & -2336093.274 \\
\hline MAR & 3803904.880 & -4521713.938 & -2394685.994 \\
\hline PANO & 3670533.996 & -4672740.215 & -2311180.069 \\
\hline PIRA & 4002793.694 & -4359603.636 & -2371053.002 \\
\hline REG I & 3903906.728 & -4302834.990 & -2622964.200 \\
\hline SAGR & 3778535.527 & -4503385.859 & -2467128.200 \\
\hline $\mathbf{S P P}$ & 3885859.072 & -4527017.954 & -2249305.416 \\
\hline TAQU & 3628144.712 & -4644483.158 & -2431011.166 \\
\hline UEPP & 3687624.348 & -4620817.985 & -2386880.661 \\
\hline USPP & 4010143.192 & -4260160.934 & -2533046.258 \\
\hline VAU & 4009161.997 & -4294202.580 & -2477228.599 \\
\hline
\end{tabular}

As coordenadas prelimina res para a Estratégia 2, com as seguintes caracteństic as: 
$\checkmark$ injunções VT-CHUA e CAPA,

$\checkmark$ valores atmosféric os rea is,

$\checkmark$ efeméridesprecisas

$\checkmark$ tempo de 2:30h de observação, estão a presentadas na TABELA 98.

TABELA 98 - Coordenadas prelimina res para a Estratégia 2

\begin{tabular}{cccc}
\hline \hline ESTAÇÃO & $\mathbf{X}(\mathbf{m})$ & $\mathbf{Y}(\mathbf{m})$ & $\mathbf{Z}(\mathbf{m})$ \\
\hline AVAN & 3810096.785 & -4573379.565 & -2284127.506 \\
AVER & 3831167.173 & -4620392.280 & -2151402.330 \\
BEA & 4103079.723 & -4154778.095 & -2557306.285 \\
BOTU & 3903909.515 & -4401321.614 & -2457094.693 \\
BUNA & 4098261.277 & -4184077.907 & -2518883.817 \\
CAPA & 4164684.614 & -4162401.031 & -2445011.073 \\
CHUA & 4010548.440 & -4470076.610 & -2143179.020 \\
FRN & 3833416.837 & -4598317.878 & -2194086.842 \\
ARCA & 4045413.870 & -4396419.831 & -2228473.665 \\
IBIT & 3889007.347 & -4472649.582 & -2349378.787 \\
IEVA & 3836011.930 & -4394329.982 & -2572921.332 \\
IIHA & 3732193.780 & -4674885.988 & -2206380.892 \\
TAP & 3914762.365 & -4349289.061 & -2530873.698 \\
JABO & 3958010.918 & -4440248.333 & -2295902.813 \\
UMO & 4044554.097 & -4339987.154 & -2336093.268 \\
MARI & 3803904.991 & -4521714.032 & -2394686.044 \\
PANO & 3670534.346 & -4672740.660 & -2311180.255 \\
PIRA & 4002793.654 & -4359603.581 & -2371052.992 \\
REGI & 3903907.406 & -4302836.333 & -2622964.596 \\
SAGR & 3778535.851 & -4503386.337 & -2467128.372 \\
S RP & 3885859.001 & -4527017.904 & -2249305.389 \\
TAQU & 3628144.970 & -4644483.594 & -2431011.322 \\
UEPP & 3687623.494 & -4620816.657 & -2386879.791 \\
USPP & 4010143.826 & -4260162.303 & -2533046.613 \\
VAU & 4009161.454 & -4294202.533 & -2477228.791 \\
\hline \hline
\end{tabular}

As coordenadas preliminarespara a Estratégia 3, com as seguintes características:

\footnotetext{
$\checkmark$ injunções VT-CHUA e CAPA,

$\checkmark$ valores atmosféric os rea is,

$\checkmark$ efeméridestransmitidas,

$\checkmark$ tempo de 2:30h de observação, estão a presentadas na TABELA 99.
} 
TABELA 99 - Coordenadas prelimina res para a Estratégia 3

\begin{tabular}{cccc}
\hline \hline ESTAÇÃO & $\mathbf{X}(\mathbf{m})$ & $\mathbf{Y}(\mathbf{m})$ & $\mathbf{Z}(\mathbf{m})$ \\
\hline AVAN & 3810097.552 & -4573380.185 & -2284131.64 \\
AVER & 3831167.572 & -4620392.623 & -2151406.258 \\
BELA & 4103079.708 & -4154777.566 & -2557306.158 \\
BOTU & 3903909.154 & -4401321.326 & -2457095.224 \\
BUNA & 4098261.784 & -4184077.287 & -2518883.824 \\
CAPA & 4164684.614 & -4162401.031 & -2445011.073 \\
CHUA & 4010548.44 & -4470076.61 & -2143179.02 \\
FERN & 3833417.267 & -4598318.272 & -2194087.064 \\
RCA & 4045413.61 & -4396419.346 & -2228473.522 \\
IBIT & 3889007.894 & -4472650.016 & -2349381.58 \\
IEVA & 3836011.098 & -4394329.418 & -2572920.828 \\
IUHA & 3732193.677 & -4674886.092 & -2206380.797 \\
TAP & 3914761.746 & -4349288.42 & -2530873.26 \\
JABO & 3958010.527 & -4440247.713 & -2295902.61 \\
UMO & 4044553.71 & -4339986.916 & -2336093.095 \\
MARI & 3803905.421 & -4521714.192 & -2394686.902 \\
PANO & 3670534.598 & -4672741.283 & -2311180.276 \\
PIRA & 4002793.327 & -4359602.396 & -2371052.803 \\
REGI & 3903906.564 & -4302836.102 & -2622964.268 \\
SAGR & 3778536.79 & -4503386.131 & -2467128.081 \\
S RP & 3885858.765 & -4527017.451 & -2249305.214 \\
TAQU & 3628144.542 & -4644483.818 & -2431011.04 \\
UEPP & 3687623.636 & -4620816.999 & -2386879.69 \\
USPP & 4010143.388 & -4260161.991 & -2533046.418 \\
VAU & 4009161.555 & -4294202.237 & -2477228.686 \\
\hline \hline
\end{tabular}

As coordenadas preliminares para a Estratégia 4, com as seguintes caracteństicas:

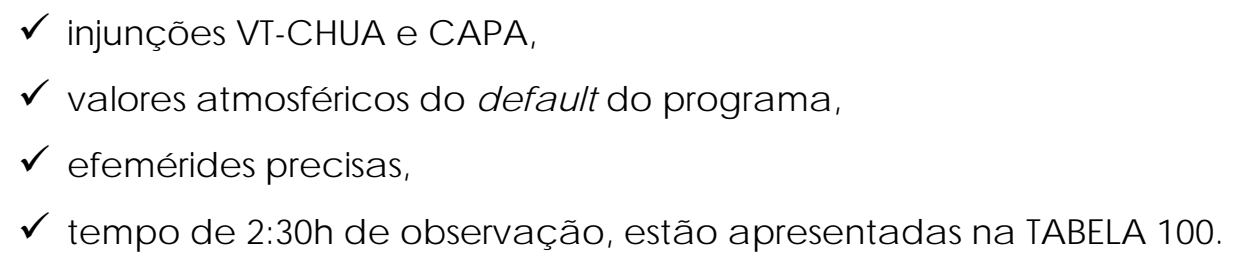


TABELA 100 - Coordenadas prelimina res para a Estratégia 4

\begin{tabular}{cccc}
\hline \hline ESTAÇÃO & $\mathbf{X}(\mathbf{m})$ & $\mathbf{Y}(\mathbf{m})$ & $\mathbf{Z}(\mathbf{m})$ \\
\hline AVAN & 3810097.634 & -4573380.602 & -2284128.026 \\
AVER & 3831167.634 & -4620392.844 & -2151402.610 \\
BELA & 4103079.574 & -4154778.143 & -2557306.227 \\
BOTU & 3903909.315 & -4401321.798 & -2457094.584 \\
BUNA & 4098261.465 & -4184077.780 & -2518883.823 \\
CAPA & 4164684.614 & -4162401.031 & -2445011.073 \\
CHUA & 4010548.440 & -4470076.610 & -2143179.020 \\
FER & 3833417.781 & -4598318.966 & -2194087.423 \\
FRA & 4045413.655 & -4396419.726 & -2228473.611 \\
IBIT & 3889008.088 & -4472650.456 & -2349379.232 \\
IEVA & 3836011.246 & -4394329.669 & -2572920.917 \\
IUHA & 3732194.283 & -4674886.467 & -2206381.238 \\
ITAP & 3914761.672 & -4349288.731 & -2530873.279 \\
JABO & 3958010.914 & -4440248.335 & -2295902.813 \\
UMO & 4044553.996 & -4339987.097 & -2336093.241 \\
MARI & 3803905.032 & -4521714.670 & -2394686.095 \\
PANO & 3670533.849 & -4672741.069 & -2311180.027 \\
PIRA & 4002793.682 & -4359603.597 & -2371052.997 \\
REGI & 3903906.657 & -4302836.098 & -2622964.201 \\
SAGR & 3778535.474 & -4503386.640 & -2467128.168 \\
S RP & 3885858.972 & -4527017.846 & -2249305.362 \\
TAQU & 3628144.601 & -4644483.963 & -2431011.134 \\
UEPP & 3687623.141 & -4602817.051 & -2386879.610 \\
USPP & 4010143.158 & -4260162.222 & -2533046.324 \\
VAU & 4009160.931 & -4294202.255 & -2477228.449 \\
\hline \hline
\end{tabular}


TABEA 101 - Valores de $\Delta X, \Delta Y$ e $\Delta Z$

\begin{tabular}{|c|c|c|c|c|c|}
\hline & $\begin{array}{c}\text { VEIOR } \\
\text { DE }\end{array}$ & $\begin{array}{l}\text { VEIOR } \\
\text { PARA }\end{array}$ & $\Delta X(\mathbf{m})$ & $\Delta \mathbf{Y}(\mathbf{m})$ & $\Delta \mathbf{Z}(\mathbf{m})$ \\
\hline $\begin{array}{l}1 \\
2\end{array}$ & $\begin{array}{l}\text { AVAN } \\
\text { AVAN }\end{array}$ & $\begin{array}{l}\text { FERN } \\
\text { IBIT }\end{array}$ & $\begin{array}{l}23320.011 \\
78910.574\end{array}$ & $\begin{array}{l}-24938.258 \\
100730.035\end{array}$ & $\begin{array}{r}90040.730 \\
-65251.279\end{array}$ \\
\hline 3 & AVAN & IBIT & 78910.635 & 100730.029 & -65251.302 \\
\hline 4 & AVAN & ILHA & -77903.370 & -101505.885 & 77746.846 \\
\hline 5 & BELA & BUNA & -4818.173 & -29299.707 & 38422.407 \\
\hline 6 & BELA & USPP & -92936.153 & -105384.127 & 24259.816 \\
\hline 7 & BELA & USPP & -92936.108 & -105384.156 & 24259.788 \\
\hline 8 & BOTU & ITAP & 10852.576 & 52033.039 & -73778.853 \\
\hline 9 & BOTU & MARI & -100004.270 & -120392.869 & 62408.495 \\
\hline 10 & BUNA & BELA & 4818.165 & 29299.672 & -38422.425 \\
\hline 11 & BUNA & BELA & 4818.117 & 29299.644 & -38422.412 \\
\hline 12 & BUNA & USPP & -88118.063 & -76084.414 & -14162.587 \\
\hline 13 & BUNA & USPP & -88117.992 & -76084.548 & -14162.634 \\
\hline 14 & BUNA & VAU & -89100.240 & -110124.596 & 41655.278 \\
\hline 15 & BUNA & VAU & -89099.653 & -110125.517 & 41654.817 \\
\hline 16 & BUNA & VAU & -89100.050 & -110124.665 & 41655.267 \\
\hline 17 & CAPA & BELA & -61604.945 & 7622.873 & -112295.153 \\
\hline 18 & CAPA & BUNA & -66423.293 & -21676.808 & -73872.760 \\
\hline 19 & CHUA & FRCA & 34865.475 & 73656.793 & -85294.656 \\
\hline 20 & CHUA & $\mathrm{J} A B O$ & -52537.475 & 29828.214 & -152723.808 \\
\hline 21 & FERN & AVAN & -23320.030 & 24938.280 & -90040.667 \\
\hline 22 & FERN & AVER & -2249.675 & -22074.392 & 42684.515 \\
\hline 23 & FERN & ILHA & -101223.470 & -76567.518 & -12293.821 \\
\hline 24 & FRCA & பMO & -859.750 & 56432.639 & -107619.598 \\
\hline 25 & $\mathrm{IBIT}$ & AVAN & -78910.599 & -100729.985 & 65251.273 \\
\hline 26 & IBIT & BOTU & 14901.615 & 71328.774 & -107715.601 \\
\hline 27 & IBIT & MARI & -85102.604 & -49064.079 & -45307.141 \\
\hline 28 & IEVA & BOTU & 67897.888 & -6992.154 & 115826.460 \\
\hline 29 & IEVA & SAGR & -57475.759 & -109056.936 & 105792.752 \\
\hline 30 & ITAP & IEVA & -78750.423 & -45040.893 & -42047.632 \\
\hline 31 & ITAP & IEVA & -78750.431 & -45040.925 & -42047.638 \\
\hline 32 & $\mathrm{~J} A B O$ & FRCA & 87402.893 & 43828.556 & 67429.166 \\
\hline 33 & $\mathrm{~J} A B O$ & IBIT & -69003.571 & -32401.205 & -53475.973 \\
\hline 34 & $\mathrm{~J} A B O$ & பMO & 86543.194 & 100261.193 & -40190.445 \\
\hline 35 & $\mathrm{~J} A B O$ & SJ RP & -72151.903 & -86769.562 & 46597.416 \\
\hline 36 & $\mathrm{~J} A B O$ & SJ RP & -72151.900 & -86769.542 & 46597.416 \\
\hline 37 & $\mathrm{~J} A B O$ & SJ RP & -72151.880 & -86769.576 & 46597.406 \\
\hline 38 & பMO & PIRA & -41760.466 & -19616.433 & -34959.729 \\
\hline 39 & MARI & SAGR & -25369.405 & 18328.099 & -72442.183 \\
\hline
\end{tabular}


TABELA 101 - Valores de $\Delta \mathrm{X}, \Delta \mathrm{Y}$ e $\Delta \mathrm{Z}$

\begin{tabular}{|c|c|c|c|c|c|}
\hline $\begin{array}{l}40 \\
41\end{array}$ & $\begin{array}{l}\text { MARI } \\
\text { PANO }\end{array}$ & $\begin{array}{l}\text { UEPP } \\
\text { ILHA }\end{array}$ & $\begin{array}{c}-116281.633 \\
61658.852\end{array}$ & $\begin{array}{l}-99102.345 \\
-2144.616\end{array}$ & $\begin{array}{c}7806.340 \\
104799.726\end{array}$ \\
\hline 42 & PIRA & FRCA & 42620.224 & -36816.219 & 142579.307 \\
\hline 43 & PIRA & $\mathrm{JABO}$ & -44782.718 & -80644.750 & 75150.166 \\
\hline 44 & PIRA & VAU & 6367.097 & 65402.121 & -106175.446 \\
\hline 45 & REG I & IEVA & -67895.421 & -91493.592 & 50043.279 \\
\hline 46 & REG I & ITAP & 10855.041 & -46452.685 & 92090.885 \\
\hline 47 & SAGR & BOTU & 125373.587 & 102064.813 & 10033.729 \\
\hline 48 & SAGR & MARI & 25369.330 & -18328.072 & 72442.215 \\
\hline 49 & SAGR & UEPP & -90912.277 & -117430.429 & 80248.532 \\
\hline 50 & SJ RP & AVAN & -75762.274 & -46361.637 & -34822.101 \\
\hline 51 & SJ RP & AVER & -54691.866 & -93374.365 & 97903.058 \\
\hline 52 & SJ RP & AVER & -54691.852 & -93374.314 & 97903.053 \\
\hline 53 & SJ RP & IBIT & 3148.299 & 54368.325 & -100073.386 \\
\hline 54 & TAQU & PANO & 42389.268 & -28257.016 & 119831.115 \\
\hline 55 & UEPP & PANO & -17089.236 & -51923.971 & 75699.574 \\
\hline 56 & UEPP & TAQU & -59478.547 & -23666.911 & -44131.522 \\
\hline 57 & UEPP & TAQU & -59478.527 & -23666.832 & -44131.481 \\
\hline 58 & USPP & REG I & -106236.444 & -42673.909 & -89917.938 \\
\hline 59 & USPP & VAU & -982.050 & -34040.182 & 55817.826 \\
\hline 60 & USPP & VAU & -983.566 & -34040.780 & 55818.044 \\
\hline 61 & VAU & ITAP & -94399.316 & -55086.326 & -53644.822 \\
\hline 62 & VAU & REG I & -105254.302 & -8633.663 & -145735.732 \\
\hline 63 & VAU & REG I & -105254.270 & -8633.644 & -145735.740 \\
\hline 64 & VAU & USPP & 982.132 & 34040.241 & -55817.817 \\
\hline
\end{tabular}




\section{ANEXO G}

As coordenadas ajustadas da rede GPS do Estado de São Paulo, ofic ia is do IBGE, estão a presentadas na TABELA 102.

TABELA 102 - Coordena s geodésic as - IBGE (WG S 84)

\begin{tabular}{|c|c|c|c|}
\hline Estação & Latitude & Longitude & $\begin{array}{l}\text { h } \\
(\mathrm{m})\end{array}$ \\
\hline AVAN & $\begin{array}{lll}-21^{\circ} & 07^{\prime} & 19.29745^{\prime \prime}\end{array}$ & $\begin{array}{lll}-50^{\circ} & 12^{\prime} & 07.97015^{\prime \prime}\end{array}$ & 346.443 \\
\hline AVER & -19o $50^{\prime} 31.82443^{\prime \prime}$ & $\begin{array}{lll}-50^{\circ} & 20^{\prime} 05.75989^{\prime \prime}\end{array}$ & 390.385 \\
\hline BEA & $\begin{array}{llll}-23^{\circ} & 47^{\prime} 33.45700^{\prime \prime}\end{array}$ & $-45^{\circ} 21^{\prime} 31.28945^{\prime \prime}$ & 55.043 \\
\hline BOTU & $-22^{\circ} 48^{\prime} 17.26005^{\prime \prime}$ & $-48^{\circ} \quad 25^{\prime} 38.74548^{\prime \prime}$ & 745.473 \\
\hline BUNA & $\begin{array}{lll}-23^{\circ} & 24^{\prime} & 41.20002^{\prime \prime \prime}\end{array}$ & $-45^{\circ} 35^{\prime} 37.08891^{\prime \prime}$ & 717.575 \\
\hline CAPA & $-22^{\circ} 41^{\prime} 13.06838^{\prime \prime}$ & $-44^{\circ} 59^{\prime} 03.41112^{\prime \prime}$ & 620.492 \\
\hline CHUA & $-19^{\circ} 4^{\prime} 43.34590^{\prime \prime}$ & $\begin{array}{lllll}-48^{\circ} & 06^{\prime} & 05.67319^{\prime \prime}\end{array}$ & 754.150 \\
\hline FERN & $-20^{\circ} 15^{\prime} 08.86650^{\prime \prime}$ & $-50^{\circ} 11^{\prime} 00.62710^{\prime \prime}$ & 427.616 \\
\hline FRCA & $-20^{\circ} 34^{\prime} 54.87338^{\prime \prime}$ & $-47022^{\prime} 51.41592^{\prime \prime}$ & 1004.883 \\
\hline IBIT & $-21^{\circ} 45^{\prime} 17.71754^{\prime \prime}$ & $-48^{\circ} \quad 59^{\prime} 33.93369^{\prime \prime}$ & 402.453 \\
\hline IEVA & $-23^{\circ} 56^{\prime} 39.05342^{\prime \prime}$ & -48 o $52^{\prime} 50.87603^{\prime \prime}$ & 707.007 \\
\hline IUHA & $-20^{\circ} 22^{\prime} 16.37035^{\prime \prime}$ & $\begin{array}{lll}-51^{\circ} & 23^{\prime} & 52.41503^{\prime \prime}\end{array}$ & 323.452 \\
\hline ITAP & $-23^{\circ}$ 31' 45.61796" & $-480 \quad 00^{\prime} 35.48208^{\prime \prime}$ & 746.774 \\
\hline JABO & $-21^{\circ} 1^{\prime} \quad 06.60022^{\prime \prime}$ & -48 & 606.034 \\
\hline UMO & $-21^{\circ} 37^{\prime} 30.59642 "$ & $-47^{\circ} 01^{\prime} \quad 04.82185^{\prime \prime}$ & 580.068 \\
\hline MARI & $-22^{\circ} 11^{\prime} 42.91330^{\prime \prime}$ & $-49^{\circ} \quad 55^{\prime} 39.64049^{\prime \prime}$ & 637.470 \\
\hline PANO & $\begin{array}{lll}-21^{\circ} & 23^{\prime} & 03.19693^{\prime \prime}\end{array}$ & $-51^{\circ} 50^{\prime} 58.67638^{\prime \prime}$ & 333.248 \\
\hline PIRA & $-21^{\circ} 57^{\prime} 54.33850^{\prime \prime}$ & $-47^{\circ} 26^{\prime} 35.64730^{\prime \prime}$ & 600.721 \\
\hline REGI & $-24^{\circ} \quad 26^{\prime} 31.77123^{\prime \prime}$ & $-47^{\circ} \quad 46^{\prime} 58.61318^{\prime \prime}$ & 44.282 \\
\hline SAGR & $-22^{\circ} 54^{\prime} 16.10678^{\prime \prime}$ & $\begin{array}{lll}-50^{\circ} 00^{\prime} 06.81968^{\prime \prime} & 0\end{array}$ & 386.816 \\
\hline $\mathbf{S J P}$ & $\begin{array}{llll}-20^{\circ} & 47^{\prime} & 04.77279^{\prime \prime}\end{array}$ & $-49^{\circ} 21^{\prime} 29.44212^{\prime \prime}$ & 520.850 \\
\hline TAQU & $-22^{\circ} 33^{\prime} 04.55534^{\prime \prime}$ & $-52^{\circ} \quad 00^{\prime} 14.42958^{\prime \prime}$ & 288.643 \\
\hline UEPP & "220 $07^{\prime \prime} 11.65957^{\prime \prime}$ & $-51^{\circ} 24^{\prime} 30.72136^{\prime \prime}$ & 430.946 \\
\hline USPP & $-23^{\circ} 33^{\prime} 03.05751^{\prime \prime}$ & - 460 43' 53.65408"' & 718.203 \\
\hline VAU & $-23^{\circ}$ 00'06.16757" & $-46^{\circ} 57^{\prime} 57.94358 "$ & 856.934 \\
\hline
\end{tabular}

As coordenadas ajustadas da rede GPS do Estado de São Paulo, a presentadas por SEG ANTINE (1995), estão a presentadas na TABELA 103. 
TABEA 103 - Coordena s geodésicas - SEG ANTINE (1995) (WG S 84)

\begin{tabular}{|c|c|c|c|}
\hline Estação & Latitude & Longitude & $\begin{array}{l}\text { h } \\
\text { (m) }\end{array}$ \\
\hline AVAN & $-21^{\circ} \quad 07^{\prime} 19.29840^{\prime \prime}$ & $\begin{array}{llll}-50^{\circ} & 12^{\prime} & 07.97194^{\prime \prime}\end{array}$ & 346.583 \\
\hline AVER & -190 $50^{\prime} 31.82550^{\prime \prime}$ & $\begin{array}{llll}-50^{\circ} & 20^{\prime} 05.76243^{\prime \prime}\end{array}$ & 390.711 \\
\hline BEA & -230 $47^{\prime} 33.45637^{\prime \prime}$ & $-45^{\circ} 21^{\prime} 31.29329^{\prime \prime}$ & 55.163 \\
\hline BOTU & $-22^{\circ} 48^{\prime} 17.26039^{\prime \prime}$ & $-48^{\circ} 25^{\prime} 38.74939^{\prime \prime}$ & 745.364 \\
\hline BUNA & -23० 24' $41.19942^{\prime \prime \prime}$ & $-45^{\circ} 35^{\prime} 37.09374 "$ & 717.670 \\
\hline CAPA & $-22^{\circ} 41^{\prime} 13.06739^{\prime \prime}$ & -44'59'03.41144" & 620.349 \\
\hline CHUA & $-19^{\circ} 45^{\prime} 43.34588^{\prime \prime}$ & $\begin{array}{llll}-48^{\circ} & 06^{\prime} & 05.67324^{\prime \prime}\end{array}$ & 754.150 \\
\hline ERR & $-20^{\circ} \quad 15^{\prime} 08.86737^{\prime \prime}$ & $-50^{\circ} 11^{\prime} 00.63004^{\prime \prime}$ & 427.738 \\
\hline RCA & $-20^{\circ} 34^{\prime} 54.87322^{\prime \prime}$ & $-47^{\circ} 22^{\prime} 51.41916^{\prime \prime}$ & 1004.996 \\
\hline IBTT & $-21^{\circ} 45^{\prime} 17.71844^{\prime \prime}$ & $-48^{\circ} 59^{\prime} 33.93521^{\prime \prime}$ & 402.507 \\
\hline IEVA & $-23^{\circ} 56^{\prime} 39.05327^{\prime \prime}$ & $-48^{\circ} 52^{\prime} 50.88098^{\prime \prime}$ & 706.982 \\
\hline IUHA & $-20^{\circ} 22^{\prime} 16.37093^{\prime \prime}$ & $-51^{\circ} \quad 23^{\prime} 52.41910^{\prime \prime}$ & 323.530 \\
\hline ITAP & $-23^{\circ} 31^{\prime} 45.61824^{\prime \prime}$ & $-48^{\circ} 00^{\prime} 35.48670^{\prime \prime}$ & 746.796 \\
\hline JABO & $\begin{array}{llll}-21^{\circ} & 14^{\prime} & 06.60023^{\prime \prime}\end{array}$ & $\begin{array}{llll}-48^{\circ} & 17^{\prime} & 10.96519^{\prime \prime}\end{array}$ & 606.167 \\
\hline LMO & -210 $37^{\prime} \quad 30.59679 "$ & $\begin{array}{llll}-47^{\circ} & 01^{\prime} & 04.82828\end{array}$ & 580.313 \\
\hline MAR & $-22^{\circ} 11^{\prime} 42.91389^{\prime \prime}$ & $-49^{\circ} 55^{\prime} 39.64264^{\prime \prime}$ & 637.488 \\
\hline PANO & $\begin{array}{lll}-21^{\circ} & 23^{\prime} & 03.19748 "\end{array}$ & $\begin{array}{lll}-51^{\circ} 50^{\prime} 58.67980^{\prime \prime} & 5\end{array}$ & 333.275 \\
\hline PIRA & $-21^{\circ} 57^{\prime} 54.33867^{\prime \prime}$ & $-47^{\circ} 26^{\prime} 35.65129^{\prime \prime}$ & 600.895 \\
\hline REGI & $-24^{\circ} 26^{\prime} 31.77184^{\prime \prime}$ & $-47^{\circ} \quad 46^{\prime} 58.61671^{\prime \prime}$ & 44.332 \\
\hline SAGR & $-22^{\circ} 54^{\prime} 16.10706^{\prime \prime}$ & $\begin{array}{lll}-50^{\circ} 00^{\prime} 06.82340^{\prime \prime} & 0\end{array}$ & 386.807 \\
\hline S RP & $\begin{array}{llll}-20^{\circ} & 47^{\prime} & 04.77323^{\prime \prime}\end{array}$ & $-49^{\circ} 21^{\prime} 29.44422^{\prime \prime}$ & 521.083 \\
\hline TAQU & $-22^{\circ} 33^{\prime} 04.55621^{\prime \prime}$ & $\begin{array}{llll}-52^{\circ} & 00^{\prime} & 14.43115^{\prime \prime}\end{array}$ & 288.746 \\
\hline UEPP & $-22^{\circ} 07^{\prime} 11.66746^{\prime \prime}$ & $-51^{\circ} 24^{\prime} 30.70102^{\prime \prime}$ & 431.081 \\
\hline USPP & $-23^{\circ} 33^{\prime} 03.05748^{\prime \prime}$ & - $46^{\circ} \quad 43^{\prime} 53.65875^{\prime \prime}$ & 718.314 \\
\hline VAU & $-23^{\circ} 00^{\prime} 06.16713^{\prime \prime}$ & $-46^{\circ} 57^{\prime} 57.94806^{\prime \prime}$ & 857.005 \\
\hline
\end{tabular}


As coordenadas ajustadas da rede GPS do Estado de São Paulo, a presenta das por FO NSECA J r. (1996), estã o a presenta das na TABELA 104.

TABELA 104 - Coordenas geodésic as - FONSEC A J r. (1996)

(WG S84)

\begin{tabular}{|c|c|c|c|}
\hline Estação & Latitude & Longitude & $\begin{array}{l}h \\
(m)\end{array}$ \\
\hline AVAN & $\begin{array}{lll}-21^{\circ} & 07^{\prime} & 19.29828 "\end{array}$ & $\begin{array}{lll}-50^{\circ} & 12^{\prime} & 07.97154^{\prime \prime}\end{array}$ & 346.543 \\
\hline AVER & $-19^{\circ} 50^{\prime} 31.82523^{\prime \prime}$ & $-50^{\circ} 20^{\prime} 05.76071^{\prime \prime}$ & 390.447 \\
\hline BEA & $-23^{\circ} 47^{\prime} 33.45641^{\prime \prime}$ & $-45^{\circ} 21^{\prime} 31.29222^{\prime \prime}$ & 55.179 \\
\hline BOTU & $-22^{\circ} 48^{\prime} 17.26022^{\prime \prime}$ & $-48^{\circ} 25^{\prime} 38.74809^{\prime \prime}$ & 745.545 \\
\hline BUNA & -230 $24^{\prime} 41.19962 " '$ & $-45^{\circ} 35^{\prime} 37.09181^{\prime \prime}$ & 717.701 \\
\hline CAPA & $-22^{\circ} 41^{\prime} 13.06726^{\prime \prime}$ & $-44^{\circ} \quad 59^{\prime} 03.41475^{\prime \prime}$ & 620.505 \\
\hline CHUA & $-19^{\circ} 45^{\prime} 43.34590^{\prime \prime}$ & $-48^{\circ} 06^{\prime}$ 05.67319" & 754.150 \\
\hline FERN & $-20^{\circ} \quad 15^{\prime} 08.86727^{\prime \prime}$ & $-50^{\circ} 11^{\prime} 00.63002^{\prime \prime}$ & 427.643 \\
\hline RRCA & $-20^{\circ} 34^{\prime} 54.87330^{\prime \prime}$ & $-47^{\circ} 22^{\prime} 51.41805^{\prime \prime}$ & 1005.164 \\
\hline IBIT & -210 $45^{\prime} 17.71831^{\prime \prime}$ & -48 59'33.93509" & 402.468 \\
\hline IEVA & $-23^{\circ} 56^{\prime} 39.05342^{\prime \prime}$ & $-48^{\circ} 52^{\prime} 50.87603^{\prime \prime}$ & 707.007 \\
\hline IUHA & $-20^{\circ} 22^{\prime} 16.37119^{\prime \prime}$ & $-51^{\circ} 23^{\prime} 52.41695^{\prime \prime}$ & 323.554 \\
\hline ITAP & $-23^{\circ} 31^{\prime} 45.61772^{\prime \prime}$ & $-48^{\circ} 00^{\prime} 35.48632^{\prime \prime}$ & 746.883 \\
\hline JABO & $-21^{\circ} 14^{\prime} 06.60033^{\prime \prime}$ & $-48^{\circ} 17^{\prime} 10.96365^{\prime \prime}$ & 606.055 \\
\hline LMO & $-21^{\circ} 37^{\prime} 30.59655^{\prime \prime}$ & $-47^{\circ} 01^{\prime} 04.82610^{\prime \prime}$ & 580.154 \\
\hline MAR & $-22^{\circ} 11^{\prime} 42.91374^{\prime \prime}$ & $-49^{\circ} 55^{\prime} 39.64295^{\prime \prime}$ & 637.549 \\
\hline PANO & $-21^{\circ} 23^{\prime} 03.19743^{\prime \prime}$ & $-51^{\circ} 50^{\prime} 58.68031^{\prime \prime}$ & 333.317 \\
\hline PIRA & $-21^{\circ} 57^{\prime} 54.33869^{\prime \prime}$ & $-47^{\circ} 26^{\prime} 35.64984^{\prime \prime}$ & 600.781 \\
\hline REGI & $-24^{\circ} 26^{\prime} 31.77147^{\prime \prime}$ & $-47^{\circ} 46^{\prime} 58.61562^{\prime \prime}$ & 44.460 \\
\hline SAGR & $-22^{\circ} 54^{\prime} 16.10720^{\prime \prime}$ & $-50^{\circ} 00^{\prime} 06.82253^{\prime \prime}$ & 386.834 \\
\hline $\mathbf{S} \mathbf{R P}$ & $-20^{\circ} 47^{\prime} 04.77333^{\prime \prime}$ & $-49^{\circ} 21^{\prime} 29.44347^{\prime \prime}$ & 520.933 \\
\hline TAQU & $\begin{array}{lll}-22^{\circ} & 33^{\prime} 04.55620^{\prime \prime}\end{array}$ & $\begin{array}{lll}-52^{\circ} & 00^{\prime} & 14.42985^{\prime \prime}\end{array}$ & 288.746 \\
\hline UEPP & $-22^{\circ} 07^{\prime} 11.66722^{\prime \prime}$ & $-51^{\circ} 24^{\prime} 30.70095^{\prime \prime}$ & 430.064 \\
\hline USPP & $-23^{\circ} 33^{\prime} 03.05740^{\prime \prime}$ & - $46^{\circ} \quad 43^{\prime} 53.65646^{\prime \prime}$ & 718.345 \\
\hline VAU & -230 $00^{\prime} 06.16724^{\prime \prime}$ & $-46^{\circ} 57^{\prime} 57.94527^{\prime \prime}$ & 857.041 \\
\hline
\end{tabular}




\section{REFERÊNCIAS \\ BIBLIOGRÁFICAS}

ALBER, C.; JOHNSON, J.; ROCKEN, C.; HOVE, T.V.; SOLHEIM, F.; WARE, R. (1995). GPS Sensing of Atmospheric Water Vapor. Geoscientific Research and the Global Positioning System, v.17, n.5.30, Agu.

ALTAMIMI, Z (1999). Explanations about WGS 84 and ITRF92. altamini@ensg.ign.fr (27/10/99).

BERNESE GPS SOFTWARE. Transformation of Trimble Navigation data into RINEX - Format v1.1. Astronimic al Institute, University of Beme.

BOUCHER, B (199). Tra nsfomation parameters. boucher@ensg.ign (27/10/99).

CANNON, M.E., LACHAPELLE, G., LU, G. (1992). Ambiguity Resolution without Static Initialization using a High Performance C/A Code Receiver. In: Proceed ings of $48^{\text {th }}$ Annual Meeting, The Institute of Navigation, Washington, DC. p.161-166.

COLUMBUS BEST-FIT (1996). Windows User's Manual, version 1.1. Beaverton, Oregon 97006, USA.

COMBS, L.; VIERECK, R., eds. (1996). Aurora. Space Environment Center. 325 Broadway, Blouder. http://sec.noaa.gov.

CORNMAN, J. (1999). Explanations about WGS 84 and ITRF92. commanj @nima.mil (13/10/99).

DANA, P. H. (1999). Researches using the real values. pdana@mail.utexas.edu (09/03/99).

DEPARTMENT OF DEFENSE AND DEPARTMENT OF TRANSPORTATION (1996). Federal Ra diona vigation Plan. Washington, D.C.

DEPARTMENT OF THE AIR FORCE - HEADQUARTES AIR FORCE SPACE COMMAND (1995). Global Positioning System Standard Positioning Service Signal Spec ific a tiony - G loball Positioning System. 2 ed. Coast Guard Liaison.

EFEMÉRIDES PRECISAS. Endereços eletrônicos para download: ftp://igscb.jpl.nasa.gov/igscb/product/ - IGS Central Bureau Information System; ftp://www.ngs.noaa.gov/cors/dist/ - NGS.

EFEMÉRIDES. In. NOVO DICIONÁRIO AURÉUO (1995). Rio de J a neiro, p.234. EPUSP. ESCOLA POUTÉC NICA DA USP (1998). Descrição dos vértic es da rede GPS do Estado de São Paulo. Rela to GPS-Revista Latino Americana de GPS. n.7, p.04-19, mar/abr. 
EVANS, D. (1999). Auroral a ctivity devans@sec.noaa.gov (20/12/99).

FABRY, F. (1999). Real values with G PS. frederic @ra da r.mc gill.ca (11/03/99).

FONSECA J r., E. S. (1996). Estudo e a va lia ção Metodológica da Rede G PS do Estado de São Paulo. 120p. Dissertação (Mestrado) - Escola Politécnica da Universida de de São Paulo.

GEMAEL, C. (1981). Referencia is cartesianos utiliza dos e geodésia. Apostila. Curitiba, PR, Publicação Departamento de Geociências - UFPr.

GISPERT. J r., J. S. (1999). Números de PRN do satélite do GPS. J oseph.Gispert@peterson.af.mil (30/08/99).

G REER, S. (1999). Solar a c tivity of year 1994. sgreer@sec .noaa .gov (17/12/99).

GUTMAN, S. I. (1997). Prototype GPS water vapor monitoring network for NOAA.

http://www.unavco.ucar.edu/community/activities/science_snap/gutman1.html (15 abr/99).

HECKMAN, G., ed. (1999). Solar Maximum. Space Environment Center. 325 Broadway, Blouder. http://sec.noaa.gov.

HILLA, S. (1999). A more recent version of OMNI on the NGS a nonymous $\mathrm{ftp}$ server. (OMNI version 4.0x). steveh@ngs.noaa.gov ( 25/03/99).

HOFMANN-WELLWNHOF,B. et al. (1997). Global Positioning System - Theory and Practice.4 ed. Springer-Verlag Wien New York.

HUDNUT, K. W. (1999). GPS. hudnut@usgs.gov (05/02/99).

IBGE (1994). Especific ação e Nomas gerais para levantamentos GPS. Parte 1. Revista Fator GIS, v.2, n.5, p.29-32.

IBGE (1994). Especific ação e Nomas gera is para levanta mentos GPS. Parte 2. Revista Fator GIS, v.2, n.6, p.31-34.

INSTITUO BRASILEIRO DE GEOGRAFIA E ESTATÍSTICA - IBGE (1997). Sistema de Referência Geocêntrico para a América do Sul - SIRGAS. Relatório Final. Rio de J a neiro.

INTERAGENCY GPS OF EXECUTIVE BOARD (1999). Implementation of a Third Civil G PS Signal - Final Report, Oct.

ITRF94. Transfomation Parameters from ITRF94 to individual frames. ftp://la reg.ensg.ign.fr/pub/itrf/old/itrf94.tp.

J OHASSO N, J . M.; EMARDSON, T. R.; J ARLEMARK, P. 0. J .; GRADINARSKY, L. P.; ELGERED, G. (1998). The Atmospheric Influence on the Results from the Swedish GPS Network. Physics and Chemistry of the Earth, v.23, n.1, p.107112. 
KNIGHT, M.; FINN, A. (1997). The effects of lonospheric Sc intillations on GPS. In: ION GPS 97. - The 10 $10^{\text {th }}$ Intemational Technical Meeting of the satellite Division of The Institute of Navigation. Kansas C ity, Missouri.

KOVALESKY, J.; MUELER, I.I.; KOLAC正K, B. (1989). Reference frames astronomy and geophysic s. Dord rec ht, Kluwer Aca demic .

KRAKIWSKY, E. J . et al. (1986). Geodesy: The Concepts. 2.ed. Fredericton, N.B., Canada, Elsevier Science Publishers B. V.

LAROCCA, .A P. C. (1996). Estudo da Resolução da Ambigüidade. In: IV SIMPÓSIO DE INICIAÇÃO CIENTíFICA DA UNIVERSIDADE DE SÃO PAULO., São Carlos, 1996. Ana is. v.2, p.44.

LARSON, K. M. (1999). Researches that compare the real values with values of default. kristine.larson@Colorado.edu (10/03/99).

LEICK, A. (1995). GPS Satellite Surveying. 2.ed. Orono, Maine, J ohn Wiley \& Sons, Inc.

LUNT, N.; Kersleu, L; Bailey, G. J . (1998). The influence of the protonosphere on GPS observations: Simulations using the SUPIM model. Joumal of Geophysical Research.

MADER, G. et al. (1999). OMNI4.0 - UPDATE. ftp://www.ngs.noaa.gov no diretório pub/omni/update.

MADER, G.; SCHNEWERK, M.; CHIN, M.; KELECY, T.; HIШA, S.; ADAMS, G. (1998). OMNI 4.0 - UPDATE OF USER'S GUIDE- NEW MERGE. Rockville, Maryland.

MALYS, S. (1999). Explanations about WGS 84 and ITRF92. malyss@nima.mil (21/10/99).

MALYS, S.; SLATER, J.A.; SMITH, R.W., KUNZ, L.E.;KENYON, S.C. (1997). Refinaments to The World Geodetic System 1984. NIMA. In: ION GPS 97 - The $10^{\text {th }}$ Intemational Technical Meeting of the satellite Division of The Institute of Navigation. Kansas City, Missouri.

MCCARTHY, D.D (1992). IERS Conventions (1992).U.S. Naval Observatory. (Technical Note 13).

MCCARTHY, D.D (1996). IERS Conventions (1996).U.S. Naval Observatory. (Technic al Note 21).

MENZORI, M. (1999). Marcos GPS/ Correspondência/. Campinas.

NIMA - NATIONAL IMAGERY AND MAPPING AGENCY. (1997).. Department of Defense World Geodetic System 1984. Its Definition and Relationships with Local Geodetic Systems. 3.ed. J ul. (Technic al Report 8350.2).

PARKINSON, B.W. et al. (1996). Global Positioning System - Theory and Apllications. Volume II. Washington, DC, American Institute of Aeronautics and Astronautics, Inc. 
PEREIRA, K D. (2000). Informação:RBMC. Katiaduarte@ibge.gov.br (09/02/2000).

PESSOA, P. (1999). Marcos GPS. diretoria @a erocartq.com.br (10/11/99).

PEIERSON, A.F.B., ed. (1997). Space Environmental Impacts on DoD Operations. Published by Air Wea ther Service. Colorado. (FYI 37).

REMONDI, B. W (1994). The NGS GPS Orbital Formats. http://www.ngs.noaa.gov/G PS/Utilities/ format.txt (01/09/1999).

RIGHETtO, A. M. (1998). Hidrologia e Recursos Hídricos. 1 ed. São Carlos, SP, Public ação EESC-USP.

ROCKEN, C.; SOLHEIM, F. S.; WARE, R. H.; EXNER, M.; MARTIN, D. (1997). Application of IGS Data to GPS Sensing of the Atmosphere for Weather and Climate Research. http://www.unavco.ucar.edu/science_tech/technology/public ations/pots_ pap/index.html (3 Mar/99).

SANTOS, J. L. (1998). Implantação de Redes Geodésicas sub-regiona is e loca is com o sistema NAVSTAR/GPS: metodologia e aplicações. São Paulo. 92p. Dissertação (Mestrado) - Escola Politécnica da Universidade de São Paulo.

SCHAAL, R. E. (1998). Medições de deslocamentos em obras c ivis de grande porte com GPS. Proposta de Metodologia de Análise dos Resultados e Tratamento dos Dados. São Paulo. 113p. Tese (Doutorado) - Escola Politécnica da Universida de de São Paulo.

SCHENEWERK, M.; VANDAM, T.M.; SASAGAWA, G.; PHILIPSEN, S.; LARSON, K. (1998). A Detailed Analysis of Tropospheric Effects on Geodefic Observations at TMG O. Physics and Chemistry of the Earth, v.23, n.1,p.103-106.

SCHERNECK, H.G (1999). GPS and meteorology. hgs@oso.chalmers.se (12/03/99).

SEEBER, G. (1993). Satellite Geodesy: foundations, methods, and applications. Berlin, Walter de Gruyter.

SEGANTINE, P. C. L. et al. (1996). ITRF: Definição, Realiza ções e Aplic ações. Cartografia e Cadastro, n.5, p.31-36, dez.

SEGANTINE, P. C. L. et al. (1997). Considerações A respeito do Processamento de Dados GPS. Cartografia e Cadastro, n.6, p.13-17, jun.

SEGANTINE, P. C. L. et al. (1999). Testing J PL's PPP Service. GPS Solutions, v.3, n.1, p.73-76, summer 1999.

SEGANTINE, P.C.L (1995). Estabelecimento e ajuste de uma rede geodésica no Estado de São Paulo com o sistema de posicionamento NAVSTAR/GPS. São Paulo. 216p. Tese (Doutorado) - Escola Politécnica da Universidade de São Paulo. 
SEG ANTINE, P.C.L. (1998). GPS - Sistema de Posic ionamento Global. Apostila. São Carlos, SP, Publica ção EESC-USP.

SHUM, C.K. (1999). GPS meteorology. ckshum@osu.edu (07/01/99).

SNGS ORBIT UTLITES. Instructions to translate orbital files from one format to a nother. http:// www.ngs.noaa.gov/GPS/Utilities/ utility.d oc (01/09/1999).

SOFTWARES. Programs to translate orbital files from one format to a nother. PROGRAM EF18_SP3.EXE $\quad$ version $1.1 .0 \mathrm{~b}$ ftp://www.ngs.noaa.gov/cors/ utilities/Dos/ (01/09/1999).

STAR *NET - Least Square Survey Adjustment Programs (1995). User's Manual Addendum. Intemational Editions - version 5. Boulevard Way, Oakland, CA 94610.

THOMSON, D.B. (1976). Combination of Geodetic Networks. Universit of New Brunswick. Technical Report No. 30.

TRIMBLE NAVIGATION (1989). Model 4000 SST GPS Surveyor - Operation Manual. Revision A. Sunnyvale, Trimble Navigation Limited. Part Number 14907. 585 Noth Mary Avenue Sunnyvale, CA 94086-3642.

WARE, R.; ALBER, C.; SO HHEIM, F.; RICKEN, C.; J OHNSON, J .; VAN HOVE, T. (1995). GPS Sensing of Atmospheric Water. Geoscientific Research and the G lobal Positioning System, v.17, n. 5.30, Agu.

WARNANT, R. (1997). Influence of the lonosphere Refraction on the Repeatability of Distance Computed by GPS. In: ION GPS 97. - The $10^{\text {th }}$ Intemational Technical Meeting of the satellite Division of The Institute of Navigation. Kansas City, Missouri.

WELLS, D. et al. (1986). Guide to GPS Positining. 2 ed. Fredericton, N.B., Canada. Printed by the University of New Bruswick Graphic Services.

ZUMBERG E, J . F. (1999). Automated GPS Data Ana lysis Service. GPS Solutions, v.2, n.3, p.76-78. 


\section{APÊNDICE I}

Na TABELA a seguir estão a presenta dos os sa télites exc luíd os a ntes do processamento.

TABEA 105 - Sa télites Exc luídos (com menos de 15\% do total de épocas reg istra das)

\begin{tabular}{cc}
\hline \hline DOY & $\begin{array}{c}\text { Satélites Exc luídos } \\
(S V)\end{array}$ \\
\hline 069 & 1429 \\
070 & 5141629 \\
071 & 5141629 \\
072 & 5141629 \\
073 & 51629 \\
074 & 51629 \\
075 & 5141629 \\
076 & 1416 \\
327 & 4718 \\
328 & 12161824 \\
329 & 51219 \\
332 & 171819 \\
334 & 060714 \\
335 & 060717 \\
\hline \hline
\end{tabular}


